\title{
AN ARCHAEOLOGICAL STUDY OF THE ZIMBABWE CULTURE CAPITAL OF KHAMI, SOUTH-WESTERN ZIMBABWE
}

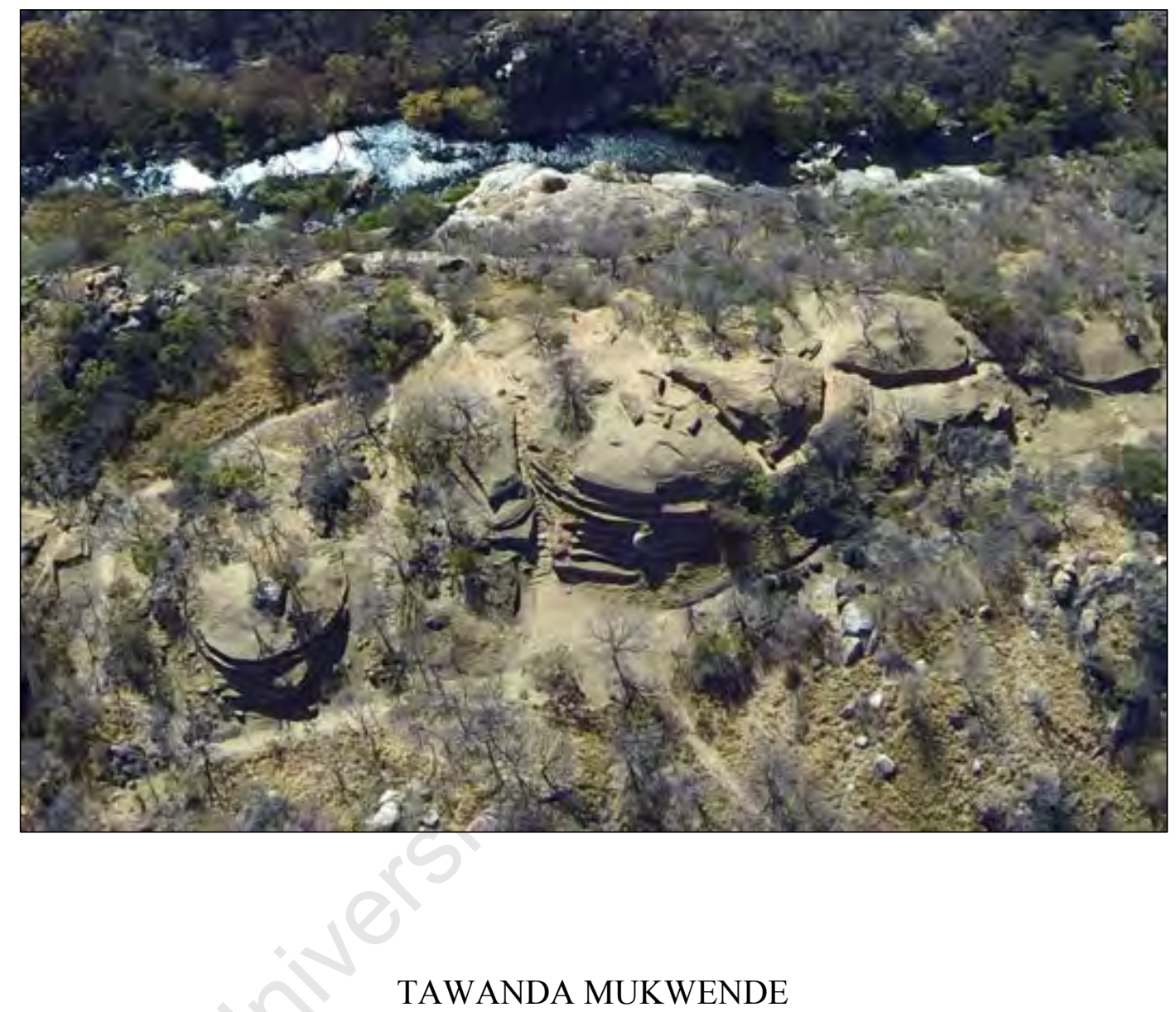

Supervisor: Associate Professor Shadreck Chirikure

Co-Supervisor: Associate Professor Simon Hall

Thesis Presented for the Degree of Doctor of Philosophy in the Department of Archaeology

University of Cape Town 
The copyright of this thesis vests in the author. No quotation from it or information derived from it is to be published without full acknowledgement of the source. The thesis is to be used for private study or noncommercial research purposes only.

Published by the University of Cape Town (UCT) in terms of the non-exclusive license granted to UCT by the author. 


\begin{abstract}
This study sought to understand the archaeology of the Zimbabwe Culture capital of Khami through synchronic and diachronic analyses of its material culture. The research employed a number of methodological approaches that included a review of historic documents, surveying and mapping, excavations, museum collection analysis, and artefact studies, in order to collect datasets from various sections of the site, including the walled and the nonwalled areas. The main indication is that there is a great deal of similarity in material culture distribution across the whole site. An analysis of objects by stratigraphic sequence exposes continuity and change in local and imported objects. Dry stone-wall architectural data suggests that the site was constructed over a long period, with construction motivated by a number of expansionary factors. The study confirms that Khami began as a fully developed cultural unit, with no developmental trajectory recorded at Mapungubwe or Great Zimbabwe, where earlier ceramic units influenced later ones. Consequently, this study cautiously suggests that Khami represents a continuity with the Woolandale chiefdoms that settled in the south-western parts of the country and in the adjacent areas of Botswana. On the basis of the chronological and material culture evidence, Khami is unlikely to have emerged out of Great Zimbabwe. However, more research is needed to confirm these emergent conclusions, and to better understand the chronological and spatial relationships between not just Woolandale and Khami sites but also Khami and the multiple Khami-type sites scattered across southern Zambezia.
\end{abstract}




\section{ACKNOWLEDGEMENTS}

The success of this study owes a great deal to a number of individuals and institutions that contributed in one way or the other to the project. I thank my two supervisors, Associate Professor Shadreck Chirikure and Associate Professor Simon Hall, for the guidance and support offered during the course of this study. Associate Professor Chirikure suggested the topic and provided useful ideas and suggestions that helped in shaping this thesis. He also read several draft chapters and provided useful comments, ideas and direction. I am also grateful to Dr. Foreman Bandama for the intellectual support during the course of my studies and also helping me integrate into the Archaeology Department at UCT. Dr. Bandama also read various drafts of this thesis and provided useful comments, making him my unofficial third supervisor.

I acknowledge financial support of the National Research Foundation (NRF) through grants to Associate Professor Shadreck Chirikure's Metals and Urbanism Project, which helped cover my tuition and research costs for the duration of my studies. The support of my Executive Director, Dr Godfrey Mahachi and Regional Director Dr Moira Fitzpatrick in affording me study leave to undertake studies leading to this thesis is greatly appreciated. They also offered me the relevant research permit that enabled me to excavate at Khami.

My fieldwork at Khami benefitted from the support offered by a number of colleagues. Associate Professor Chirikure not only provided critical intellectual guidance and direction towards the project but he also took part in fieldwork activities at Khami. I also thank Dr. Bandama for his contribution and guidance during fieldwork. To my colleagues from the Materials Laboratory - Abigail Moffett, Michelle House, Robert Nyamushosho and Catherine Schenk, I say thank you for all the support and for your contribution during my fieldwork. Dr. Per Fredriksen and Katrine Furu Dyvart from the University of Oslo also participated in the fieldwork at Khami. In particular, I note the support of Associate Professor Simon Hall for his support and for his offering of useful insights during the 2015 fieldwork. I am also grateful to Katrine and Kith Mkwananzi (from the Natural History Museum) for helping me with my faunal analysis. I am indebted to my colleagues from Khami World Heritage Site for 
their contribution towards the success of this project. These include Mr Lonke Nyoni, Obert Mangwana, Maxwell Fumula, Joseph Tasikani and Herp Ncube. These colleagues provided support and the necessary logistics that enabled the smooth running of fieldwork at the site as well as participating in the fieldwork activities.

I am also grateful for the encouragement that I have received from Professor Gilbert Pwiti, University of Zimbabwe; Professor Innocent Pikirayi, University of Pretoria and Dr Munyaradzi Manyanga, University of Zimbabwe. Their ideas and tremendous influence on Zimbabwean archaeology over the years have been an important source of inspiration that I will forever cherish.

I say thank you to my mother and my late father for the support and guidance that they have offered me over the years. My siblings have also been pillars of strength for me, and I am deeply grateful to them. 


\section{TABLE OF CONTENTS}

ABSTRACT

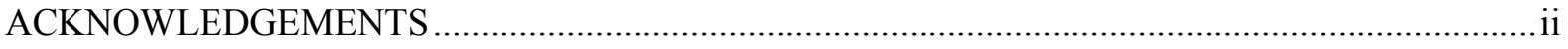

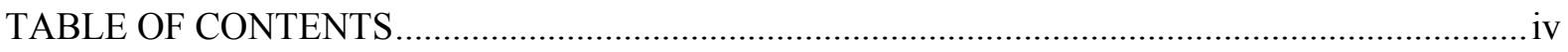

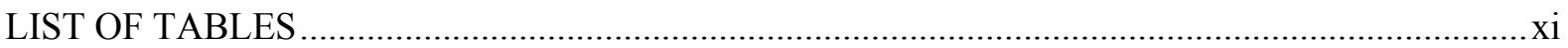

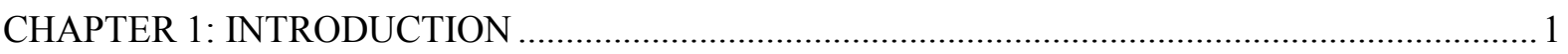

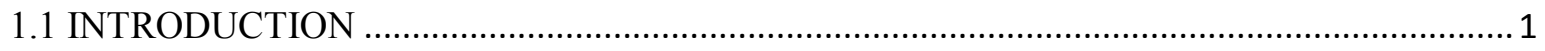

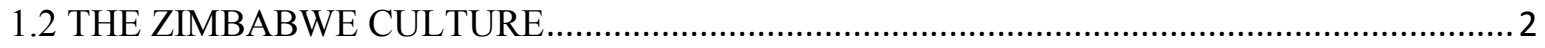

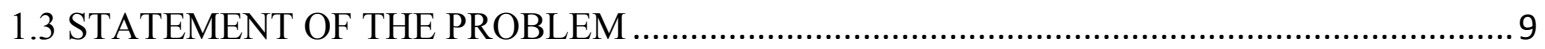

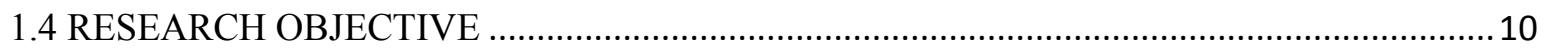

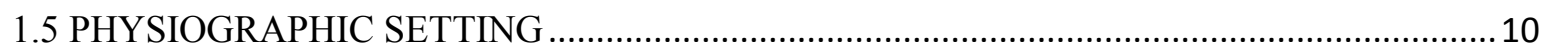

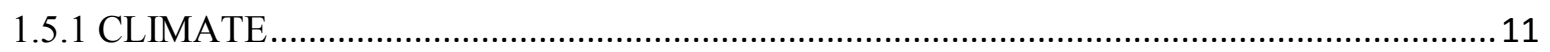

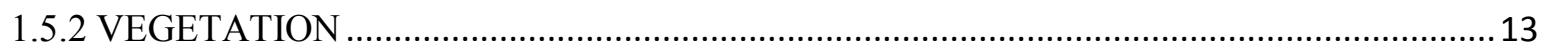

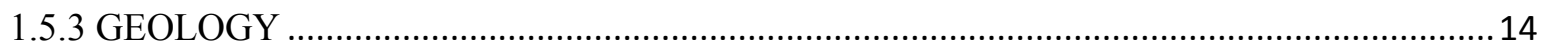

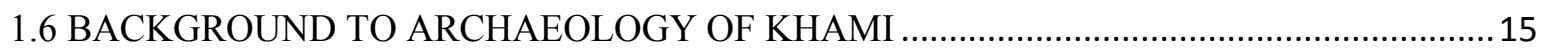

1.7 THEORETICAL AND METHODOLOGICAL FRAMEWORK …........................................... 17

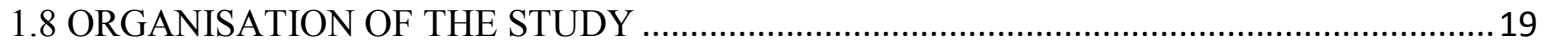

CHAPTER 2: APPROACHES TO MATERIAL CULTURE STUDIES IN ARCHAEOLOGY ........20

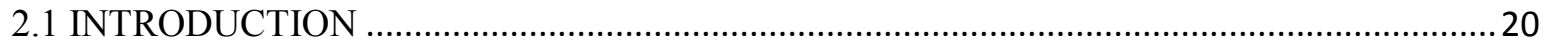

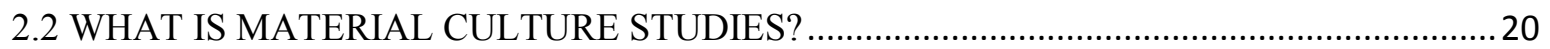

2.3 MATERIAL CULTURE STUDIES: A REVIEW OF GLOBAL TRENDS …............................25

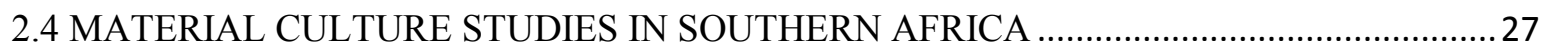

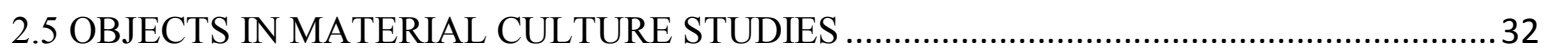

2.6 APPLICATION OF MATERIAL CULTURE THEORY TO CURRENT STUDY ....................33

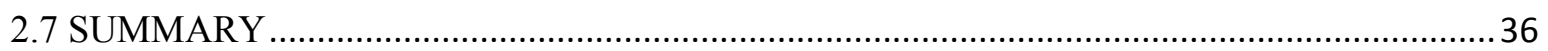

CHAPTER 3: CURRENT UNDERSTANDING OF THE ARCHAEOLOGY OF KHAMI.................37

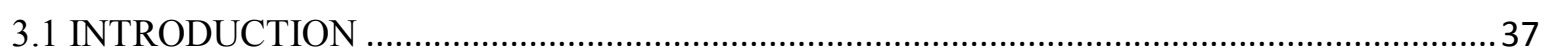

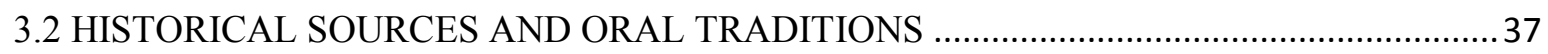

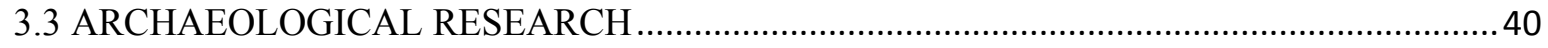

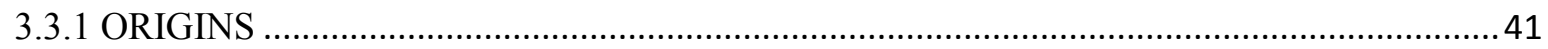

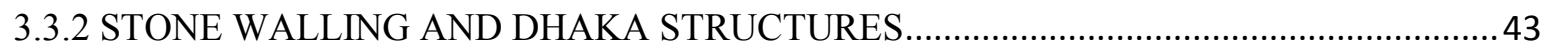

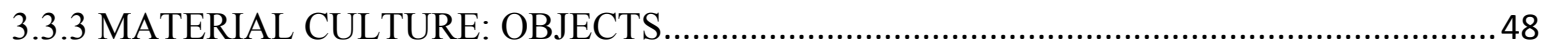

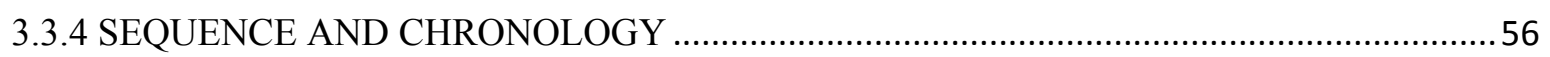

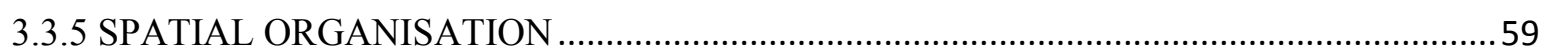




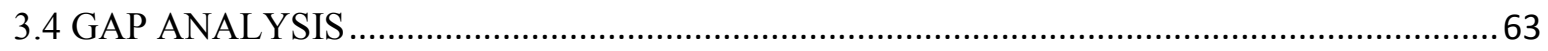

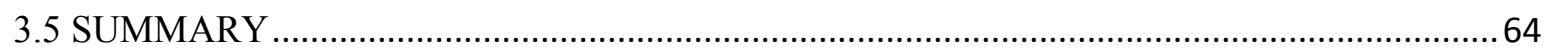

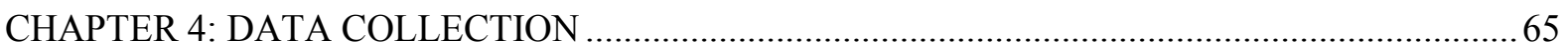

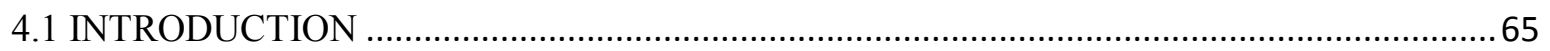

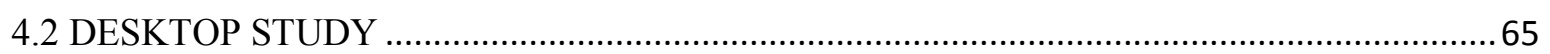

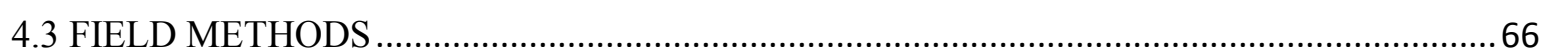

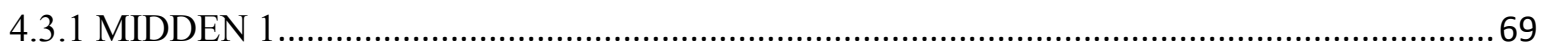

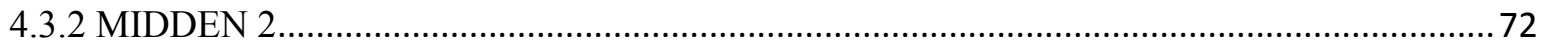

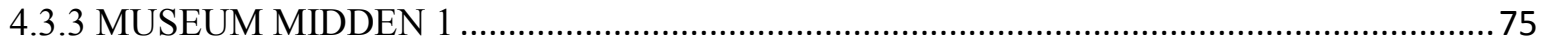

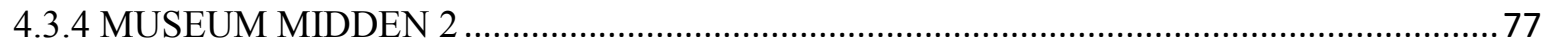

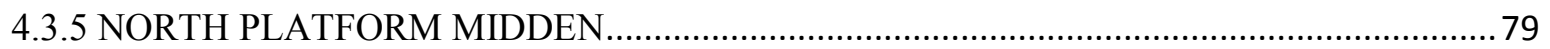

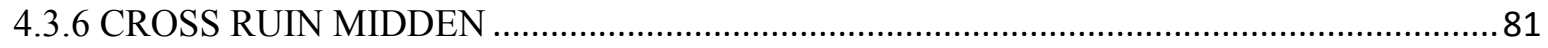

4.3.7 MAPPING OF CIRCULAR PLATFORM, EAST OF KHAMI RIVER ….............................. 82

4.4 ANALYSIS OF MUSEUM COLLECTIONS FROM KHAMI ................................................. 84

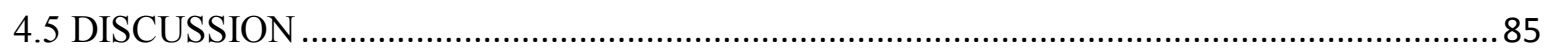

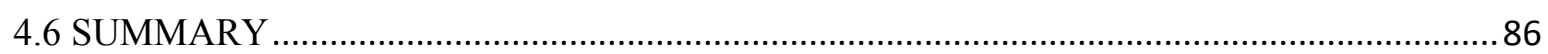

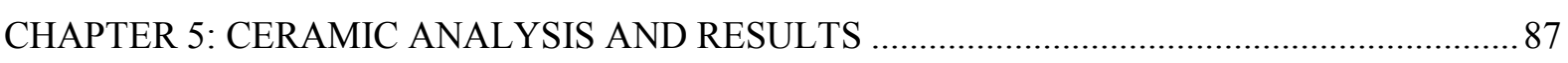

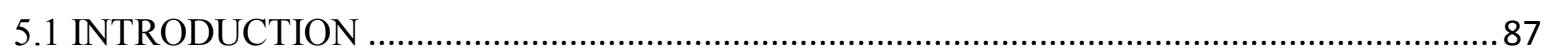

5.2 CERAMIC THEORY AND METHOD IN SOUTHERN AFRICA …...................................... 87

5.3 METHODOLOGICAL APPROACH IN CERAMIC ANALYSIS ......................................... 90

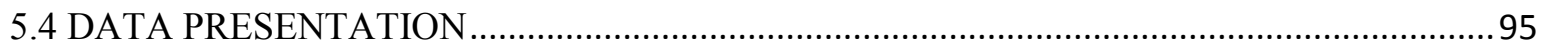

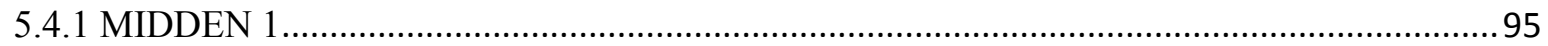

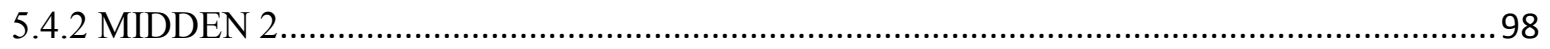

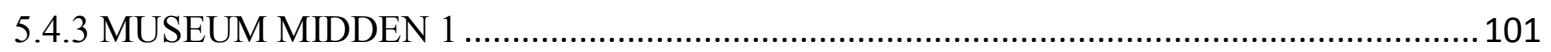

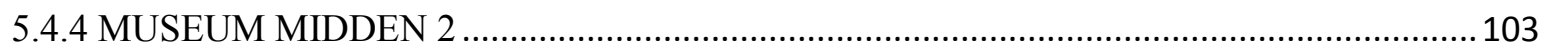

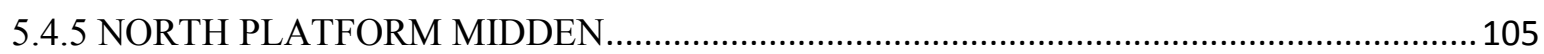

5.4.6 MACIVER'S HILL COMPLEX MIDDEN EXCAVATION …......................................... 107

5.4.7 ROBINSON CERAMICS FROM EXCAVATION 19, EAST OF CROSS RUIN ................109

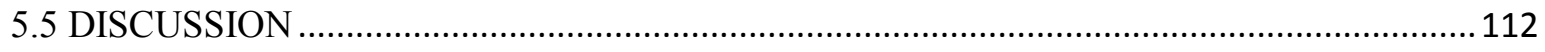

CHAPTER 6: GLASS BEADS ANALYSIS AND RESULTS …….............................................. 117

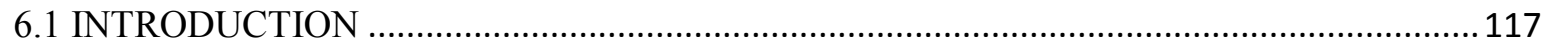

6.2 BACKGROUND TO GLASS BEAD STUDIES IN SOUTHERN AFRICA …......................117

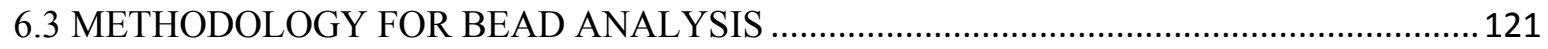

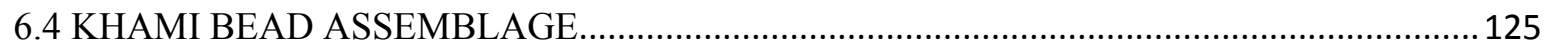


6.5 DISCUSSION 134

6.6 SUMMARY 135

CHAPTER 7: FAUNAL ANALYSIS ... 137

7.1 INTRODUCTION 137

7.2 OVERVIEW OF FAUNAL STUDIES IN SOUTHERN AFRICAN ARCHAEOLOGY 137

7.3 CURRENT SPECIES DISTRIBUTION AROUND KHAMI 140

7.4 METHODOLOGY 140

7.5 KHAMI FAUNAL ASSEMBLAGE 142

7.6 DISCUSSION 148

7.7 SUMMARY 152

CHAPTER 8: CRAFT PRODUCTION AT KHAMI. 153

8.1 INTRODUCTION 153

8.2 UNDERSTANDING CRAFT PRODUCTION 153

8.3 OVERVIEW OF STUDIES ON CRAFT PRODUCTION IN SOUTHERN AFRICA 154 8.4 METHODOLOGY 158

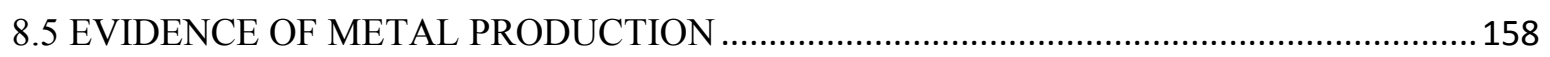

8.6 EVIDENCE OF BONE AND IVORY OBJECTS PRODUCTION .......................................... 168

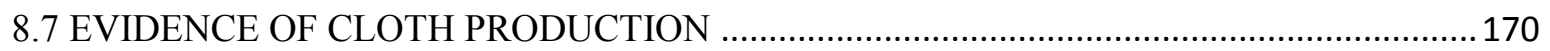

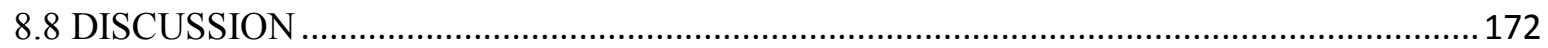

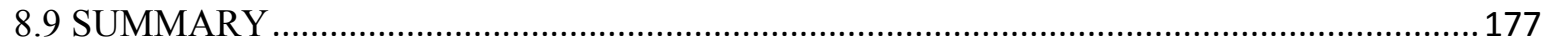

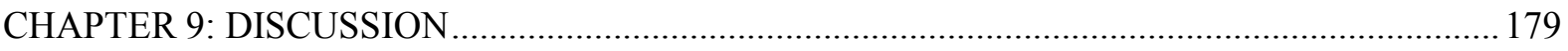

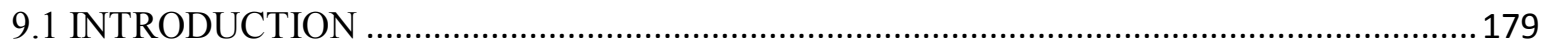

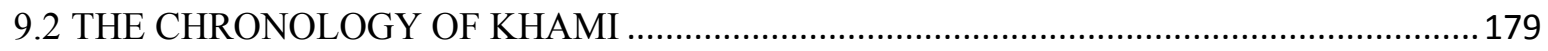

9.3 MATERIAL CULTURE AND DISTRIBUTION OF ACTIVITIES AT KHAMI ..................181

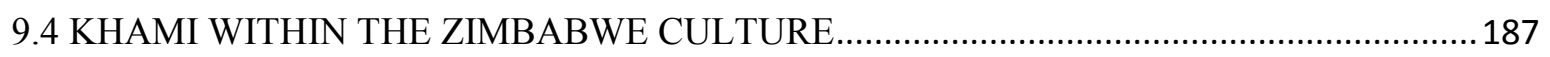

9.5 CONCLUSION AND DIRECTION FOR FUTURE RESEARCH.......................................... 193

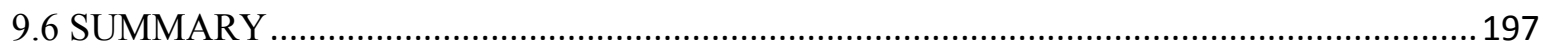

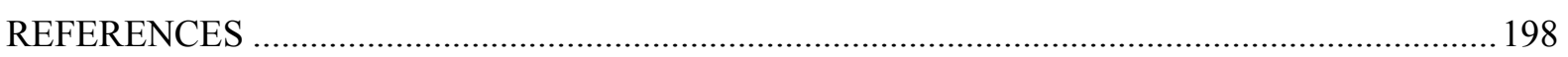

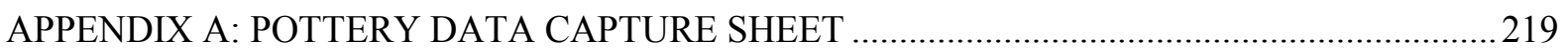

APPENDIX B: XRF READINGS FOR METAL SAMPLES FROM KHAMI MIDDEN 1 TRENCH 2

APPENDIX C: SPINDLE WHORLS FROM KHAMI 221

APPENDIX D: METAL OBJECTS FROM PREVIOUS EXCAVATIONS (MACIVER 1906; ROBINSON 1959). 


\section{LIST OF FIGURES}

Figure 1.1 Map showing the approximate extents of precolonial Zimbabwe Culture states and major pre-historic centres in southern Africa including Khami (Chirikure et al. 2013b) ......... 1

Figure 1:2 Map of southern Africa showing the position of Khami in relation to other sites in the region

Figure 1.3: Plan of Khami showing the various platforms and other settlement areas as evidenced by the presence of middens.

Figure 1:4 Natural farming regions of Zimbabwe (after Vincent and Thomas 1960). Khami is located in region IV.

Figure 3.1: Plan of the Passage (A) and Precipice platforms (B) showing the position of the excavation trenches by Neal and Johnson (Hall and Neal 1902).....

Figure 3.2: The western slopes of the Hill Complex, showing terraces 1-8 (from the bottom upwards). Teracces 3 and 6-8 are profusely decorated with checkers but Terrace 5 has a cord pattern.

Figure 3.3: Wall decorations styles at Khami

Figure 3.4: The Passage platform showing contrasting coloured blocks, on the left side, for aesthetic effect at the entrance to the platform.

Figure 3.5: Drystone wall construction at Khami also incorporated other materials to stabilise the uneven surface. Here, wood was used to create an even surface across a boulder on the Cross platform.

Figure 3.6: Terraced walling on the Cross Platform (A) and the Hill Complex (B). A schematic (C) of dry-stone terraced platform (left) and freestanding wall (right) (Ndoro 2005).

Figure 3.7: Plan of a typical house at Khami with various compartments (Garbutt and Johnson 1912). There is no indication of the location of this structure.

Figure 3.8: An illustration of the various forms of Khami ceramics according to Robinson (1959: 131, 132, 133, 134, 137)

Figure 3.9: An illustration of the three major ceramic vessels according to Hughes (1997: 11;

12). These are, from top, the short-necked, tall-necked and neckless vessels.

Figure 3.10. Metal items from the site. These include a selection of hoes from the site and

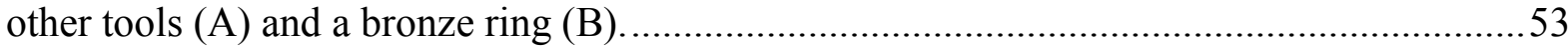

Figure 3.11: Imported ceramics recovered from Khami (Robinson 1961:66-67).................56 
Figure 3.12: Plan of the Hill Complex showing the excavations where Leopard's Kopje material was recovered (Robinson 1959: 16). These are E19 and E20 on the flats and an excavation on House $\mathrm{Cb} 1$ on the hilltop.

Figure 3.13: Plan of Khami showing settlement distribution by status (Huffman 2007). This view of settlement organisation at Khami dichotomised society at Khami, with an elite class that lived within the walled area and a commoner class that occupied the non-walled areas. 61

Figure 4.1: Plan of Khami showing the positions of the various platforms that make up the settlement (based on Robinson 1959:15). Leopard's Kopje settlement, which preceded Khami, is located about 700 m north of the Hill Complex, as measured on Google Earth.....67

Figure 4.2: Midden 2 showing material dug up through the activities of burrowing by antbears (A) and cenchrus ciliaris grass growing (B).

Figure 4.3: Picture showing Midden 1, which is dominated by the Cenchrus ciliaris grass from the eastern end of the midden.

Figure 4.4: Midden 1 plan and profile of Trench 2. 70

Figure 4.5: Large diagnostic faunal samples were recovered from Trench 2. On the left is a mandible of a Bov III next to a sherd decorated with incised triangles. On the right is a pot associated with faunal material from Trench 1 Midden 1.

Figure 4.6: Surface finds and features from Midden 2. Top, a possible bead mould, slag, grinding stone, dhaka fragments, pottery scatters and a burrow that has exposed midden material in the form of pottery sherds and bone fragments.

Figure 4.7: Plan and trenches profile drawings for Midden 2. ......................................... 74

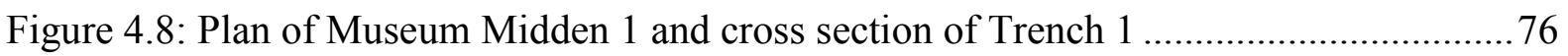

Figure 4.9: Trench 1 on Museum Midden 1 in progress. Bedrock had already been reached on Square A0 (left side).

Figure 4.10: Museum Midden 2 covered by thickets of grass. In the background is the Vlei

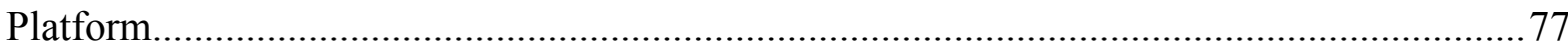

Figure 4.11: Museum midden 2 plan and sections .............................................................. 78

Figure 4.12: The natural stratigraphy of Square C0, Trench 1, Museum Midden 2...............79

Figure 4.13: Plan of Khami showing the position of the North Platform Midden. ................. 80

Figure 4.14: Section drawing of the North Platform Midden Trench 1................................81

Figure 4.15: Section drawing of the stratigraphy at Cross Platform Midden. ........................ 82

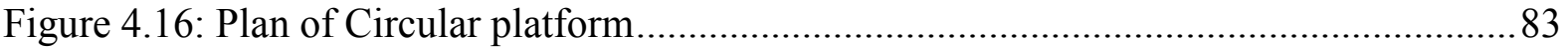


Figure 4.17: A view of Circular Platform from the north-west, showing the terraced wall radiating from the stone walled enclosure. The mound in the background is the collapsed house inside the platform.

Figure 5.1: Vessel forms that were noted from the Khami ceramic assemblage. 1 - shortnecked vessel; 2 - tall-necked vessel; 3 - neckless vessel; 4 -bowl. .................................... 91

Figure 5.2: Vessel forms from Khami showing the decoration placement areas. ..................93

Figure 5.3: Vessel types from Trench 1 on Midden 1........................................................98

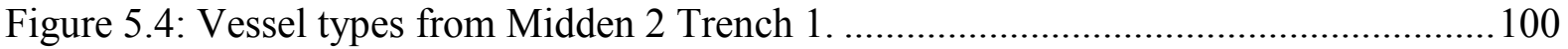

Figure 5.5: Vessel types from Trench 1, North Platform Midden....................................... 107

Figure 5.6: Vessel types from MacIver's (1906) excavation on the Hill Complex............... 109

Figure 5.7: Vessel types from Excavation 19 East of the Cross Ruin. ................................110

Figure 5.8: Vessel types from the Northwest ridge. Much of the decoration was executed on the shoulders.

Figure 5.9: Vessel types from Excavation 19 East of the Cross Ruin.....................110

Figure 5.10: Decoration motifs from Khami according to context.

Figure 6.1: Beads from the various bead series of southern Africa discussed (Robertshaw 2010:1900).

Figure 6.2: Glass beads from Khami showing the varied colours that were recovered......... 132

Figure 6.3: An Indian red cylinder and a cerulean blue oblate.

Figure 7.1: NISP/MNI count for assemblage from the North Platform Midden. 145

Figure 7.2: NISP/MNI count for the assemblage from Midden 2. .................................... 146

Figure 8.1: Some of the objects recovered from Midden 1 Trench 2 ................................. 160

Figure 8.2: Part of the metals collection recovered from Midden 2 Trench 2. Twisted wire (A) and axe head (B). 162

Figure 8.3: A selection of metal objects from Museum Midden 1 Trench 1. Coiled wire (A); twisted wire (B) and piece of wire (C) 163

Figure 8.4: A sample of metal pieces from Museum Midden 2 Trench 1. Coiled copper wire (A); Iron wire (B); and more coiled copper wire (C). 164 
Figure 8.5: Evidence of metal processing at Khami. Copper mould (A) copper slag (B) from the eastern slopes of the Hill Complex and copper slag (C) from the Hill Complex (Robinson 1959). The objects are housed in the Zimbabwe Museum of Human Science.

Figure 8.6: Utilitarian metal objects from the Hill Complex (MacIver 1906; Robinson 1959). These are copper and iron needles (A); iron nails and a selection of iron hoes (C and D) housed in the Zimbabwe Museum of Human Sciences.

Figure 8.7: The hoard of weaponry recovered from House CB1 on the Hill Complex on display at the Natural History Museum of Zimbabwe.

Figure 8.8: A collection of ivory and bone objects and debris. Amulets made from bone recovered on the Hill Complex (A); ivory waste recovered from the Passage Platform (B); armbands made from ivory also recovered from the Passage Platform (C), MacIver (1906) and Robinson (1959). The objects are housed in the Zimbabwe Museum of Human Sciences.

Figure 8.9: Spindle whorls from Khami. Some spindle whorls were decorated (A) while others were made from soapstone and clay and had multiple perforations (B). These are all from the Hill Complex. (C) shows a spindle whorl that was still in the production stage and (D) shows a plain one, both from the Passage Platform. 


\section{LIST OF TABLES}

Table 1:1 Classification Scheme for Agro-ecological zones of Zimbabwe (Vincent and Thomas 1960)

Table 3.1: List of imported objects recovered by Robinson at Khami minus glass beads (Robinson 1961: 66-67). .56

Table 3.2: Dates for Khami from Excavation 17a by Robinson on Platform B and structural posts in the upper passage of Platform $\mathrm{C}$ on the Hill Complex........................58

Table 4.1: Radiocarbon dates from Midden 1 Trench 2 ................................................... 71

Table 4.2: Dates from Museum Midden 2, Trench 1 ............................................................ 79

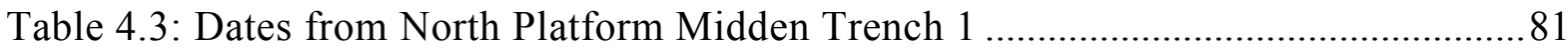

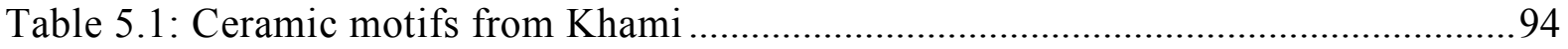

Table 5.2: Ceramic attributes for ceramics from Trench 1, Midden 1 .............................96

Table 5.3: Ceramics from Trench 1, Midden 2 ..................................................................99

Table 5.4: Ceramic attributes for sherds from Trench 2, Midden 2. .................................. 101

Table 5.6: Ceramic attributes for sherds from Trench 1, Midden 2. .................................... 104

Table 5.7: Ceramic attributes from Trench 1, North Platform Midden................................. 106

Table 5.8: Ceramic attributes from a reanalysed Hill Complex midden excavated by MacIver

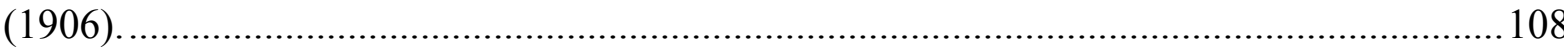

Table 5.9: Ceramic attributes for sherds from Excavation 19 by Robinson (1959)............. 109

Table 5.10: Ceramic attributes for sherds from the Northwest Ridge. ...............................111

Table 5.11: Vessel shape categories according to context.................................................115

Table 5.12: Decoration techniques noted at Khami according to context. ........................... 115

Table 6.1: Bead size range categories as developed by Wood $(2005: 34)$............................ 122

Table 6.2: Length ratio designation formula (after Wood 2005:34).................................. 122

Table 6.3: Table showing the range of translucency used in the analysis of southern African

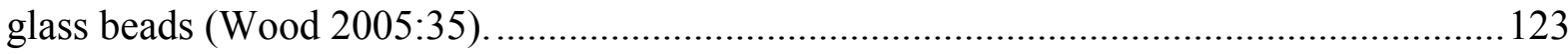


Table 6.4: Glass bead classification from southern Africa based on morphological characteristics and chemical composition (after Wood 2011; Robertshaw et al. 2010)........123

Table 6.5: Distribution of glass beads from Midden 1 Trench 1 by excavation layers. ........ 127

Table 6.6: Distribution of glass beads from Midden 1 Trench 2A by excavation layers. ..... 127

Table 6.7: Distribution of glass beads from Midden 2 Trench 2 by excavation layers......... 128

Table 6.8: Distribution of glass beads from Midden 2 Trench 1 by excavation layers.......128

Table 6.9: Distribution of glass beads from North Platform Midden 1................................129

Table 6.10: Distribution of glass beads from Museum Midden 1 Trench 1.........................129

Table 6.11: Distribution of glass beads from Museum Midden 2 Trench 1 Square C0........ 130

Table 6.12: Distribution of glass beads from Museum Midden 2 Square A0. ..................... 130

Table 6.13: Total number of glass beads recovered from each excavated area by colour. ...131

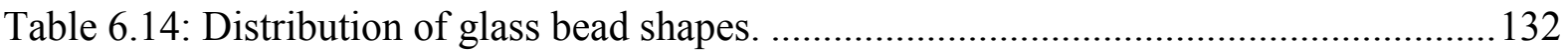

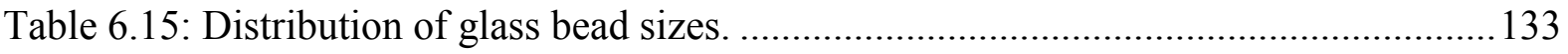

Table 6.16: Length ratio designations for glass beads from Khami................................... 134

Table 7.1: Class sizes for bovid species found in Zimbabwe (Manyanga 2001). ................. 142

Table 7.2: Bone count of the Khami faunal assemblage according to skeletal part. Tooth enamel as well as identifiable bone were the two skeletal compositions that were used in

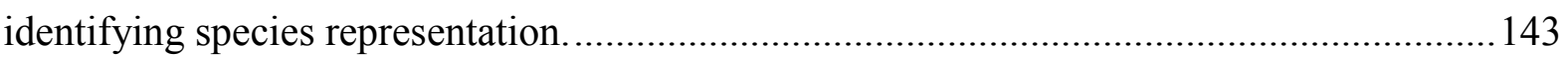

Table 7.3: Bone count according to identifiable and non-identifiable samples.................... 143

Table 7.4: Summary of faunal species from North Platform Midden 1 Trench 1 according to

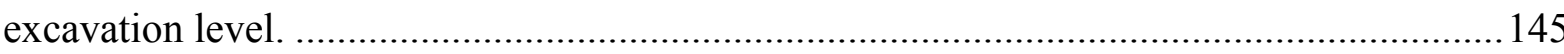

Table 7.5: Summary of faunal species from Midden 2 Trench 1 according to excavation level. 146

Table 7.6: Weights of the exploited animals at Khami North Platform Midden 1 by Bovid class.

Table 7.7: Weights of the exploited animal species at Khami Midden 2 by Bovid Class..... 147

Table 8.1: Metal recovered from Midden 1, Trench 1........................................................ 159

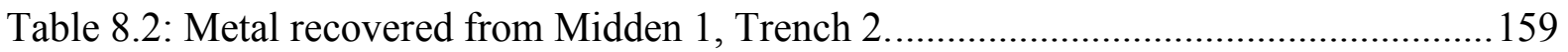

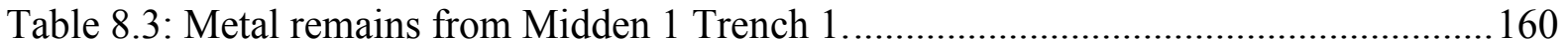


Table 8.4: Metal fragments from Midden 2 Trench 1.

Table 8.5: Metal fragments from Midden 2 Trench 2.

Table 8.6: Various metal pieces recovered from the North Platform Midden 1 Trench 1.... 162

Table 8.7: Metal objects recovered from Museum Midden 1 Trench 1.

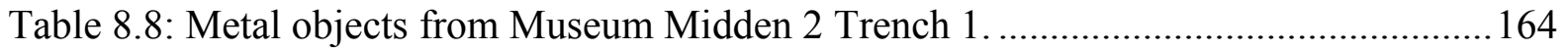

Table 8.9: Some of the ivory objects recovered from Khami............................................ 170

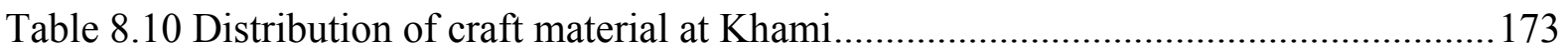

Table 8.11 Distribution of objects at the site according to material. ................................... 174 


\section{CHAPTER 1: INTRODUCTION}

\subsection{INTRODUCTION}

This research investigated the archaeology of Khami, a dry-stone-walled site, located in the south-western parts of Zimbabwe (Figure 1.1), with a particular focus on understanding its chronology and material culture. The emphasis of the study was on developing a tight chronology of the site, with a view to understanding how it developed through time. This was enabled by the diachronic and synchronic understanding of material culture recovered. This is important so as to understand the various components that make up the site without focusing on one area alone, which has been a major limitation of previous studies at the site (Robinson 1959; Thorp 1995). The understanding of the archaeology of Khami has been one of the missing link in the archaeology of southern Africa, due to the importance of the site as a former capital of one of the major precolonial state formations in the region (Huffman 2007; van Waarden 2012; Chirikure et al. 2013a). Using this evidence, this study contextualises the development of the site of Khami within a framework of the development of other precolonial formations to build a regional understanding of the development of precolonial state and urban formation in southern Africa.

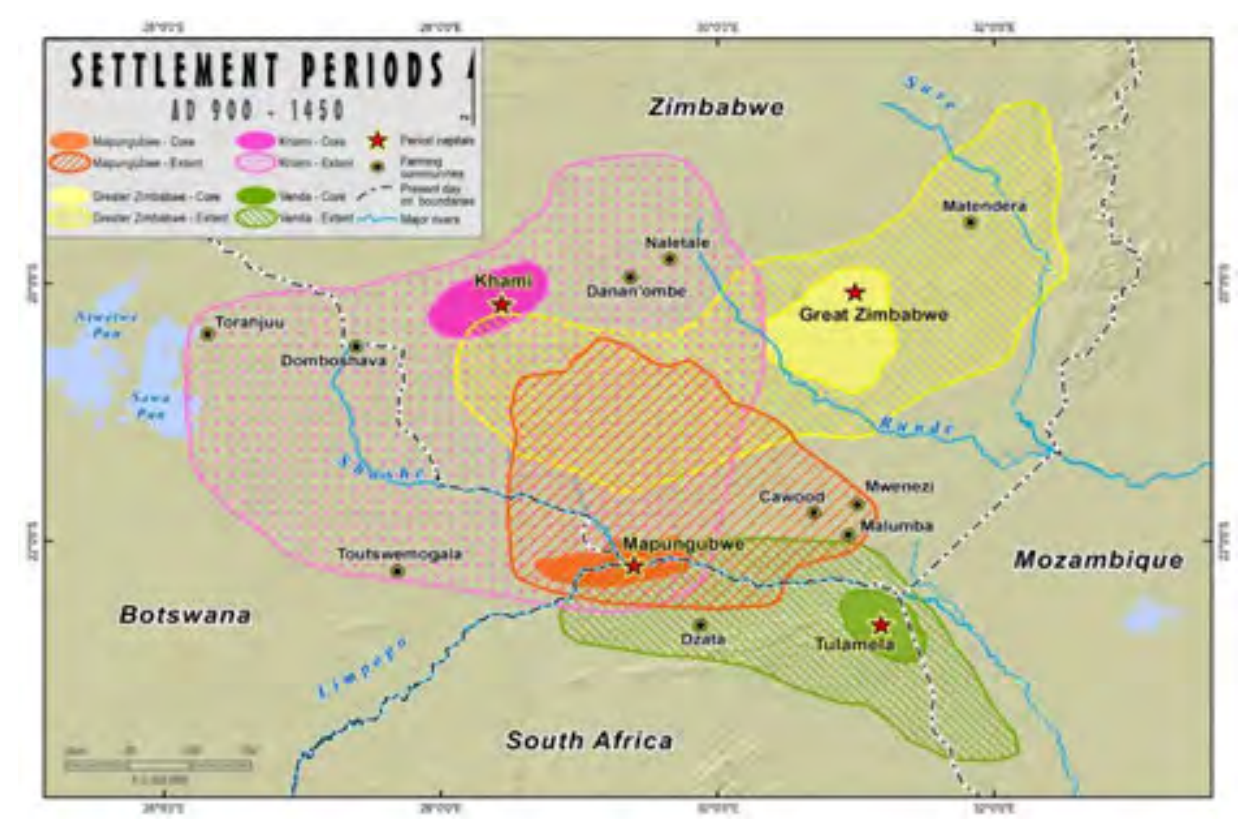

Figure 1.1: Map showing the approximate extents of precolonial Zimbabwe Culture states and major pre-historic centres in southern Africa including Khami (Chirikure et al. 2013a). 
Previous systematic archaeological research at Khami has primarily focused on the dry stonewalled sections, and particularly the Hill Complex, to the exclusion of large sections that did not have monumental architecture but showed evidence of past settlement (Robinson 1957; 1959; Thorp 1984; 1995). The challenge with this approach is that we understand the archaeology of a single section of the site that might not be representative of the whole site. The exclusion of other areas meant that most of the scholarly work done on Khami did not provide a clear picture of the organisation of the site. Successive scholars at the site have also based their interpretations on these excavations (Huffman 1996; 2007). In fact, because monumental architecture is often associated with elites only (Childe 1950), the main assumption was that the walled areas of Khami were inhabited by the elite, while the nonwalled areas were occupied by the non-elites (Huffman 1996). Even with the walled parts of the site, the research focus has mainly been on the Hill Complex, despite the fact that structural interpretations have been extended to cover the whole site (Huffman 1996; 2007). This trend in archaeological bias towards the stone-walled sections is, however, not unique to Khami alone (see Sinclair and Lundmark 1984; Manyanga 2006; Chirikure et al. 2014 for a detailed critique). The practice typically results in an incomplete understanding of the archaeology of any site and calls for broader investigations that incorporate different areas of a site (Connah 1987: 18). This broader approach is especially important in the case of Khami, given that the site was part of a broader network of similar and contemporary sites within the region collectively referred to as the Zimbabwe Culture (Pikirayi 2001).

\subsection{THE ZIMBABWE CULTURE}

The Zimbabwe Culture refers to the remains of the centres of pre-colonial Shona states that existed between AD 950 and AD 1900 (Caton-Thompson 1931; Pikirayi 2001; Huffman 1996, 2007). These remains are characterised by dry stone-wall construction to demarcate space and separate elite and non-elite residential areas, as well as by the nucleation of activities on a particular site (Huffman 1996; 2007; Pikirayi 2001; van Waarden 2012). The raw materials for the dry-stone walls differ from area to area, although granite seems to be the most preferred rock type due to its widespread availability on the Zimbabwe plateau and its environs (Garlake 1970; Summers 1971). Zimbabwe Culture sites appear in different sizes, from very large centres with monumental walling, such as Great Zimbabwe and Khami, to very small ones, like Nenga (Pwiti 1997). It has been argued that this is an indication of the 
different political and socio-economic roles that the various places played locally and regionally (Garlake 1982; Chirikure et al. 2012). Archaeological research has shown that there are over five hundred stone-walled Zimbabwe Culture sites in southern Africa (van Waarden 2012), but very few have been the subject of intensive research (Chirikure et al. 2013a). The result has been a generalisation of the nature of the Zimbabwe Culture, with little regard to individual site archaeology.

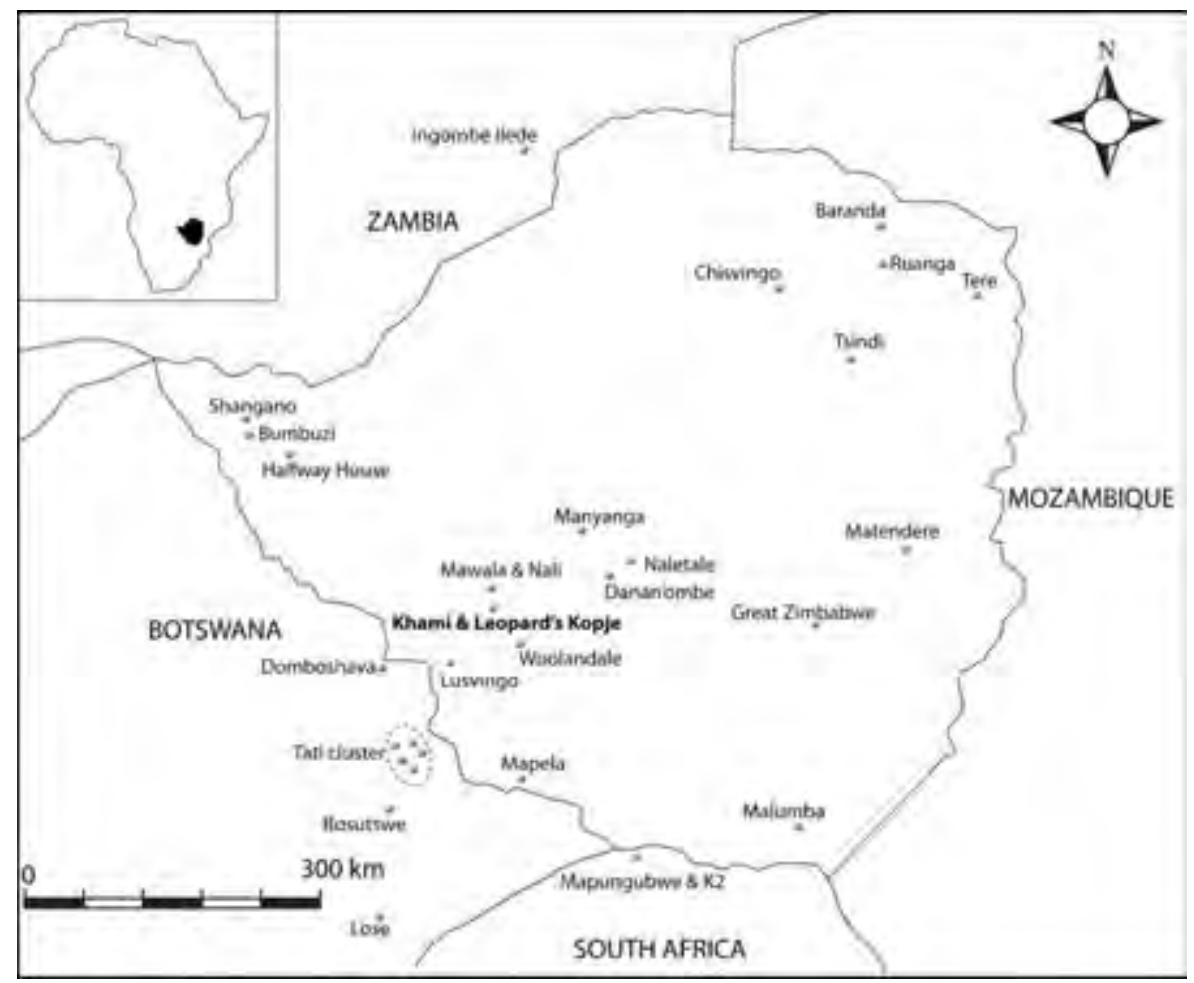

Figure 1.2: Map of southern Africa showing the position of Khami in relation to other sites in the region.

Society in the Zimbabwe Culture is argued to have been stratified into two tiers: the elite and the non-elite. This distinction was made primarily on the basis of walling, where the elite are those who lived within the walled areas and the non-elite are those who resided outside the stone walls (Robinson 1959; Huffman 2000; 2009). According to Huffman $(2000 ; 2014)$, the elites distributed wealth, political power and social status among themselves. Non-elites were generally the opposites of elites, and lacked access to elite privileges, such as wealth, power and social status. This dichotomy is said to have been legitimated by an ideology of sacred leadership that favoured the perpetuation of power by the elite against the commoners (Huffman 1996; 2007; 2014). Such stratification is said to have been maintained through a 
system of symmetrical marriage arrangements, which meant that commoners could not cross the social divide to become members of the elite through marriage or any other form of alliance.

The Zimbabwe Culture was also characterised by the rise of international trade between states of the Zimbabwe Culture and traders from the East African coast (Garlake 1973; Pikirayi 1993; Pwiti 1991; 1996; Wood 2000; 2011; Huffman 2000; Mudenge 1988; Beach 1980). These traders - initially Swahili and later on the Portuguese - were mainly after gold, ivory and animal skins from southern Africa. These were exchanged with glass beads, cloth and ceramics from Asia and Europe. Some scholars have argued that the region's participation in international trade, which went on to become a critical component of Zimbabwe Culture states' economies, precipitated state formation and urban development in the region (Garlake 1973; Huffman 1972; 1984; 2000). However, other scholars, such as Pwiti (1996a, 1996b; 2005); Connah (2001) and Manyanga (2006), have cautioned against arguments that attribute the development of the Zimbabwe Culture to foreign trade. Pwiti (1996a), for example, criticises the exclusivist tendencies of the trade hypothesis in explaining the development of the Zimbabwe Culture. External factors, such as international trade, are viewed as catalysts that took advantage of an organised Shona system, integrating it into the international trade network. They point to local factors that promoted the development of an indigenous economy, and that were critical in the development of the Zimbabwe Culture. These include local trade among various indigenous groups, which brought communities together; cattle herds, which were a critical aspect of the Shona lifeway and a mainstay of the local economy (Barker 1978; Garlake 1978; Denbow 1984; Pwiti 1996b; Pikirayi 2001); and the development of agriculture, which has been observed in the Shashe-Limpopo valley (Manyanga 2006).

Within the limitations of coverage in terms of research, it is generally assumed that there are four distinct phases of the Zimbabwe Culture in southern Africa (Huffman 2000; 2007; Pikirayi 2001). The Mapungubwe state (AD 1220-AD 1290), whose capital was situated near the confluence of the Shashi and Limpopo Rivers on Mapungubwe Hill, is generally assumed to be the genesis of the Zimbabwe Culture. Mapungubwe is argued to represent the earliest manifestation of the Zimbabwe Culture (Huffman 2000; 2007). Material culture evidence at 
this site, including exotic glass beads, has been used as evidence of the trading contacts with the international community through the Indian Ocean East African coast (Huffman 2000; 2009; Wood 2000). The collapse of the Mapungubwe state is said to have coincided with the development of the Zimbabwe state (AD 1300-AD 1450), centred on Great Zimbabwe in the south-central part of southern Zambezia (Garlake 1973; 1982; Huffman 2000; 2009; Pikirayi 2001; 2006). Huffman (2000) proposes that a section of the ruling elite at Mapungubwe participated in the rise and development of Great Zimbabwe as a new centre of power. However, this participation is not reflected in the material, since there are no similarities between the material culture from the two sites that would suggest continuity (Robinson 1961b). The Zimbabwe state, with its capital near the modern-day town of Masvingo in Zimbabwe, became the most powerful state in the region. Numerous dry stone-wall structures characterise the capital such as the Hill Complex, the Great Enclosure and the Valley Enclosures, as well as other sites that are associated with this phase (Summers 1971; Garlake 1973). Dry-stone walling at Great Zimbabwe composed mainly of freestanding walls, decorated primarily with chevron patterning (Garlake 1970; 1973; Summers 1971). Houses were constructed inside the enclosures, creating a barrier between those inside and outside the stone enclosures. As is typical of all the other Zimbabwe Culture sites, the elite at Great Zimbabwe occupied the stone-walled enclosures, while the rest of the community occupied outside the enclosures. Material evidence recovered from the site points to a number of economic activities that helped sustain the state, including cattle herding, local and international trade, gold mining, metal working, farming and hunting, among other activities (Garlake 1973; 1978; Sinclair et al. 1993b; Pikirayi 2001; 2006). Great Zimbabwe is said to have collapsed during the mid-fifteenth century, with a number of reasons being presented for this collapse (Huffman 2000, 2009; van Waarden 2012). These include loss of control of trade to other centres in the south-western and northern parts of the Zimbabwe plateau. Pikirayi (2006) has however argued that the Great Zimbabwe did not 'collapse' but entered a period of 'decline' which was precipitated by a period of environmental stress as the local natural resources were stretched to such a point that they could no longer sustain the capital.

The decline of Great Zimbabwe, during the mid-fifteenth century, is said to have been followed by the rise of two separate successor states: the Mutapa and Butua states. The Mutapa state (AD 1450-1900) was based in northern Zimbabwe and its adjacent lowlands 
(Mudenge 1988; Pikirayi 1993; 2001; Pwiti 1996). Our understanding of the development of the Mutapa state is much broader, since Portuguese traders who ventured into northern Zimbabwe left written records that have been synthesised by a number of historians working on the Mutapa state (Mudenge 1974; 1988; Beach 1980; Randles 1981). The settlements of the Mutapa state are similar in nature and form to those found at Great Zimbabwe. Various explanations have been posited regarding the northward expansion of the Zimbabwe state, which culminated in the Mutapa state (Pwiti 1996). Garlake $(1973 ; 1978)$ has argued that this northward expansion was a reflection of the semi-autonomous nature of provincial centres, which took advantage of a collapsing centre at Great Zimbabwe to establish a rival state in northern Zimbabwe. Beach (1983) saw the emergence of the Mutapa state as a territorial expansion of the Karanga dynasties from Guruuswa, with no direct links to what was happening at Great Zimbabwe. It has also been posited that the northward expansion represents peer-polity interaction occurring on the landscape (Pwiti 1996). The rich agricultural lands of northern Zimbabwe, together with the presence of the gold-bearing greenstone belts, were also a factor in the northward expansion to the Mutapa state; the mines in particular contributed the gold that was much sought after by the Portuguese and Swahili traders (Pikirayi 1993; 2001; 2006). The movement of trade routes from the Save River to the Zambezi River around the early fifteenth century is also said to have contributed to the transfer of power to northern Zimbabwe, since most trade was now conducted via the Zambezi River, effectively cutting off Great Zimbabwe from one of its economic activities (Mudenge 1988; Pikirayi 1993; 2001; van Waarden 2012).

While the Mutapa state was developing in the northern parts of the country, the Butua state (AD 1400-1680), with its capital at Khami, was evolving in present-day south-western Zimbabwe, north-eastern Botswana and parts of the Soutpansberg (Beach 1980; Mudenge 1988; Pikirayi 2001; van Waarden 2012). It is worth explaining the terminology behind the names applied to the state based at Khami, since scholars have tended to use these names interchangeably. Most scholars agree that the state was referred to as Butua, as is noted in Portuguese documents (Mudenge 1988; Beach 1980; Randles 1975; van Waarden 2012). Beach argues that the term 'Torwa' was used to refer to the ruling dynasty based at Khami, and its reference as Torwa (loosely meaning 'foreigners') might have derived from how the Karanga perceived their relations with the dynasty, as outsiders. The tradition of stone- 
building was also common at Khami, but this was in a way different from the mostly freestanding stone-walled enclosures that were typical of the Great Zimbabwe and Mutapa states. The builders at Khami employed terracing to produce platforms. Houses were then constructed on top of the platforms. As a result, houses at Khami were in full view, as opposed to Great Zimbabwe, where houses were secluded in stone enclosures (Robinson 1959; Garlake 1970; Summers 1971; Pikirayi 2013). The walls at Khami and other Khami phase sites are profusely decorated in a number of patterns that include checker, herringbone, dentelle, cord and chevron. Archaeologists have used the differences in the construction traditions between Great Zimbabwe and Khami as chronological markers, and argued for two separate entities: the Zimbabwe state and the Butua state.

The above, orthodox view suggests that Khami was established around AD 1400, as the capital of the Butua state (Robinson 1959; Sherpard and Swart 1967; Beach 1980; Huffman 2000; 2007; Pikirayi 2001; van Waarden 2012). After its destruction due to a civil war, around $\mathrm{AD} 1650$, the centre of power shifted to the Rozvi Changamire capital of Danangombe. The Rozvi state flourished until its collapse as a result of constant invasions by Nguni groups fleeing the Mfecane wars in Zululand (Beach 1980). Khami was the largest of the centres that made up the Butua and later the Rozvi states. There were also other centres, such as Naletale, Manyanga, Regina, Danangombe, Domboshaba, Majande and Vumba, which were part of the complex network of centres within the state, but their relative position in this network is not well known. However, this orthodox view does not take into consideration a number of important observations relating to the archaeology of southwestern Zimbabwe. Notably, it does not take into account the Woolandale phase of the Leopard's Kopje, which was a forerunner to Khami (Robinson 1966; 1985; Huffman 1974). Interestingly, in some of the Leopard's Kopje sites, such as Nali Hill and Mawala, affinities have been noted with Khami sites, specifically in the form of terraced walling, preference for hilltop settlements, and lavish decoration of ceramics with incisions (Robinson 1985; van Waarden 2011; 2012; Chirikure et al. 2013a). In her investigations in northern Botswana, van Waarden (2012: 155-158) has also noted that Woolandale and Khami stratigraphically overlay each other at a number of sites such as at Selolwe. These gaps in the orthodox view of Khami and its development calls for a re-examination of the archaeology of the site, in order to better understand its chronological evolution and material culture. 
Due to a limited understanding of the archaeology of Khami, archaeologists have only made cursory reference to the site in their discussions of the development of the Zimbabwe Culture, and of precolonial urban formation in general (Connah 2001; Huffman 2000; 2009; Kim and Kusimba 2008). Prominence has been given to the evidence recovered from Great Zimbabwe and Mapungubwe, with less attention devoted to understanding how other sites, such as Khami, can contribute to the understanding of the evolution of the Zimbabwe Culture. Urbanisation in the region is thus largely conceptualised within the framework of the development of Mapungubwe and Great Zimbabwe (Connah 2001; Huffman 2000; 2009; Pikirayi 2001; Kim and Kusimba 2008). This has beed challenged by Chirikure et al. (2014) who suggest the presence of polities such as Mapela that not only share similar attributes with Mapungubwe but also chronologically overlap. Because Khami is considered to be later in chronology, it does not feature in studies of state formation. And yet Robinson (1985), van Waarden (2011) and Chirikure et al. (2013a; 2014) have demonstrated the presence of Khami features, such as dry-stonewall platforms from the early second millennium $\mathrm{AD}$, in the "earlier" sites. This invites work that reassesses the place of Khami as a site, and as a phase within the Zimbabwe Culture. Van Waarden $(1987 ; 1989 ; 2011 ; 2012)$ has carried out work at various Khami-phase sites in north-eastern Botswana that has helped clarify the chronological development of the Khami phase in north-eastern Botswana. However, it is important that this work be supported by an understanding of the evolution of the capital together with its material culture, so as to build relations within the region.

A review of the archaeology of the Zimbabwe Culture also suggests that there has been an over simplification of a complex situation for a number of reasons. Firstly, the chronological development of Khami and its relationship with the Leopard's Kopje culture have not been explored in detail. This exploration is critical because Robinson (1985), van Waarden (1987; 1998; 2010), Chirikure et al. (2013b) and Huffman (2007) have detected significant similarities between the terraced platforms of the Leopard's Kopje and Khami-phase sites. For instance, terraced hills characterise both the Woolandale sites near Francistown (van Waarden 1998) and some Leopard's Kopje sites in the Shashe-Limpopo valley (Manyanga 2006; Huffman 2007), as well as other Woolandale sites in south-western Zimbabwe, such as Nali and Mawala (Robinson 1966, 1985). Because the radiocarbon dates from Leopard's 
Kopje sites in the Shashe-Limpopo valley overlap with Mapungubwe and other early second millennium $\mathrm{AD}$ walled sites, it has been argued that this demonstrates a wider distribution of the sites with terraced walls in the region that are contemporaneous (Chirikure et al. 2013a). Secondly, the recent Bayesian modelling of radiocarbon dates from elite sites in southern Africa indicates that Khami was already an important place long before the collapse of Great Zimbabwe (Chirikure et al. 2012). This suggests that the rise of Khami might not necessarily be related to the collapse of Great Zimbabwe. Thirdly, the differences in the architecture of Khami-phase sites and Great Zimbabwe-related sites may indicate the presence of separate traditions in the south-western and south-central parts of Zimbabwe respectively. These differences become more significant if the qualitative similarities between Khami and Leopard's Kopje material culture are considered. For instance, pottery from both sites is lavishly decorated with complex motifs and designs, which are remarkably different from the mostly plain but graphited Great Zimbabwe pottery (Chirikure et al. 2013a: 11). Lastly, no major work has been carried out to establish temporal relationships between the different parts of Khami itself. As Huffman (2007) has noted, radiocarbon dates for Khami are not conclusive, which calls for an in-depth study into the chronology of the site.

\subsection{STATEMENT OF THE PROBLEM}

The current understanding of the evolution of Khami is compromised by the limited datasets that are available (Chirikure et al. 2013a). This understanding is based on evidence recovered from excavations conducted exclusively on the stone-walled sections of the capital, in particular the Hill Complex, with no comparative material evidence from the non-stonewalled sections of the site. This exclusion creates a bias when one tries to explain the development of the capital in its entirety. In addition, there are very few dates for the site (Sherpard and Swart 1967; Huffman 2007), which has led to a reliance on imported material objects to understand the chronology of the site. The lack of sufficient absolute dates (Cooke, Summers and Robinson 1966; Huffman 2007; Chirikure et al. 2013a) for the site limits our understanding of its development. 


\subsection{RESEARCH OBJECTIVE}

The major objective of the study is to understand the chronology and the material culture of Khami, and to establish its place in the development of socio-political complexity in southern Africa.

This will be achieved through the following:

a. Carrying out excavations at Khami to develop a chronological sequence of the site through the analysis of its material culture;

b. Understanding material culture distribution at the site; and

c. Establishing a robust radiocarbon chronology of the site that takes advantage of radiocarbon dates and proxy dates from local and imported material culture.

The realisation of these objectives is critical for better understanding state-formation in southwestern Zimbabwe and will provide the basis for a re-examination of the development of the Zimbabwe Culture in the region.

\subsection{PHYSIOGRAPHIC SETTING}

Khami lies in the south-western part of Zimbabwe (Figure 1.2), $22 \mathrm{~km}$ south-west of the modern town of Bulawayo. A major river, Khami, runs through this former capital. The core of the site is comprised of fourteen stone-walled house platforms. Some of these are located on the west bank of the Khami River (Figure 1.3). These are the Hill Complex, North, Funerary House, Vlei, No 6, Monolith, Passage, Precipice and No 11 platforms. No 10, No 12, No 13, and Circular platforms are all located on the eastern side of the river. In describing the site, most archaeologists tend to discuss the larger, more finely built platforms, such as the Hill Complex, Cross, Passage and Precipice platforms, ignoring the smaller platforms and non-walled areas and therefore giving a distorted picture of the site of Khami (Ndoro and Pwiti 1999). In 1929, the Khami River was dammed to create the Khami Dam, close to the Precipice Platform. This act inundated a lot of material culture in the area (Ndoro and Pwiti 1999). For example, MacIver (1906) made reference to the presence of a number of houses on the eastern side of the Precipice platform. These were all destroyed, possibly along with numerous other material remains from the eastern side of the river that had not been 
documented. In addition to the dam, a water-reticulation plant was constructed on the eastern side of the Khami River, about 300 metres from the Hill Complex. These modern developments at the site have a bearing on our understanding and interpretation, as we are not certain of what was destroyed in the process.

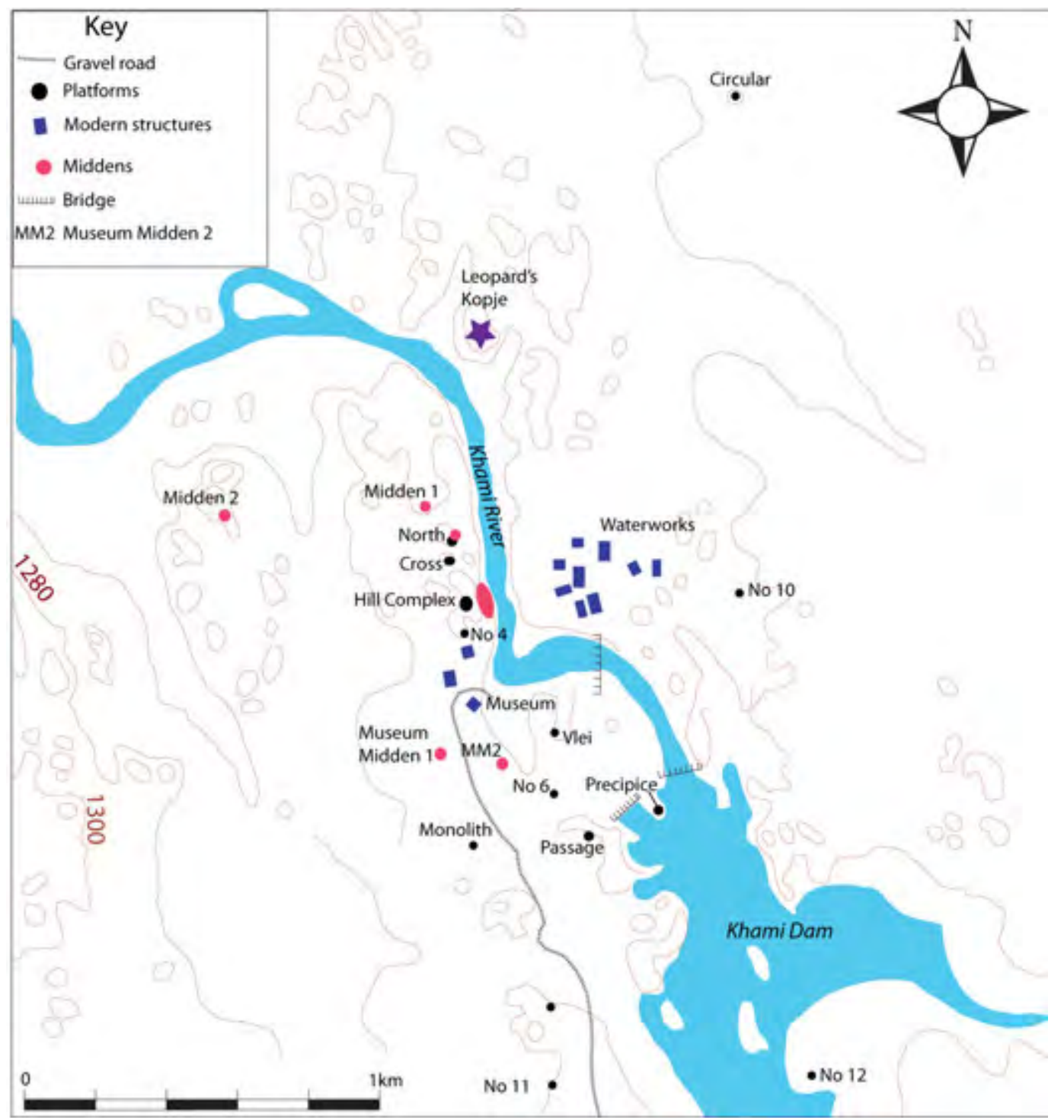

Figure 1.3: Plan of Khami showing the positions of various platforms and other settlement areas as evidenced by the presence of middens (Modified after Robinson 1959: 15).

\subsubsection{CLIMATE}

Khami is located in the natural farming region IV, which covers the south-western end of the Highveld. The region is characterised by rocky outcrops and small granite kopjes (Vincent 
and Thomas 1960). The Highveld was and continues to be favoured for settlement because of the fertile soils and good pasturages that it provides (Beach 1980; Ndoro and Pwiti 1999). The region receives an average annual rainfall of between 450 and $650 \mathrm{~mm}$. The result has been the development of subsistence activities that focus on animal husbandry, a key factor in the development of states and urban centres in southern Africa (Garlake 1978; Beach 1980; Thorp 1995).

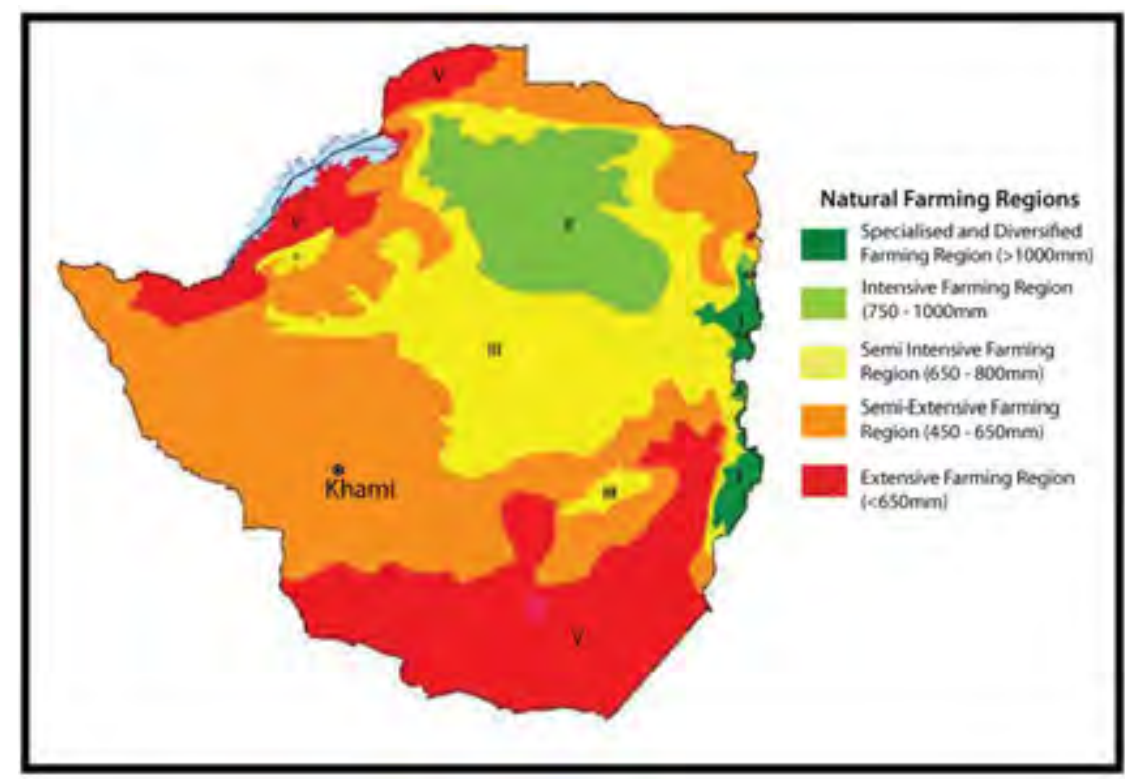

Figure 1.4: Natural farming regions of Zimbabwe (after Vincent and Thomas 1960). Khami is located in region IV.

Table 1:1 Classification Scheme for Agro-ecological zones of Zimbabwe (Vincent and Thomas 1960)

\begin{tabular}{llllll}
\hline Zone & Rainfall $(\mathbf{m m})$ & Mean annual temp $\left({ }^{\circ} \mathbf{c}\right)$ & Relief & Vegetation & Usage \\
\hline I & 1000 & 18 & Highlands & Mountain forest & Specialised \\
II & $700-1050$ & $18-19$ & Subdued & Miombo woodland & Intensive \\
III & $560-700$ & $18-21$ & Undulating & Mixed woodland & Semi-intensive \\
IV & $400-600$ & $19-21$ & Broken & Deciduous woodland & Semi-extensive \\
V & 500 & $21-29$ & Flat/Broken & Mopane & Extensive \\
\hline
\end{tabular}


There is a predictable monthly variation in temperatures and rainfall at Khami. Generally, there is no rain from May to September, with temperatures ranging from $14-19^{\circ} \mathrm{C}$ (Unganai 1996). Significant rainfall is received in November (c. $42 \mathrm{~mm}$ ), lasting until around March (c. $27 \mathrm{~mm}$ ) (Table 1.1). Such a climate created a situation where activities could be carried out with seasonal variation. For instance, most farming is done between September and April, the rainy season, while other non-climate-based activities, such as mining and craft production, could be done during the agricultural break season that ran from May to September.

\subsubsection{VEGETATION}

There are a number of tree species in the region, such as Ximenia caffra, Acacia ataxacantha, Combretum hereroense, Grenia monticolla, that have a high forage value and were thus important in sustaining the cattle economy at Khami (Sibanda and Ndlovu 1992; Timberlake et al. 1999). Some of the tree species at the site could have been exploited to support the local manufacturing industry. These include Colophospermum mopane (for ornaments and carvings) and Dicrostachys cinerea (for construction). Others were probably exploited to supplement the dietary requirements of the people at Khami. These include Dicrostachys cinerea, Cassia abbreviate, Azanza garckeana, Combretum hereroense, Grewia monticolla, Sclerocargo birrea caffra and Carrisa edulis (Timberlake et al. 1999).

The grass species comprise a wide variety of mixed types (Ndoro and Pwiti 1999; Chapano 2002). A number of these, including Eragrostis rigidior Panicum dregeanum, Panicum coloratum, Hemarthria altissima, have good forage value (Gambiza and Nyama n.d.). Such an environment can explain why the area of Khami attracted the Torwa people, who settled in the area and took advantage of its natural grazing resources for the rearing of their domestic stock. In addition, the rich natural grazing also attracted a variety of wildlife species, which were also exploited by the Torwa. Some of these animal species will be presented in Chapter 7. 


\subsubsection{GEOLOGY}

An understanding of the geology of the south-western region is an important part of this study. The area was famed for producing gold, which was in demand from Swahili and Portuguese traders (Beach 1980; Randles 1981; Mudenge 1988). There are several separate geologic systems that can be distinguished in south-western Zimbabwe (Amm 1940). These include the greenstone series, which occupies the greater part of the schist belt and is of considerable importance, given that the majority of mineral deposits of economic value occur in this series. The greenstones were overlain by the intrusion of the granitic rocks on a large scale. Granite is made up of medium- to coarse-grained soda-rich rocks intrusive into the greenstone schists and sediments that comprise the Bulawayo gold belt. The large expanse of granitic rock is a composite mass composed of younger and older granites. The gneissic granite is the oldest. The porphyritic granite was injected into the gneissic granite and schist from the west. This injection was followed by the fine massive granite, which never had contact with the greenstones.

Porphyritic granite is a pale grey rock, characterised by the presence of conspicuous phenocrysts of oligoclase and microcline (Amm 1940). In some instances, the rock has a reddish tinge, owing to the pink colour of phenocrysts. Porphyritic granite has played an important part in the mineralisation of south-western Zimbabwe. Most of the workable gold deposits in south-western Zimbabwe are located within short distances of the margins of the intrusions and tend to be concentrated around the smaller stocks (Summers 1969). Research on ancient mining has also shown that most of these mineral deposits were exploited by precolonial communities in the region, for domestic consumption as well as for regional and international trade (Summers 1969; Swan 1994: 121-124). Swan (1994) has shown that there is evidence for gold processing at Khami and other sites in the region.

The above physiographic description has shown that the landscape around Khami was highly endowed with natural resources, which acted as a pull factor for settlement around the site. In particular the availability of a constant water source coupled with quality pasturage ensured the growth of domestic stock for the site (Beach 1977; 1980; Mudenge 1988). The setting also sustained a diversity of wild animal species, some of which were exploited for a variety 
of purposes, including consumption and trade (animal hides and elephant tusks). The abundance of granite in the area made raw materials easily available. The geology of the area with granitic formations such as hillcrops, dwalas and boulders provided a ready source of material for drystone wall construction.

\subsection{BACKGROUND TO ARCHAEOLOGY OF KHAMI}

Some of the early visitors to the site noted its monumentality and argued that the site was an important precolonial settlement area. These observations aroused the interest of antiquarians, keen to recover artefacts of significance, and also of enthusiasts who hoped to understand the history of the site, particularly in relation to the more popular Great Zimbabwe. The earliest works focused on providing a description of the site (White 1901; 1903; Hall and Neal 1902) and comparing it to Great Zimbabwe (Gill 1903). Others focused on the material culture of the site, such as housing structures (Garbutt and Johnson 1912), a battle axe from the Hill Complex (Jones 1934; de Jager 1964), and engraved pottery (Balfour 1906). Most of these recoveries were in the locality of the dry-stone-walled section, particularly the Hill Complex. The colonialist antiquarians believed that the local indigenous population could not have independently developed the technology required to manufacture such items. Thus, they argued that the material was proof that Khami, like other dry-stone-walled sites, had been built by the Phoenicians (Hall and Neal 1902).

Exotic material objects from the site were selectively used to argue for a foreign origin, with no regard for the numerous pieces of indigenous evidence, which were discarded and dismissed as belonging to 'later Shona occupants after the Phoenicians had left' (Hall and Neal 1902). This selective consideration of material culture and antiquarian works at the site led to outcries from a number of scientific bodies, resulting in the British Society for the Advancement of Science sending David Randall-MacIver, a British archaeologist, to carry out an independent study that would scientifically determine the provenance of Khami. MacIver (1906) undertook excavations on parts of the site, including the Hill Complex and two houses associated with the Precipice platform. Based on the local material culture, some of which he had observed among contemporary Shona communities, he argued that Khami was the product of Shona groups on the Zimbabwe plateau and not Phoenicians. Protestations 
were made by the white settler community, who argued against the capacity of the indigenous Shona groups to construct such monumental structures (Hall 1909). Further investigations in the country by Gertrude Caton-Thompson in 1929 confirmed the identity of the builders as local Shona groups, as had earlier been suggested by MacIver (Caton-Thompson 1931).

Following the enactment of the Monuments and Relics Act in 1936, Keith Robinson was appointed to survey, record and excavate Khami, as well as other sites in the south-western parts of the country (Ndoro and Pwiti 1999). Robinson produced maps of the site and of the individual platforms. He also excavated the Leopard's Kopje and provided a description of its material culture (Robinson 1959: 25-39; 1966). Based on his excavations on the Hill Complex, Robinson argued that the Leopard's Kopje Culture was earlier to Khami as he recovered Leopard's Kopje material stratified below Khami deposits (Robinson 1959: 27, 29). He argued that the two cultures were not related based on evidence from an excavation east of Cross Platform (Robinson 1959: 26-27). This was in the form of an erosion prior to occupation by the Khami people. On the Hill Complex and Passage platform, Robinson (1959: 40-103) carried out a series of excavations which targeted collapsed houses to understand the nature of their construction as well as collect associated material objects. The understanding of the nature and form of construction of the stone walled structures at the site was also made through these systematic excavations, which revealed that the structures were heightened and enlarged with time - an indication of the growing nature of the site (Robinson 1953: 365; 1959: 46, 57, 62, 81).

After Robinson's research (1959), a number of studies were carried out at Khami by other archaeologists (Thorp 1984; 1995; Hughes 1997; Sinclair 1984; 1987). Thorp (1984; 1995) focused on faunal analysis, showing that bone remains had an important cultural value attached to them, which reflected in their use for manufacturing regalia and tools used in ritual activities. Hughes (1997) carried out excavations on the Northwest Ridge, with a view to determining the spatial organisation of a commoner settlement area. He noted that the housing of the Northwest Ridge was similar to that of the walled section of the site (MacIver 1906; Robinson 1959) and of Danangombe (Muringaniza and Ruwitah 1996). He therefore concluded that the similarities in these structures call into question the simple dichotomy 
between 'elite areas' and 'commoner areas' based on housing structures. In this context, he observes that the only notable distinction at the site was the monumental walling. Hughes thus argues that the organisation of space at the site was more complex than what Huffman's structuralist models suggested. However, some scholars argue that the area Hughes excavated was actually part of the elite zone, hence the similarities in material culture (Huffman 1996). Sinclair's (1987) work focused on the spatial analysis of Zimbabwe Culture sites. His research served as an illustration of the potential of the information held in the archaeological survey record using Geographic Information Systems (GIS). He analysed the settlement patterns of farming communities in relation to the environment and the resources found within the locality of Zimbabwe Culture sites.

Since the 1990s, the focus surrounding the site has been on its conservation and management (Ndoro and Pwiti 1999; Sinamai 2009; Chirikure et al. 2015). Of late, conservation of the dry-stone walls and dhaka structures has taken precedence over archaeological research. In particular, since the year 2000 massive wall-restorations have been carried out on various platforms at Khami, including the Hill Complex, the Cross Platform and the Passage Platform. The dry-stone-wall restorations exposed material culture like pottery and beads. The material was deposited with the Natural History Museum of Zimbabwe.

Huffman (1974) investigated the Leopard's Kopje site, located within the precinct of Khami. He refined Robinson's (1965) earlier chronology at Leopard's Kopje, with Zhizo (seventh to tenth centuries) occupying the lower levels, followed by Mambo (tenth to thirteenth centuries) and Woolandale (thirteenth to fifteenth centuries) (Huffman 1974). In spite of the close chronology between Woolandale and Khami, as exhibited by radiocarbon dates, no attempt has been made to relate the two traditions in south-west Zimbabwe.

\subsection{THEORETICAL AND METHODOLOGICAL FRAMEWORK}

This work is premised on the understanding that material culture plays an important role in conceptualising past societies and how they evolved (Jones 2002). Material evidence, both in the historic and precolonial periods, illuminates the lives of the people who used or interacted 
with the objects. Thus, for instance, at Khami, the material evidence from the site should provide information on the economic, social and spatial organisation of the settlement. Accordingly, parts of the site were mapped and excavated in this study.

Another element that material evidence illuminates is the craft-production processes at a site. It is important to understand the manner in which craft production was carried out, including whether it was centralised or carried out by individual household units (Costin 2001; 2005). Craft production also helps to show trends in local and international trade. For instance, it is important to understand where materials that were used in the production of crafts at the site were acquired and how the acquisition was organised. Subsistence patterns and cultural beliefs are also revealed through studying the material culture from a site.

Methodologically, this study focused on surveys around the site to determine its extent and identify its components. In the first instance, areas that were excavated by previous researchers were noted and mapped. This process showed that the major focus on all the excavations at the site had been on the stone-walled sections. The survey also showed areas that could be investigated further to collect material for further analysis. I therefore selected and excavated specific areas of the site, taking into account the need to sample material evidence from different components of the site, such as the stone-walled and the non-stonewalled areas. To obtain dates for the site, charcoal was collected from the excavation and sent for radiocarbon dating. Use was also made of museum collections of the previously excavated material by MacIver (1906), Robinson (1959), Thorp (1995) and Hughes (1997). This material is housed at the Zimbabwe Museum of Human Sciences in Harare and the Natural History Museum of Zimbabwe in Bulawayo. The material collected was analysed, with a viewing to understand material culture from specific areas and also patterns of distribution at the site. However, some challenges arose in terms of context for some of the material from the early excavations lacked details about stratigraphic layers. 


\subsection{ORGANISATION OF THE STUDY}

The theoretical approaches that have been used in this study are presented in Chapter 2. These focus on understanding the material culture of the site, as a way of reconstructing the lifeways of the people who were settled at Khami. The current archaeological knowledge on Khami is discussed in Chapter 3. This discussion aims to highlight the gaps and deficiencies in the status quo, thereby providing the context, rationale and direction for the present research. Chapter 4 discusses the approaches to data collection. These were largely informed by the theory as well as the knowledge deficiencies on the archaeology of the site. The findings on ceramic studies are presented in Chapter 5. Chapter 6 focuses on the presentation and analysis of the beads recovered from the excavation. Faunal remains from the site were also identified and analysed, and the results are presented in Chapter 7. Material culture that aids in our understanding of craft-production processes at Khami is presented and discussed in Chapter 8. Chapter 9 discusses the implications of the research with regard to the site chronology, material culture distribution, and the relationship between the site and other similar sites such as Great Zimbabwe and Mapungubwe. In the end, an attempt is made to reconstruct the nature of relations between Khami and other major Zimbabwe Culture centres. 


\section{CHAPTER 2: APPROACHES TO MATERIAL CULTURE STUDIES IN ARCHAEOLOGY}

\subsection{INTRODUCTION}

An archaeological study such as the one pursued in this thesis cannot be approached outside the confines of Material Culture Studies. In their quest for survival, human beings interact with the world around them to produce artefacts that are used for a variety of purposes (Caple 2006; Miller 1987). Some objects are used for everyday purposes, ranging from utilitarian functions to more ceremonial and symbolic functions. As such, human beings indirectly reproduce themselves during the production and or consumption of the material objects (Prown 1982; Joy 2009). By extension, any study of material culture, whether in the past or present, can enlighten us about its producers and users. The range of spheres that can be examined through the material evidence include the economy, technology, cultural contact, interaction, ritual and belief systems, as well as the social organisation (Prown 1982; Voigt 1983; Pwiti 1991; Pikirayi 1993; Schmidt 1996; Gosden and Marshall 1999; Manyanga 2000; Joy 2009). This chapter discusses some of the major issues in Material Culture Studies and how they help us to understand past societies. The rationale for the chapter is to show that the material culture at Khami provides an important window through which we can learn about the site.

\subsection{WHAT IS MATERIAL CULTURE STUDIES?}

Scholars have long realised that there is a symbiotic relationship between people and material culture, and that one cannot be divorced from the other. People are defined by their objects and their material culture, which give them an identity; thus, archaeologists use material culture to investigate precolonial groups (Pikirayi 2007). Prown (1982) defines Material Culture Studies as the study through artefacts of the beliefs of a particular community or society at a given time. One of the characteristics of Material Culture Studies is the way in which artefacts are implicated in the construction, maintenance and transformation of social identities (Miller and Tilley 1996; Fletcher 1989; Tilley 1989). As a result, there is a dialectical and recursive relationship between people and objects, with people making and using objects and the objects making the person. This consequently makes material culture 
part and parcel of the human culture in general. In this regard, a study of material culture associated with a particular social group should enlighten us on that group in terms of subsistence, economy, social organisation and belief systems. For instance, in ancient Egypt, certain artefacts that were made for funerary rites help illuminate the Egyptians' beliefs on life after death (Meskell 2005: 53). Egyptians valued the construction of large pyramids as a memorialisation and preparation for the after-life period. These resting places were furnished with all the basic necessities that Egyptians felt their departed would need in their after-lives. As such material culture is important in storing and preserving social information and beliefs about a society (Tilley 1989; Leach 1994; McGhee 1994).

Material culture can also be regarded as a kind of text that manifests as a silent form of writing and discourse. Artefacts and objects from the past are a critical part of evidence about the past, aiding in understanding that past as well as its technical attributes. In addition, Lubar (1996) is of the opinion that objects should be read as cultural texts, for information about their writers and those who have come into contact with the object. Material analysis therefore aids in understanding the social groups that manufactured, used and reused the objects. For instance, glass beads in southern Africa have been used to reconstruct past African societies in the interior. However, these beads' journey to the interior is a long one that begins in south-east Asia, where they were manufactured before being shipped to Africa (Wood 2000). Scholars are now beginning to focus on understanding this long path in the bead history of the region. For instance, chemical analysis is now showing that beads from southern Africa came from different sources in south-east Asia (Robertshaw et al. 2010; Koleini 2015). Scholars can also now understand the period of manufacture, which is important in pointing out possible periods of arrival on the Zimbabwean plateau. Prinsloo et al. $(2011 ; 2012)$ and Koleini et al. (2015) are using such information to refine the chronology of sites in the Shashe-Limpopo region.

Material Culture Studies is based on an understanding of the various disciplines and subdisciplines that contribute to understanding objects. The specialist nature of most subdisciplines of material culture enables a detailed understanding of the nature of objects. These disciplines include metallurgy, zoology, anthropology, physical sciences and archaeology, among others. These varied disciplines are complementary rather than competing elements in Material Culture Studies. This is important, because objects do not have a single 
interpretation: they are capable of transformations of meaning across time and space contexts (Pearce 1994a; Tilley 1989; 1994). The tendency for certain disciplines to work alone negates the ultimate objective of an integrated and unified approach to the archaeological past.

The interdisciplinary nature of Material Culture Studies has been developing for a long time now. It is reflected, for instance, in the relationship between archaeology and the physical sciences, which resulted in the development of revolutionary radiocarbon dating by Willard Libby in 1949 (Kingery 1996). As Tite (1996: 22) points out, radiocarbon dating now enables both artefact dating, in the case of organic material, as well as contextual dating where the artefact was found. Other technologies, such as thermoluminescence dating, now ensure a more precise dating process for objects beyond the 40000-year practical upper limit for radiocarbon dating. This is particularly important on early hominid sites, such as those in East Africa and South Africa. Archaeo-metallurgical studies have shown that the development of technology on the continent has a long history, stretching back to the precolonial period (Chirikure 2007). Archaeozoological studies have also increased our understanding of the relationship between man and the environment. In particular, archaeologists can now understand the dietary patterns of precolonial peoples (Voigt 1983; Thorp 1995; Manyanga 2000) and also reconstruct prehistoric environment (Tyson and Lindesay 1992).

The material sciences are broadly concerned with the selection, processing, production, structure, properties and applications of materials like glass, ceramics, stone, wood, bone, paper, metals and composites of these (Kingery 1996). These are some of the materials that are used in the everyday manufacturing of objects and tools, both in the present-day and in the past. In material sciences, material selection and processing leads to particular structures of artefacts, giving rise to properties that determine artefact performance. Artefact performance has been defined as the "behavioral capabilities that an artefact must possess in order to fulfil its functions in a specific activity' (Schiffer and Skibo 1987). The role of material scientists is thus to make explicit the nature and characteristics of a structure, and to use that knowledge as a guide for realising particular structures and properties. The material sciences illuminate a wide array of structures associated with artefacts, ranging from chemical composition to spatial patterning and provenience (Kingery 1996: 176). As a result 
of the application of the material sciences, archaeologists are able to discern the source-origin of raw materials for most artefacts that they interact with. For instance, in southern Africa, archaeologists now know the source of beads, as a result of a firmer understanding of the chemical compositions of the major bead groups (Robertshaw et al. 2010; Prinsloo et al. 2011; Koleini et al. 2015). This discovery has enabled a retracing of the beads to their point of manufacture in south-east Asia. Archaeo-metallurgists also apply material sciences to understand sources for the ores used in the manufacturing of numerous metal products during the Iron Age of southern Africa.

One approach that has been used to understand the production-related aspects of prehistoric societies is the chaine operatoire. This approach examines the sequence of events and decisions employed during the manufacturing process of an object, with a special emphasis on the technology. It is a technological approach that seeks to reconstruct the organisation of a technological system at a given archaeological site (Sellet 1993: 106). Emphasis in this approach is placed on every stage of object production, from the supply of raw materials to the associated use and reuse of the object. This ensures that all information related to the object is captured, and helps explain the life-history of the object. The chaine operatoire concept has been applied mostly to the study of archaeo-metallurgy and lithics, as a way to understand how prehistoric societies developed technologies that enabled them to manufacture advanced tools and objects. The chaine operatoire concept also takes into consideration the social meanining and symbolism associated with material culture (Lindahl and Pikirayi 2010; Pikirayi and Lindahl 2013).

In seeking to understand the past, some scholars argue that we can ask objects questions, similar to the ones we ask people when writing biographies (Kopytoff 1986). In this way, it is possible to understand, for instance, how an object has changed since its time of manufacture and how different it is from other objects. This process conforms to the logic that object-lives are not static (Joy 2009). More importantly, studying the life-histories of objects also illuminates the relationships surrounding objects. These could be between people and people, between object and object, and between object and people. A biography of an object is created as it goes through a series of transformations: for example, from gift to commodity, 
and eventually to inalienable possession (Hoskins 2006). Objects are seen as possessing their own agency and actively having effects in relation to persons. Tilley (1996) gives an example of the shield of a warrior, which has the effect of frightening the enemy in addition to its utilitarian role of protecting the warrior. Therefore, objects are important not because of their utilitarian value but because of what they do - that is, the influence they exert on persons. In these social lives of objects, the meanings and interpretations attached to objects are relatively fluid and flexible over time and space. For instance, at a certain point an object may be recognised for its commodity status and value, which is important because of its exchange value (Kopytoff 1986). However, the object may be de-commodified as it is incorporated by people according to personal meanings, relationships or rituals, thereby attaining another value (Miller 1987; Kopytoff 1986). The restriction of certain objects from commodification is common in many societies. These restrictions are cultural and are held collectively by a society. Objects are also used to assert power symbolically, when people insist on their right to singularise an object or a set or class of objects (Kopytoff 1986). For instance, in many traditions the right to use certain animals and animal products rests with the chief or king.

The above discussion shows that objects are an important element in Material Culture Studies. Miller (1987: 3) notes that the 'academic study of the specific nature of the material artefact produced in society has been remarkably neglected'. As such, there is a need to refocus on Material Culture Studies if archaeologists are to come up with meaningful discussions on prehistoric societies. Miller (1998) also argues that by focusing on objects in a way that is inclusive of the subjects who use them, as well as their motives and meanings, research can avoid the fetishisation of material culture.

Joy (2009) has noted, though, that there are a number of challenges related to the application of a biographical approach to the analysis of archaeological assemblages. The first is related to the quality of the information that the archaeologist can get from the object. He argues that, in the absence of recorded history, the evidence available is insufficient to reconstruct a full history. Another problem is that archaeologists come into contact with most of these objects at the end of their social lives. Thus, there is a gap in terms of the life-history of the object, which the archaeologist has to conjure up. This process is complicated by the fact that most 
objects are not restricted to one single life-path and do not follow a linear pattern. Other objects, including monuments, have their biographies complicated as they extend over many generations. Successive generations come up with their own meanings and attitudes towards the material, which complicates the archaeologist's role in trying to interpret the material.

\subsection{MATERIAL CULTURE STUDIES: A REVIEW OF GLOBAL TRENDS}

The development of the discipline of Material Culture Studies can be related to a range of theoretical literatures and research traditions, which include evolutionary anthropology, modern sociology and social theory, as well as new anthropologies of consumption and economic behaviour. Early studies in material culture had a very narrow focus. Anthropological research in the nineteenth century was mostly concerned with the collecting, classifying, and studying of artefacts (Tilley 2006; Woodward 2007). Most of the studied objects were of non-Western origin. This was motivated by a concern on the part of Western scholars and collectors to 'rescue' what were perceived to be primitive cultures throughout the non-Western world. The looting of a great deal of objects from various colonies is a case in point (Shepherd 2002). In this way, huge museum collections were established in most of the capitals of Europe. Objects were interpreted as having a simple functional role, with the form and construction of the object being indicative of the technological development of the society that made and used the object (Caple 2006). The overarching goal in such studies was to use artefacts as a means of retrospectively understanding human behaviour and culture (Woodward 2006). However, in reality, such studies led to the creation of a hierarchical system of the cultures of the world, with those from the non-Western world occupying the lower levels of development. At places such as Great Zimbabwe, foreign material culture was used to argue for an exotic origin of the settlement (Hall and Neal 1902; Hall 1909), or a foreign-inspired origin through participation in international trade (Garlake 1973; Huffman 2000; 2009), based on the presence of trade materials from Europe and Asia. Innovation and development was viewed as having trickled from the 'more developed' West to Africa. In short, most innovations during this period were (and still are) defined by some scholars in terms of diffusion from the West (Garlake 1973; Huffman 2000; 2009). As a result, Material Culture Studies in the nineteenth century provided the empirical basis for grand schemes of social evolution, diffusion, acculturation and change (Tilley 1996). The display of material culture in museums and galleries was used to demonstrate the evolutionary stages and models 
of cultural development, implicitly communicating the superiority of Western cultures and the inferiority of non-Western societies, and providing a justification for the imperial efforts of Western countries in Africa, Asia and the Americas (Jacknis 1985).

Evolutionism was replaced in the 1920s by functionalist-structuralist theories (Trigger 1989). The primary concern of functionalist-structuralists was with social relations rather than objects and things. The major problem with evolutionism had been the implicit hierarchical ordering of the value of other cultures. McGuire (1983) noted that typological approaches did not deal with the internal workings of cultural change in a society, and expressed a concern at the emptiness and isolation of objects, which were presented apart from their original cultural and spatial contexts. As Tilley (2006) put it, 'artefacts were conceived as dead, inert matter, primarily conceived as having a utilitarian significance fulfilling the basic needs of human adaptation to different environments as tools, a technological substrate of life or as passive markers of social status and ethnic differences'. These major problems resulted in the failure of Material Culture Studies to develop independently as a discipline. The field remained limited to the work of museum curators, as its focus continued to be collecting, cataloguing and setting up displays in which artefacts were made to signify different peoples on a comparative basis (Trigger 1989).

Another shift in theoretical perspective occurred in the 1960s, this time towards structuralism and symbolic anthropology (Trigger 1989). This shift resulted in the introduction of Material Culture Studies into the mainstream of anthropological research. In this updated approach, objects were no longer viewed in their utilitarian sense; they were reconceptualised as having a deeper meaning. The 1980s saw the reintegration of ethnographic and archaeological conceptualisations of material culture, giving birth to the broader field of Material Culture Studies. Tilley (1989) argues that the 1980s saw a paradigm shift in archaeology. Material culture was now conceived of as 'a signifying system in which the external physical attributes of artefacts and their relationships were not regarded as exhausting their meaning'. 
In their quest to clarify the role of material culture in archaeology, researchers have turned to science to better understand the physical and mechanical properties of material culture. An example of this is the useful translation of techniques of characterisation, such as petrology, into archaeological problems (Jones 2002). Schmidt (1996) used scientific analysis in an effort to re-examine conventional colonialist histories of Africa. He aligned the data that he derived from detailed micro-scale scientific analysis with an investigation of the symbolism that explicated certain problems inherent in the understanding of belief systems and history. Jones (2002) has noted that the use of science-based techniques enables laboratory-based scientific analysis while also retaining a focus on the historical and cultural context of the objects and samples that are analysed. This is important, because prioritising modes of analysis that focus on large-scale structures reveals little about how people lived and structured their lives on a day-to-day basis.

\subsection{MATERIAL CULTURE STUDIES IN SOUTHERN AFRICA}

As noted earlier, Material Culture Studies during the early colonial period was mostly concerned with collecting objects as representations of the various ethnic groups of southern Africa (de Maret 1999: 161). This approach, according to de Maret (1999), was based on a desire on the part of the colonial authorities to foster a sense of pure ethnicity and to regroup people into large ethno-political structures that would be easier to subject to colonial rule. Evidently, the collected cultural objects would have been moved from their cultural contexts, so in most instances their interpretation was bound to be biased. However, the need to write the prehistory of the country saw archaeologists turning to material objects as evidence of the material record of the past. In Zimbabwe, as in the rest of the southern African region, ceramics have been the single most investigated material culture in archaeological studies, largely due to their perceived ability to identify prehistoric groups, and the construction of relative chronologies based on ceramics (Robinson 1959; 1961d; 1966; Huffman 1974; 1980; 2007; Pikirayi 1993; 1997; 1999; 2002; 2007; Ndoro 1996; Lindahl and Matenga 1995). While ceramics have dominated Material Culture Studies, other material remains have also been studied, albeit on a smaller scale. These include metallurgical artefacts (Herbert 1996; Chirikure 2007; Thondlana and Martinon-Torres 2009; Bandama et al. 2015; 2016), both glass and shell beads (Bvocho 2005; Antonites 2014), ivory remains (Reid and Segobye 2000; Forssman et al. 2014; Coutu forthcoming), and faunal remains (Voigt 1983; Thorp 
1995; Shenjere-Nyabezi 2013). In the few cases where these have been studied, they have been studied separately and independently of each other, and have not contributed much to the discourse on the development of the Iron Age in the region. However, there is a need to study material culture remains in a holistic manner, so as to create a better understanding of their unique spatial and temporal cultural identities (Schoeman 2014). Integrated research also enables researchers to make inferences based on object-to-object relation. It is, however, refreshing to note that a number of material studies are being done that are influencing our understanding of the nature of the development of the Zimbabwe Culture in the region. Chemical analysis on beads is shedding light on the source of most of the beads that came to southern Africa (Robertshaw et al. 2010; Prinsloo et al. 2011; 2012; Koleini et al. 2015), while studies on other foreign materials are showing that our previous understanding of the chronology of the Zimbabwe Culture, which was based on radiocarbon dates, is skewed (Koleini et al. 2015; Prinsloo et al. 2005; 2011; 2012).

The earliest focus in Material Culture Studies in southern Africa was on the early discoveries and descriptions of lithics particularly in the Cape region of South Africa (Deacon and Deacon 1999). Antiquarians such as Bent (1896) and Hall and Neal (1902) used evidence of foreign material to argue for an exotic origin of the builders of the dry-stone-walled structures dotted around the Zimbabwe plateau. This material included glass beads, Chinese celadon, glazed stoneware and various types of glasses imported from Europe and Asia. While MacIver (1906) and Caton-Thompson (1931) acknowledged the role of the indigenous Shona populations in the authorship of the Zimbabwe Culture, they also used foreign objects to argue that it was trade with the outside world that provided the stimulus for the development of the state systems and centres associated with the Zimbabwe Culture.

One of the overarching features of Material Culture Studies in southern African archaeology has been the need to define the cultural history of the region (Wyne-Jones 2013). Accordingly, typological analysis of material culture from archaeological sites was used to build up site-chronologies. This exercise was the preoccupation of early European archaeologists on the continent, who felt they had to construct a history of the continent because none existed prior to their arrival. Hall (1983) noted that archaeological-culture 
societies were then seen as unchanging entities that were only replaced through a process of either migration or diffusion. This view resulted in settlement sequences at sites such as Great Zimbabwe being attributed to migrations, without any consideration of the possibility of continuity (Garlake 1973, Hall 1983). As such, early Material Culture Studies focused on creating typologies based mainly on stone tools for the Stone Age period and ceramics for farming community societies, resulting in publications such as Schofield's Primitive Pottery (1948), which attempted to distinguish various ceramic remains in time and space. Prior to this, Caton-Thompson (1931) had built a ceramic sequence for Great Zimbabwe and other sites that she excavated. Summers (1958) also attempted to develop a chronology of Eastern Zimbabwe from his research, which was focused on the site of Ziwa in Nyanga Mountain. As noted earlier, all these studies focused on creating a chronology of the area, with less energy spent on trying to understand other pertinent issues like related material culture and the implications of ceramics in the reconstruction of the lifeways of prehistoric communities. The 1970s witnessed the definition of a new ceramic typology framework that focuses on the three dimensions of shape, size and decoration (Huffman 1980). This framework has since been widely applied in most southern African archaeological studies, with ceramic typology being incorporated into the model to identify prehistoric groups (Huffman 1980; Pikirayi 1993; Pwiti 1996; Manyanga 2006; van Waarden 1987; Denbow 1981; Denbow et al. 2008; Hanisch 1980). Wynne-Jones (2013) has noted that ceramics have been central to Material Culture Studies in Africa because of the perceived links between style and cultural identity.

The ceramic typology framework developed by Huffman has been criticised on a number of grounds. Foremost is the framework's problematic emphasis on material culture classification as a means for establishing site and regional chronologies. This emphasis is placed at the expense of other key issues, such as ideology, social organisation, and gender relations (Hall 1984; Pikirayi 1999; 2007). The focus on ceramic typologies has framed material culture as "things", ignoring the people and communities behind them. Put otherwise, the current framework in southern African archaeology allows us to understand the pots and not the individuals who manufactured and used them (Pikirayi 2007: 298). Pikirayi in particular has bemoaned the lack of ethnographic enquiry into ceramic studies, which he claims could help in understanding the social and symbolic meanings of ceramics and their production process. As it stands, there is no understanding of the dynamic nature of prehistoric African societies, 
which are all clustered according to ceramic decoration similarity. As Dores Cruz (2011) argues that a focus on material objects and their correlation with ethnicity is limiting and does not take into account the day-to-day lifeways of the people who made and used these objects. More recently, a number of archaeologists have begun to focus on ethno-archaeological ceramic enquiries (Lindahl and Matenga 1995; Pikirayi and Lindahl 2013).

Material culture has also been used to identify prehistoric groups, mainly through ceramic typology (Huffman 1974; 1980). This approach has been criticised for assuming that ceramic boundaries were all inclusive and static (Pikirayi 2007; Dores Cruz 2011). The subsuming of other material culture gives the impression that they had no contribution to the formation of the identities of prehistoric groups. The lack of interdisciplinary research in this area has resulted in archaeologists largely ignoring the many decorative similarities that occur on a variety of material culture, including ceramics, wooden objects and stone-walling, which have the potential to enrich our understanding of prehistoric social groups (Pikirayi 2007). However, of late, other researchers have begun to focus on the meanings and symbolism behind pottery making, as a way to understand prehistoric pottery making and use (Lindahl and Matenga 1995; Pikirayi and Lindahl 2013).

As indicated earlier, other material culture remains have been recorded from southern African archaeological contexts. These include metallurgical assemblages, such as weaponry, construction material, farming implements, domestic tools, as well as items of personal adornment. Early studies in southern African archaeology focused on making inventories of metallurgical artefacts and identifying metals in the archaeological record (Robinson 1959; Fouche 1936; Gardner 1963; Garlake 1973). This approach was taken despite the fact that metallurgical assemblages can help illuminate the role of metallurgy in the development of non-stratified and stratified societies, the lifeways of these people, internal and external trade, and the craft-production industry of precolonial societies. However, scholars have more recently been focusing on a number of issues related to metallurgical studies in the region. These include understanding the organisation and control of precolonial mining and ore processing, the manufacture of metal products, the acquisition of mineral ores for those areas that did not have a local supply, and the exchange arrangements that were in place regionally 
and internationally (Huffman et al. 1994; Chirikure 2006; 2007; Chirikure and Rehren 2004). Focus is also being placed on ritual and power relations resulting from the availability of metals such as iron (Schmidt 1997; Childs 1991; Herbert 1996).

Other important material culture objects in southern African archaeology are glass beads. Glass beads were brought into the region via the East African Indian ocean trade. Most of the glass beads have been traced back to southern Asia through chemical analysis (Robertshaw et al. 2010; Prinsloo et al. 2011; Koleini et al. 2015). Early bead studies in the region sought to use glass beads as temporal markers (Caton-Thompson 1931; Robinson 1958; 1961c). However, the major constraint in this endeavour was the lack of knowledge about the time periods of the different glass beads as well as the lack of comparative data (Wood 2000). Wood $(2000 ; 2011)$ has focused on describing the main glass bead series in southern Africa and their potential in dating sites. She has also focused on identifying the trade networks through which the glass beads reached southern Africa. Of late, scholars have applied technologies from other sciences in a bid to answer questions relating to the origins of various glass beads found in the interior and refine Wood's chronology (Dussubieux et al. 2009; Robertshaw et al. 2010; Koleini et al. 2015). Robertshaw et al. (2010) used laserablation inductively coupled plasma mass spectrometry (LA-ICP-MS) and concluded that some of the early glass beads of the first millennium were made from Iranian glass. Beads linked to later farming communities were made of glass manufactured in south Asia, though there are changes through time on both south Asian glass recipes and bead morphologies.

An important element of the Iron Age in southern Africa is the presence of dry-stone-walled structures across the region. Van Waarden (2012: 73) has suggested that there are 558 sites of the Zimbabwe Culture in Botswana, Mozambique, South Africa and Zimbabwe. Scholars have used dry-stone-walling construction techniques to define the various phases of the Zimbabwe Culture. These Great Zimbabwe phase, which was based in the south-central and northern parts of the Zimbabwe plateau was characterised by freestanding walls that formed enclosures in which houses were constructed. This pattern was distinct from Khami and Mapungubwe, where artificial tiered platforms were constructed around kopjes, dwalas and large boulders (Robinson 1959; Summers 1971; Pikirayi 2013). 
The above synthesis of Material Culture Studies in southern Africa has shown that typological characterisation has been and continues to be the cornerstone of all studies in the region. As highlighted earlier, the challenge with typological characterisation is that we learn very little about the life of the object as it was used by the people who engaged with it. There is also very little interaction during analysis between different material culture objects, as there is a tendency to analyse and study objects separately. As a result, archaeologists fail to discuss lifeways at sites based on all the materials recovered. In this regard, LaViolette (2008: 43) proposes the need to discuss the African past without having to typologise and differentiate the indigenous from the exotic. This principle applies to artefacts, idea and even religious persuasions. In the next section, I present how I applied Material Culture Studies to the present investigation.

\subsection{OBJECTS IN MATERIAL CULTURE STUDIES}

It is important to provide a review of what objects are and how they can assist archaeologists in their investigations. Objects have been defined as 'symbols encapsulating the beliefs of a given culture at a particular moment in time through their physical form and decoration' (Ames 1994). Objects are like palimpsests, having an evolving series of meanings over time that is largely dependant on context. Three forms of identity have been noted for objects (Hodder 1987; Pearce 1994b). The first refers to their functional or utilitarian value, which is important to the individual or society that owns the object. The functional role of an object can be inferred from its design and the materials from which it is formed (Maquet 1993; Horsfall 1987).

Secondly, objects have a symbolic meaning. Symbols can mean different things to different people at different times (Clarke et al. 1985; Schiffer 1999). For instance, an axe may be a fighting weapon for a warrior, yet in the hands of a community leader it performs a ceremonial or ritual function as a symbol of authority. Objects also embody and shape the identity of their makers and users (Chilton 1999). In some societies, the belief that spirits can reside in objects makes them significant and important to believers, and places restrictions on 
use, ownership and handling. The symbolism of objects can also be deduced from the way a society values the object. These values include the intrinsic, aesthetic, social and exchange values. The values that objects are ascribed are also important in promoting exchange within and outside a society and, in turn, wealth accumulation, which has been argued to lead to the formation of hierarchical societies (Renfrew 1986; Kopytoff 1986).

Thirdly, objects embody and signify past experiences. Through the application of a number of technical skills and analytical techniques, it is possible to discern more information relating to an object that was made in the past. This information can include the material's composition, the manner in which it was assembled, and possibly some of the incidences in its life. Nineteenth-century scholars systematically grouped similar objects together by various typologies, including shape, function, material and decoration (Woodward 2007). These could be correlated with historically known peoples, periods or places. It is also possible to have an understanding of prehistoric technological traditions through object analysis. This includes understanding prehistoric mining and mineral processing, smithing, tool manufacture, construction techniques, hunting strategies, agricultural mechanisms, among other technologies.

\subsection{APPLICATION OF MATERIAL CULTURE THEORY TO CURRENT STUDY}

Material Culture Theory was applied to this study due to its potential to extract information from the objects recovered or associated with Khami. An analysis of the material culture distribution from Khami will assist in understanding the relative status of the people at Khami according to their settlement areas. Some scholars have dichotomised prehistoric society into the elite and the commoner based on access to certain material culture (Costin and Earle 1989; Chase and Chase 1992; Huffman 1996). The elite are generally assumed to have had better access to housing, wealth and luxury goods, particularly foreign imports. I will therefore look out for trends in the distribution of all material culture so as to understand the dynamics of status distinction at Khami based on artefact distribution. These trends essentially also bring out the relationships that existed among the people who inhabited the site. These relationships are important to understand because they help in explaining how the people at Khami organised themselves the way they did; they can only be understood by 
reading from the material record, which speaks about the various parts that make up the site. As such, a focus in this study was also on broadening the investigation to incorporate material evidence from various parts of the site, including the walled and non-walled contexts. The dichotomisation of society at Khami has resulted in a narrative in which all the components of the site are dichotomised too. As such, in terms of settlement, there are elite and commoner zones, but with no specific indication of who is elite and who is commoner. This dichotomisation evinces very little understanding of the distribution and spread of material culture at the site, hence the need to investigate multiple areas and compare the material record.

Material culture also aids in understanding economic activities at the site. For instance, foreign imports point to trading activities with the outside world (Wood 2000; Bvocho 2005; Manyanga 2006). It is important to understand how trade was organised with the outside world and who participated in it. Historical syntheses of Portuguese observations about the Mutapa state to the north (Mudenge 1974; 1988; Beach 1980; Randles 1981; van Waarden 2012) were also consulted to supplement the material evidence from the site. While the Portuguese did not write much about the site, they did make references that attest to Khami's importance in the region. Specifically, their reports speak of Khami's fame as a goldproducing country, a commodity that was much sought after by both Swahili and Portuguese traders from the East Indian Ocean coast (Ellert 1993). The discussion on trade will also attempt to understand the nature of local relations between the people at Khami and those within the wider Butua state. As shown in Chapter Three, the Butua state, of which Khami was the capital, stretched to as far as the north-eastern parts of Botswana and the Soutpansberg region in South Africa. I will therefore seek to understand the nature of relations between Khami and these satellite centres based on their material culture. The nature of craft production at the site will also help clarify the nature of local trade and organisation of production. For instance, we know that there are no copper mines around the Khami area. Yet copper smelting and object manufacturing was done at Khami (Robinson 1959). Understanding the distribution of copper mines in the region can assist in plotting the nature of local trade in this region. 
The economic basis of the state will also be understood by looking at the manufacturing industry at the site. The presence of slag and ivory waste are pointers to the presence of such an industry. However, there is need to understand how this industry was organised, specifically whether it was a large-scale workshop-based or a simple household-based subsistence mode of production. Large-scale workshop-based production is identified with large amounts of waste and is ordinarily located outside the domestic sphere (Costin and Hagstrum 1995). On the other hand, subsistence-based domestic production is ordinarily meant to fulfil the needs of the household and facilitate the limited trading of surplus. The recovery of material objects like agricultural tools also points to the importance of agriculture in the economy of the site. While it is difficult to recover cloth in the archaeological record, I will use material evidence such as spindle whorls to understand the organisation of cotton production at the site. Special emphasis will be placed on identifying the context of production.

Overall, the recovered material culture should be able to assist in creating an understanding of the distribution of activities at the site. For instance, particular concentrations of particular objects, such as spindle whorls, in one context might be pointers to a centralised workshopbased mode of production. On the other hand, if distribution is dispersed across the site, this will point to individual household-based production. The nature of the production model at the site will have an implication for the relations of the people at Khami. Centralised and workshop-based production is ordinarily associated with a controlling elite in charge of production - in short, a hierarchy-based class system. In contrast, subsistence-based household production is ordinarily controlled at the household or lineage level, with no central elite control. In such a scenario, even social relations are horizontal, with members of society having more or less equal status. Generally, the settlement is divided into walled and non-walled areas. Particular attention will be paid to the differences or similarities in the material record from the two areas, as a way of understanding status.

Material culture and objects also help in identifying differences in social status and ethnicity (Crabtree 1990:156). In particular, studies of faunal remains can contribute to an understanding of urban processes, especially when one compares hunter-gatherer 
communities and farming communities. In the context of southern Africa, the development of sedentary communities has also been accompanied by increased domestication and the rearing of cattle and other small stock. Thus, for instance, it has been noted that the later farming communities in southern Africa depended on cattle resources more than their counterparts in the early farming communities (Pwiti and Mawoko 1997).

Objects also have important social and religious significance among people. In most societies, communities have expressed their religious beliefs through material culture (Meskell 2005). In certain instances, objects may appear to be merely ordinary, utilitarian objects, but the manufacturers or users would have seen them with a different eye, infusing them with spiritual significance. This significance therefore requires that Material Culture Studies be supplemented with an understanding of local knowledge systems, in order to elucidate the meaning of objects in Shona traditions (Chirikure 2015). Accordingly, Chirikure (2015: 709) and Bvocho (2005: 419) point to the religious significance that beads had in society, particularly red-, white- and black-coloured beads, because of the association of these colours with traditional religious rites.

\subsection{SUMMARY}

In order to reconstruct the lifeways of the people at Khami, it is important to study its material culture through excavations and existing museum collections. Excavations at the site will take into consideration the various parts that make up the site. In particular, focus will be placed on the non-stone-walled components of the site, which have not received any attention in the past (Robinson 1959; Thorp 1995; Hughes 1997). An analysis of museum collections from past excavations will be conducted, to come up with comparative data for the stonewalled sections of the site that were excavated by Robinson (1959) and Thorp (1984; 1995). Before deciding on areas of further investigation, I carried out a review of current knowledge on the archaeology of Khami, which is the focus of the next chapter. 


\section{CHAPTER 3: CURRENT UNDERSTANDING OF THE ARCHAEOLOGY OF KHAMI}

\subsection{INTRODUCTION}

Having explored the centrality of Material Culture Studies in archaeology in general, and the disciplines's potential to enhance our understanding of Khami, I now provide a detailed review of existing research on the site. This review considers historical sources, specifically Portuguese documents from the sixteenth century (Beach 1980; Randles 1981; Mudenge 1988; Pikirayi 2001; van Waarden 2012). Portuguese missionaries and traders did make important observations that enable a partial reconstruction of the development of the site, its subsistence strategies, political organisation and eventual demise. Oral traditions have also been used in reconstructing the history of the Butua state (Beach 1980; van Waarden 1988; 2012). Van Waarden (2012) provides a synthesis of some of the oral traditions that assist in illuminating social organisation in the Butua state. Archaeological research has also been carried out on the site, shedding light on a number of issues, including the culture history, subsistence strategies, economy, architectural tradition and spatial organisation at the site. As the following discussion shows, there are a number of issues that previous researchers acknowledge as requiring more investigation (Robinson 1959; Huffman 2007; van Waarden 1998; 2011). These issues, which include the origin and chronology of the site, its material culture, the need to reconstruct lifeways at the site, and the relationships between the various components that make up the site, provide the rationale for this study.

\subsection{HISTORICAL SOURCES AND ORAL TRADITIONS}

There are very few historical sources that relate to Khami. This paucity is owing to the fact that the Portuguese, who provide some of the earliest accounts on precolonial Zimbabwe, were mainly focused on northern Zimbabwe, where they were conducting trade with the Mutapa state. However, a number of scholars have used these Portuguese sources, along with oral traditions from south-western Zimbabwe and northern Botswana, to recreate a historical account of Khami (Mudenge 1974; Beach 1980; Randles 1981; van Waarden 2012). Various sources give insight into the origins, economic subsistence, organisation and eventual demise of Khami. Portuguese records show that Khami was the centre of a state that was referred to 
as Butua, while the rulers were referred to as the Torwa (Beach 1980: 198; van Waarden 2012). Oral records collected by Wentzel among the Kalanga groups in northern Botswana (quoted in van Waarden 2012: 51) show, however, that the local rulers at Khami were from the Chibundule lineage. This lineage continued to rule until the demise of the state and the takeover by the Changamire dynasty, which ruled from Danangombe from the 1680s to 1831 (van Waarden 2012).

Portuguese sources show that the earliest reference to Khami was made in 1502 by Ahmad Ibn-Madjid, an Arab pilot of Vasco da Gama (Beach 1980; Randles 1981: 9; van Waarden 2012). Ibn-Madjid made reference to the gold-mining activities in the Butua state. In particular, he noted that by this period the Torwa were trading via the Zambezi River, thereby circumventing Great Zimbabwe in the process. Antonio Fernandes, another Portuguese trader, also mentions the Butua state and makes reference to its gold mines and its strength, which he equated to that of the Mutapa state (Beach 1980: 49; van Waarden 2012). The rise of the Butua state is said to have been precipitated by a decision in the early fifteenth century by the Sultanate of Angoche to establish alternative trading routes along the Zambezi River (Beach 1980:48; van Waarden 2012). This effectively meant that trade from the southwestern Woolandale chiefdoms was able to by-pass Great Zimbabwe, a situation that is argued to have possibly contributed to the decline of Great Zimbabwe as a regional centre of power, since the community now had no effective control over the gold mines in the southwest (van Waarden 1998; 2012). As a result, Khami was established as a new centre of power and the capital of the Butua state, trading directly with the Portuguese via Ingombe Ilede on the Zambezi River. Therefore, van Waarden (2012) is of the opinion that the rise of Khami as a capital could probably have led to the demise of Great Zimbabwe and not the other way round, as Huffman $(1981 ; 1984: 603)$ has postulated. She argues that the rerouting of trade routes via the Zambezi River had an economic impact on Great Zimbabwe, since control of trade was said to be one of the major pillars of the society's economy (Garlake 1974; Beach 1977; 1980). Van Waarden has also dismissed the suggestion that a ruler from Great Zimbabwe moved west to establish Khami. She has shown that the terraced-walling architecture of Khami and that of the preceding Woolandale phase of Leopard's Kopje had a great deal in common, suggesting that Khami developed as a result of the rise to prominence 
of a local Leopard's Kopje chief (Robinson 1985; van Waarden 1998; 2011; Chirikure et al. 2013: 15).

Oral traditions have shown that land was an important means of production, and one that was highly valued at Khami for its reproductive value. Various crops, such as sorghum and millet, were cultivated. Cattle also played an important role in the economy of the country. A herdmanagement strategy based on use-loan of cattle ensured that a lot of people had access to cattle for farming and other activities (Mudenge 1988). Under this practice, the owner gave control of his cattle to another person but retained ownership. The person receiving the cattle could use them for farming, milking and other activities, but could not kill or dispose of them. In this way, even ordinary members of society benefitted from a system that encouraged production and limited the redistribution of wealth. On the other hand, those with more cattle would subsequently be in a position to command respect and authority from those who did not, and so have influence in the society. Mining was another important economic activity. Portuguese documents by Barretto in the seventeenth century show that mining was normally done during the winter season, when there was little agricultural work (Mudenge 1974: 389; Randles 1981: 53). The scale of gold mining and trade in the region resulted in the Portuguese referring to the Butua state as the 'Mother of Gold' (Beach 1980; Mudenge 1988; Ellert 1993: 22). However, Mudenge (1974: 389) has noted that it appeared the Torwa valued their farming pursuits more than the mining of gold. One Portuguese observer, Fr Joao dos Santos (quoted in Mudenge 1974: 389), complained that the Torwa were preoccupied with cattle breeding and had little interest in digging for gold, thus attesting to the importance that the Torwa placed on their cattle as a form of wealth even more valuable to gold.

Historical records have also shed light on the circumstances leading to the demise of Khami as a capital. It is known that the demise of Khami occurred during the $1680 \mathrm{~s}$, when Changamire, a Karanga chief from the north-east usurped power (Beach 1980; Pikirayi 2001; van Waarden 2012). The takeover was precipitated in the 1640 s by a fallout between the ruling Mambo and his brother, who eventually took over the seat of the Mambo at Khami after the Mambo fled to Manyika. The deposed brother sought the assistance of the Portuguese and eventually reoccupied the throne at Khami. However, the intervention of the 
Portuguese weakened the capital considerably. The weakening of the capital and the vast mineral wealth in the form of gold could have pushed Changamire to attack and takeover the rulership of the state, establishing his capital at Danangombe. The new capital continued to thrive until the 1830s, when Nguni groups fleeing the Mfecane wars in South Africa began to arrive, threatening the stability of the state, which was assimilated into the new Nguni states established by Soshangane and Mzilikazi in south-eastern and south-western Zimbabwe respectively (Beach 1980: 265; Pikirayi 2001: 218).

\subsection{ARCHAEOLOGICAL RESEARCH}

Archaeological research on Khami has sought to answer a number of questions primarily related to the origins, economy, socio-political organisation and identity of its people. The question of the identity of the builders of Khami was tackled during the early days of colonialism, in the face of competing claims to the authorship of the site (Hall and Neal 1902; MacIver 1906). Antiquarians attributed the construction of the sites to Phoenicians from the Arab world (Hall and Neal 1902). Further investigations at the site were carried out by a professional archaeologist, David Randall-MacIver in 1905, following concerns about the destructive nature of some of the antiquarians' activities, which were disguised as archaeological research. Randall-MacIver argued that the sites were local in origin, products of the local Shona groups, due to similarities in material culture. His findings were confirmed by Getrude Caton-Thompson (1931) who, despite not having excavated at Khami, showed that the site was the product of local Shona groups, on the basis of evidence from similar sites as Danangombe.

Keith Robinson carried out the most extensive investigations at the site, focusing on trying to understand the nature of the stone-walled sections of the site, in particular the Hill Complex, which he argued was the seat of the leader at the site. Very little was done at the other walled platforms making up Khami, and virtually nothing in the non-walled sections of the site. Carolyn Thorp excavated a midden associated with the Hill Complex in 1979, with the intention of recovering a faunal assemblage to reconstruct the dietary patterns of the people at Khami (Thorp 1995). In 1989, Gwilym Hughes excavated two house floors on the Northwest Ridge, in an area he described as a commoner settlement area (Hughes 1997). All these 
research efforts have contributed a body of knowledge related to the site that has enriched our current understanding of the archaeology of the site. The following sections focus on various aspects of the archaeology of Khami, including its origins, stone-walling and dhaka structures, other material culture, sequence and chronology, as well as spatial organisation.

\subsubsection{ORIGINS}

The question of the origin of the builders of Khami attracted the attention of early antiquarians and the white settler community in general, who marvelled at the monumentality of its structures (Hall and Neal 1902; White 1901; 1903; Gill 1903; Garbutt and Johnson 1912). Due to this monumentality, the local white population felt that Khami could not have been designed and constructed by local groups, and instead attributed the structures to some Phoenician groups from the Arab world (Hall and Neal 1902; Hall 1905). To support their propositions, the proponents of this idea turned to antiquarianism in search of evidence that would support their claims. As a result, objects of foreign import in the archaeological record were argued to have been brought into the country by Phoenicians during the period of their occupation of the site. These included glass beads and ceramics of Asian or European design. It is critical to note that most of the publications that were released during the early twentieth century by antiquarians on the archaeology of the site were not archaeological in nature. Instead they were attempts to justify their antiquarian activities in the face of outrage from the scientific community and the general public regarding the destruction they were effecting to the site. Hall and Neal (1902) detail some of these excavations (Figure 3.1), which were done on No. 8 (Passage) and No. 9 (Precipice). However, as noted earlier, these excavations were selective, with consideration being given to material of European origin as confirmation of the Phoenician-origins theory. 

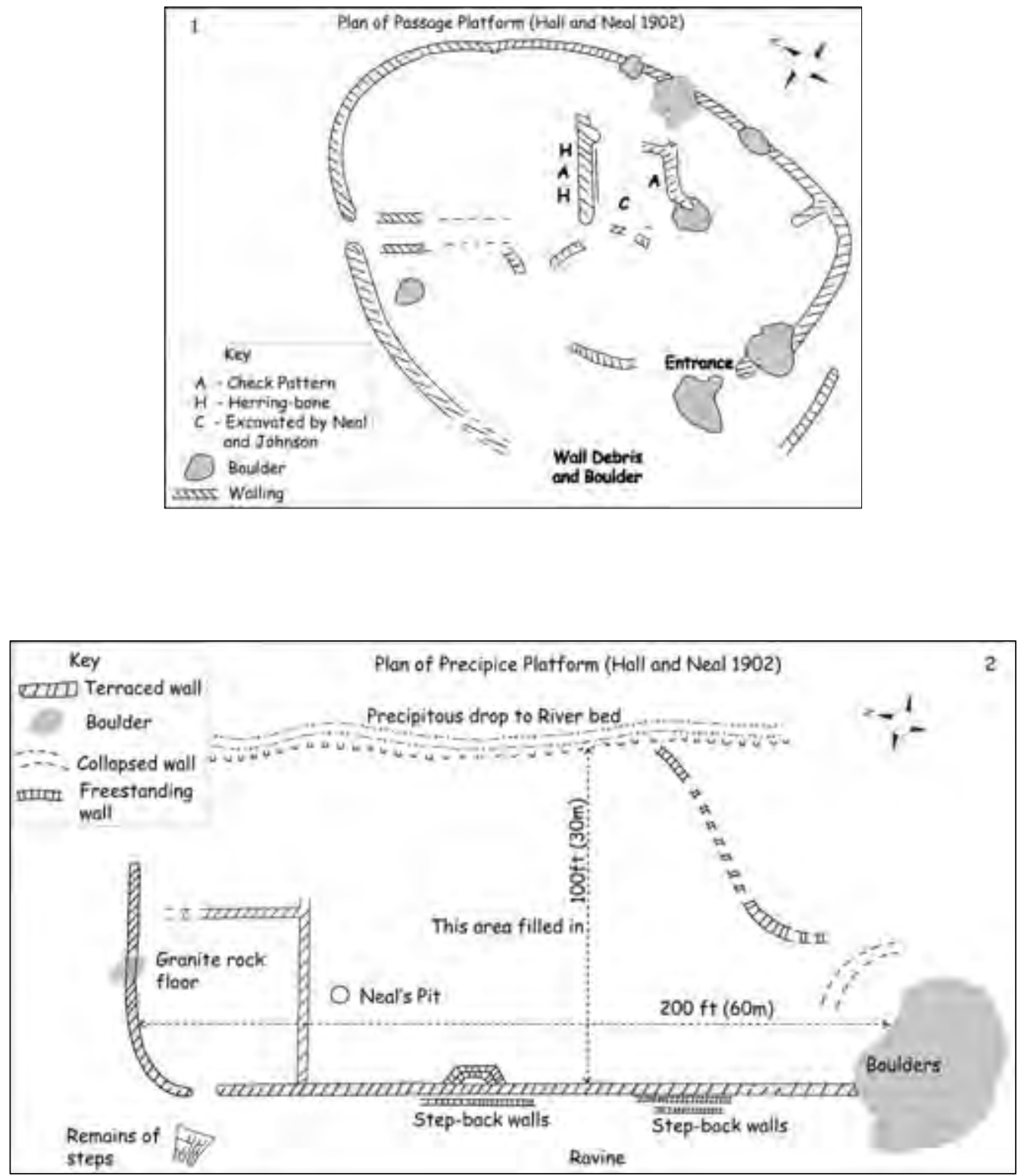

Figure 3.1: Plan of the Passage (1) and Precipice Platforms (2) showing the position of the excavation trenches by Neal and Johnson (Redrawn after Hall and Neal 1902).

Following protestations about the destructive work of Hall and Neal, a professional archaeologist, David Randall-MacIver was engaged by the British Society for the Advancement of Science to investigate the site. The objective of his assignment was to determine its origin and the builders of the stone walls. In this regard, MacIver (1906) excavated the site and studied the housing structures. He noted similarities with material from contemporary Shona communities and argued that ancestors of contemporary Shona groups should be credited with the building of the stone-walled structures. He attributed the presence 
of material of Asian and European origin to trade with the Swahili and Portuguese from the East Indian Ocean Coast. MacIver's findings were confirmed by Gertrude Caton-Thompson (1931) who inspite of not having worked at the site investigated similar sites such as Danangombe and Great Zimbabwe.

\subsubsection{STONE WALLING AND DHAKA STRUCTURES}

The structures at Khami are important as markers of chronology and identity (Summers 1971; Garlake 1970; Pikirayi 2013). These stone walls form the largest visible remains at the site. Terracing to create platforms enabled the construction of houses on top of the platforms. Terracing is the most common structural construction type, although there are a few low freestanding walls that demarcated space.

The dry-stone-walls at Khami are profusely decorated with a variety of patterns. The most popular pattern is checker (Figure 3.2; 3.3), which occurs on most of the platforms at the site. Other patterns include herringbone, cord, dentelle, contrasting slabs of blue dolerite (Figure 3.4) and chevron. The Hill Complex, which is the most impressive of all the platforms, has been described as the King's residence (Robinson 1959; Huffman 1996). Access to the Hill Complex is by way of three entrances: the western entrance, which leads directly to some of the houses on the summit of the complex, and the passage or southeastern entrance, which meanders its way to the summit of the complex. The third access leads from the north-east and leads directly to the river. An analysis of the structures along the southern passage suggests that it was difficult to access the summit (Robinson 1959). 


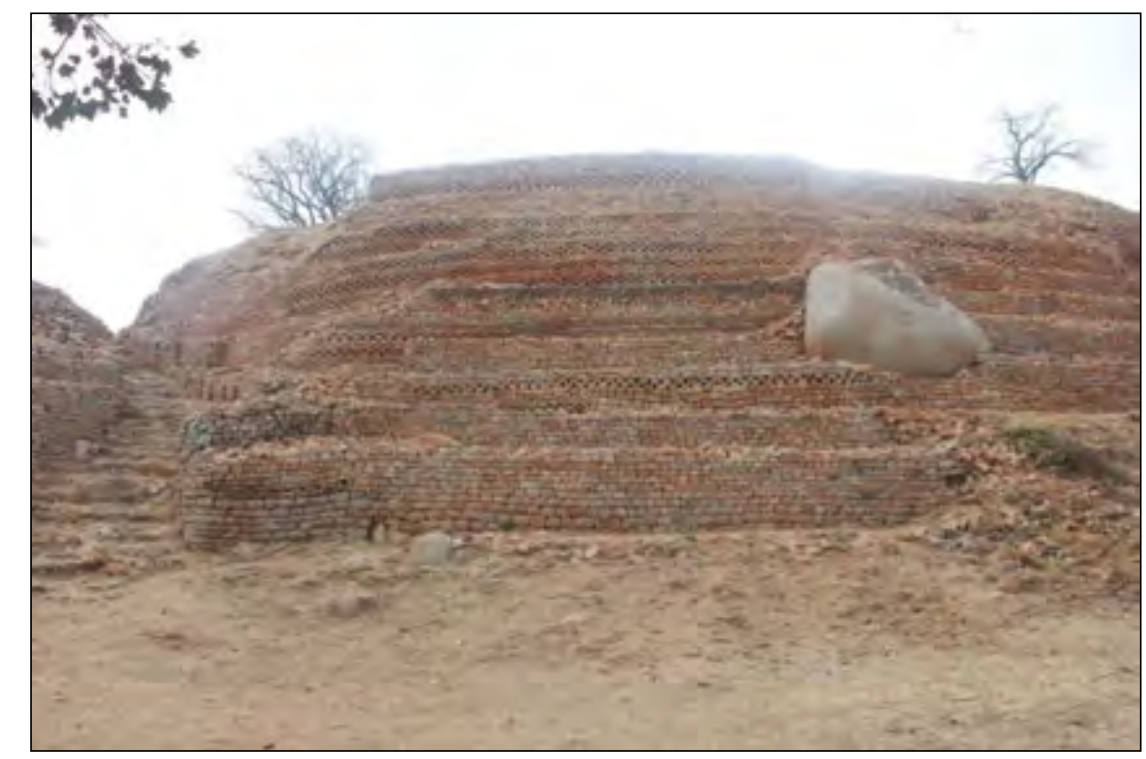

Figure 3.2: The western slopes of the Hill Complex, showing terraces 1-8 (from the bottom upwards). Terraces 3 and 6-8 are profusely decorated with checkers but Terrace 5 has a cord pattern.

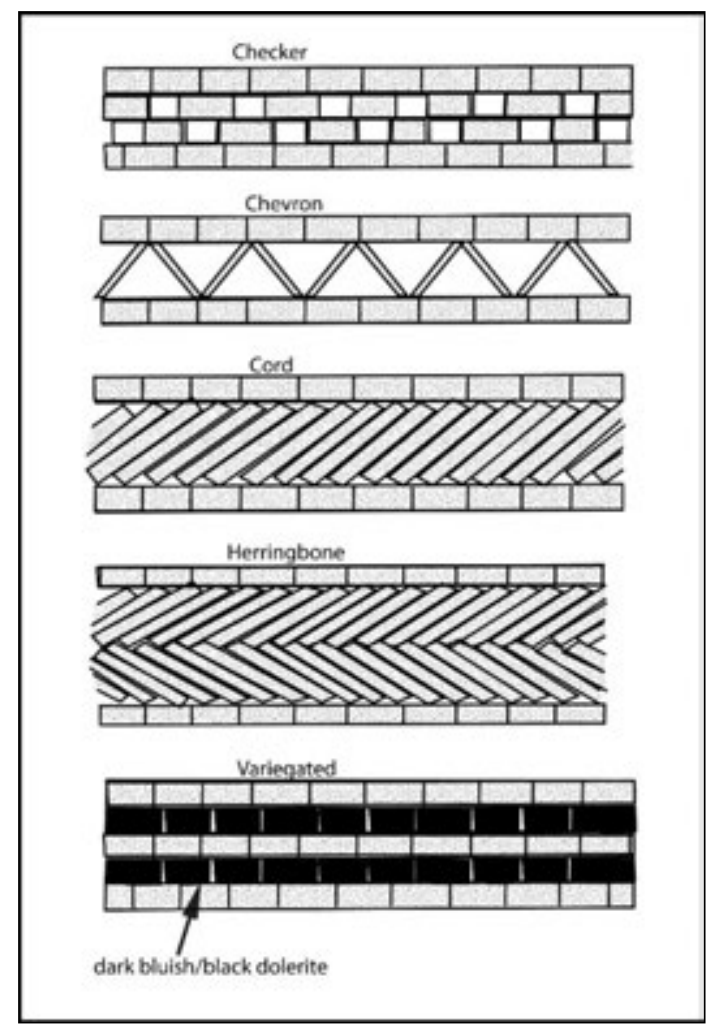

Figure 3.3: Wall decorations styles at Khami (Adapted from van Waarden 2012: 74). 


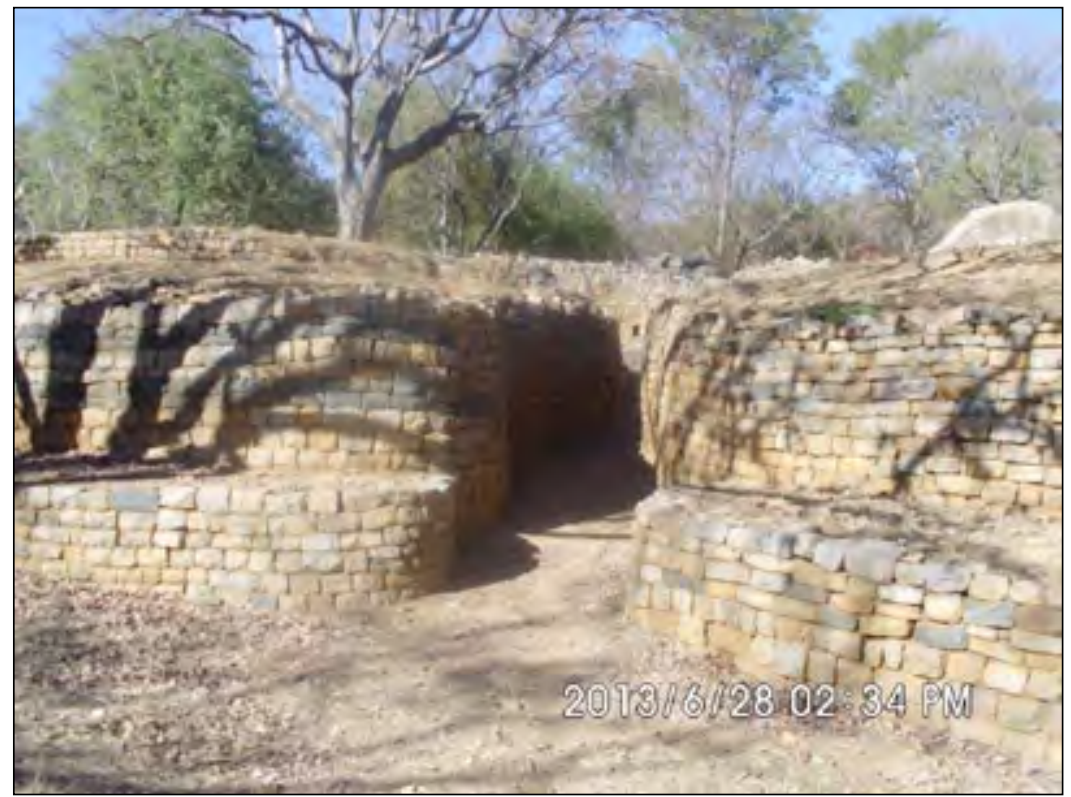

Figure 3.4: The Passage platform showing contrasting coloured blocks, on the left side, for aesthetic effect at the entrance to the platform.

Construction of the walls at Khami also involved use of other materials, such as wooden posts and boards (Figure 3.5). Wooden posts were used to support the roof on the passage leading up the Hill Complex. They were also used as supports for houses at the site. Wooden boards were incorporated into wall construction as lintels, particularly in instances where a surface was uneven and it was difficult to build a stable wall.

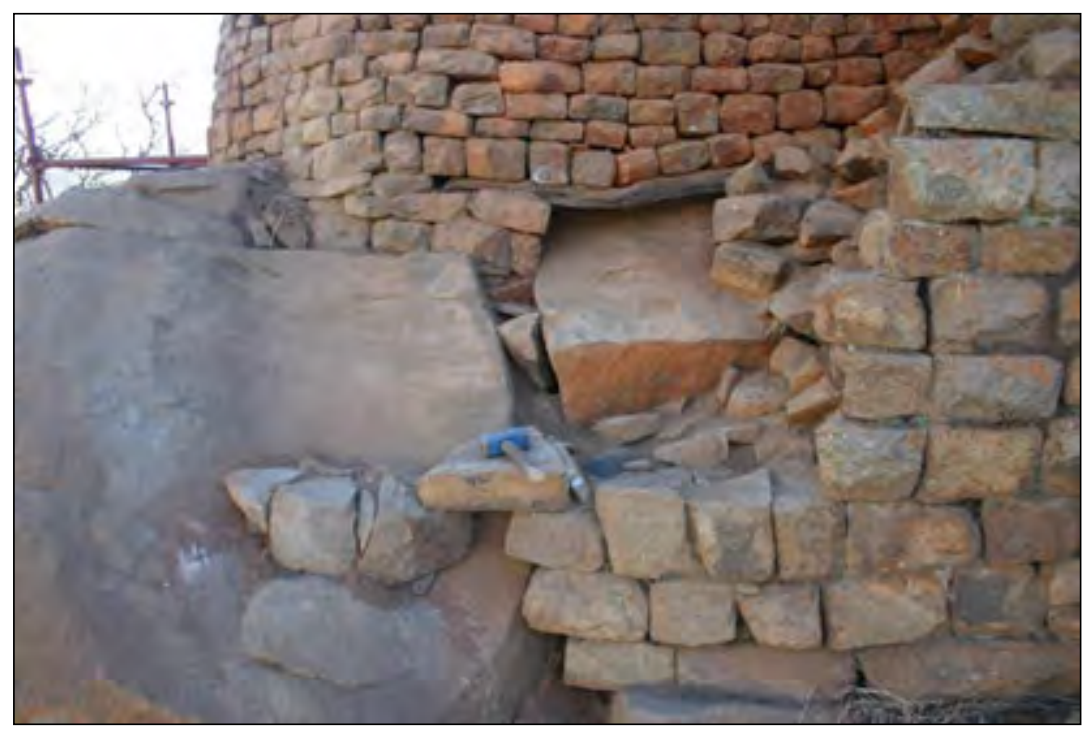

Figure 3.5: Drystone wall construction at Khami also incorporated other materials to stabilise the uneven surface. Here, wood was used to create an even surface across a boulder on the Cross platform. 
Cooke et al. (1966: 7) used dry-stone-walling classification to develop a chronology of the site based on that developed for Great Zimbabwe. The researchers argued that the drystone-walled architecture at Khami was similar to that of Period IV at Great Zimbabwe, and that Khami therefore fell into the same time-bracket as Period IV at Great Zimbabwe and was a south-western variation of Great Zimbabwe. However, Garlake (1970: 503) noted that there were fundamental differences in the form, function and decoration of Great Zimbabwe and Khami, which made them two separate phases. While Great Zimbabwe walls are mainly freestanding, those from Khami are terraced to create platforms (Figure 3.6). Decorations applied on the walling of the two sites differ, with Great Zimbabwe dominated by chevron patterning and Khami dominated by checker patterning.
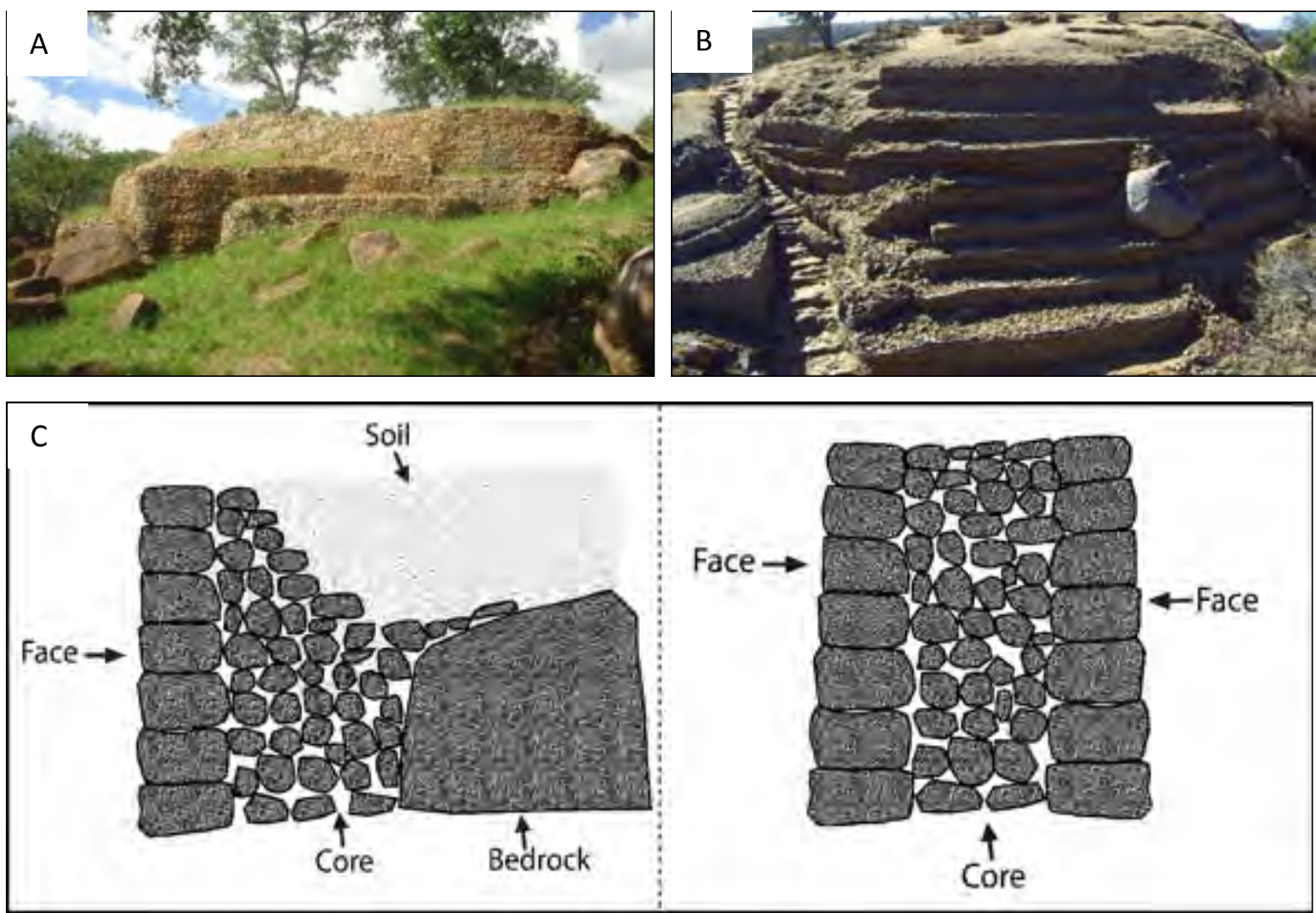

Figure 3.6: Terraced walling on the Cross Platform (A) and the Hill Complex (B). A schematic (C) of dry-stone terraced platform (left) and freestanding wall (right) (Ndoro 2005: 23).

Garlake (1970) has classified the settlement wall structures of the Zimbabwe Culture into three distinct styles. Style I and II are dominated by freestanding walls. These walls form 
enclosures inside which houses for the elite were constructed. The chevron design is the most dominant design in this style. Style III is dominated by terraced walls constructed to create platforms on top of which clay-plastered houses for the elite were built (Figure 3.6) (Garlake 1970; Pikirayi 2001; 2013; van Waarden 1998; 2012). A geographical variation of wall styles has been noted, with freestanding walls dominating the south-eastern and northern parts of Zimbabwe, while terraced platforms dominate the south-central and southwestern parts of Zimbabwe, extending into north-eastern Botswana and northern South Africa. Van Waarden (2011) and Chirikure et al. (2013a) have also noted a number of similarities between Khami-phase settlement structures and those of the Leopard's Kopje, which preceded Khami. However, no developmental relationship has been drawn between Khami and Leopard's Kopje. Instead, as a result of its late chronology and perceived similarities with Great Zimbabwe, based on the presence of dry-stone walling, Khami has been argued to be a successor to Great Zimbabwe (Robinson 1959; Huffman 1984: 603).

Stone walling at Khami was always accompanied by dhaka (earthen) structures, which are remnants of houses at the site. These were recorded both on top of the platforms as well as outside the stone-walled platforms (MacIver 1906; Robinson 1959; Hughes 1997). Researchers at the site have exposed a number of housing units, with a view to understanding their structure and material composition (MacIver 1906; Garbutt and Johnson 1912; Robinson 1959; Hughes 1997) (Figure 3.7). One important realisation that has emerged is that most houses at Khami tend to be complex and multi-compartmental. Others were simple single-compartmental houses. Most of the complex houses have central circular rooms, sometimes as long as six metres in diameter. Radial walls from the central compartment resulted in the creation of more compartments, usually between five and six (MacIver 1906: 85; Garbutt and Johnson 1912; Hughes 1997: 5-7). This kind of housing has also been observed at Danangombe and Naletale (MacIver 1906; Muringaniza and Ruwitah 1996). Houses were normally constructed from wooden poles, which were mudplastered to produce a strong wall. The surface was made up of beaten earth, which hardened to form a very strong dhaka floor. 


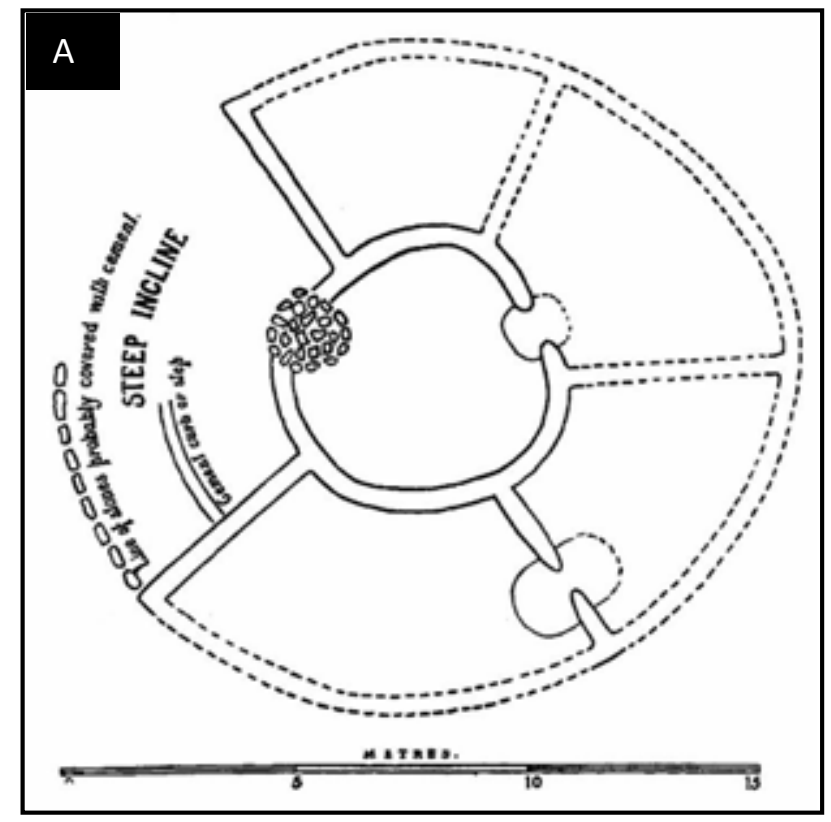

Figure 3.7: Plan of a typical house at Khami with various compartments (Garbutt and Johnson 1912). There is no indication of the location of this structure.

Stone walling at the site has thus played an important role as an identity marker because of its uniqueness in the form of terraced platforms. This uniqueness has resulted in scholars arguing that the builders of the terraced walling at Khami were different from those from Great Zimbabwe (van Waarden 2011; 2012; Chirikure et al. 2013a). Knowledge about these walls has also been used to build a chronology of the Zimbabwe Culture in the region, with freestandings walls being the earliest followed by the terraced walling of Khami. This conclusion, however, ignored evidence from Leopard's Kopje sites, which demonstrate the presence of terraced walling prior to Great Zimbabwe (Robinson 1966; 1985; van Waarden 2011; Chirikure et al. 2013a; 2014). Having discussed the structures at the site I now focus on the objects that have been recovered at the site over the years.

\subsubsection{MATERIAL CULTURE: OBJECTS}

A significant amount of objects have been recovered at the site, from the times of the antiquarians to the present. Most of this material is housed in the Zimbabwe Museum of Human Science in Harare. However, some of the material was taken into personal ownership. The following section synthesises our understanding of the various objects from Khami. 


\section{Ceramics}

Ceramic remains have been recorded at Khami by various researchers (MacIver 1905; Robinson 1959; Thorp 1984; and Hughes 1997). Robinson (1959) provides a general overview of the vessel types he recovered at the site. He also comments on the dominant motifs as well as shapes. Using attributes of vessel type, decoration style, finish and fabric, Robinson (1959) classified ceramics from Khami into two groups: Leopard's Kopje and Khami.

Leopard's Kopje ceramics from Khami have generally been divided into three types. These are pots, bowls and beakers. The basic form of the pot is the shouldered pot, which merges into the concave-necked pot of which there are many variations. Most of the pots are decorated, and the finish is usually black or brown burnish (Robinson 1966: 15). Bowls also vary greatly in size and shape, with some being deep and sub-spherical, while others tend to be shallower, with sharply incurving rims. Decoration on the bowls is mainly restricted to the rims. Beakers are not common, and in most cases they include beaker-bowls, which are neither beaker nor bowl (Robinson 1959). Decorations on Leopard's Kopje pottery were applied in the form of incision, comp-stamping and dragging by means of a stock, bone or bunch of grass stalks (Robinson 1959; 1966: 15). The popular designs consist of simple chevrons or triangles around the neck or shoulder. Others also consisted of a narrow band bounded by stamp impressions and filled in with oblique flowing channels, narrow bands of alternating perpendicular and horizontal incisions, a single row of stamps or single groove around the shoulder, a raised cord pattern and a meander executed by dragging stalks. However, it is also important to note that in some instances the designs could be combinations of the above.

Based on his extensive investigations into south-western Zimbabwe, Robinson (1966) argued that Leopard's Kopje had three phases: Leopard's Kopje I; Leopard's Kopje II; and Leopard's Kopje III. The distinction was based on a typology of built structures, ceramics and glass beads. Huffman (1974) refined this chronology, following his investigation of the Leopard's Kopje site and the Blue Jay site and reanalysis of material from Woolandale. He argued that Leopard's Kopje I was in fact Zhizo and not part of the Leopard's Kopje 
tradition. He assigned Leopard's Kopje II to Mambo (AD tenth to thirteenth centuries) and Leopard's Kopje III to Woolandale (AD fourteenth to sixteenth centuries), as the two main variants of the tradition in south-west Zimbabwe. Following his investigation of the Leopard's Kopje site, he concluded that the site had a Mambo occupation with no Woolandale (Huffman 1974: 96). Mambo ceramics from Leopard's Kopje were characterised by jars with arcades, incised bordered bands, high-burnished beakers, and both restricted and open bowls. In comparison, the ceramics collected from Woolandale and Blue Jay consisted of recurved jars with multiple dragged meanders and chevrons in the neck, a high-burnished and small-necked bowl with a band of interlocking triangles on the shoulder.

Robinson (1959: 139) classified the Khami-period ceramics into the following five types (Figure 3.8):

Form A: Spheroidal, without neck and everted rim with occasional decoration.

Form B: Spherical with short concave neck, rim rolled. This form is rarely decorated. It has two variants. The first one has a vertical neck and plain rim, and the second one has a vertical or slightly conical neck with everted rim.

Form C: Spheroidal with comparatively high neck. It takes many forms and may be vertical concave or convex, conical, bowl shaped or funnel shaped. The neck is frequently highly decorated but may also be plain. Decoration also occurs below the neck.

Form D: Gourd shaped.

Form E: Zoomorphic.

Bowls are not common but appear to be decorated and of the hemispherical type. Robinson also recovered three beakers. The first one was decorated in polychrome band and panel style. The second was plain with a reddish burnish. The third one had a rim everted to form an almost flange, while the base is slightly flared. It is also decorated in finely executed polychrome band and panel style. 


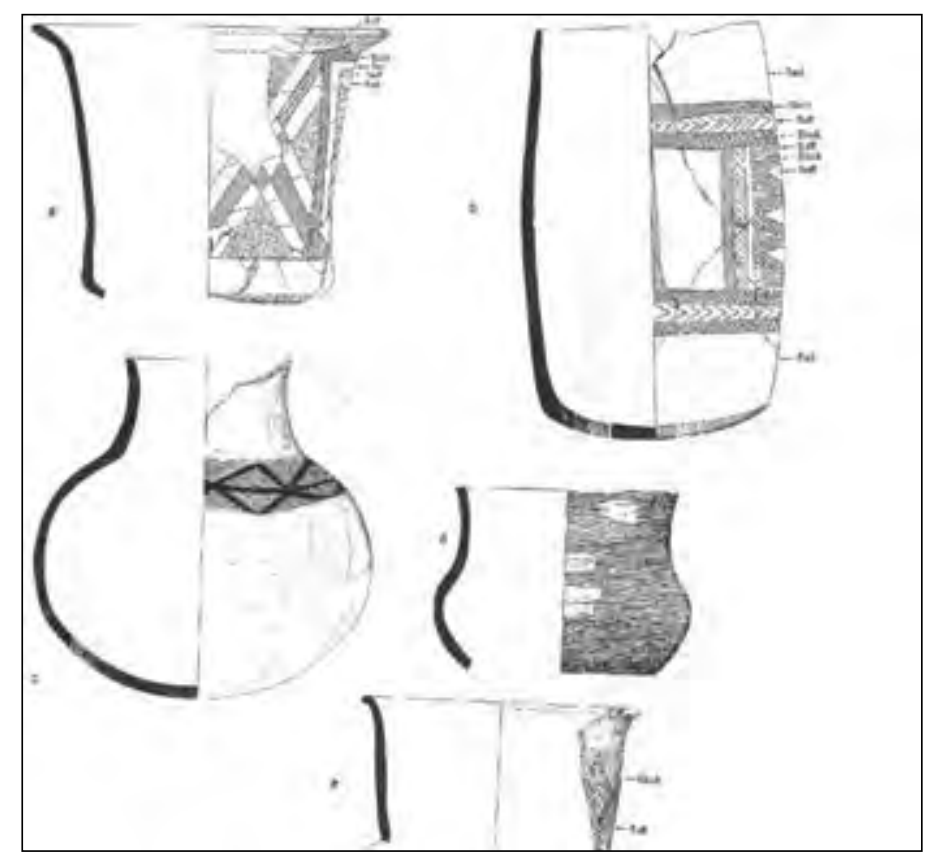

Figure 3.8: An illustration of the various forms of Khami ceramics according to Robinson (1959: $131 ; 132 ; 133 ; 134 ; 137)$

Hughes (1997) also classified the decoration and finish types for the Khami-phase pottery assemblage (Figure 3.9). These include:

Type A - Plain (burnished or unburnished)

Type B - Graphited

Type $\mathrm{C}$ - Graphited with a band of graphite on the inside of the rim

Type D - Bands of graphite and ochre on the outside of the neck and a band of graphite on the inside of the rim

Type E - Band of incised interlocking triangles or triangles and cross-hatching on the shoulder

Type F - Complex panel motifs on upper shoulder

Type $\mathrm{G}$ - Complex panel motifs on neck and band of interlocking triangles on shoulder.

Hughes used this information to produce a total of 17 ceramic classes, together with their stratigraphic distribution. Using ceramic and other lines of evidence, he suggested two distinct periods of occupation at the site. Period I was characterised by necked jars while Period II was associated with constricted globular pots. 


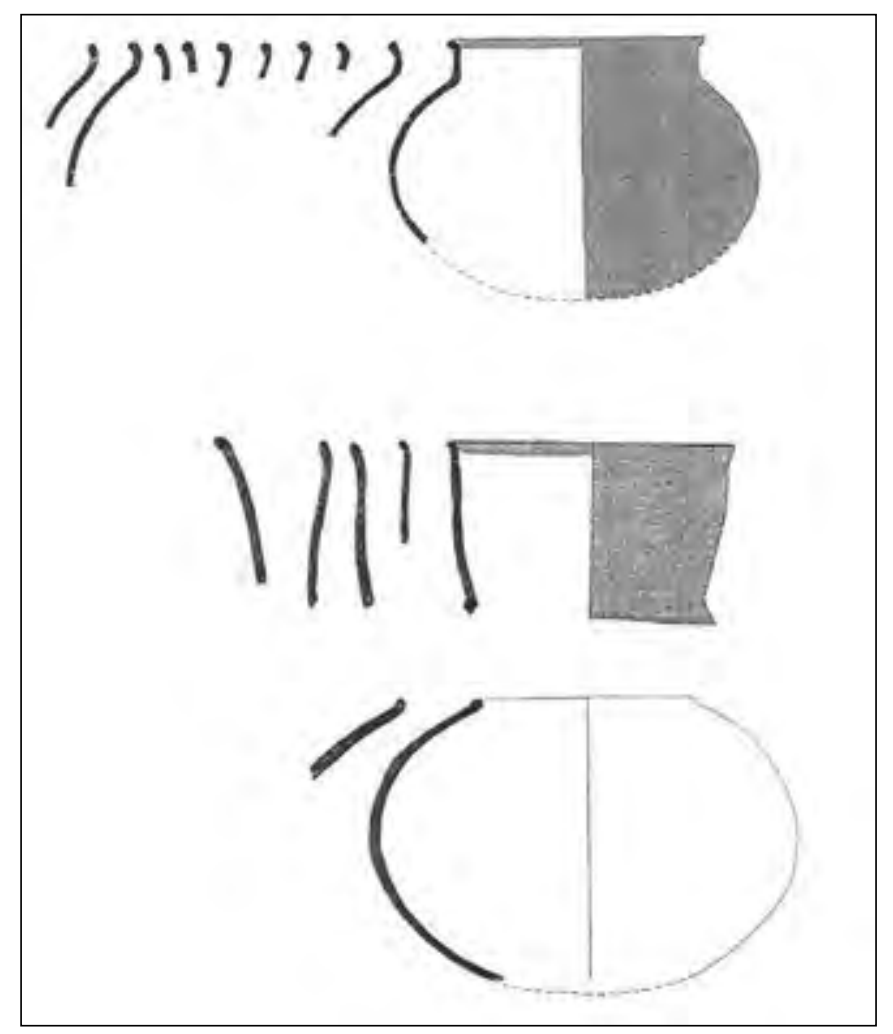

Figure 3.9: An illustration of the three major ceramic vessels according to Hughes (1997: 11; 12). These are, from top, the short-necked, tall-necked and neckless vessels.

Chirikure et al. (2002) carried out a detailed classification of the ceramics from Khami while doing a comparative study of ceramics from the site and other Zimbabwe Culture sites in the Zambezi valley. They focused on ceramics from various parts of the site and consequently came up with nine vessel profiles for the comparative study. While the study was a comparative one, it gives a basis for further re-evaluating our current understanding of ceramics from Khami, in relationship to other sites of the Zimbabwe Culture. However, they used material from Robinson's excavation, housed in the Zimbabwe Museum of Human Science, which has no stratigraphic information. This made it impossible to compare the frequency of attributes by provenance (Chirikure et al. 2002). This lack of proper documentation for most of the material culture from Khami is a cause for concern, since it limits what one can do in the absence of information on stratigraphic sequence.

Metals

A number of metal objects have been recorded at Khami (Figure 3.10) (Randall-MacIver 1906; Robinson 1959; Hughes 1997). The most common of them are tools such as hoes, 
axes, razors, needles, pins and hooks. Metal working tools, such as wire drawers and gads, have also been recorded, showing that there was metal working at the site. Most of the tools were manufactured from iron, with the exception of small tools like needles and razors, which were made of copper or bronze. Ornamental objects were also recovered from the site. These included rings, bracelets, anklets, head rings and beads. They were manufactured from a variety of metals, including gold, copper, bronze and iron. Evidence of metal production was also recovered in the form of slag from both iron and copper (Randall-MacIver 1906; Robinson 1959; Hughes 1997).
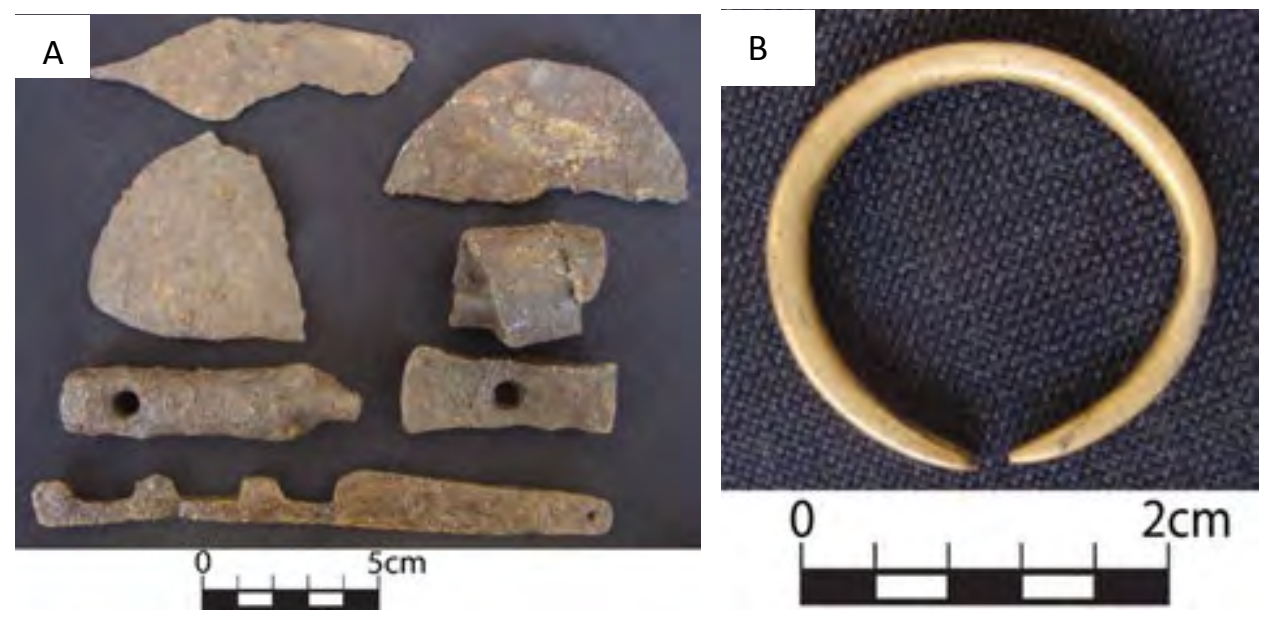

Figure 3.10: Metal objects from the Hill Complex. These include a selection of hoes from the site and other tools (A) and a bronze ring (B).

Fauna

Robinson (1959) records the recovery of faunal remains from his excavations at Khami. However, the material could not be analysed because of the lack of comparative material. As such, he could not make an inventory of the faunal remains, save to suggest the presence of antelope species. His 'rubbish heap' was later re-excavated and analysed by Thorp $(1984 ; 1995)$.

Thorp (1995) identified twenty animal species from her excavation. The major food animals she noted include cattle, sheep, goats, zebra, bushpig, ant bear, dassie, springhare, hare, tortoise and guinea fowl and francolin-sized bird. Non-domesticated species include duiker, steenbok, klipspringer, jackal, wild dog, hyena, civet, genet, mongoose, wild cat, serval, leopard, lion, cheetah and ant bear. Her excavation also revealed a large proportion of faunal remains used by traditional healers. She singled out bone from certain species, 
such as tortoise, springhare, hyrax, ant bear and hare, as being used for divination by traditional healers. This finding was based on the assertion that traditional healers use animal bones from both edible and inedible species as divining dice and for their necklaces, and animal skins for dress (Thorp 1995). Thorp thus concludes that elements in the Khami faunal sample represent items used in divination and traditional-healing activities. In a more comparative study involving Khami and other sites, such as Great Zimbabwe, Harleigh Farm, and Manekweni, Thorp (1995) has shown that domestic stock were more important as a meat source than game on Zimbabwe Culture sites. Thorp's pioneering faunal studies at the site call for the need to broaden our understanding of the animal economy through evidence from various areas of the site, since her research focused only on the Hill Complex. This is important, as it has the potential to help interrogate a number of questions regarding the socio-economic and political organisation of the state. For instance, did the various inhabitants of the site have different diets and, if so, what could this mean in terms of the organisation of the various parts of the site? If there were no significant differences in the animals exploited by the occupants of the various parts of the site, would it then suffice to continue to dichotomise the social organisation at Khami in terms of elite and commoner distinction? Thirdly faunal remains help in the reconstruction of the past environment at archaeological sites (Manyanga 2000; 2006).

Beads

Various types of beads have been recovered from Khami during all the excavations that have been done at the site (MacIver 1906; Robinson 1959; Thorp 1995; Hughes 1997). Robinson classified his glass beads into two groups according to bead size. Group I composed of minute cylinders and oblates made from canes, which are less than $1.5 \mathrm{~mm}$ on average length and diameter. These beads occurred in Indian red, dark blue, light blue, green and black. Group II is made up of larger glass cylinders that have an average length of 2-5 $\mathrm{mm}$ and a diameter of 3-4 $\mathrm{mm}$.

Hughes (1997) recovered a total of 516 glass beads from his excavation of the peripheral area at Khami. A total of 16 colours were represented in the bead assemblage, compared to the five colours that Robinson (1959) recorded from the stone-walled section of the site. However, not much can be read from this difference in the number of colours represented, 
since Hughes used an artist's water-colour chart produced by Windsor and Newton of London, which is more detailed in terms of colour identification, while Robinson most probably relied on primary colours only. There is therefore a need for a bead analysis that uses a similar colour chart, to enable a comparative analysis of the beads from various sections of the site. Wood $(2000 ; 2005)$ has classified beads in southern Africa according to period, including the Zhizo, K2, Mapungubwe, Great Zimbabwe, Khami and Historic periods. From her analysis of the recovered samples, she has argued that the beads of the Khami period show continuity with the Great Zimbabwe period, with less orange and more opaque. The earliest white (oyster white) and a new honey colour appear for the first time during the Khami period (Wood 2000; 2005). Thorp (1995) documented the recovery of 151 beads during her 1979 Hill Midden excavation.

Shell beads that were recorded were made from ostrich eggshell and Achatina or freshwater mussel shell, usually between 4 and $10 \mathrm{~mm}$ in diameter. Some marine shell (Polinices $s p$ ) beads were also recovered at Khami, providing further evidence of the trade between the site and the Indian Ocean coast. Of the metal beads recovered at Khami, copper and bronze beads are the most common. They resemble those recovered by MacIver (1906) and CatonThompson (1931) at Great Zimbabwe and other sites. Over eighty gold beads were also recovered in the Upper Passage of the Hill Complex (Robinson 1959). Robinson also recorded bone beads measuring about $1 \mathrm{~cm}$ in length, which were most probably from birds and used as spacer beads.

\section{Imported objects}

Imported objects have also been recovered at Khami (Hall 1910; Robinson 1959; 1961a). As discussed, archaeologists used the presence of imported goods as evidence of foreign trade and influence in the socio-political developments happening in southern Africa (Hall 1910; Caton-Thompson 1931; Summers 1969; Huffman 1972; 1981; 2000; Garlake 1978). Thus, the establishment of Khami was seen as a direct result of the trade networks with the Indian Ocean coast. The recovery of foreign items such as blue and white porcelain, Chinese celadon, glass beads and glass was evidence of participation in this exchange network (Figure 3.11). Foreign goods have also been used to date the site of Khami 
(Robinson 1961a; Garlake 1968). Robinson also recovered imported goods, which he submitted to the Keeper of Ceramics at the Victoria and Albert Museum in London for further analysis on their provenance. The periods corresponding to their known periods of manufacture are presented in Table 3.4 .

Table 3.1: List of imported objects recovered by Robinson at Khami minus glass beads (Robinson 1961: 66-67).

\begin{tabular}{|c|c|c|}
\hline & Object & Provenance \\
\hline 1 & $\begin{array}{l}\text { Fragment of an open bowl and tall closed } \\
\text { vessel - blue and white }\end{array}$ & $\begin{array}{l}\text { First half of the } 17^{\text {th }} \text { century. Of } \\
\text { Portuguese origin }\end{array}$ \\
\hline 2 & Cover of a jar - blue and white & $\begin{array}{l}\text { First half of the } 17^{\text {th }} \text { century. Of } \\
\text { Portuguese origin }\end{array}$ \\
\hline 3 & Fragments of salt-glazed stoneware jug & Late $16^{\text {th }}$ century. German \\
\hline 4 & $\begin{array}{l}\text { Fragments of soft whitish earthenware } \\
\text { bowl with white and marble glaze }\end{array}$ & $\begin{array}{l}\text { First half of the } 17^{\text {th }} \text { century. Of } \\
\text { Portuguese origin }\end{array}$ \\
\hline 5 & Blue and white fragments & $\begin{array}{l}\text { Late Ming reign of Wan Li (1573- } \\
\text { 1619). Chinese porcelain }\end{array}$ \\
\hline 6 & $\begin{array}{l}\text { Bulging mammiform drinking spout from } \\
\text { a kendi }\end{array}$ & Typical Wan Li (1573-1619) \\
\hline 7 & Green glazed rim of jar & $\begin{array}{l}\text { Approximately } 17^{\text {th }} \text { century and most } \\
\text { probably from North Africa }\end{array}$ \\
\hline 8 & Blue and white dish painted with two deer & Typical Wan Li (1573-1619) \\
\hline 9 & Silver fragment, chased & Early $17^{\text {th }}$ century. Of Spanish origin \\
\hline
\end{tabular}

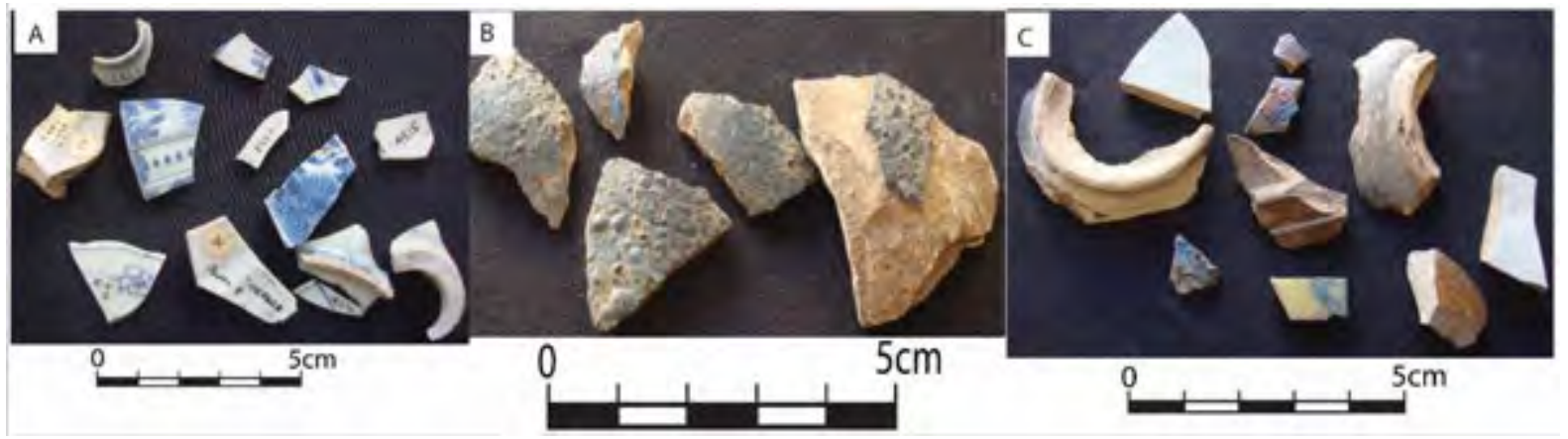

Figure 3.11: Imported ceramics recovered from Khami (Robinson 1961: 66-67).

\subsubsection{SEQUENCE AND CHRONOLOGY}

Excavations done by Keith Robinson and also Cran Cooke in the 1940s and 1950s have enabled the reconstruction of a settlement sequence for Khami. Hunter-gatherers occupied the 
area prior to the settlement by farming groups (Cooke 1950; 1953). However. the first agriculturalists to settle at the site were people identified by Robinson $(1959,1966)$ as belonging to the Leopard's Kopje Culture. Material associated with Leopard's Kopje was recovered stratified under Khami layers (Robinson 1959). The excavated areas that showed this evidence include House $\mathrm{Cb} 1$ on the Hill Complex, an area east of the Cross Platform (Excavation 19), and Excavation 20 beneath a basal terrace wall on Platform $\mathrm{C}$ of the Hill Complex (Robinson 1959; Figure 3.12). They were also metal users as evidenced from iron and copper remains that were also recovered (Robinson 1959; Huffman 1974).

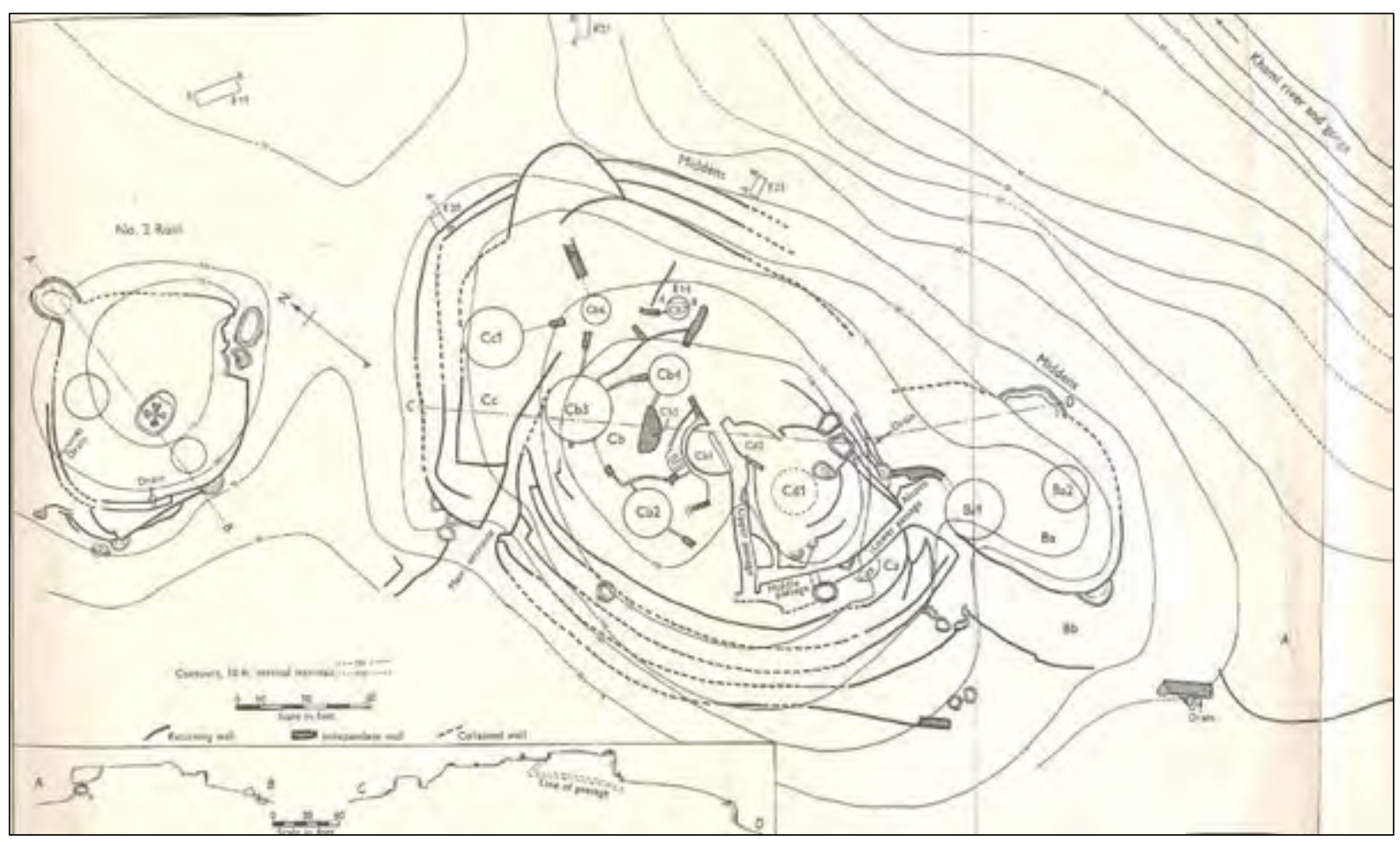

Figure 3.12: Plan of the Hill Complex showing the excavations where Leopard's Kopje material was recovered (Robinson 1959: 16). These are E19 and E20 on the flats and an excavation on House $\mathrm{Cb} 1$ on the hilltop.

Following the Leopard's Kopje phase was the Khami phase, which maintained occupation of the site until its abandonment in the nineteenth century (Robinson 1959; Pikirayi 2001). Robinson (1959) suggested that Leopard's Kopje did not give rise to Khami because of a stratigraphic break he noted between the Leopard's Kopje and Khami periods in his excavations. As a result he argued that the origins of Khami lay at Great Zimbabwe (Robinson 1959: 115). Robinson's conclusion was driven by the belief that the tradition of 
dry-stone walling in the region could be traced to a single source, hence his argument of Great Zimbabwe as the source of Khami. Radiocarbon dates for the site also seemed to confirm this position: they placed the establishment of Khami around AD 1450 (Sheppard and Swart 1967). This was the same period that Great Zimbabwe was argued to have collapsed, based on radiocarbon dates from the Western Enclosure (Robinson 1961b: 161). The correlation between the earliest date for Khami (1420 AD) and the terminal date for Great Zimbabwe (1450 AD) has been used to support the idea that Khami developed as a result of the collapse of Great Zimbabwe (Huffman 1981; Huffman and Vogel 1991). Robinson (1959: 116) also makes the suggestion that, since polychrome band and panel ware were recovered at Great Zimbabwe in the upper levels of the Maund Ruins by Gertrude Caton-Thompson (1931) and at all levels at Khami, Great Zimbabwe was the source of the ware, and that the ware was later introduced at Khami by the people who moved from Great Zimbabwe, after its collapse, to establish Khami. However, Chirikure et al. (2013b) and van Waarden (2011) have shown that polychrome band and panel ware might have its origins in the early Leopard's Kopje culture of south-western Zimbabwe.

Robinson also made an attempt at understanding the spatial development of the site over time. He suggested that settlement at the site was initially centred on the Hill Complex, before spreading out via the construction of more platforms away from the Hill Complex. He noted the presence of deep and dense middens around the Hill Complex, in contrast to other platforms that are not as dense. Architectural evidence, coupled with radiocarbon dates, also suggested that the site was constructed over a long period of time, in phases that were characterised by the expansion of platforms to create more space. Radiocarbon dates from Platform B show that the site was constructed over about a hundred years (Table 3.2 and Figure 3.13).

Table 3.2: Dates for Khami from Excavation 17a by Robinson on Platform B and structural posts in the upper passage of Platform C on the Hill Complex.

\begin{tabular}{|l|l|l|l|}
\hline Lab number & Context & Material dated & Uncalibrated dates \\
\hline SR 94 & Plat B Basal & Charcoal & $495+/-95 \mathrm{BP}$ \\
\hline Pta 2680 & Plat B L2 & Charcoal & $440+/-40 \mathrm{BP}$ \\
\hline Pta 744 & Passage post 1 & Wood & $570+/-50 \mathrm{BP}$ \\
\hline Pta 748 & Passage post 2 & Wood & $440+/-50 \mathrm{BP}$ \\
\hline Pta 1928 & Passage post & Wood & $530+/-40 \mathrm{BP}$ \\
\hline Pta 2430 & Passage roof & Alcove thatch & $240+/-40 \mathrm{BP}$ \\
\hline
\end{tabular}




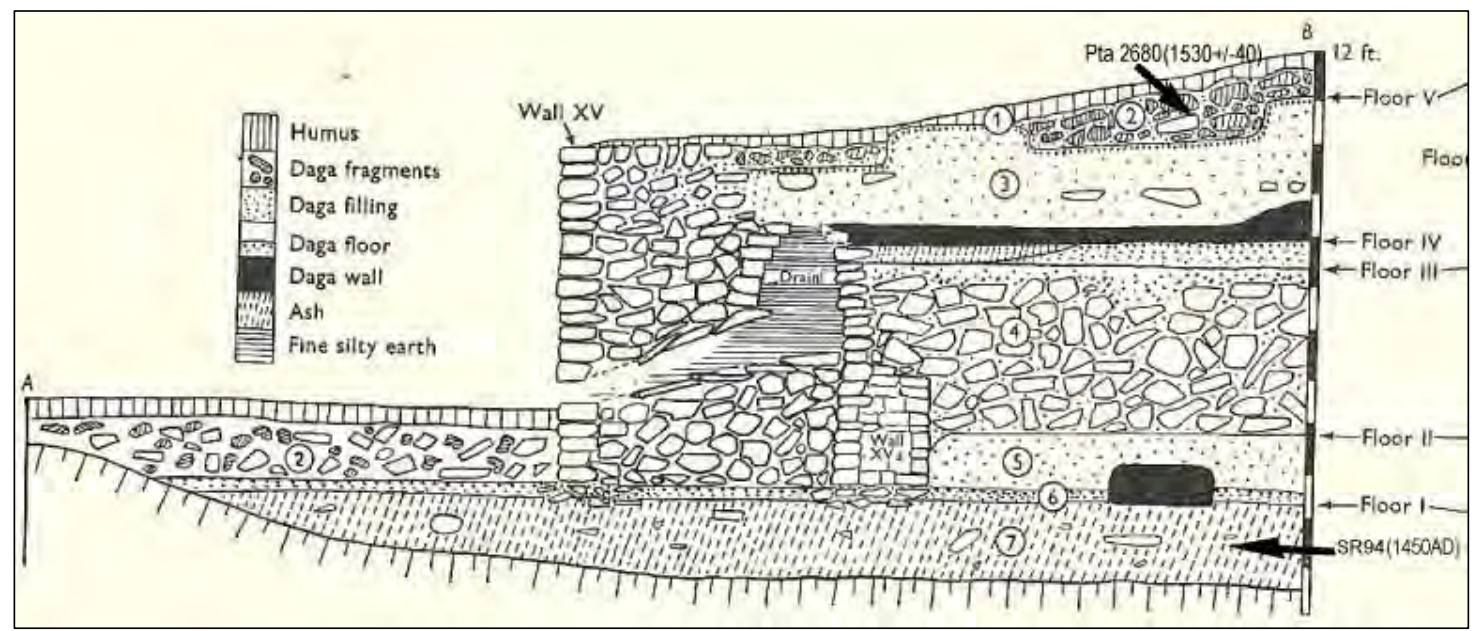

Figure 3.13: Excavation 17a showing the areas where samples for dating were collected. The excavation demonstrates the gradual development of the platform which at one time was made up of Wall XVa as the outer wall before the platform was expanded with Wall XV now serving as the outer wall (Robinson 1959: 81).

\subsubsection{SPATIAL ORGANISATION}

The excavations that were done at the site, in particular by Robinson (1959), have provided a basis for archaeologists to hypothesise about the spatial organisation of the site. The two researchers who have attempted this hypothesis are Robinson (1959) and Huffman (1981; 1996). The following section provides a synthesis of their interpretations of spatial organisation at the site.

Robinson focused on a reconstruction of lifeways on the Hill Complex, since he had explored it in detail. He identified the Hill Complex as the residence of the king, based on a number of objects that were recovered there. The relics that Robinson used to identify the Hill summit with the king include the remains of two elephant tusks, a hoard of bronze and iron weapons, ivory carvings of lions, and the head of an ivory staff, most of which were recovered from House $\mathrm{Cb} 1$. Other material, such as divining pallets and a necklace of bored bones, were interpreted as divining objects critical in ritual activities at the site. The central location of House $\mathrm{Cb} 1$ was explained as being a way of hiding the house from public view because of the important role it played in safekeeping relics associated with the king. Robinson also associated other platforms with other members of the ruling lineage, 
although he could not be specific due to limited datasets on individual platforms. However, Robinson (1959) makes the important observation that the site showed evidence of a site in continuous development. He noted this from the limited density of midden material around platforms further from the Hill Complex. As such, he argued that settlement at the site was initially concentrated around the Hill Complex and expanded with time as the site developed.

Huffman $(1981 ; 1984 ; 1986 ; 1996 ; 2007)$ has applied a cognitive structuralist framework in his interpretation of the use of space at Khami. This section presents the model as it has been applied at Khami, and provides a critique of this application. Huffman (1996) employed a direct historical approach in which a model is derived from the relevant ethnography of a prehistoric group's living descendants. The model is then applied back in time to the archaeological situation. As a result, in interpreting Khami, Huffman (1996) argues that it is important to understand modern groups that trace their roots to the Torwa people. In this regard, he makes reference to Shona and Venda customs and oral traditions (Huffman 1996). Portuguese documents from the seventeenth century are also used in developing the model.

The settlement model at Khami is known as the Zimbabwe Pattern. According to this model, the ruler lived a secluded life on the Hill Complex. In the discharge of his duties, the leader was assisted by a designated sister and brother. Other members of the royal household lived around the Hill Complex, as a form of protection for the leader. Society at the site is argued to have been dichotomised into elite and non-elite-elite members being the royal lineage who had certain established rights, duties and behaviour (Huffman 2007: 366). On the other hand, the non-elite lacked access to the same wealth, status and political power that were the privileges of the elite. Special marriage patterns, where one could not marry into the other status group, ensured that such class distinction was perpetuated. This dichotomy also manifested in two distinct settlement zones at the site (Figure 3.14). The elite zone was characterised by the presence of dry-stone-walled platforms, on top of which houses were constructed, while the non-elite lived away from the platforms on the flats. 


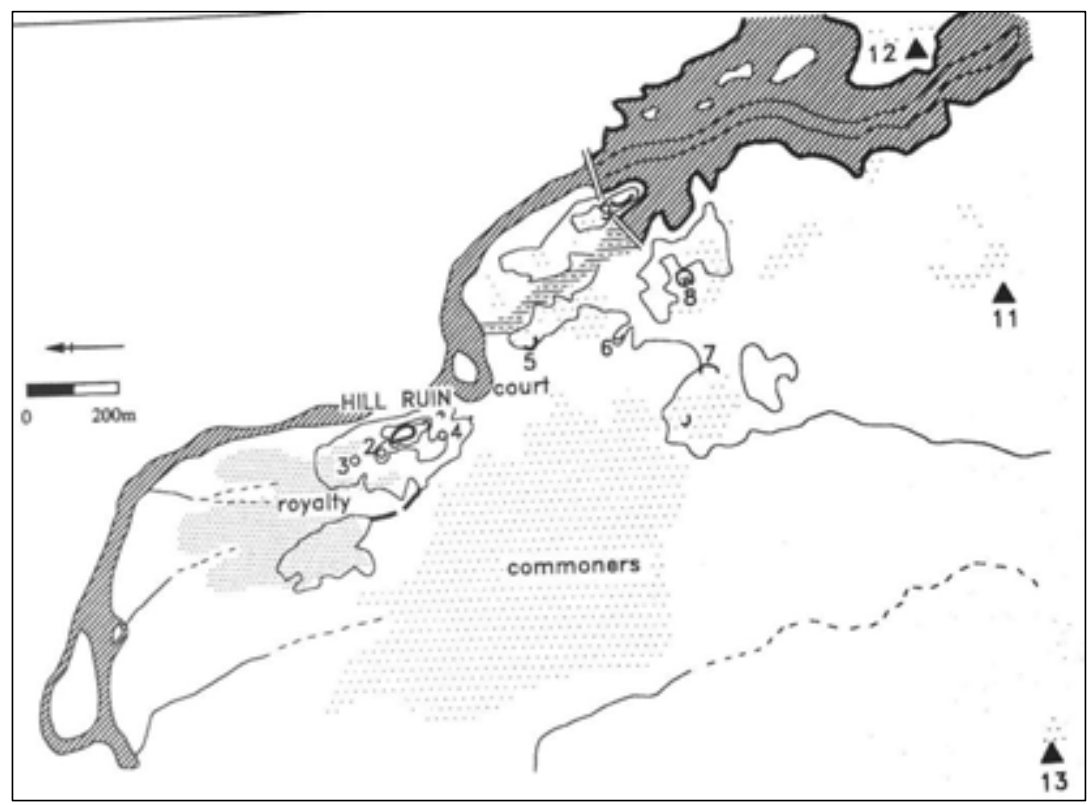

Figure 3.14: Plan of Khami showing settlement distribution by status (Huffman 2007: 415). This view of settlement organisation at Khami dichotomised society at Khami, with an elite class that lived within the walled area and a commoner class that occupied the non-walled areas.

The idea of sacred leadership is argued to have been the basis of the elite's control of power at the site (Huffman 1996; 2007). Sacred leadership meant that the leader was appointed by God and could intercede for his people with God through his ancestors. Because of his association with God through his ancestors, the leader had power to bring success to his country and people. This concept of scared leadership served to perpetuate the elite/nonelite dichotomy at the site.

Class distinction and sacred leadership are said to have been perpetuated by the presence of walling (Huffman 2007: 46), specifically the elite platforms, hut terracing, and the presence of a perimeter wall. Elite platforms were constructed to house the leader and other members of the elite. Using ethnographically derived symbolism, Huffman $(1996 ; 2007)$ assigned the Vlei Platform as the residence of the muchinda, the one who oversaw the activities at the court, because of the presence of checker design on the entrance to the Vlei. The Cross Platform is thought to be the king's bodyguards' area, because of its likeness to the thondo structure that is found in Venda society. The king's sister was assigned the North platform, 
because of a strip of herringbone above the pool and spaced check designs. The first wife lived on Platform No 6, according to a tradition that her area was located below the hill and the court. The Monolith platform had a pool design, which, according to Huffman (1996), would have referred to the womb and birth. As such, this was the confinement area where the kings' wives resided during the childbirth period. Another smaller, low platform to the south of the Hill Complex was inhabited by the royal mother. The Precipice was designated as the residence of the man in charge of the royal wives because of its proximity to the women's area. Huffman $(1984 ; 1996)$ argued that the Passage platform was an initiation centre, because of its similarity to the Great Enclosure at Great Zimbabwe, which he argued served the same purpose.

There has, however, been a number of criticisms of Huffman's application of cognitive structural archaeology to Khami (Beach 1998; Beach et al. 1997; Soper 1997; Chirikure and Pikirayi 2008; Pikirayi and Chirikure 2011; Chirikure et al. 2012; Fredriksen and Chirikure 2015). Beach (1998) criticised Huffman's methodology and in particular questioned the oral traditions that he collected among the Venda. Huffman's framework has also been found to be faulty in that it ignores other material culture associated with the site (Chirikure and Pikirayi 2008). Huffman's model presents a preconceived settlement organisation that is in statis for the duration of its occupation (Chipunza 1994; Beach et al. 1997; Beach 1998). This concept of a static settlement is present in Huffman's interpretation of Khami. Huffman $(1984 ; 1996)$ also failed to take into account the archaeological evidence that Robinson gathered during his excavations in the 1950s.

In addition, his model has been criticised by other scholars for offering a rigid model of the spatial dynamics at the Zimbabwe Culture site (Collett et al. 1992; Beach et al. 1997; Chipunza 1994; Chirikure and Pikirayi 2008; Chirikure et al. 2012; Pikirayi 2013). The model does not provide an understanding of the daily experiences of various Zimbabwe Culture sites, as it blankets these all under one organisational model. Pikirayi and Chirikure (2011) have cautioned against the universalisation of interpretations of different Zimbabwe Culture sites without a thorough understanding of individual sites. Pwiti (1997) is critical of 
Huffman's failure to take into account the cultural dynamism that must have resulted from the many generations that had a hand in the shaping of society at sites such as Khami.

\subsection{GAP ANALYSIS}

As noted in the review, most of the research has focused on the walled section of the site, with no comparative investigations on the non-walled sections. As a result, we only know of the archaeology of a small group of the population who occupied the stone-walled areas and know nothing about those who lived outside these platforms. Globally, the focus of archaeology is shifting to also look at peripheral and outlying areas, which over the years have been neglected in terms of research, particularly in Africa (S K McIntosh 1997; Fleisher and La Violette 1999; Antonites 2012). As Fleisher and LaViolette (1999: 87) have observed in East Africa, the rich archaeology of the stone-walled areas can only be understood in combination with the archaeology of the 'rest'. Accordingly, there is a need to focus on the non-stone-walled areas at Khami so that the archaeology of Khami can be broadly understood in its totality and diversity. This broader focus is critical, especially if we are to understand the spatial relationships among the various parts of the site, which can only be achieved through a diachronic and synchronic study. For a site the size of Khami, it is important to understand spatial layout and distribution in order to come up with meaningful site interpretation. This requires a thorough survey and mapping of the various components of the site so that they can be understood in relation to one another.

The review has also shown that there is a lack of understanding of the chronology of Khami due to the limited datasets available. Currently, there are only six radiocarbon dates associated with the site (Sheppard and Swart 1967; Huffman 2007). Of these, only two are from an excavation. Other parts of the walled sections that were excavated were not dated. Similarly, because the outlying areas at Khami were not targeted for investigation, we have no idea of their chronological order in relation to the built up areas. As a result, we have only a flimsy idea of the chronological development of the site. Chronological data for the other areas making up the site is lacking, and this makes it difficult to understand the site's evolution or to compare the various areas of the site in terms of their chronological development. Without understanding the chronological development of Khami, it is 
difficult to place the site's evolution within the overall development of the Zimbabwe Culture.

There is also a need to understand the material culture of Khami through an analysis of objects from previous excavations and other in-situ materials, such as walling and dhaka remains. Currently, our understanding of the site's material culture derives primarily from the stone-walled areas, with no corresponding understanding of the non-stone-walled areas. This understanding is important if we are to answer questions regarding the differences and relations between the occupiers of the stone-walled areas and the non-stone-walled areas. Currently, besides the differences expressed in the architecture of these two zones (Robinson 1959; Huffman 1996), there is no other material evidence that reflects a distinction between the occupiers of these two zones. A material culture analysis should help cover these gaps and elaborate on the diversity or similarity of the community at Khami.

\subsection{SUMMARY}

In summation it can be noted that while archaeological research has been conducted at the site there has been a specific bias toward the stone-walled section of the site, where the elites are believed to have lived. As shown above, MacIver (1906) excavated the Hill Complex and Precipice platform. Similarly, all of Robinson's works were centred on the stone-walled platforms: the Hill Complex, Cross Ruin, Passage Ruin, Vlei Ruin and No. 4. Outside these areas, he also excavated the Leopard's Kopje site in the vicinity of Khami. Thorp also focused on a midden associated with the Hill Complex. Such a scenario is concerning, since it is bound to create a distorted picture of the archaeology of the site. This ultimately affects our interpretation of the site, which becomes limited by the lack of evidence from other equally important parts of the site. In order to address these gaps in the research, a robust data-collection methodology was employed. This process is outlined in the next chapter. 


\section{CHAPTER 4: DATA COLLECTION}

\subsection{INTRODUCTION}

A variety of data-collection methods were employed in order to come up with relevant datasets that address the research gaps that have been highlighted. These include desktop surveys, which were conducted to deepen our current understanding of the site. Additionally, reference was made to previously published material on the site (Hall and Neal 1902; MacIver 1906; Robinson 1959; Thorp 1995). Recourse was also made to unpublished reports on some of the works that have been carried out at the site. The desktop survey helped in clarifying the physiographic setting of the area, its historical record and current understanding of the archaeology. An analysis of museum objects in the Zimbabwe Museum of Human Science in Harare was also conducted to better understand the material culture from the stone-walled sections that was excavated by previous researchers (Hall and Neal 1902; MacIver 1906; Robinson 1959; Thorp 1995). The reanalysis also informed the research strategy, as new areas that had not been investigated before were targeted, in particular the areas outside the platforms. A survey of the site and its environs was also conducted. A survey is meant to help the researcher better understand the archaeological resource of an area (Roskams 2002: 46). A survey also helps researchers identify areas for further investigation by way of excavation, depending on one's research question (Roskams 2002: 46). Excavations were conducted to collect subsurface material that could be used to understand the development of the site. In particular, carbon material was also collected for radiocarbon dating. Other parts of the site that had not been mapped in the past were also mapped and included in a plan of the site.

\subsection{DESKTOP STUDY}

A desktop study was done by reading through literature on the archaeology and history of Khami. This was an important step, as it illuminated the focus of past research at the site. An important element of the desktop study was a review of Portuguese documents from the fifteenth century onward. These have been synthesised by Beach (1980), Randles (1981), Mudenge (1988) and van Waarden (2012) to produce a historical account of the state. The desktop study also included other previously published material on research conducted at the 
site (Hall and Neal 1902; MacIver 1906; Caton-Thompson 1931; Robinson 1959; Thorp 1995; Hughes 1997). Hence, my desktop study was important in elucidating avenues of necessary research, based on previous research related to the site.

\subsection{FIELD METHODS}

\section{ARCHAEOLOGICAL SURVEY AND MAPPING}

An intensive survey of Khami was performed, to examine its spatial extent and identify the general distribution of cultural material within it. This process is important for identifying potential areas for excavation (Roskams 2002: 46). Guided by the overall map created by Robinson (1959:15) and Ndoro and Pwiti (1999), pedestrian surveys were performed on the areas with and without the stone-walled platforms. Within the walled areas, the main aim was to identify visible features on the platforms and the patterning of material culture on the surrounding flats. The main observation was that some platforms only had a few houses on top but were surrounded by numerous houses on the flats. The surveys were extended to nonwalled areas lying within a two-kilometre radius from the cluster of platforms along the river. A significant amount of middens were recorded in various parts of the site, such as the southwestern, western, northern and north-eastern parts of the site. The presence of the grass Cenchrus ciliaris was used to identify middens, as this grass thrives on midden areas (Denbow 1979). Numerous burrowing by antbears also helped in identifying middens aand subsurface deposits and as such no subsurface testing was necessary. Because the area to the east of the Hill Complex and related platforms is outside the official borders of the Khami National Monument and World Heritage site, it is not well looked after in terms of vegetation control. As a result, significant challenges with archaeological visibility were encountered.

The survey identified dense concentrations of archaeological material, ranging from middens and collapsed houses to isolated scatters of pottery and faunal remains. During the survey, most of the activity areas were recorded using a GPS receiver and were plotted on the Khami sitemap (Figure 4.1). 


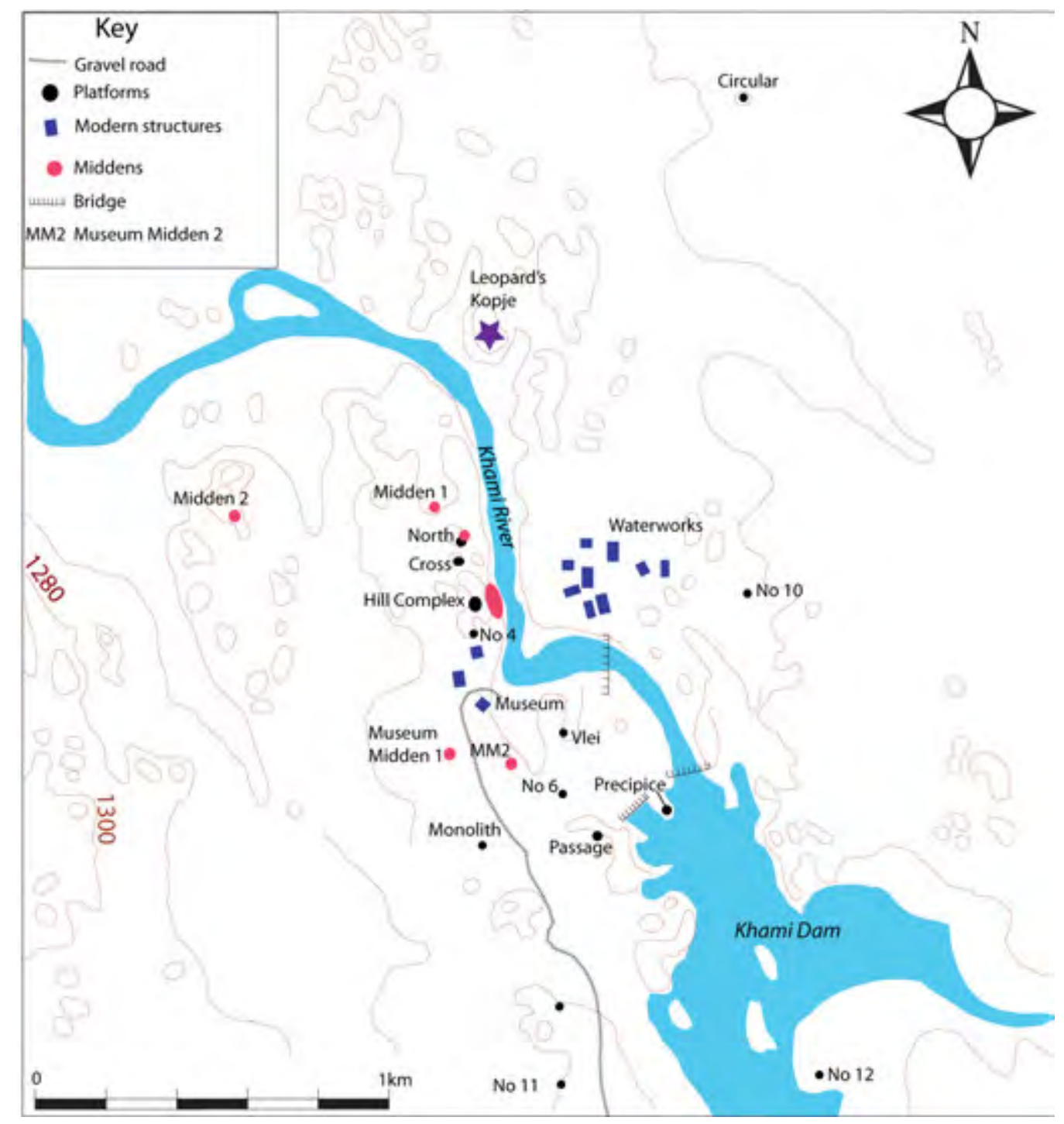

Figure 4.1: Plan of Khami showing the positions of the various platforms that make up the settlement and the middens that were targeted for further investigation (based on Robinson 1959:15). Leopard's Kopje settlement, which preceded Khami, is located about $800 \mathrm{~m}$ north of the Hill Complex, as measured on Google Earth.
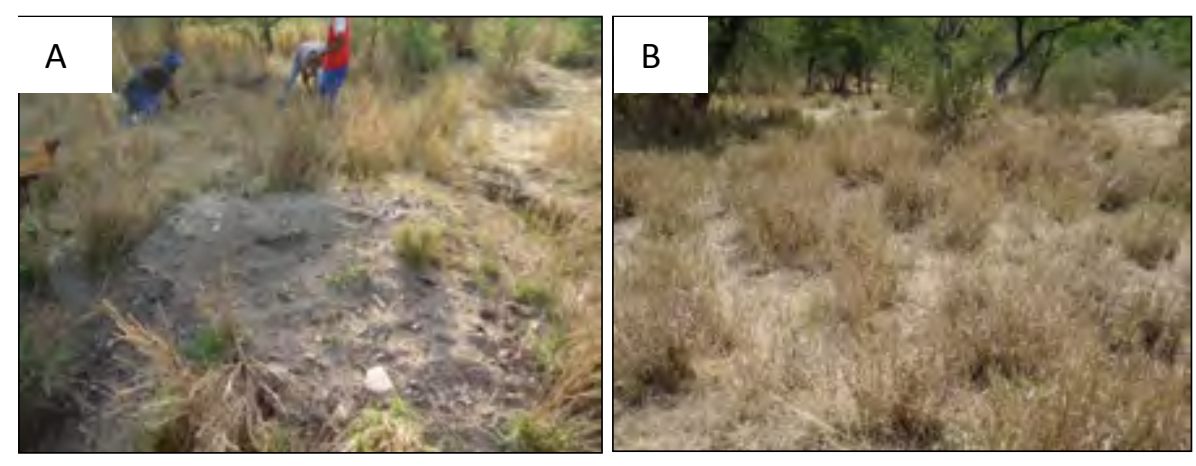

Figure 4.2: Midden 2 showing material dug up through the activities of burrowing by antbears (A) and cenchrus ciliaris grass growing (B). 
The survey showed that significant material culture concentrations occur not just on the platforms but also on the surrounding flats. In some areas, particularly those to the south-west and the west of the site, there are fairly extensive middens dominated by typical Khami band and panel ware, occasional crucibles, spindle whorls, slag and dhaka fragments. Clearly, excavations were necessary to help the researcher understand the material from these areas in detail and to establish chronological and material culture relationships with the material from excavated walled areas such as the Hill Complex (MacIver 1906; Robinson 1959).

\section{EXCAVATIONS}

The strategy for excavations evolved out of previous work carried out at the site and the results of the survey discussed above. Robinson (1959) carried out a detailed study of walled areas such as the Hill Complex, while MacIver (1906) also excavated the Hill Complex together with the Precipice Ruin. Furthermore, Hughes (1997) excavated house floors on the ridge to the northwest of the Hill Complex. Because this material is in the museum, and because walled areas are very sensitive due to the destruction by antiquarians in the late nineteenth and early twentieth century, a decision was made to target areas outside the walls on the flats. Apart from generating material culture, excavations were designed to produce stratified material for radiocarbon dating. The selected areas for excavations shown in Figure 4.1 are as follows: Midden 1, Midden 2, Museum Midden 1, Museum Midden 2, North Platform Midden, Cross Platform Midden. They are outlined in later sections. Excavation trenches were also named sequentially at each midden. Thus, the first trench became Trench 1 and the $1 \mathrm{~m}^{2}$ grids were assigned letters according to the grid system on the midden.

Standard archaeological excavation procedures were employed in this study (Roskams 2002). Excavations proceeded in $10 \mathrm{~cm}$ spits vertically and by $1 \mathrm{~m}^{2}$ grids horizontally. This allowed the researcher to clearly define the context of material finds during the analysis stage. All cultural material was collected and recorded. Excavated soil was sieved through a $1.5 \mathrm{~mm}$ sieve. Recovered material was recorded in field notebooks and bagged separately, together with contextual information. Siting of excavation units was based on the presence of surface finds. Areas with animal burrows were avoided because the stratigraphy would have been compromised. At the end of each excavation, a section drawing of each trench was made. 


\subsubsection{MIDDEN 1}

GPS Readings $\left(20^{0} 08^{\prime} 47^{\prime \prime}\right.$ South and $28^{0} 25^{\prime} 38^{\prime \prime}$ East)

Midden 1 is located on the northern end of the site (Figure 4.1). It is located east of an excavation that was done by Hughes in 1989 on the Northwest Ridge. The midden was easily identifiable from the presence of the Cenchrus ciliaris grass. Surface finds on the midden included pottery fragments and faunal material. An inspection of these burrows showed that the area had significant midden material. In this regard, it is important to note that, in his survey along the Northwest Ridge, Hughes (1997) recorded evidence for the presence of at least 58 dhaka structures within an area of 10 ha. The midden could have resulted from the activities of the occupiers of these structures. Evidence of housing floor remains and low walling was also noted in the area (Figure 4.4).

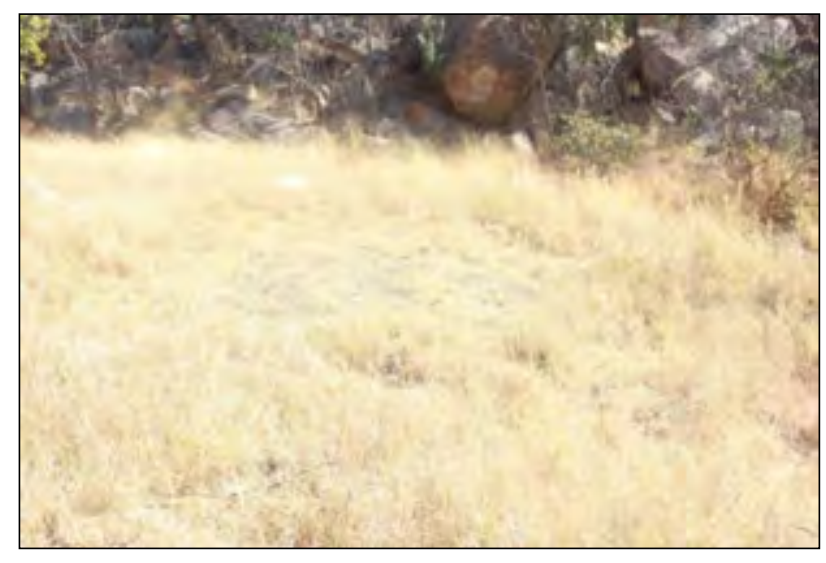

Figure 4.3: Picture showing Midden 1, which is dominated by the Cenchrus ciliaris grass from the eastern end of the midden. 


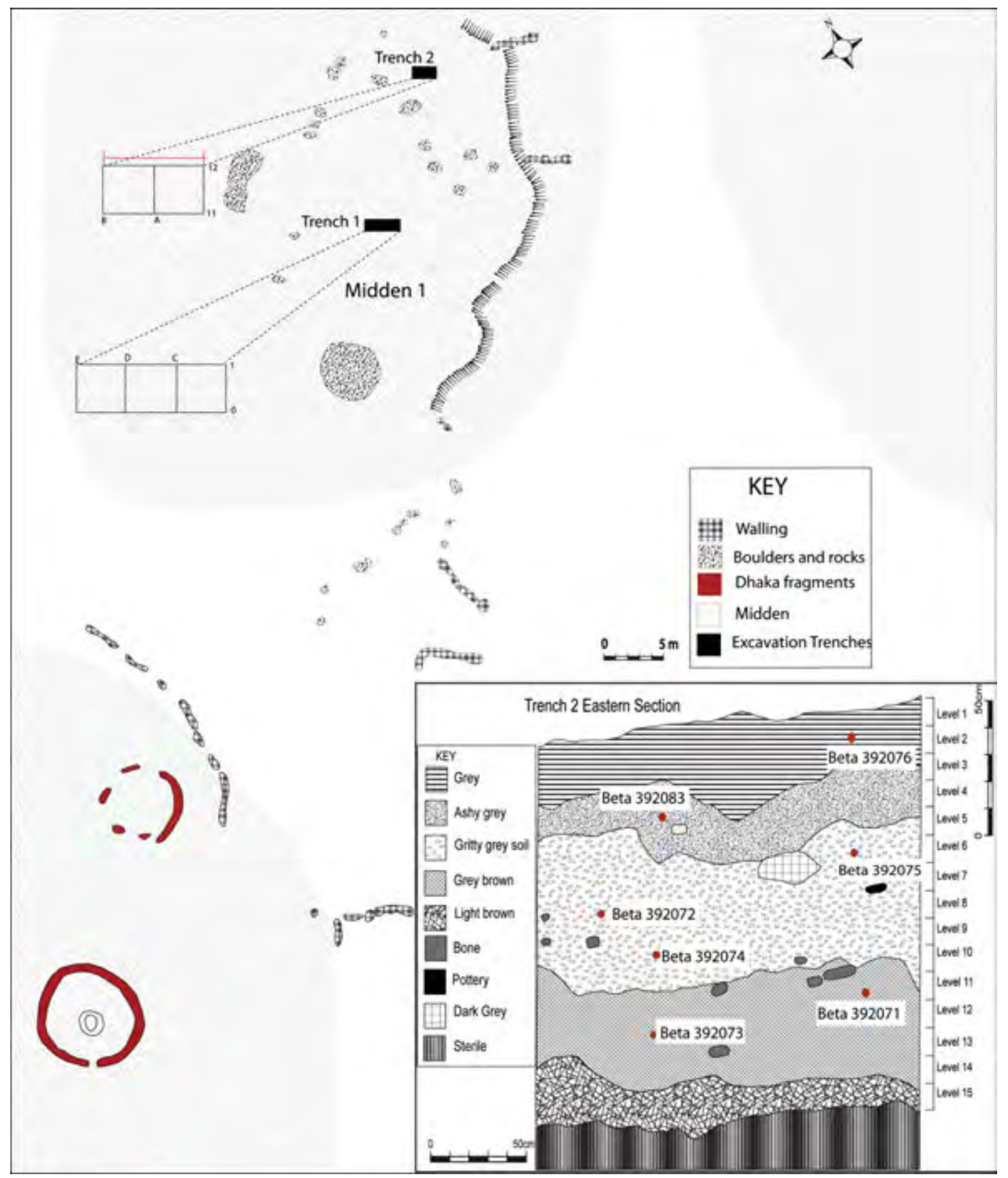

Figure 4.4: Midden 1 plan and profile of Trench 2.

Two excavation trenches were placed on Midden 1 (Figure 4.4). Trench 1 was placed near the centre of the midden. Trench 2 was placed towards the northern periphery of the midden. This location was informed by the need to avoid animal burrows, which are rampant around the site. Trench 1 was extended north-east by a further square metre when burrows were 
encountered in Square C. More burrows were also encountered in Square E, leaving Square D as the only intact unit, hence a decision was taken to continue excavating Square D for the purpose of analysing and understanding the stratigraphic sequence of the material culture. Material from Squares C and E was not used for analysis for the present study but could be used for comparative purposes once a chronological sequence for the site has been developed using material from areas that were not affected by burrowing. Trench 2 was excavated to a depth of $150 \mathrm{~cm}$. The upper levels of the trench $(30 \mathrm{~cm})$ had grey gritty soils that yielded little amounts of material. The following $80 \mathrm{~cm}$ of the trench was ashy and had increased amounts of diagnostic material. The final $40 \mathrm{~cm}$ was less ashy with light brown soils. Finds recovered include pottery, fauna, glass beads, metal objects, charcoal and shell beads. Samples of charcoal from Trench 2 were dated (see Table 4.1). The trench was dated because its stratigraphy was intact and there was no evidence of any disturbances. Seven dates were obtained from the trench to get an understanding of the evolution of the site with time, and these dates could be correlated with the material recovered from the trench.

Table 4.1: Radiocarbon dates from Midden 1 Trench 2

\begin{tabular}{|c|c|c|c|c|}
\hline Laboratory number & Context & Material dated & Uncalibrated dates & Calibrated dates @ 2 sigma \\
\hline Beta - 392076 & KM01T2B11L 2 & Charcoal & $360+/-30 \mathrm{BP}$ & AD 1465 to 1645 \\
\hline Beta - 392083 & KM03T2B11L 4 & Charcoal & $290+/-30 \mathrm{BP}$ & AD 1620 to 1665 \\
\hline Beta - 392075 & KM05T2B11L 6 & Charcoal & $430+/-30 \mathrm{BP}$ & AD 1440 to 1500 \\
\hline Beta - 392072 & KM07T2B11L 8 & Charcoal & $340+/-30 \mathrm{BP}$ & AD 1495 to 1650 \\
\hline Beta - 392074 & KM09T2B11L 10 & Charcoal & $350+/-30 \mathrm{BP}$ & AD 1460 to 1640 \\
\hline Beta - 392071 & KM11T2B11L 12 & Charcoal & $290+/-30$ BP & AD 1620 to 1665 \\
\hline Beta - 392073 & KM12T2B11L 13 & Charcoal & $290+/-30$ BP & AD 1620 to 1665 \\
\hline
\end{tabular}

The radiocarbon dates from the Khami Midden 1 Trench 2 (Table 4.1 and Figure 4.6) estimate its duration of occupation to be between AD 1440 and 1665. These dates are comparable to those recovered from other parts of the site (Sheppard and Swart 1967; Table 3.2). There appears to be a discrepancy in the distribution of the dates from this trench such that older dates are found in the upper levels. This can be explained by disposal patterns, which did not necessarily result in the disposed material creating perfect successive layers. 

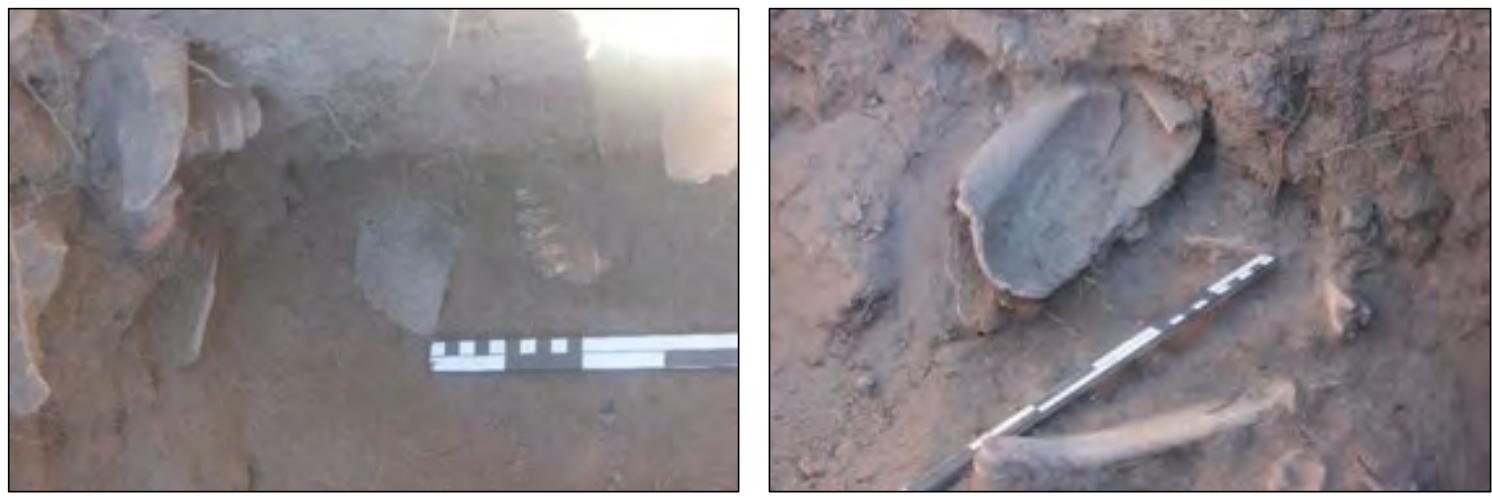

Figure 4.5: Large diagnostic faunal samples were recovered from Trench 2. On the left is a mandible of a Bov III next to a sherd decorated with incised triangles. On the right is a pot associated with faunal material from Trench 1 Midden 1.

\subsubsection{MIDDEN 2}

GPS Readings $\left(20^{0} 08^{\prime} 32^{\prime \prime}\right.$ South and $28^{0} 25^{\prime} 02^{\prime \prime}$ East)

Midden 2 was also identifiable by the presence of Cenchrus ciliaris grass and animal burrows that revealed sub-surface deposits. The surface finds recorded include metal piecesprincipally iron and copper, pottery fragments, faunal remains, a metal bead mould, slag and grinding stones. The bead mould was identified on the basis of another mould housed in the Natural History Museum of Zimbabwe that was used in the manufacture of gold beads. The recovery of the bead mould was thus a pointer to bead manufacturing at Khami, a clear sign of the processing of minerals at the site. This midden was specifically chosen for further investigation because of its spatial location in relation to other excavated units and also to the built-up area of the site (Figure 4.1). The midden is located approximately 790 metres northwest of the nearest built-up area. There is no stone walling within its vicinity. The area has therefore been defined as a commoner settlement area (Robinson 1959; Huffman 1996; 2007). As such, further investigation of this area was carried out to clarify its material culture identity and how it related to that of the stone-walled area. This process would in turn help in refining our understanding of the horizontal and vertical arrangement of society at Khami. 

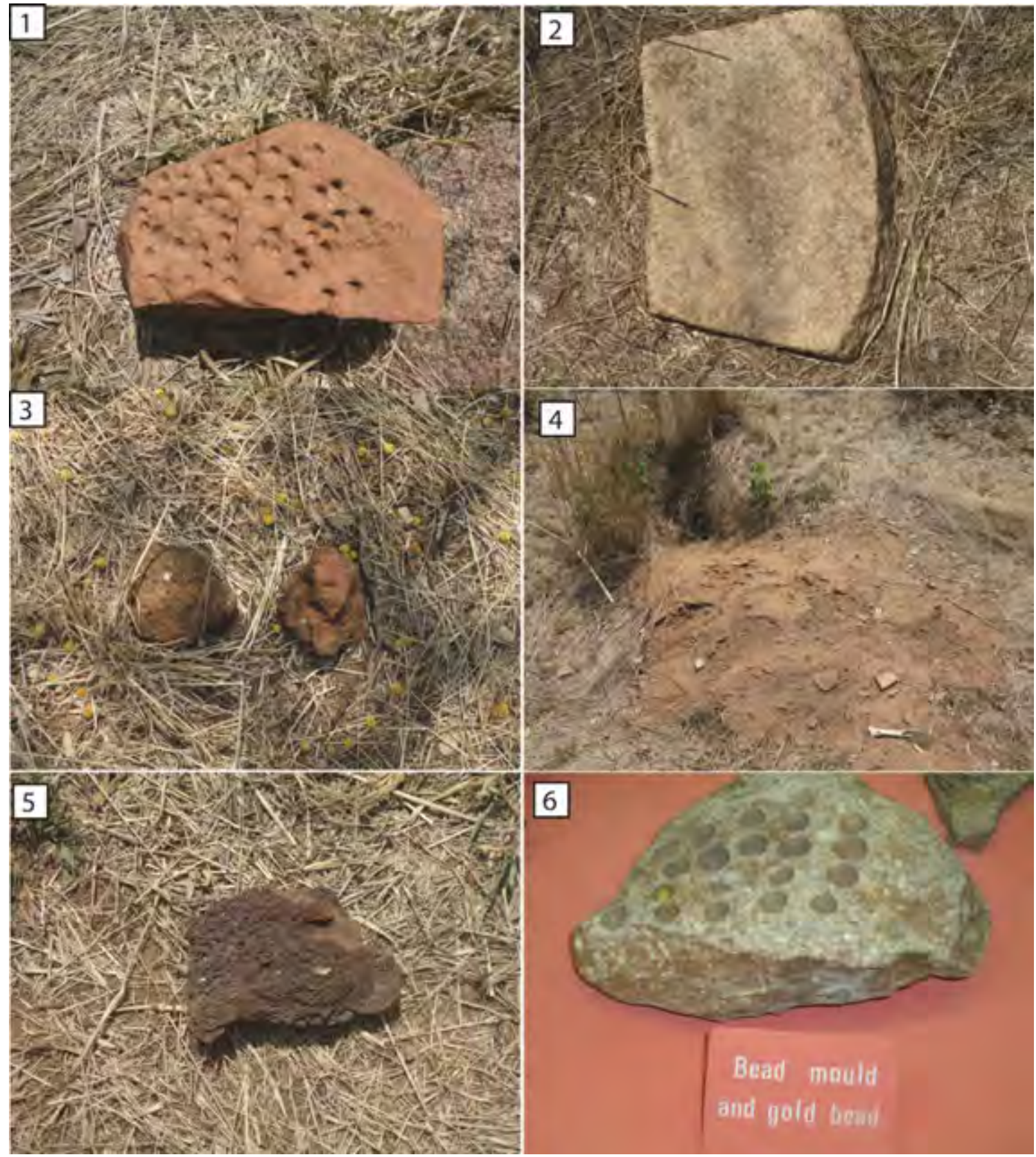

Figure 4.6: 1. Possible bead mould 2. Lower grinding stone 3. Dhaka fragments 4. Scatters of bone and pottery from a burrow 5. Slag 6. Comparative bead mould from the Natural History Museum of Zimbabwe

Two trenches were excavated on Midden 2 (Figure 4.5). Trench 1 was a $2 \mathrm{~m} \mathrm{x} 1 \mathrm{~m}$ unit located on the western end of the midden and excavated in $1 \mathrm{~m}^{2}$ grids. The area was purposely selected because there was minimal burrowing evidence on the surface, thus reducing the chance of meeting sub-surface disturbances. The excavation went $0.4 \mathrm{~m}$ deep. The stratigraphy consisted of brown humic soils that formed the uppermost levels of the 
trench. Some faunal material, pottery sherds, and shell beads were recorded in this layer. The second layer was very ashy and a significant number of animal teeth were found, including bone, beads and metals. The fourth level was sterile with predominantly red soils.

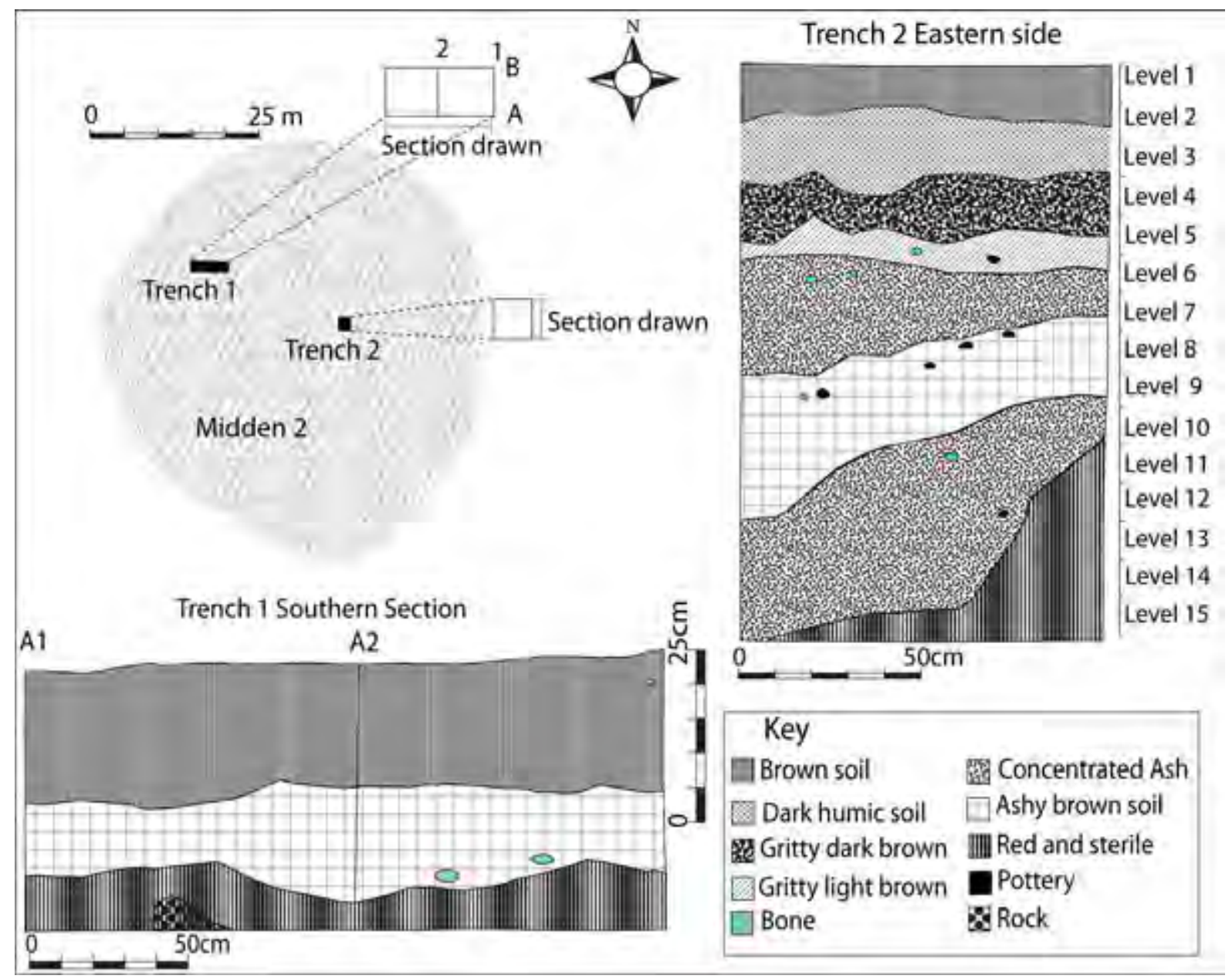

Figure 4.7. Plan and trenches profile drawings for Midden 2.

Trench $2(1 \times 1 \mathrm{~m})$ was sunk approximately $20 \mathrm{~m}$ east of Trench 1 . Faunal remains, metal pieces and artefacts, and glass beads were some of the finds recorded from Trench 2. While pottery fragments were collected, they were significantly fewer compared to other trenches, both on this midden and on Midden 1 . The first $20 \mathrm{~cm}$ of this trench did not yield any material. Trench 2 was characterised by the presence of very ashy soils, from level 5 down to level 16. 


\subsubsection{MUSEUM MIDDEN 1}

GPS Readings $\left(20^{\circ} 08^{\prime} 45^{\prime \prime}\right.$ South and $20^{0} 25^{\prime} 23^{\prime \prime}$ East $)$

Museum Midden 1 is located approximately 42 metres south-west of the Khami Site Museum (Figure 4.1). The midden was identifiable from the ashy soil and presence of fauna and pottery. House floors were noted close to the Site Museum but these were not mapped. The presence of house floors as well as game boards and lower grinding stones suggests a household area. It was hoped that the area would also yield a sample of cultural material that would help clarify and reconstruct the archaeology of the area as well as enable a comparative analysis with other areas of the site.

A $2 \times 2$ m trench was laid on Museum Midden 1 in $1 \mathrm{~m}^{2}$ grids (Figures 4.8, 4.9). Since the overall objective was to understand the vertical material distribution on the midden, initially a $1 \mathrm{~m}^{2}$ grid was excavated (Square A0). However, a decision was taken to extend this by another $1 \mathrm{~m}^{2}$ after bedrock was reached at $50 \mathrm{~cm}$ on the northern part of the trench. The first $10 \mathrm{~cm}$ had brown soil, followed by $80 \mathrm{~cm}$ of ashy soils. However, patches of red soils were also encountered, particularly in the eastern end of the trench from level 4 to level 9. The upper layers were characterised by mostly undiagnostic pottery fragments. Faunal samples were recorded across the whole trench. An interesting characteristic of the faunal assemblage was the presence of large intact and diagnostic samples of cattle and wild animals. Some of them showed evidence of having been modified for other uses: for example, ribs that had smooth, rounded ends that could have been used in the treatment of hides. The upper layers contained mostly red and blue beads. However, more colours, including turquoise blue, begin to be noted from the middle levels onward, although red continued to dominate. Ostrich egg shell beads were also recorded at all excavation levels. Strands of copper and iron were recorded in the upper levels. Midden 1 rested on an uneven granite floor; therefore, bed rock was reached at Level 9 in Square A0 and Level 5 in Square A1. 


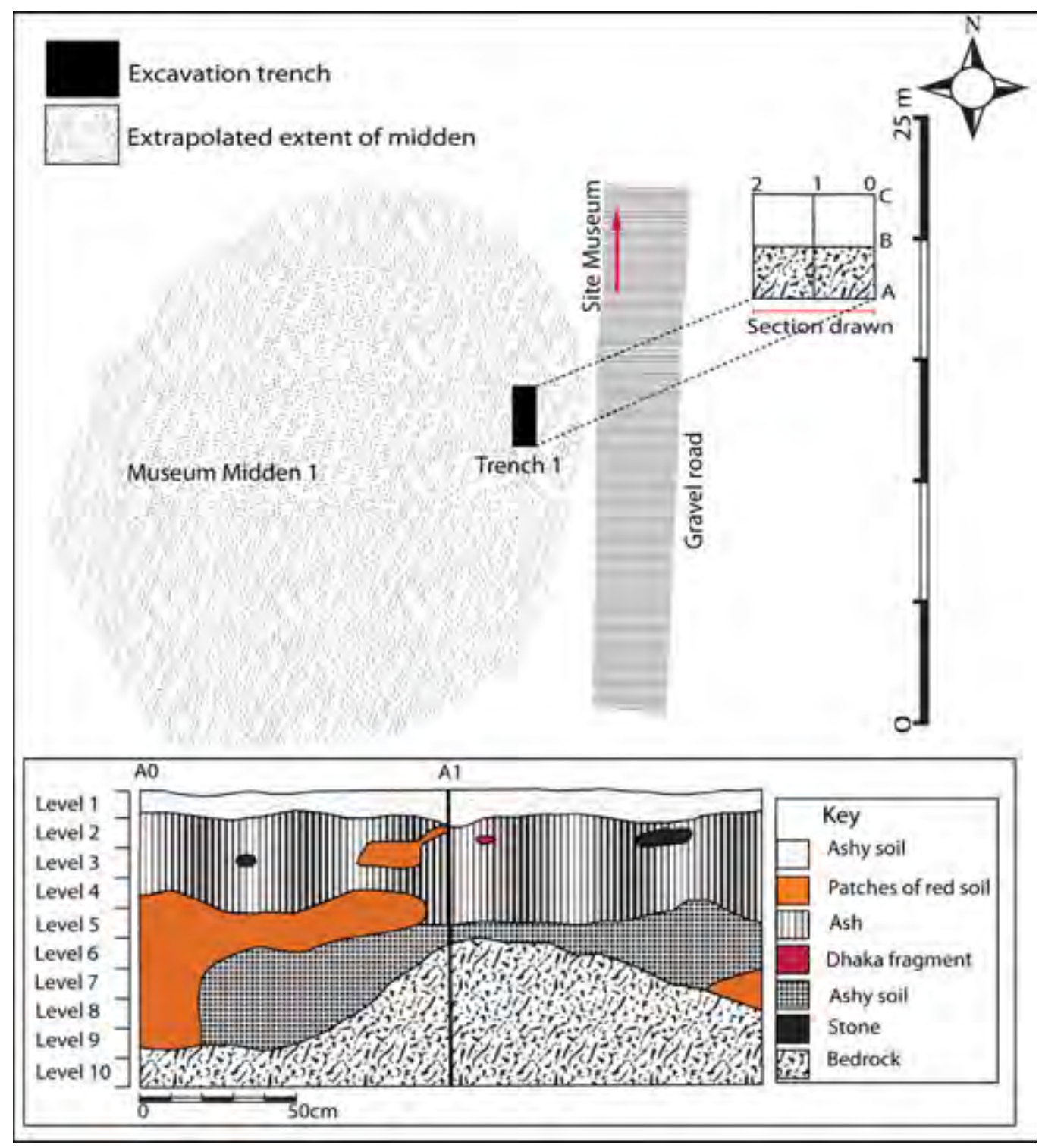

Figure 4.8 Plan of Museum Midden 1 and cross section of Trench 1

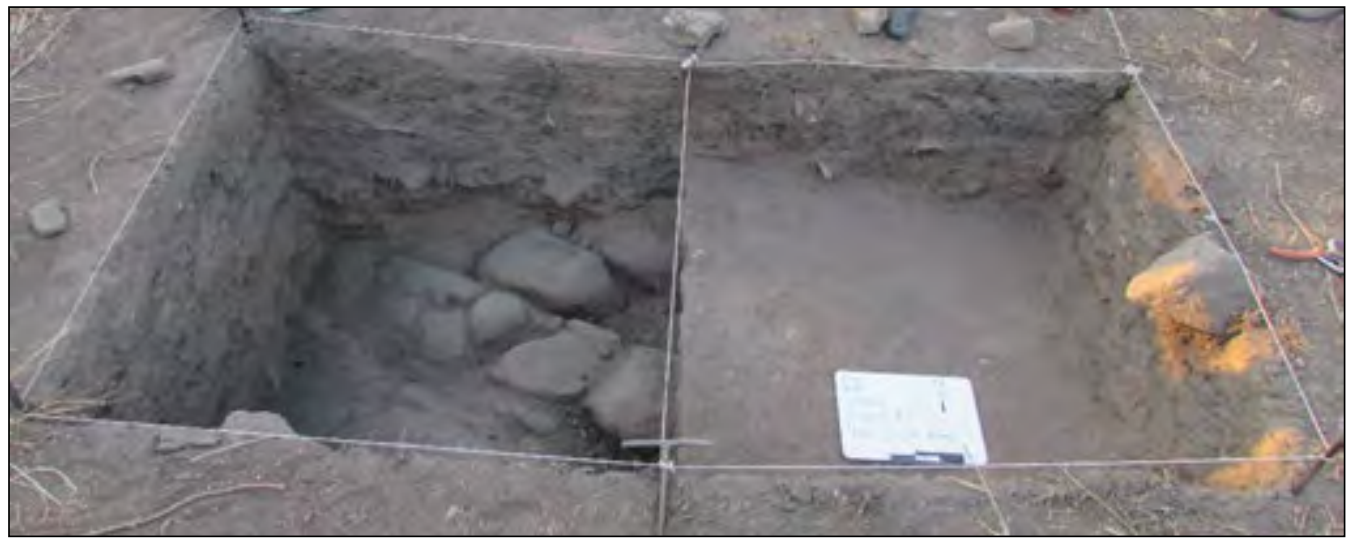

Figure 4.9: Trench 1 on Museum Midden 1 in progress. Bedrock had already been reached on Square A0 (left side). 


\subsubsection{MUSEUM MIDDEN 2}

GPS Readings $\left(20^{0} 08^{\prime} 46^{\prime \prime}\right.$ South and $28^{0} 25^{\prime} 24^{\prime \prime}$ East)

Museum Midden 2 (Figure 4.10 and 4.11) is located in a south-westerly direction from the site museum. Of particular significance was the presence of Cenchrus ciliaris grass. Museum Midden 2 is far away from the walled areas. It is approximately $297 \mathrm{~m}$ from the Hill Complex and $204 \mathrm{~m}$ from the Vlei Platform. Another midden, Museum Midden 3, is located between the Vlei Platform and Museum Midden 2, but it was not investigated further. To the north of Museum Midden 2, there are eroded house floors that can be observed just outside the present museum building. Robinson (1959), in his map of Khami, also noted the presence of house remains in the area. It is to these houses that the midden may be attributed.

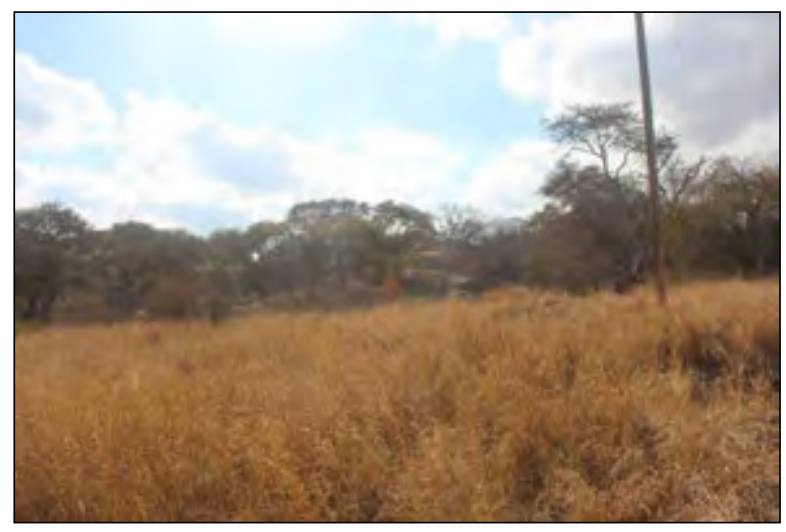

Figure 4.10: Museum Midden 2 covered by thickets of grass. In the background is the Vlei Platform

A $3 \times 1 \mathrm{~m}$ trench was laid on Museum Midden 2 (Figure 4.12). However, only two $1 \mathrm{~m}^{2}$ trenches Square A0 and C0 were excavated. The idea was to get material that could be used in understanding activities going on in that area. The material will also be used to conduct a comparative analysis with other parts of the site and to extract carbon material for dating. The upper $15 \mathrm{~cm}$ of top soil had beads of varied colours, such as cobalt turquoise, Indian red, cerulean blue. Bone fragments, shell beads and diagnostic pottery were also recovered. The next level had ashy grey soils and some dhaka inclusions. In addition to decorated pottery, diagnostic bones and glass beads, some metal pieces and a spindle whorl were also recovered. This level was followed by an ashy but gritty layer that had faunal material, glass beads and pottery. Much of the pottery was less decorated compared to the preceding level. Indications from the bone recovered in the layer showed that most of it was from Class III bovids. The 
following layer was less ashy and more light brown and gritty. The material culture was not as substantial as in earlier layers. However, the following glass bead colours were recovered: blue, turquoises and Indian red. In terms of pottery, large fragments were recovered, and herringbone decoration dominated. The soil colour also changed to a reddish brown. Worked bone, in the form of ribs, was also noted. Throughout the trench, charcoal was also collected to obtain samples that could be used to date the midden.

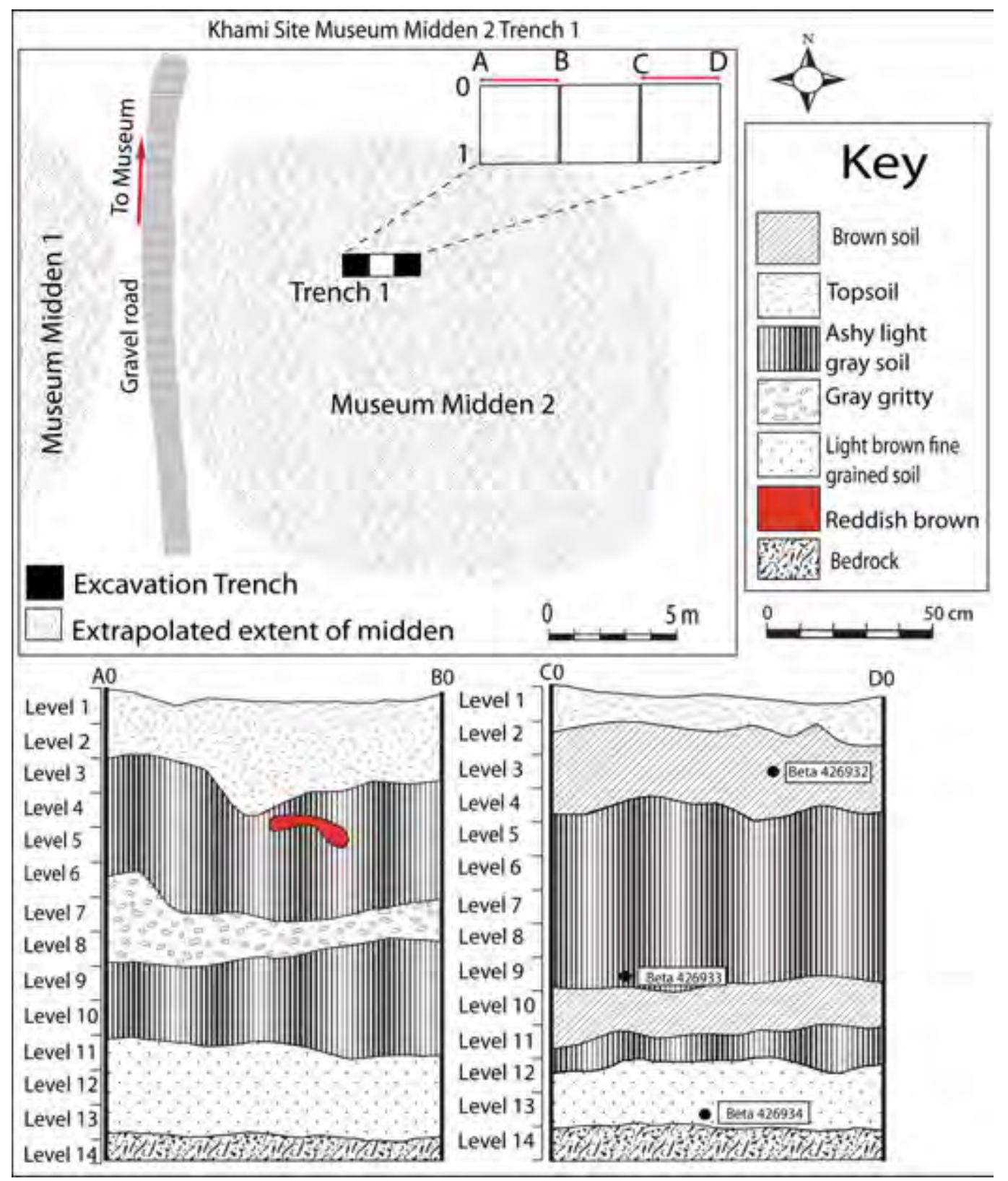

Figure 4.11: Museum midden 2 plan and sections 
Charcoal was also sent for dating from this trench, in order to get a wide sample of dates from various areas of the site. The dates range from the mid-fifteenth century to the midseventeenth century.

Table 4.2: Dates from Museum Midden 2, Trench 1

\begin{tabular}{|l|l|l|l|l|}
\hline Laboratory number & Context & Material dated & Uncalibrated dates Calibrated dates @ 2 sigm \\
\hline Beta -426932 & KMM2T1L4 & Charcoal & $360+/-30$ BP & AD 1465 to 1645 \\
\hline Beta -426933 & KMM2T1L9 & Charcoal & $340+/-30$ BP & AD 1495 to 1650 \\
\hline Beta -426934 & KMM2T1L13 & Charcoal & $350+/-30$ BP & AD 1485 to 1650 \\
\hline
\end{tabular}

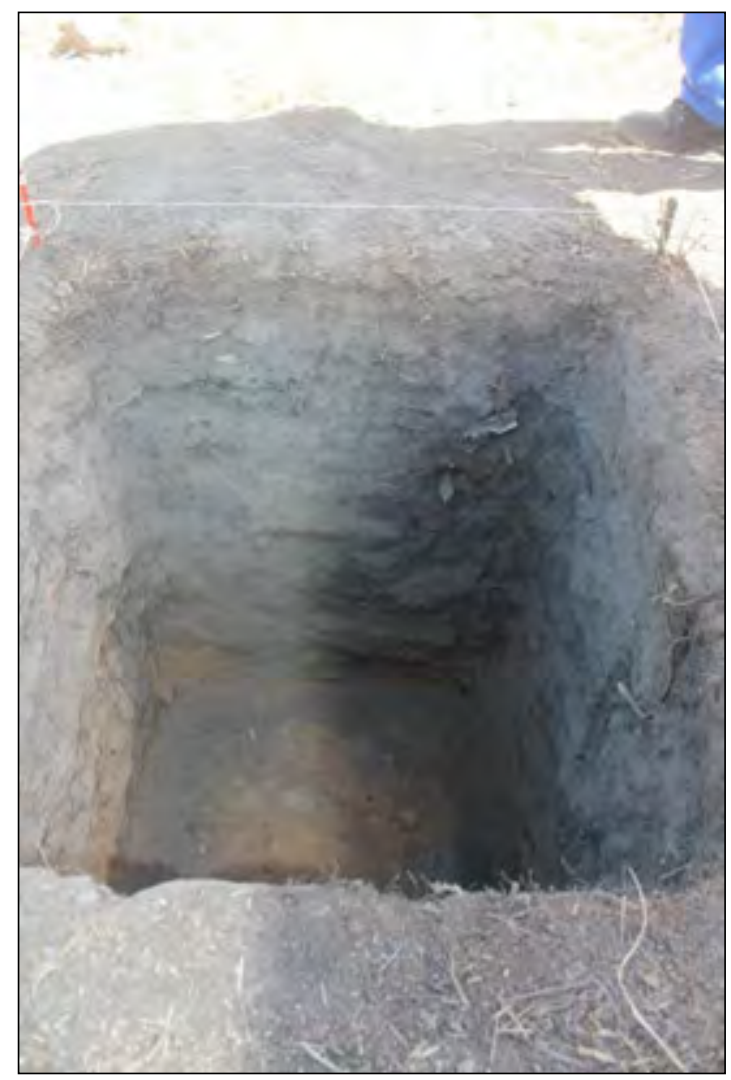

Figure 4.12: The natural stratigraphy of Square C0, Trench 1, Museum Midden 2.

\subsubsection{NORTH PLATFORM MIDDEN}

GPS Reading $\left(20^{0} 08^{\prime} 31^{\prime \prime}\right.$ South and $28^{0} 25^{\prime} 23^{\prime \prime}$ East $)$

The North Platform Midden 1 (Figure 4.13) is located approximately 100 metres to the north of the Hill Complex. During the site survey, some deep middens were observed in the area, 
outside the stone walls; thus, a decision was taken to investigate the area further. The upper $10 \mathrm{~cm}$ of this trench had dark and humic soil, followed by fragments of dhaka (Figure 4.14). It yielded ceramics, faunal material, glass beads and a coiled metal. The soil texture for levels 3 to 11 was mainly ashy. Thereafter, it was followed by red soils. The ashy levels yielded a lot of material, including diagnostic pottery, diagnostic fauna, glass beads and jewellery, and other metal products. Foot bone was the most dominant skeletal part of the faunal assemblage. A house floor was encountered at level 11, in a layer made up of light red soils. A lot of ceramics were also recorded in this layer. Bedrock was reached at $130 \mathrm{~cm}$.

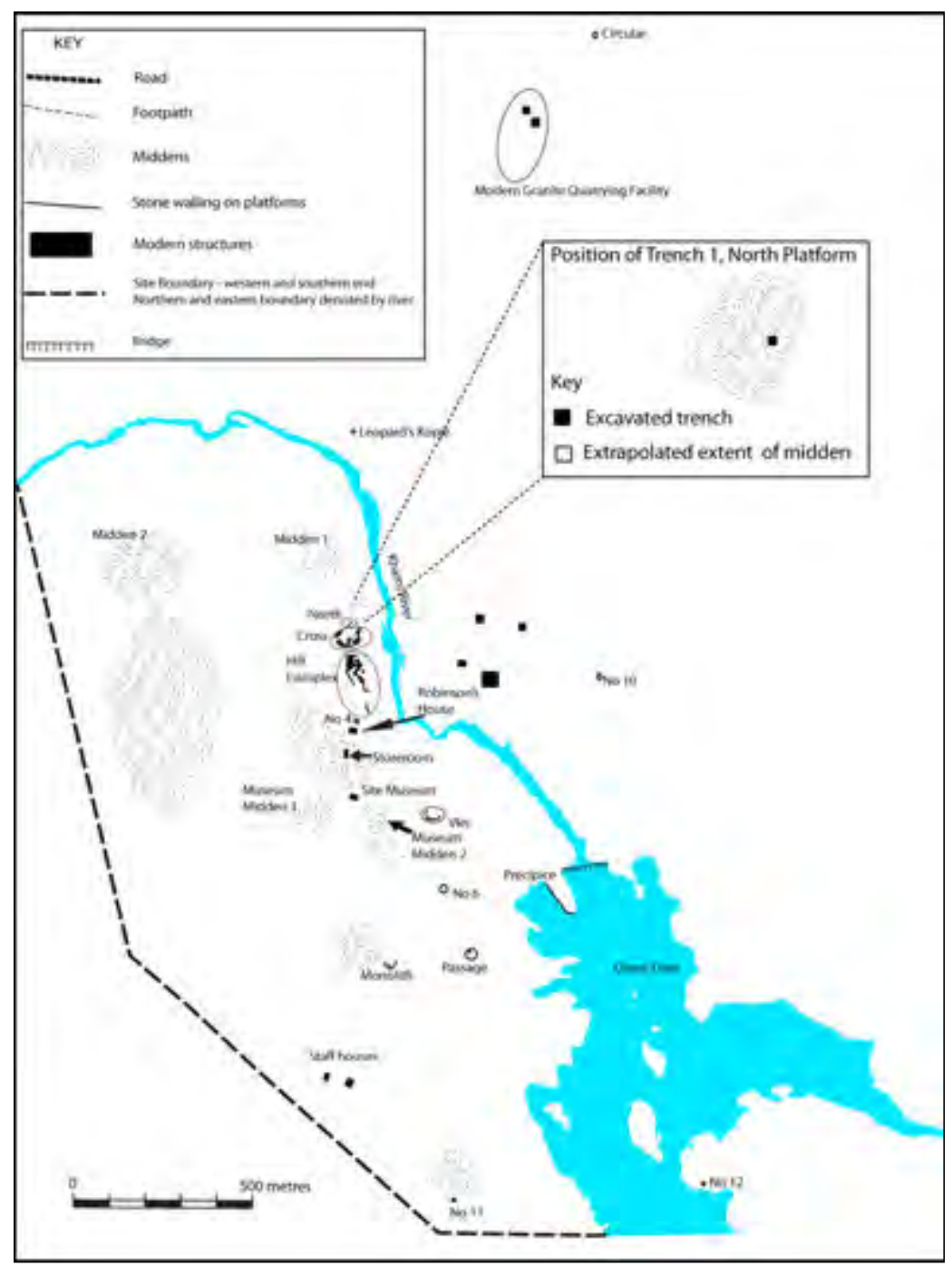

Figure 4.13: Plan of Khami showing the position of the North Platform Midden. 


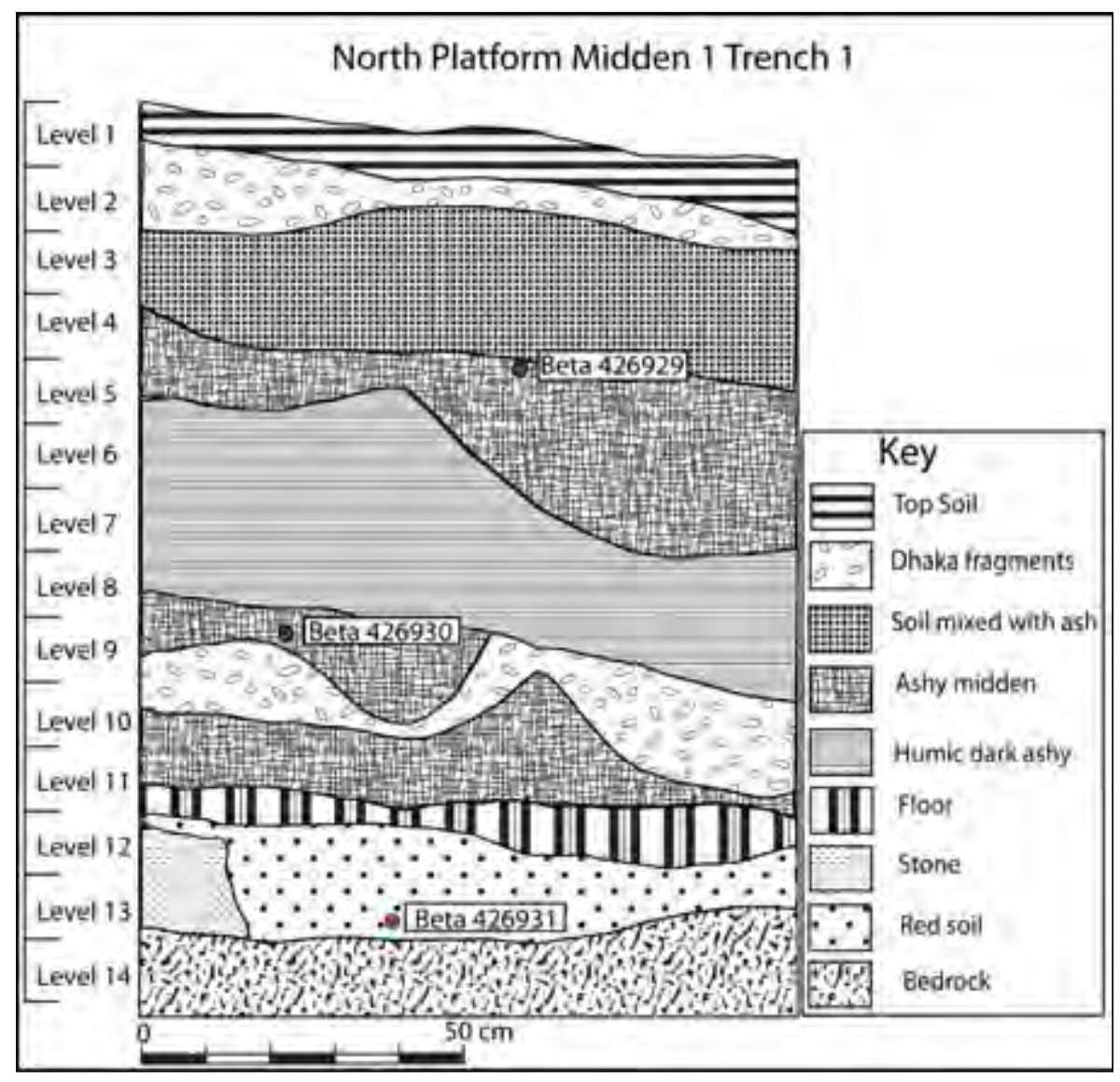

Figure 4.14: Section drawing of the North Platform Midden Trench 1.

Three dates were obtained from Trench 1 (Table 4.3). They show that the site was in occupation between the mid-fifteenth century and the mid-seventeenth century.

Table 4.3: Dates from North Platform Midden Trench 1

\begin{tabular}{|l|l|l|l|l|}
\hline Laboratory number & Context & Material dated & Uncalibrated dates & Calibrated dates @ 2 sigma \\
\hline Beta -426929 & KNPM1T1L4 & Charcoal & $350+/-30$ BP & AD 1485 to 1650 \\
\hline Beta -426930 & KNPM1T1L9 & Charcoal & $300+/-30$ BP & AD 1505 to 1585 \\
\hline Beta -426931 & KNPM1T1L13 & Charcoal & $300+/-30$ BP & AD 1510 to 1575 \\
\hline
\end{tabular}

\subsubsection{CROSS RUIN MIDDEN}

GPS Reading $\left(20^{0} 08^{\prime} 55^{\prime \prime}\right.$ South and $28^{0} 25^{\prime} 41^{\prime \prime}$ East $)$ 


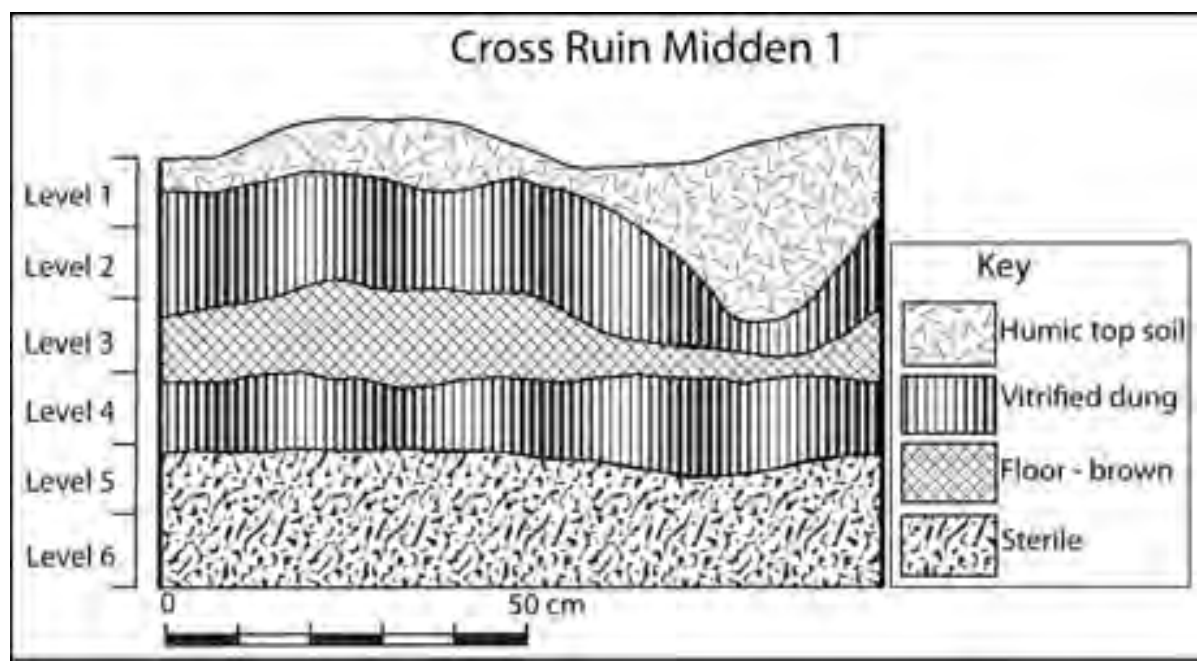

Figure 4.15: Section drawing of the stratigraphy at Cross Platform Midden.

A decision was also taken to place another trench next to Robinson's excavation east of the Cross Platform (i.e., Excavation 19) (Robinson 1959: 25). This decision was informed by the need to test the relationship between the Leopard's Kopje and the overlying Khami deposits. The trench was located $80 \mathrm{~cm}$ in a westerly direction and $120 \mathrm{~cm}$ in a southerly direction from Robinson's Excavation 19. A $1 \mathrm{~m}^{2}$ unit was set up, and excavation followed in $10 \mathrm{~cm}$ spits. The upper $10 \mathrm{~cm}$ yielded only a few bones. The next layer of about $15 \mathrm{~cm}$ was soft and ashy and yielded ceramics and bones. A layer of vitrified dung was also noted, with bones and ceramics. The rest of the stratigraphy yielded bits and pieces of material, but this was not as extensive as the other excavation units at the site.

\subsubsection{MAPPING OF CIRCULAR PLATFORM, EAST OF KHAMI RIVER}

Circular Platform is located on the eastern side of the river, approximately $2 \mathrm{~km}$ north-east of the Hill Complex (Figure 4.1). The homestead comprises a stone-built enclosure and six houses located outside the stone enclosure (Figure 4.16). Inside the enclosure there is only one dhaka house with radial walls connecting to an outer wall of dhaka. The radial walls create an additional six compartments in addition to the main circular room. There are similarities with a house observed and recorded by Garbutt and Johnson (1912: Chapter 3), though it is not clear which part of the site it was located. The platform is divided into three parts by three radial walls that connect the outer wall of the house with the outer stone wall of 
the enclosure. Half of the platform is freestanding, while the other half is terraced. There are two entrances leading into the enclosure, one facing the north-east and the other facing the north-west. The outer walling is profusely decorated with chequered pattern. Robinson (1959: 21) noted traces of herringbone pattern in the inner face of the wall and cord pattern on the outside. However, these are no longer visible, largely due to the collapses that have affected the walling.

The six houses outside the enclosure are certainly part of the platform, and any interpretation of the possible function of the platform would be incomplete without taking them into account. The presence of houses around platforms has also been noted elsewhere around the site. Floor remains were noted near the Monolith and No 6 and around the Hill Complex. This again suggests that any reading of these platforms must necessarily take these house structures into account. Circular Platform will be discussed in more detail in Chapter 9. Because no deep deposits could be found during intra-site surveys, a decision was taken to map the platform and the surrounding house structures. Most likely, this offered an opportunity to understand the spatial relationship between walled areas and adjacent houses. However, six glass beads of blue, green and Indian red colour were recovered from the surface inside the enclosure. Due to a dearth of surface material remains and the apparent lack of obvious middens around the platform, no excavation was conducted. It was felt that the mapping was sufficient in giving an idea on the spatial distribution of structures at Khami. However future research should be directed at excavating this platform with a view to understand how it relates with other components of Khami.

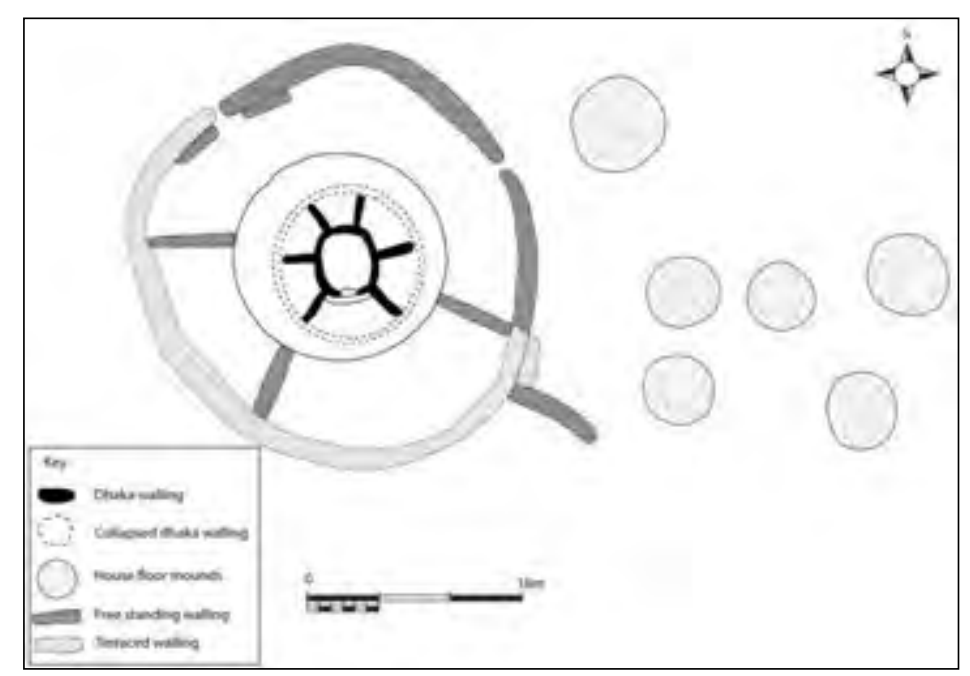

Figure 4.16: Plan of Circular platform 


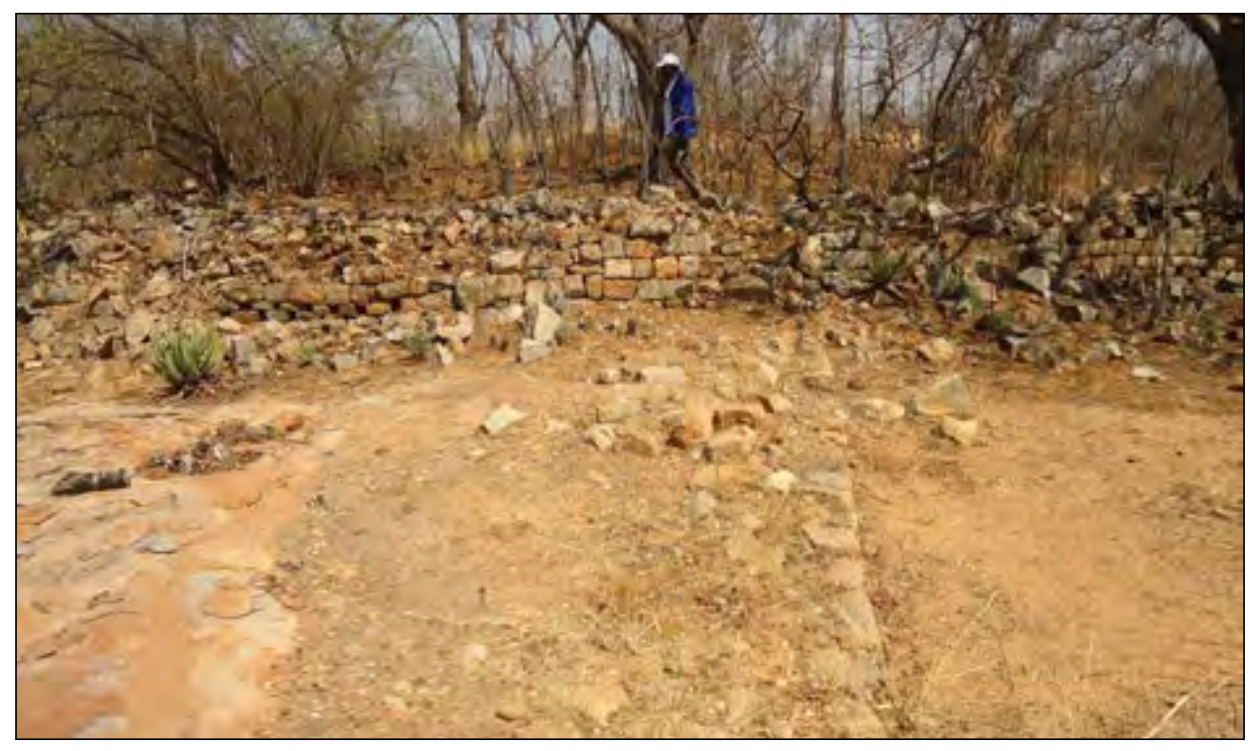

Figure 4.17: A view of Circular Platform from the north-west, showing the terraced wall radiating from the stone walled enclosure. The mound in the background is the collapsed house inside the platform.

\subsection{ANALYSIS OF MUSEUM COLLECTIONS FROM KHAMI}

The objective of the reanalysis of this material was to classify the ceramics and beads stratigraphically. This classification enabled a comparative assessment of the various spaces that made up the capital. It was also important to record other material that was recorded in the excavations, because some of these materials had not been subject to intensive study. These include metal objects like chains, bangles, wound wire, spearheads, beads, and fragments of a variety of metals. They also included ivory products, and spindle whorls. The main point here is that there is a significant amount of material reflecting the craft production industry at Khami. However, this material has never been subject to intensive study, and the nature of this industry — and, in particular, how important it was in the society at Khami-has not been well understood. Most of the material came from the stone-walled area, particularly the Hill Complex. There is reference information in terms of the provenance of these objects in the published material on the site (Robinson 1959; Thorp 1984; 1995; Hughes 1997). 


\subsection{DISCUSSION}

While the detailed results of the excavations are presented and discussed in subsequent chapters, a few general observations can be made here. The excavations have shown that there is generally a uniformity of material culture distribution at the site. In all the trenches, band- and panel-decorated ceramics, glass beads, various metal objects and fauna were recovered. This uniformity can also be observed in the three dated middens, which show that the site was occupied between the fifteenth and seventeenth centuries. At a general level, the pottery recovered from the excavations compared with that recovered by Robinson (1959) on the Hill Complex. Band and panel decorations and the use of red ochre were also recorded, as well as the dominance of incision as a form of decoration on Khami ceramics. The recovery of a variety of household goods at all the excavated units is particularly interesting, as it points to the presence of individual household units spread across the site. The mapping of Circular platform gives us an idea of the nature of these household units - an observation that was noted by Robinson (1959) at other platforms, such as the Hill Complex and Passage platform.

While early researchers at Khami recovered gold, the current excavations did not come across any. This was mainly because this investigation did not focus on house remains, which were the source of gold and gold objects in past researches (Hall and Neal 1902; Robinson 1959). Ivory, which was recovered on the Hill Complex and Passage platform, was not found in any of the excavations. However, these differences might be inconsequential, considering that excavations on the Hill Complex were widespread and involved multiple contexts, such as house floors and middens. In comparison, excavations for this study were limited as the objective was to understand the chronology and collect sample material from the various investigated units. Another important observation was the evidence of craft production at the site. This evidence was in the form of spindle whorls for cotton spinning, slag (which is evidence of metal smelting and smithing), and worked ivory remains (Hall and Neal 1902; MacIver 1906; Robinson 1959). An in-depth study of the individual artefact categories will be carried out in succeeding chapters. 


\subsection{SUMMARY}

The archaeological survey of the site showed that the spatial extent of the site has been underestimated in the past, resulting in a narrow focus on the Hill Complex. As a result, a lot of the areas outside the stone-walling areas of the site had not been investigated. This realisation informed the strategy for this study, which focused on the non-stone-walled areas that had not received attention in the past. On the whole, the investigations yielded datasets that are critical to our understanding of the material culture of the site, as well as its chronology. This material should help in illuminating individual areas around the site as well as facilitating a comparative analysis of these various areas. The next chapter presents the results of the ceramic analysis. 


\section{CHAPTER 5: CERAMIC ANALYSIS AND RESULTS}

\subsection{INTRODUCTION}

In identifying various prehistoric groups, archaeologists have turned to ceramics as a source of evidence for defining group identity (Huffman 1980; 2007; Pikirayi 1993). Ceramic styles are the foundations on which ceramic typologies have been constructed. These have resultantly formed foundation for culture-historical frameworks that have been used in the region to understand group interactions (Huffman 2007). At Khami, ceramic styles have been used to separate Leopard's Kopje settlement from the later Khami period that succeeded it (Robinson 1959). In analysing ceramics from Khami, I utilised Huffman's (1980, 2007) Multi-Dimension Approach. This approach considers the three elements of vessel shape, decoration motif and design layout to define a ceramic style. It has been widely applied by many archaeologists in the region, enabling comparability with results from other sites. Besides reflecting on group identity, ceramics also provide insights into various aspects of a society's life, such as technology, economy and social organisation (Pikirayi 1993; Lindahl and Matenga 1995; Pikirayi and Lindahl 2013). Ceramics can also be used to infer cultural interaction (Pikirayi 1993:121). Changes in the internal organisation of a society can also manifest through changes in material culture, including ceramics (Huffman 1980; 1989; Pikirayi 1993; 1996). Before moving on to the analytical approach employed and the results thereof, I will first outline an overview of ceramic studies in southern Africa.

\subsection{CERAMIC THEORY AND METHOD IN SOUTHERN AFRICA}

Ceramics have played an important role in elucidating the prehistory of southern Africa. The earliest scholars to work on some of the region's Iron Age sites made use of ceramics to identify these sites with contemporary groups (MacIver 1906; Caton-Thompson 1931; Schofield 1937; 1948; Robinson 1961; Soper 1971; Huffman 1974b; 1978; 1980; 2007; Pikirayi 1993; Pwiti 1996). The use of ceramics in identifying prehistoric societies with ceramic groupings is based on the realisation that ceramics reflect the people who make them (Pikirayi 1997). As a result, studies of Iron Age archaeological cultures and traditions in southern Africa are defined on the basis of ceramic style. Typological studies of ceramics help illuminate variations through space and time, which archaeologists use to separate one 
archaeological culture from another (Huffman 1980; Pikirayi 1993; 1997). Ceramic typology is mainly based on decoration as well as vessel shape. While a number of weaknesses have been noted in equating typological classification of ceramics and archaeological cultures, the method still remains important in creating an understanding of the various archaeological cultures (Hall 1983; Pikirayi 2007; Chirikure et al. 2013a). Developing culture history provides a framework within which to study the processes and events of the past (Huffman 1980: 168)

Huffman (1980) developed the framework for the identification of Iron Age groups in southern Africa through ceramics. He argues that individual cultural groups have specific material culture items that distinguish them from other cultural groups. The distinction can be noted in variations of their material culture, which creates a particular stylistic identity used to identify that particular cultural group. Huffman (1980: 124) argues for the use of ceramics in identifying prehistoric groups on the basis of three criteria. The first is that ceramics have stylistic variables that are quantifiable. These variables need to have many alternatives so as to limit the possibility of them occurring in different groups by chance alone. These stylistic variables are based on three aspects that include vessel shape, decoration motif and design layout. The other rationale for using ceramics is their ubiquity in the Iron Age of southern Africa. Ceramics were most likely produced locally within each individual community grouping to satisfy the need of the particular group. As a result, the potters most likely developed a group-based style that can now be used by archaeologists to correlate with archaeological cultures (Huffman 1980).

The ceramic analysis methodology developed by Huffman (1980; 2007) reflects group identity at the assemblage level. The assemblage level is the most useful to work with since it defines stylistic units based on a consistent combination of shape form, decoration layout, and motif. Huffman also introduced a number of terms that help explain the Iron Age based on ceramic analysis. The term "tradition" was used to refer to the development of a particular assemblage through time, which is the equivalent of an archaeological culture. "Phase" was used to denote a specific time segment of a tradition. He also introduced the terms "facies" to refer to a geographical variant within a tradition, and "branch" to refer to one of two or more 
facies within a phase (Huffman 1980; 2007). As a result of the application of this multidimensional analysis on ceramics from various parts of southern Africa, Huffman (1980) and subsequent scholars have been able to build a ceramic relationship that translates to cultural group relations. This was first applied to an ethnographic sample of ceramics from the Tonga of the Zambezi Valley, the Korekore of northern Zimbabwe, the Ndau of southeastern Zimbabwe, and the Pedi and Venda from the Soutpansberg region of South Africa. Stylistic variations were noted among the five groups, hence the conclusion that ceramic style was important in defining group identities (Pikirayi 2007). In the case of southern Africa, Huffman has shown that, in south-western Zimbabwe for instance, Mambo, a Leopard's Kopje variant, must have derived from $\mathrm{K} 2$ because there is a large discontinuity between Zhizo and Mambo in the area that is not present between Gokomere and Zhizo or Mambo and Woolandale (1980: 170). Relatively small change between stylistic differences, such as between Mambo and Woolandale or Gokomere and Zhizo, were said to be the result of local changes in the group and not necessarily the result of the migration of people (Huffman 1980). In this regard, a number of factors have been proffered to explain the changes that are noticed in ceramic styles. Migrations have been cited as one such factor: when people move, new alliances are made with other groups and the group also needs to adjust to the new physical setting (Schofield 1948). All these interventions can be reflected in a new ceramic style.

In spite of its widespread use, which has resulted in a better understanding of the archaeological cultures of southern Africa, typological studies of ceramics have limitations (Hall 1983; Pikirayi 1997; Chirikure et al. 2013a). Hall (1983) criticised the methodology of ceramic typological classifications, arguing that the practice's main concern appeared to have been the definition of ethnic groups instead of the understanding of prehistoric lifeways and traditions of the regions' past. Pikirayi (1997: 78) has also argued that ceramic studies needs to provide more information on the producers and users of objects, rather than focusing on their typological and material attributes. To date, there is very little understanding about the social significance of pottery in prehistoric societies, since focus is mostly on their role in building culture histories. However, despite the limitations noted, I applied ceramic typological classification to ensure comparability with research conducted elsewhere by other scholars. 


\subsection{METHODOLOGICAL APPROACH IN CERAMIC ANALYSIS}

The ceramics from the Khami excavations were examined using the multi-dimensional approach widely used in Southern Africa (Huffman 1980; 2007; Pikirayi 1993). Pwiti (1996), for example, used the same approach as the basis for the reconstruction of a more secure culture-historical framework for northern Zimbabwe. To begin the process, a data-capture sheet (Appendix A) was designed to capture the key features of the ceramics. The datacapture sheet was designed to capture attributes that built stylistic types based on the combination of vessel profile, design layout and motif categories. Analyses only targeted diagnostic pottery. Diagnostic pottery is here defined as decorated sherds or those with rims, even if they have no decoration. Conversely, fragments, and other sherds where no typological information could be obtained, were treated as undiagnostic. As a result, only sherds that exhibited one or more of the variables were analysed.

\section{Vessel profile}

Vessel profile refers to the outline of the vessel, which also determines surface to be decorated (Huffman 2007). Vessel sherds were categorised according to vessel part, i.e. rim, neck, shoulder, body, base or a combination of these. A total of four vessel forms were identified (Figure 5.1). They are:

1. Short-necked

2. Tall-necked

3. Constricted

4. Bowls 


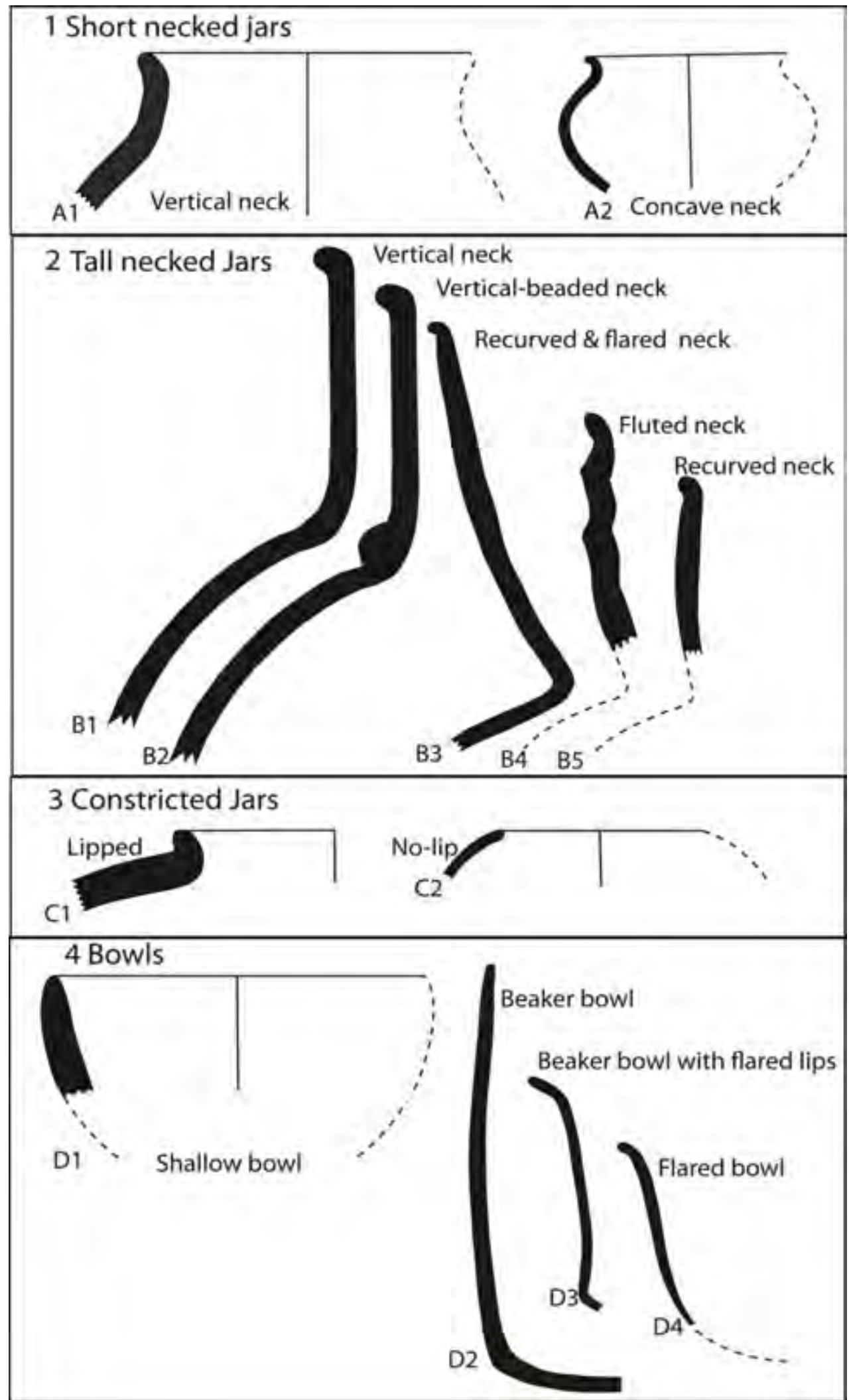

Figure 5.1: Vessel forms that were noted from the Khami ceramic assemblage. 


\section{Decoration technique}

The dominant decoration technique involved fine lines of incision, broad lines of incision and comb stamping. Other techniques include fluting, punctation and moulding. The techniques are defined below:

1. Fine line of incision (FLI) - this refers to cutting the pot with a sharp implement. This is done while the clay is still wet.

2. Broad Lines of Incision (BLI) - these are made from the use of a blunt tool to make shallow impressions on the vessel surface.

3. Comb stamping - this refers to the use of a linear multi-toothed tool to make impressions on the leather-hard vessel surface and continuous impressions to produce a repeated pattern.

4. Fluting (FLU) - this is the making of rounded ridges on the vessel with a decorative effect.

5. Punctation (PUNC) - this involves stabbing the vessel surface with a pointed tool to make various designs ranging from dots to circles.

6. Moulding (MOULD) - this is the application of bosses on the finished vessel surface.

\section{Decoration placement}

Decoration placement refers to the placement of decoration in relation to vessel shape. Decorations were limited to the body positions shown in Figure 5.2. Decoration could also be executed on two or more places. In addition, surface finish was also identified on ceramics from the site. This is polishing with a brownish grey to blackish brown colour. The vessels were burnished, smoothened, graphited or painted using red ochre. Graphite burnishing was executed on the exterior and, in some instances, on the interior upper parts of the lip. 


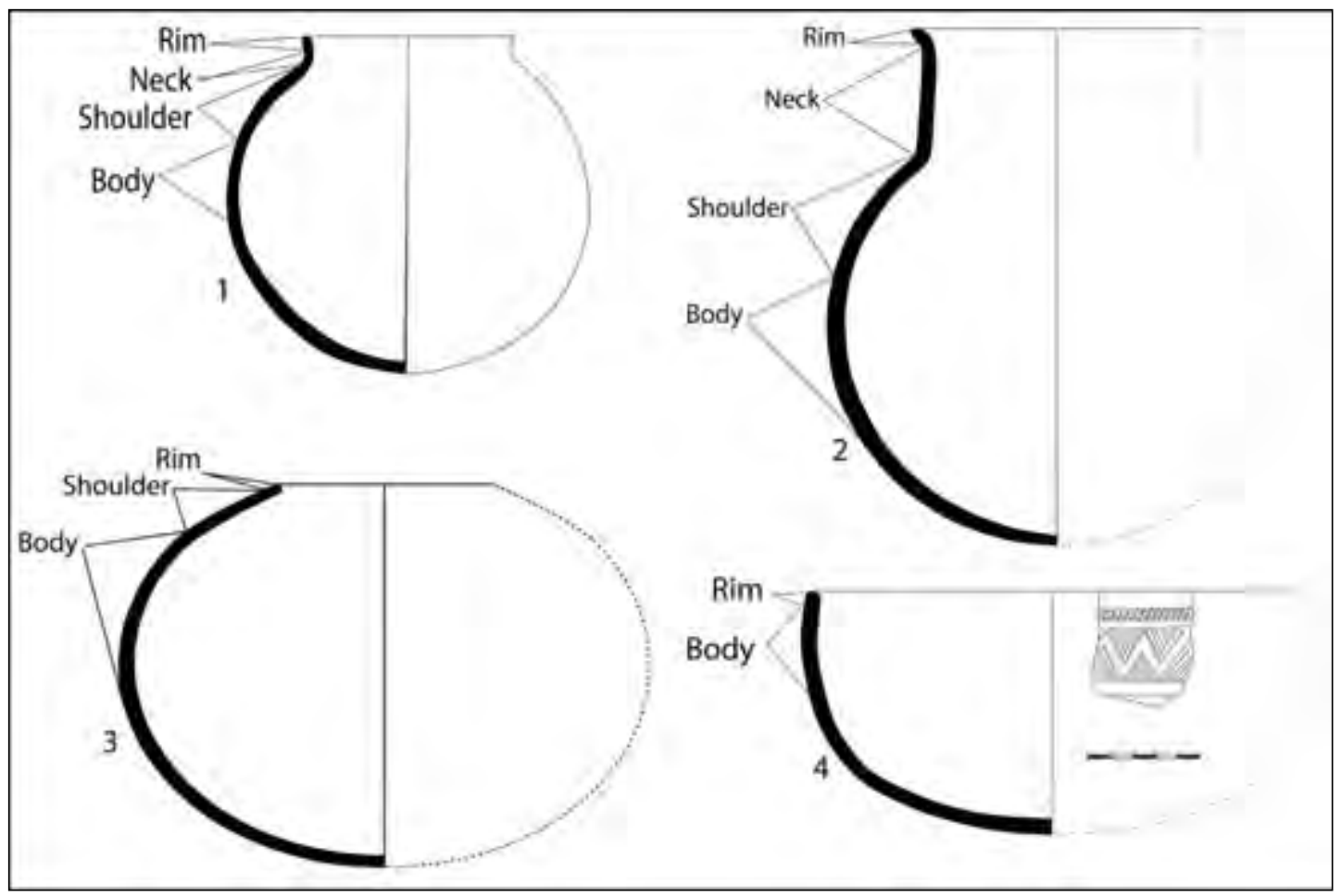

Figure 5.2: Vessel forms from Khami showing the decoration placement areas.

\section{Decoration motif}

Decoration motif refers to the complete decoration combinations found on vessels. At Khami, these can be classified according to the decoration technique employed (Table 5.1) . 
Table 5.1: Ceramic motifs from Khami
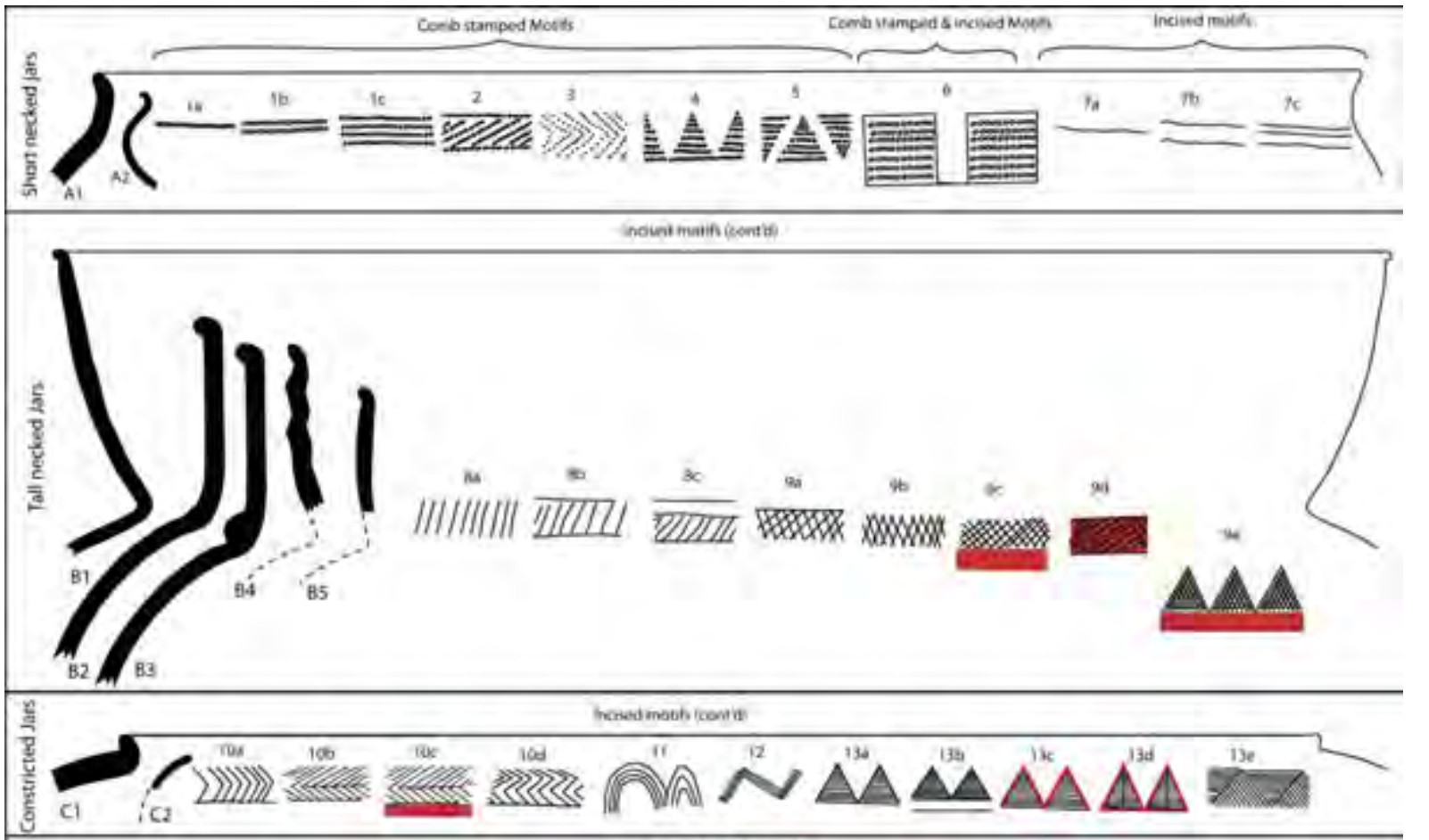

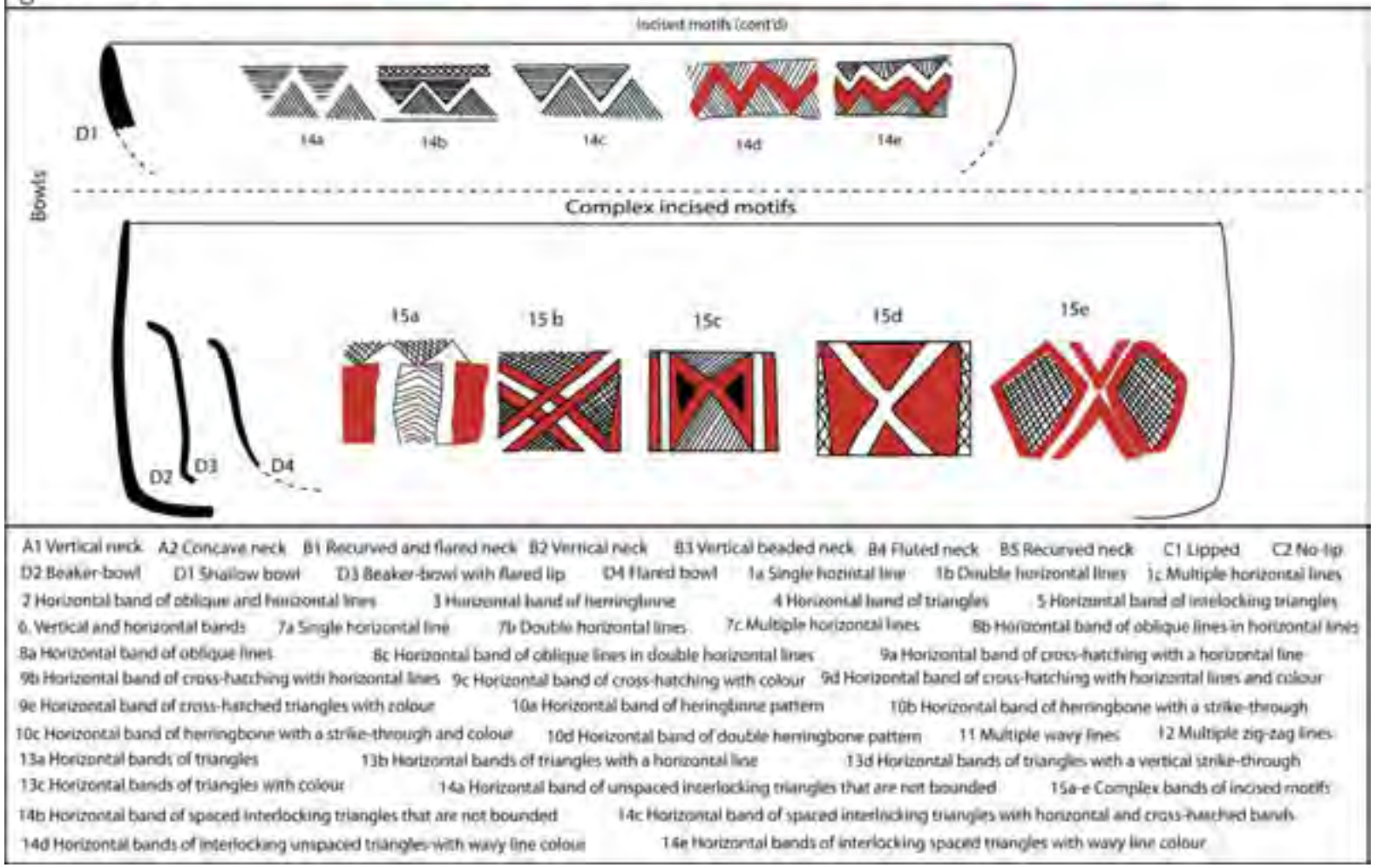




\subsection{DATA PRESENTATION}

\subsubsection{MIDDEN 1}

\section{TRENCH 1}

One hundred and fourteen diagnostic sherds were recovered from Midden 1 (Table 5.2; Figure 5.3). These included tall-necked vessels, constricted vessels, short-necked vessels and bowls. The dominant decoration technique was incision, with all the samples from the midden decorated by incision. Motifs were mainly upward-facing triangles and interlocked triangles. Both fine lines of incision and broad lines of incision dominate the upper levels of Midden 2. However, broad lines of incision are dominant throughout the rest of the deposit. The decline of both broad and fine lines of incision from level 6 might be indicative of changes in this layer. Fine and broad lines of incision reduce in size while maintaining presence at all the excavated levels. Incisions were the dominant decoration technique, accounting for $94 \%$ of the decorated sherds recovered from the midden. 
Table 5.2: Ceramic attributes for ceramics from Trench 1, Midden 1

\begin{tabular}{|c|c|c|c|c|c|c|c|c|c|c|c|c|c|c|}
\hline Attribute & & $\begin{array}{l}\text { Lev } \\
1\end{array}$ & $\begin{array}{l}\text { Lev } \\
2 \\
\end{array}$ & $\begin{array}{l}\text { LeV } \\
3 \\
\end{array}$ & $\begin{array}{l}\text { Lev } \\
4 \\
\end{array}$ & $\begin{array}{l}\text { Lev } \\
5\end{array}$ & $\begin{array}{l}\text { Lev } \\
6 \\
\end{array}$ & $\begin{array}{l}\text { Lev } \\
7 \\
\end{array}$ & $\begin{array}{l}\text { Lev } \\
8 \\
\end{array}$ & $\begin{array}{l}\text { Lev } \\
9 \\
\end{array}$ & $\begin{array}{l}\text { Lev } \\
10 \\
\end{array}$ & $\begin{array}{l}\text { Lev } \\
11 \\
\end{array}$ & $\begin{array}{l}\text { Lev } \\
12 \\
\end{array}$ & Total \\
\hline \multirow[t]{3}{*}{ 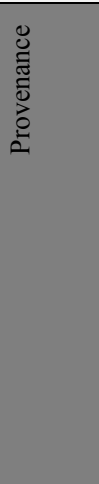 } & 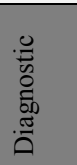 & 5 & 24 & 19 & 10 & 8 & 13 & 7 & 8 & 11 & 5 & 3 & 1 & 114 \\
\hline & 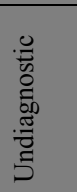 & 23 & 32 & 57 & 65 & 41 & 38 & 14 & 17 & 14 & 10 & 7 & 6 & 324 \\
\hline & 完 & 28 & 56 & 76 & 75 & 49 & 51 & 21 & 25 & 25 & 15 & 10 & 7 & 438 \\
\hline \multirow[t]{5}{*}{ 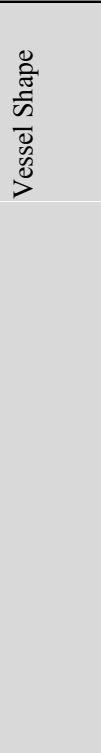 } & 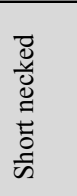 & 4 & 3 & 2 & 1 & 5 & 3 & 2 & 1 & 2 & 5 & 1 & & 29 \\
\hline & $\begin{array}{l}\text { D্ } \\
\frac{y}{0} \\
\stackrel{\Xi}{J} \\
\bar{\Xi}\end{array}$ & & 11 & 9 & 6 & 3 & 1 & 1 & 2 & 6 & & & & 39 \\
\hline & 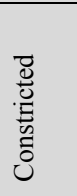 & 1 & 10 & 8 & 3 & & 9 & 4 & 5 & 3 & & 2 & 1 & 46 \\
\hline & 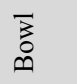 & & & & & & & & & & & & & \\
\hline & Total & 5 & 24 & 19 & 10 & 8 & 13 & 7 & 8 & 11 & 5 & 3 & 1 & 114 \\
\hline \multirow[t]{4}{*}{ 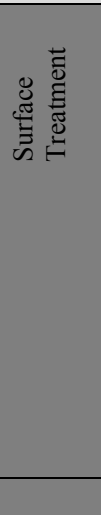 } & 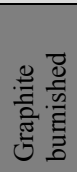 & 2 & 9 & 7 & 8 & 5 & 8 & 4 & 8 & 9 & 2 & 2 & & 64 \\
\hline & \begin{tabular}{l}
$\vec{D}$ \\
$\frac{.0}{0}$ \\
\hdashline \\
0
\end{tabular} & 3 & 9 & 2 & & & 2 & 1 & & & & & & 17 \\
\hline & $\begin{array}{l}0 \\
\stackrel{n}{0} \\
0\end{array}$ & & 6 & 10 & 2 & 3 & 3 & 3 & & 2 & 3 & 1 & 1 & 34 \\
\hline & Total & 5 & 24 & 19 & 10 & 8 & 13 & 7 & 8 & 11 & 5 & 3 & 1 & 114 \\
\hline \multirow{3}{*}{ 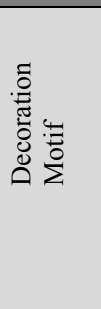 } & Ia. & & & & & & & & & & & & & \\
\hline & Ib. & & & & & & & & & & & & & \\
\hline & Ic. & & & & & & & & & & & & & \\
\hline
\end{tabular}




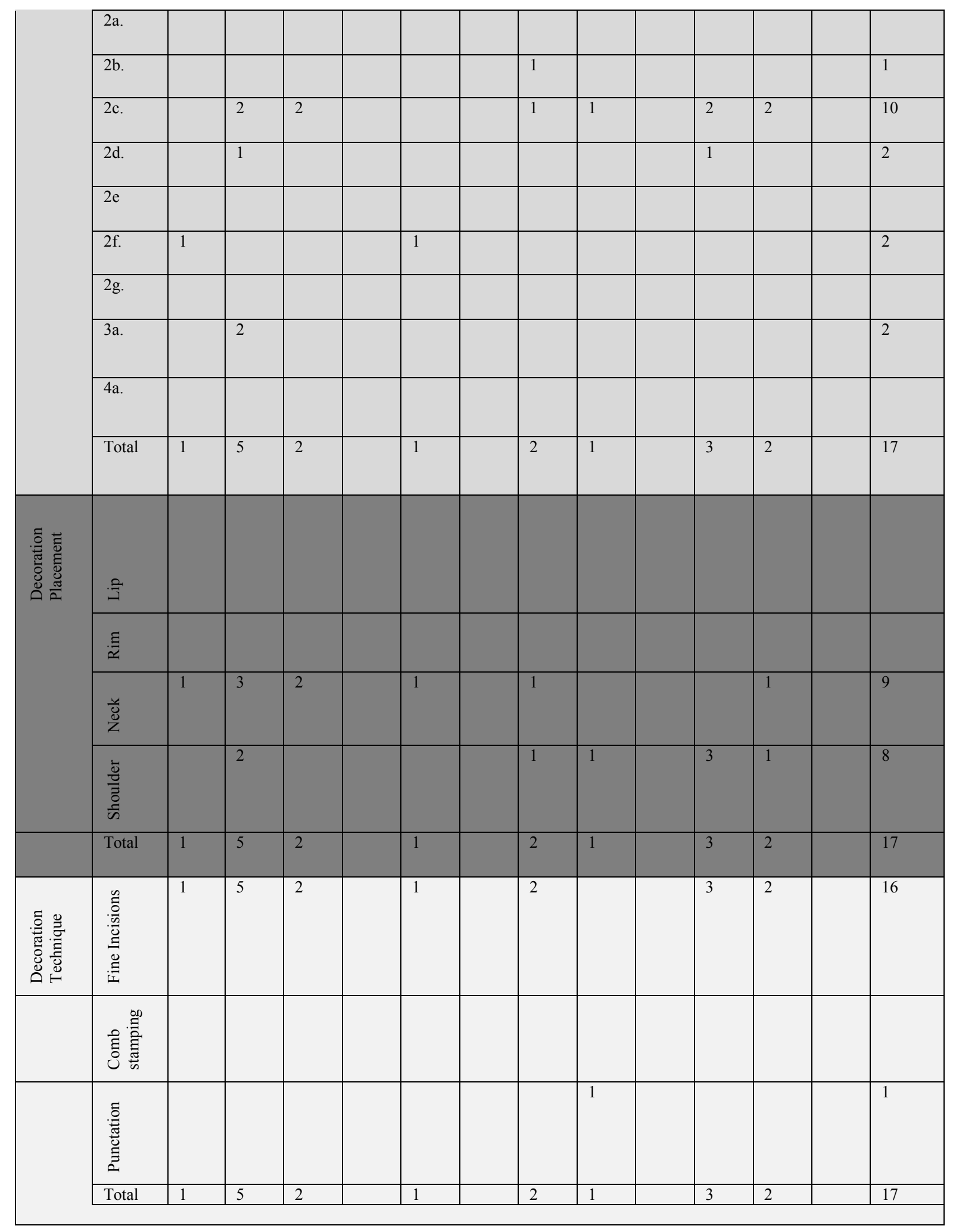




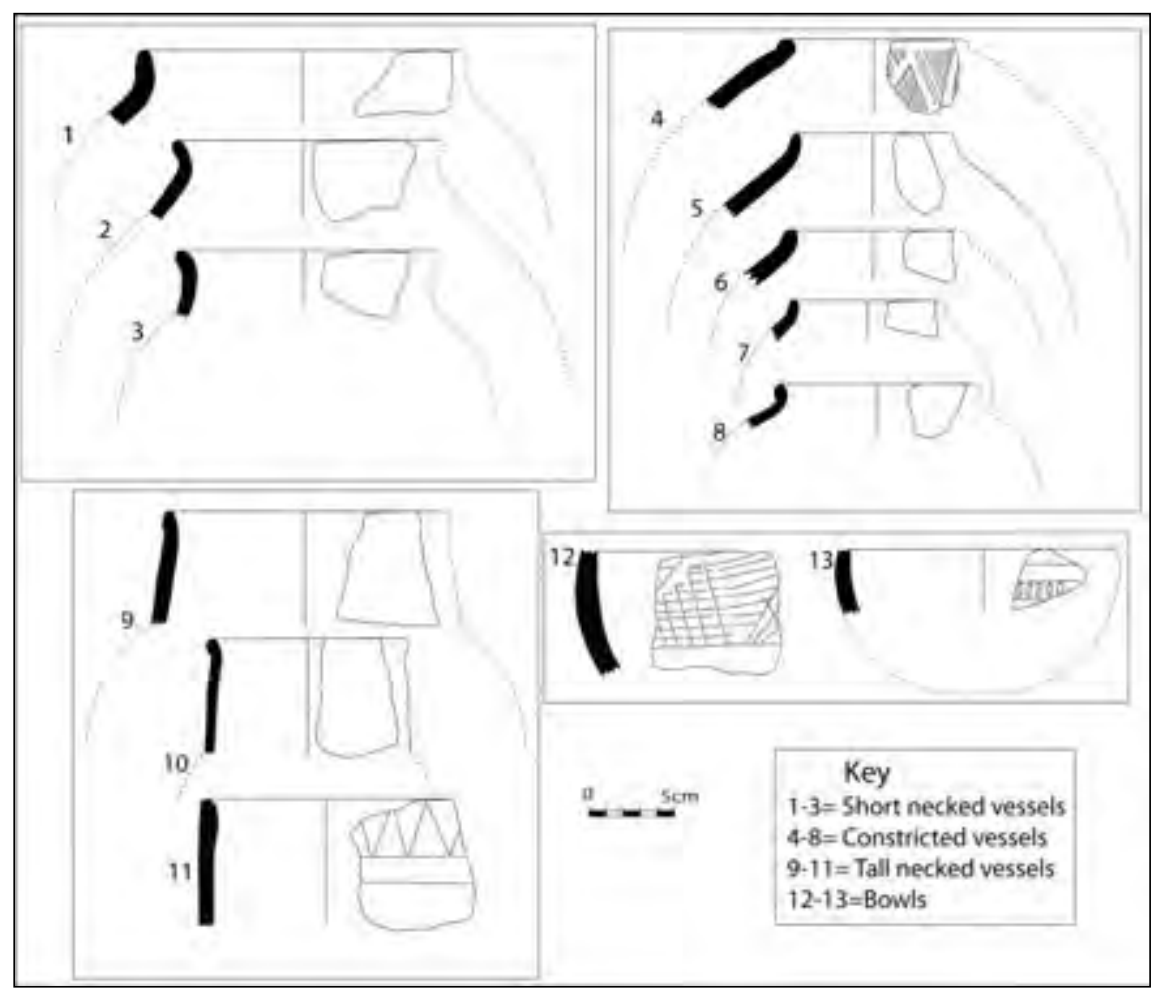

Figure 5.3: Vessel types from Trench 1, Midden 1.

\subsubsection{MIDDEN 2}

\section{TRENCH 1}

A total of 42 diagnostic sherds were recovered from Trench 1, Midden 2 (Table 5.3). Tallnecked vessels were the most popular, although they tend to be more in the upper levels. Most of these are painted with red ochre and are decorated with fine lines of incisions. Tallnecked vessels appear to be the highest number in terms of decorated vessels on Trench 1 . There is a lack of decorated sherds in the lower levels. 
Table 5.3: Ceramics from Trench 1, Midden 2

\begin{tabular}{|c|c|c|c|c|c|c|c|}
\hline \multicolumn{2}{|l|}{ Attribute } & Level 1 & Level 2 & Level 3 & Level 4 & Level 5 & Total \\
\hline \multirow[t]{3}{*}{ Provenance } & Diagnostic & 6 & 10 & 8 & 12 & 6 & 42 \\
\hline & Undiagnostic & 0 & 60 & 58 & 46 & & 164 \\
\hline & Total & 6 & 70 & 66 & 58 & 6 & 206 \\
\hline \multirow[t]{5}{*}{ Vessel Shape } & Short necked & 3 & & 2 & 2 & 3 & 10 \\
\hline & Tall necked & 3 & 8 & 3 & 4 & 1 & 19 \\
\hline & Constricted & & 2 & 3 & 6 & 2 & 13 \\
\hline & Bowl & & & & & & \\
\hline & Total & 6 & 10 & 8 & 12 & 6 & 42 \\
\hline \multirow[t]{4}{*}{$\begin{array}{l}\text { Surface } \\
\text { Treatment }\end{array}$} & $\begin{array}{l}\text { Graphite } \\
\text { burnished }\end{array}$ & 1 & 1 & & 8 & 5 & 15 \\
\hline & Polished & & & 1 & 3 & 3 & 7 \\
\hline & $\mathrm{GB} / \mathrm{RO}$ & 5 & 9 & 7 & 2 & 1 & 24 \\
\hline & Total & 6 & 10 & 8 & 13 & 9 & 46 \\
\hline \multirow{13}{*}{$\begin{array}{l}\text { Decoration } \\
\text { Motif }\end{array}$} & Ia. & & & & & & \\
\hline & Ib. & & & & & & \\
\hline & Ic. & & & & & & \\
\hline & $2 a$. & 1 & & & 2 & & 3 \\
\hline & $2 b$. & & 3 & 3 & & & 6 \\
\hline & $2 c$. & 1 & 4 & & & & 5 \\
\hline & $2 \mathrm{~d}$. & & 1 & 1 & & & 2 \\
\hline & $2 e$ & & & & & & \\
\hline & $2 f$. & 2 & & & & 1 & 3 \\
\hline & $2 \mathrm{~g}$. & & & & & & \\
\hline & $3 a$. & 1 & 2 & 3 & & & 6 \\
\hline & $4 a$. & & & & & & \\
\hline & Total & 5 & 10 & 7 & 2 & 1 & 25 \\
\hline \multirow{5}{*}{\begin{tabular}{|l} 
Decoration \\
Placement
\end{tabular}} & Neck & 5 & 8 & 4 & & & 17 \\
\hline & Shoulder & & 2 & 3 & 2 & & 7 \\
\hline & Neck/Shoulder & & & 1 & & & 1 \\
\hline & Body & 1 & & & & & 1 \\
\hline & Total & 6 & 10 & 8 & 2 & & 26 \\
\hline \multirow{5}{*}{$\begin{array}{l}\text { Decoration } \\
\text { Technique } \\
\end{array}$} & Fine Incisions & 1 & 6 & 5 & 2 & & 14 \\
\hline & Broad Incisions & 5 & 3 & 1 & 1 & & 10 \\
\hline & FLI/PUNC & & & 2 & & & 2 \\
\hline & BLI/FLI & & 1 & & & & 1 \\
\hline & Total & 6 & 10 & 8 & 3 & & 27 \\
\hline
\end{tabular}




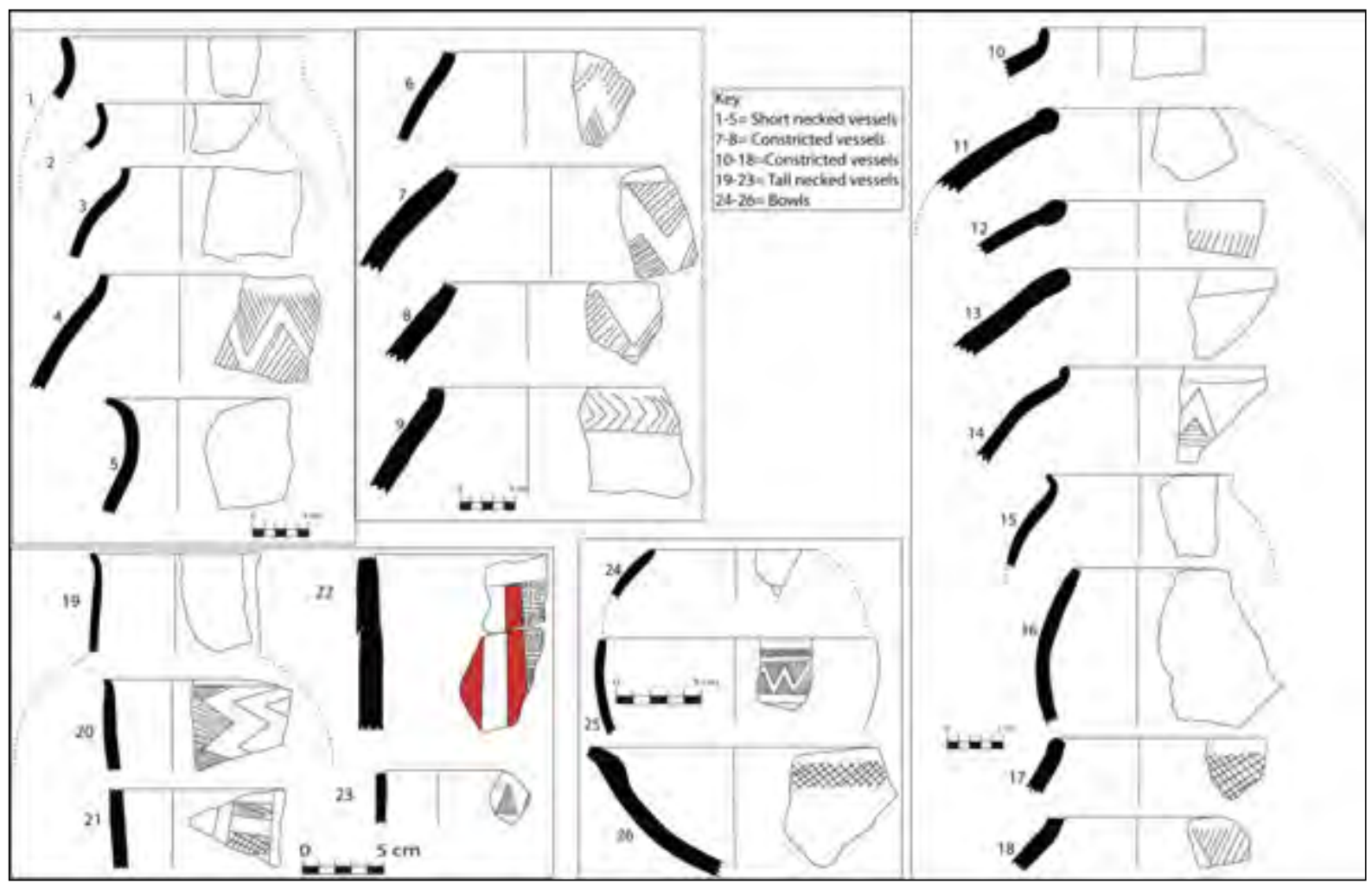

Figure 5.4: Vessel types from Midden 2.

\section{TRENCH 2}

A total of one hundred and eighty three sherds were recovered from Trench 2, Midden 2 (Table 5.4, Figure 5.4). Of these, forty-five were diagnostic. Short-necked vessels dominated the assemblage, occuring throughout the stratigraphy. An important element of the assemblage was the high number of vessels that were painted with red ochre, constituting $58 \%$ of the total assemblage. In terms of motifs, this assembalage had triangles as the dominant motif. Other motifs include complex, cross hatching and horizontal bands formed by incisions. Decorations were mostly placed on the neck and shoulder or a combination of the two. They were mostly executed through fine lines of incision, broad lines of incision or a combination of the two. 
Table 5.4: Ceramic attributes for sherds from Trench 2, Midden 2.

\begin{tabular}{|c|c|c|c|c|c|c|c|c|c|c|c|c|c|c|c|}
\hline \multicolumn{2}{|l|}{ Attribute } & L3 & L4 & L5 & L6 & L7 & L8 & L9 & L10 & L11 & L12 & L13 & L14 & L15 & Tot \\
\hline \multirow[t]{3}{*}{ Provenance } & Diagnostic & 4 & 8 & & & 1 & 8 & 3 & 4 & 8 & 1 & 3 & 2 & 3 & 45 \\
\hline & Undiagnostic & 9 & 20 & 11 & 6 & 9 & 17 & 7 & 13 & 21 & 8 & 5 & 7 & 5 & 138 \\
\hline & Total & 13 & 28 & 11 & 6 & 10 & 25 & 10 & 17 & 29 & 9 & 8 & 9 & 8 & 183 \\
\hline \multirow[t]{5}{*}{ Vessel Shape } & Short necked & 2 & 4 & & & & 6 & 2 & 1 & 2 & 1 & 1 & 1 & & 20 \\
\hline & Tall necked & 1 & 3 & & & & 2 & & 2 & 1 & & 1 & & 1 & 11 \\
\hline & Constricted & 1 & 1 & & & 1 & & 1 & 1 & 5 & & 1 & 1 & 2 & 15 \\
\hline & Bowl & & & & & & & & & & & & & & \\
\hline & Total & 4 & 8 & & & 1 & 8 & 3 & 4 & 8 & 1 & 3 & 2 & 3 & 46 \\
\hline \multirow[t]{4}{*}{$\begin{array}{l}\text { Surface } \\
\text { Treatment }\end{array}$} & $\begin{array}{l}\text { Graphite } \\
\text { burnished }\end{array}$ & & 4 & & & & 3 & 2 & 2 & 3 & & & & & 14 \\
\hline & Polished & & 1 & & & & 1 & & & & & & & & 2 \\
\hline & $\mathrm{GB} / \mathrm{RO}$ & 4 & 3 & & & 3 & 3 & 1 & 2 & 5 & 1 & 1 & 1 & 2 & 26 \\
\hline & Total & 4 & 8 & & & 4 & 7 & 3 & 4 & 8 & 1 & 3 & 1 & 2 & 46 \\
\hline \multirow{13}{*}{$\begin{array}{l}\text { Decoration } \\
\text { Motif }\end{array}$} & Ia. & & & & & & & & & & & & & & \\
\hline & $\mathrm{Ib}$. & & & & & & & & & & & & & & \\
\hline & Ic. & & & & & & & & & & & & & & \\
\hline & $2 \mathrm{a}$. & & & & & & & & & & & 1 & & & 1 \\
\hline & $2 \mathrm{~b}$. & & & & & 1 & & & & & & & 1 & & 2 \\
\hline & $2 c$. & 1 & & & & 1 & 1 & 1 & 3 & 5 & & & & & 12 \\
\hline & $2 \mathrm{~d}$. & 1 & 2 & & & & & & & & & 1 & & & 4 \\
\hline & $2 \mathrm{e}$ & & & & & & & & & & & & & & \\
\hline & $2 \mathrm{f}$. & & & & & & & & & & & & & & \\
\hline & $2 \mathrm{~g}$. & & & & & & & & & & & & & & \\
\hline & $3 a$. & & 1 & & & 1 & 2 & & & & 1 & & & 1 & 6 \\
\hline & $4 a$. & & & & & & & & & & & & & & \\
\hline & Total & 2 & 3 & & & 3 & 3 & 1 & 3 & 5 & 1 & 2 & 1 & 1 & 25 \\
\hline \multirow{5}{*}{$\begin{array}{l}\text { Decoration } \\
\text { Placement }\end{array}$} & Neck & 1 & 2 & & & & & & 2 & 3 & & 1 & 1 & 1 & 11 \\
\hline & Shoulder & 1 & 2 & & & 1 & & 1 & 1 & 3 & & 1 & & & 10 \\
\hline & Neck/Shoulder & & & & & 2 & 2 & & & & 1 & & & & 5 \\
\hline & Shoulder/Body & & & & & & 1 & & & 1 & & & & & 2 \\
\hline & Total & 2 & 4 & & & 3 & 3 & 1 & 3 & 7 & 1 & 2 & 1 & 1 & 28 \\
\hline \multirow{4}{*}{$\begin{array}{l}\text { Decoration } \\
\text { Technique }\end{array}$} & Fine Incisions & 1 & 2 & & & 1 & & & & 3 & 1 & 2 & 1 & 1 & 12 \\
\hline & Broad Incision & & 1 & & & 1 & 2 & 1 & 2 & 1 & & & & & 8 \\
\hline & BLI/FLI & 1 & 1 & & & 1 & 1 & & 1 & 3 & & & & & 8 \\
\hline & Total & 2 & 4 & & & 3 & 3 & 1 & 3 & 7 & 1 & 2 & 1 & 1 & 28 \\
\hline
\end{tabular}

\subsubsection{MUSEUM MIDDEN 1}

\section{TRENCH 1}

A total of forty-seven ceramic sherds were recovered in Trench 1of which thirteen had diagnostic features. Eleven of these were graphite burnished and two were polished. Fine lines of incisions were used to decorate the ceramics. These incisions were executed to form upward facing triangles. Another decoration noted was a sherd with triangles filled with crosshatching. 
Table 5.5: Ceramic attributes for sherds from Trench 1, Museum Midden 1

\begin{tabular}{|c|c|c|c|c|c|c|}
\hline \multicolumn{2}{|l|}{ Attribute } & L3 & L4 & L5 & L6 & Total \\
\hline \multirow[t]{3}{*}{ Provenance } & Diagnostic & 3 & 5 & 5 & & 13 \\
\hline & Undiagnostic & 7 & 15 & 9 & 3 & 34 \\
\hline & Total & 10 & 20 & 14 & 3 & 47 \\
\hline \multirow[t]{5}{*}{ Vessel Shape } & Short necked & & 2 & 2 & & 4 \\
\hline & Tall necked & 2 & 1 & & & 3 \\
\hline & Constricted & 1 & 3 & 2 & & 6 \\
\hline & Bowl & & & & & \\
\hline & Total & 3 & 6 & 4 & & 13 \\
\hline \multirow[t]{4}{*}{$\begin{array}{l}\text { Surface } \\
\text { Treatment }\end{array}$} & $\begin{array}{l}\text { Graphite } \\
\text { burnished }\end{array}$ & 3 & 3 & 5 & & 11 \\
\hline & Polished & & 2 & & & 2 \\
\hline & $\mathrm{GB} / \mathrm{RO}$ & & & & & \\
\hline & Total & 3 & 5 & 5 & & 13 \\
\hline \multirow{13}{*}{$\begin{array}{l}\text { Decoration } \\
\text { Motif }\end{array}$} & Ia. & & & & & \\
\hline & Ib. & & & & & \\
\hline & Ic. & & & & & \\
\hline & $2 \mathrm{a}$. & & & & & \\
\hline & $2 b$. & 1 & & & & \\
\hline & $2 c$. & & 4 & 1 & & \\
\hline & $2 \mathrm{~d}$. & & & & & \\
\hline & $2 \mathrm{e}$ & & & & & \\
\hline & $2 f$. & & & & & \\
\hline & $2 \mathrm{~g}$. & & & & & \\
\hline & $3 a$. & & & & & \\
\hline & $4 a$. & & & & & \\
\hline & Total & 1 & 4 & 1 & & 6 \\
\hline \multirow{4}{*}{$\begin{array}{l}\text { Decoration } \\
\text { Placement }\end{array}$} & Neck & 1 & & & & 1 \\
\hline & Shoulder & & 3 & 2 & & 5 \\
\hline & Body & & & & & \\
\hline & Total & 1 & 3 & 2 & & 6 \\
\hline \multirow{3}{*}{$\begin{array}{l}\text { Decoration } \\
\text { Technique }\end{array}$} & Fine Incisions & 1 & 3 & 2 & & 6 \\
\hline & Comb stamping & & & & & \\
\hline & Total & 1 & 3 & 2 & & 6 \\
\hline
\end{tabular}




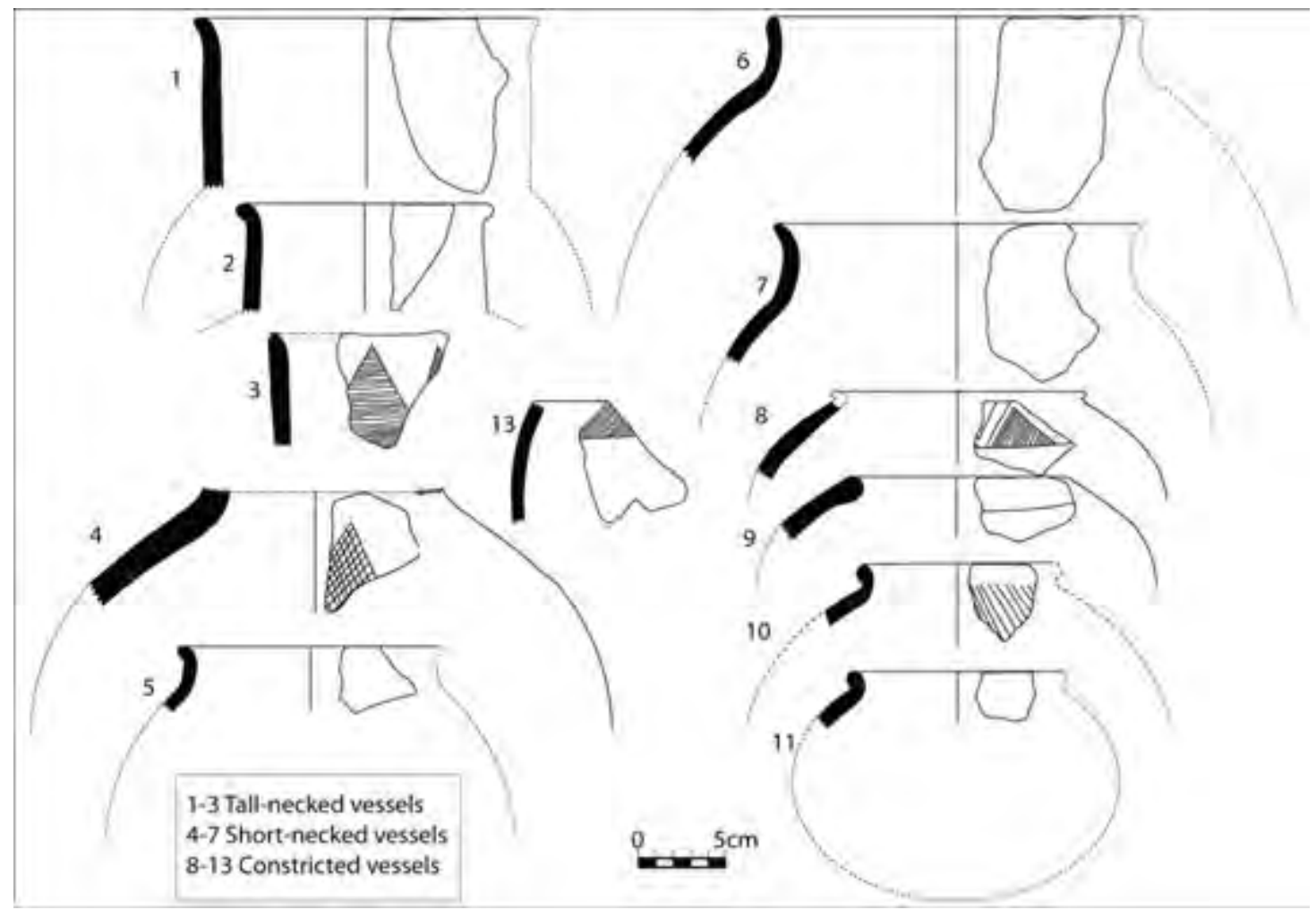

Figure 5.5: Vessel types from Museum Midden 1, Trench 1

\subsubsection{MUSEUM MIDDEN 2}

\section{TRENCH 1}

Sixty-seven diagnostic sherds were identified from the excavation of Trench 1 on Museum Midden 2 (Table 5.6; Figure 5.6). Tall-necked vessels dominated the assemblage at $43.75 \%$, and constricted vessels at $28.13 \%$. Seven bowls were also recorded. While tall-necked vessles were found throughout the stratigraphy, short-necked vessels were recovered mainly in the middle layers. Of the decoration techniques, fine lines of incision were dominant. In fact, most of the sherds analysed were decorated by fine lines of incision except two, one of which had comb-stamping and the other punctates. Most of the decoration was on the neck. A variety of motifs characterised the assemblage from Museum Midden 2 Trench 1, including bands of alternating red and black horizontal lines, interlocking triangles, herringbone patterning, cross hatching. 
Table 5.6: Ceramic attributes for sherds from Trench 1, Midden 2.

\begin{tabular}{|c|c|c|c|c|c|c|c|c|c|c|c|}
\hline \multicolumn{2}{|l|}{ Attribute } & L2 & L3 & L4 & L5 & L6 & L7 & L8 & L9 & L13 & Total \\
\hline \multirow[t]{3}{*}{ Provenance } & Diagnostic & & 9 & 20 & & 12 & 8 & 6 & 10 & 2 & 67 \\
\hline & Undiagnostic & 13 & 26 & 33 & 9 & 27 & 35 & 17 & 9 & 16 & 185 \\
\hline & Total & 13 & 35 & 53 & 9 & 39 & 43 & 23 & 19 & 18 & 252 \\
\hline \multirow[t]{5}{*}{ Vessel Shape } & Short necked & & & 2 & & 4 & 3 & 2 & 3 & & 14 \\
\hline & Tall necked & & 3 & 10 & & 4 & 2 & 2 & 5 & 2 & 28 \\
\hline & Constricted & & & 7 & & 4 & 2 & 2 & 3 & 3 & 21 \\
\hline & Bowl & & 1 & 1 & & & 1 & & & & 3 \\
\hline & Total & & 4 & 20 & & 12 & 8 & 6 & 11 & 5 & 66 \\
\hline \multirow[t]{4}{*}{$\begin{array}{l}\text { Surface } \\
\text { Treatment }\end{array}$} & $\begin{array}{l}\text { Graphite } \\
\text { burnished }\end{array}$ & & 4 & 4 & & 9 & 4 & 3 & 5 & 2 & 31 \\
\hline & Polished & & 1 & 7 & & 1 & & & & & 9 \\
\hline & $\mathrm{GB} / \mathrm{RO}$ & & & 9 & & 2 & 4 & 2 & 6 & & 23 \\
\hline & Total & & 5 & 20 & & 12 & 8 & 8 & 11 & & 63 \\
\hline \multirow{13}{*}{\begin{tabular}{|l|} 
Decoration \\
Motif
\end{tabular}} & Ia. & & & & & & & & & & \\
\hline & Ib. & & & 1 & & & & & & & 1 \\
\hline & Ic. & & & & & & & & & & \\
\hline & $2 \mathrm{a}$. & & & & & 1 & & 1 & 1 & & 3 \\
\hline & $2 \mathrm{~b}$. & & & 4 & & & & & & & 4 \\
\hline & $2 c$. & & & 2 & & & 1 & 2 & 3 & & 8 \\
\hline & $2 \mathrm{~d}$. & & & 2 & & & 1 & & 1 & & 4 \\
\hline & $2 \mathrm{e}$ & & & & & & & & & & \\
\hline & $2 \mathrm{f}$. & & & & & & & & & & \\
\hline & $2 \mathrm{~g}$. & & & & & & & & & & \\
\hline & $3 a$. & & & 2 & & 1 & & & & & 3 \\
\hline & $4 \mathrm{a}$. & & & & & & & & & & \\
\hline & Total & & & 11 & & 2 & 2 & 3 & 5 & & 23 \\
\hline \multirow{4}{*}{$\begin{array}{l}\text { Decoration } \\
\text { Placement }\end{array}$} & Neck & & 1 & 7 & & 1 & & 1 & 4 & & 14 \\
\hline & Shoulder & & & 5 & & 2 & 2 & 2 & 2 & & 13 \\
\hline & Body & & & 1 & & & & & & & 1 \\
\hline & Total & & 1 & 13 & & 3 & & 3 & 6 & & 28 \\
\hline \multirow{3}{*}{$\begin{array}{l}\text { Decoration } \\
\text { Technique }\end{array}$} & Fine Incisions & & 2 & 12 & & 3 & 2 & 3 & 4 & & 26 \\
\hline & Comb stamping & & & 1 & & & & & & & 1 \\
\hline & Total & & 2 & 13 & & 3 & 2 & 3 & 4 & & 27 \\
\hline
\end{tabular}




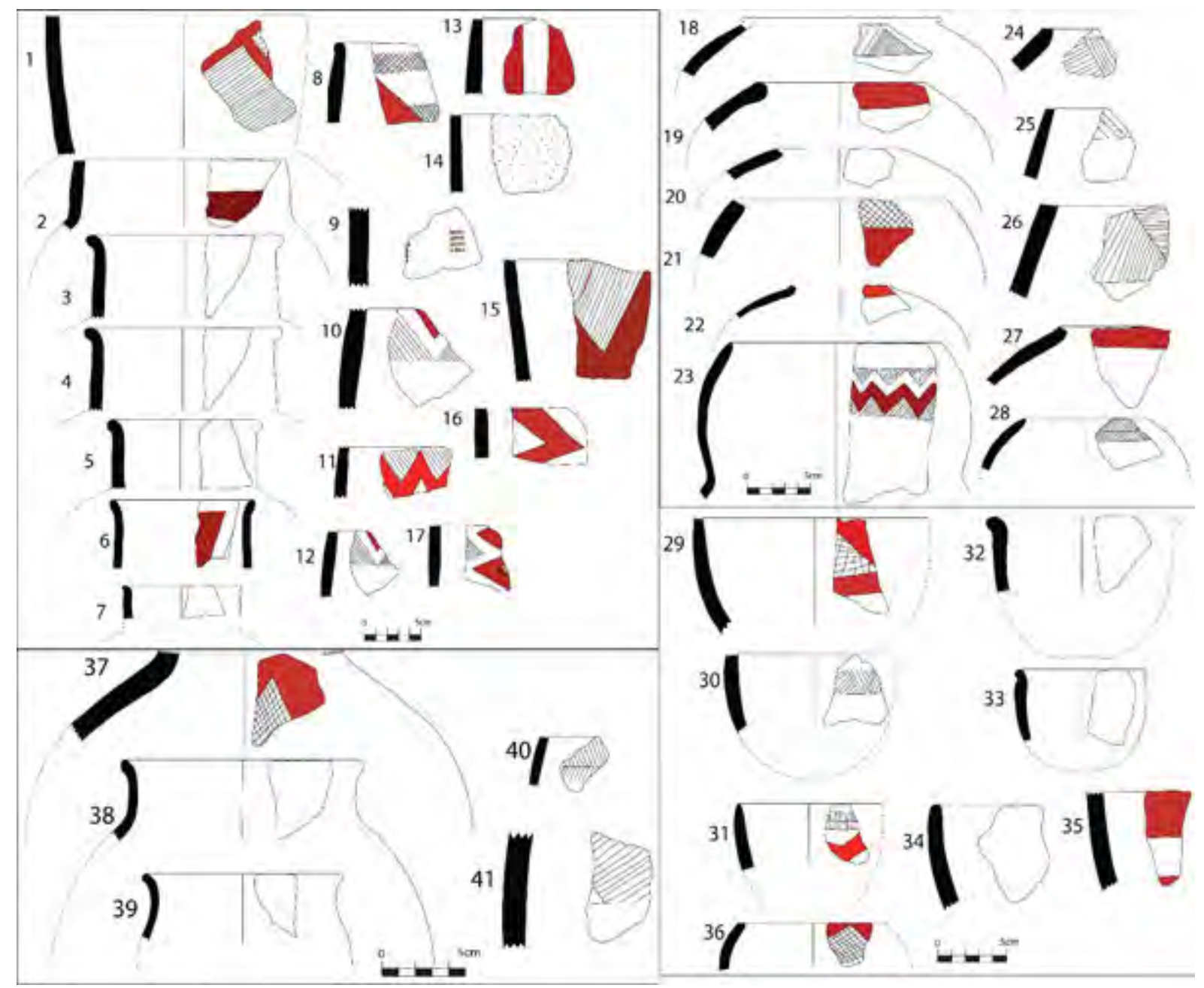

Figure 5.6 Vessel types from Trench 1, Museum Midden 2.

\subsubsection{NORTH PLATFORM MIDDEN}

\section{TRENCH 1}

Of the sixty-three diagnostic sherds recovered from the North Platform Midden excavation, $32 \%$ were short necked vessels while constricted vessels made up $24 \%$ of the assmeblage (Table 5.5; Figure 5.7). Tall-necked vessels accounted for $18.67 \%$ and four bowls were also recorded. As with most other excavated units, fine lines of incision were the dominant decoration technique, accounting for $58.82 \%$ of the assemblage. Broad lines of incision also accounted for $14.72 \%$. Other decoration techniques include combstamping (2.94\%), fluting $(5.88 \%)$, and punctates $(2.94 \%)$. It is also important to note that there were instances where decorations were combined together on an individual pot. For instance, fine lines of incision were combined with punctates $(2.94 \%)$ and also with combstamping (2.94\%). The high 
frequency of shouldered vessels also resulted in a higher frequency of vessels decorated on the neck. Some sherds that were identified as belonging to the Leopard's Kopje phase were also recovered (Figure 5.4). These were found in the lower levels Trench 1 Level 11. It was a constricted pot decorated on the shoulder with wavy lines. The sherd has affinities with material from the Woolandale phase of the Leopard's Kopje (Robinson 1966, 1985; Huffman 1974; van Waarden 1998). The profiles are similar to those identified on the Hill Complex by Robinson (1959) and Thorp (1995) and on the Northwest Ridge (Hughes (1997).

Table 5.7: Ceramic attributes from Trench 1, North Platform Midden.

\begin{tabular}{|c|c|c|c|c|c|c|c|c|c|c|c|}
\hline \multicolumn{2}{|l|}{ Attribute } & $\mathrm{L} 1$ & L2 & $\mathrm{L} 3$ & L4 & L5 & L6 & L8 & L9 & L10 & Tot \\
\hline \multirow[t]{3}{*}{ Provenance } & Diagnostic & 16 & 3 & 2 & 4 & 6 & 9 & 8 & 4 & 11 & 63 \\
\hline & Undiagnostic & 47 & 10 & 6 & 2 & 27 & 23 & 5 & 9 & 19 & 148 \\
\hline & Total & 63 & 13 & 8 & 6 & 33 & 32 & 13 & 13 & 30 & 211 \\
\hline \multirow[t]{5}{*}{ Vessel Shape } & Short necked & 5 & 1 & 2 & 1 & 2 & 4 & 2 & & 7 & 24 \\
\hline & Tall necked & 4 & 1 & & 1 & 2 & 4 & 3 & 2 & 1 & 18 \\
\hline & Constricted & 6 & 1 & & 2 & 1 & 1 & 2 & 2 & 3 & 18 \\
\hline & Bowl & 1 & & & & 1 & & 1 & & & 3 \\
\hline & Total & 16 & 3 & 2 & 4 & 6 & 9 & 8 & 4 & 11 & 63 \\
\hline \multirow[t]{4}{*}{$\begin{array}{l}\text { Surface } \\
\text { Treatment }\end{array}$} & $\begin{array}{l}\text { Graphite } \\
\text { burnished }\end{array}$ & 13 & 1 & 1 & 2 & 4 & 9 & 5 & 2 & 10 & 47 \\
\hline & Polished & & & & & & & 3 & 2 & & 5 \\
\hline & $\mathrm{GB} / \mathrm{RO}$ & 3 & 2 & 1 & 2 & 2 & & & & 1 & 11 \\
\hline & Total & 16 & 3 & 2 & 4 & 6 & 9 & 8 & 4 & 11 & 63 \\
\hline \multirow{11}{*}{$\begin{array}{l}\text { Decoration } \\
\text { Motif }\end{array}$} & Ia. & & & & & & & & & & \\
\hline & Ib. & & & & & & & & & & \\
\hline & Ic. & & & & & & & & & & \\
\hline & $2 \mathrm{a}$. & & & & & & & 1 & & 2 & 3 \\
\hline & $2 b$. & & 1 & & & & & & & 1 & 2 \\
\hline & $2 c$. & & & 2 & 1 & 2 & 2 & 1 & 1 & 2 & 11 \\
\hline & $2 \mathrm{~d}$. & 1 & & 1 & 1 & 1 & & & & & 4 \\
\hline & $2 \mathrm{e}$ & & & & & & & & & & \\
\hline & $3 a$. & 4 & & & & & & 1 & 2 & & 7 \\
\hline & $4 a$. & & & & & & & & & & \\
\hline & Total & 5 & 1 & 3 & 2 & 3 & 2 & 3 & 3 & 5 & 26 \\
\hline \multirow{4}{*}{$\begin{array}{l}\text { Decoration } \\
\text { Placement }\end{array}$} & Neck & 5 & & & 1 & 1 & 1 & 2 & 1 & & 11 \\
\hline & Shoulder & 2 & 1 & 2 & 1 & 2 & 3 & 1 & 2 & 7 & 21 \\
\hline & Body & 1 & & & & & & & & & 1 \\
\hline & Total & 8 & 1 & 2 & 2 & 3 & 4 & 3 & 3 & 7 & 33 \\
\hline \multirow{8}{*}{$\begin{array}{l}\text { Decoration } \\
\text { Technique }\end{array}$} & Fine Incisions & 3 & 1 & & 1 & 3 & 3 & 2 & 2 & 4 & 19 \\
\hline & Broad Incisions & 1 & & & 1 & & & 1 & & 1 & 4 \\
\hline & Comb stamping & 1 & & & & & & & & & 1 \\
\hline & Punctation & 1 & & & & & & & 1 & & 2 \\
\hline & BLI/FLI & 1 & & & & & & & & 2 & 3 \\
\hline & FLU & 1 & & & & & 1 & & & & 2 \\
\hline & FLI/CS & & & 3 & & & & & & & 3 \\
\hline & Total & 8 & 1 & 3 & 2 & 3 & 4 & 3 & 3 & 7 & 34 \\
\hline
\end{tabular}




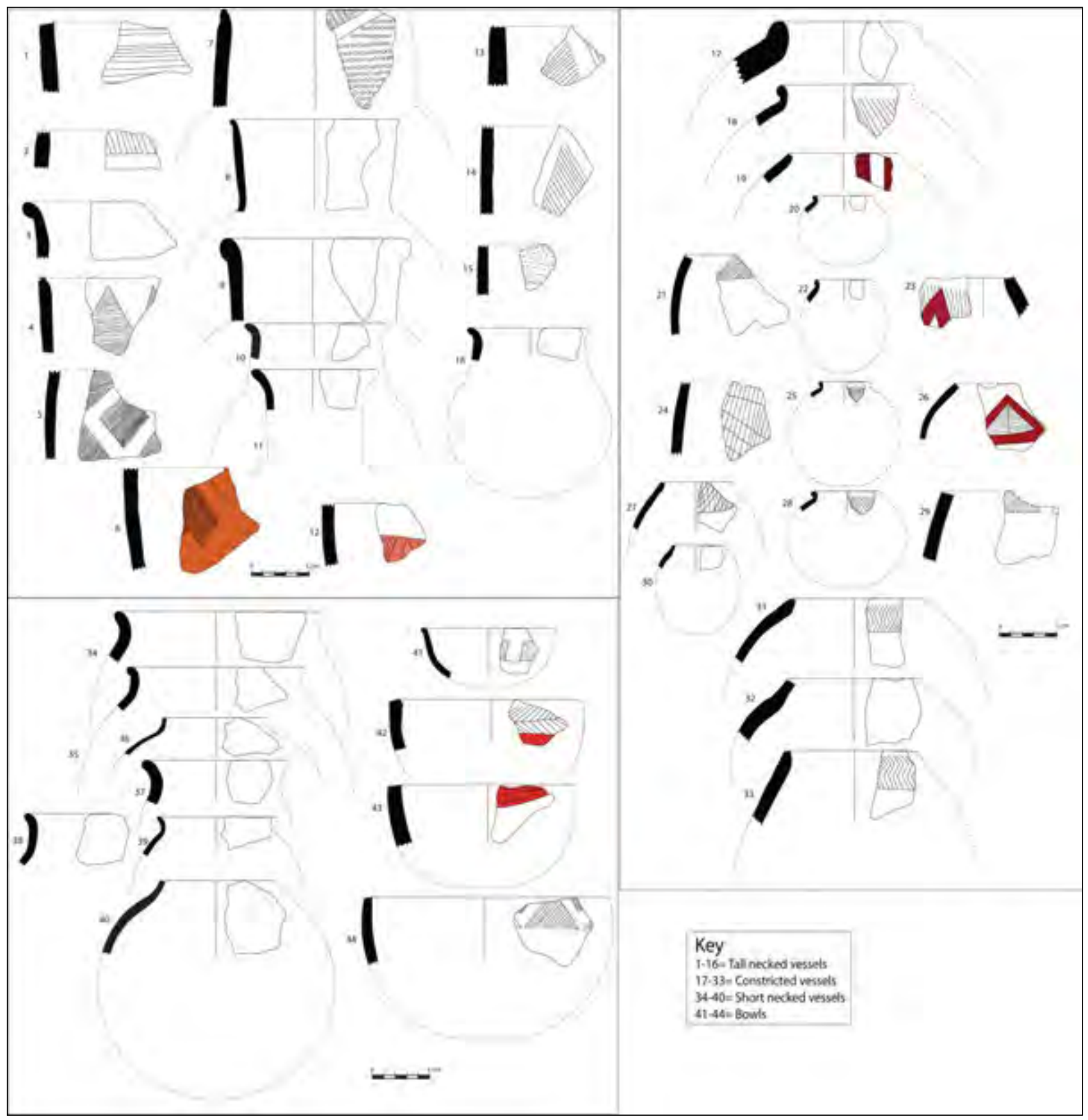

Figure 5.7: Vessel types from Trench 1, North Platform Midden.

\subsubsection{MACIVER'S HILL COMPLEX MIDDEN EXCAVATION}

One of the major challenges faced when reanalysing MacIver's collection was a lack of stratigraphic information related to the collection (Table 5.8; Figure 5.8). The collection was made up of diagnostic sherds only, but there was no information related to context. As a result, it was analysed with the idea to understand the motifs from the Hill Complex with a view to compare those motifs with the ceramics from other areas of the site. Constricted 
vessels dominate and, consequently, most vessels are decorated on the shoulder with red ochre and complex motifs. While incisions dominated, they were also applied together with punctation. Fine lines of incisions forming triangles dominated the motifs on this collection. Others include cross hatching, broad lines forming herringbone, complex motifs and horizontal bands of punctates. Decoration was mostly executed on the shoulder, which could be explained by the fact that there were more (64\%) constricted/neckless vessels in the collection.

Table 5.8: Ceramic attributes from a reanalysed Hill Complex midden excavated by MacIver (1906).

\begin{tabular}{|c|c|c|c|c|}
\hline \multicolumn{2}{|l|}{ Attribute } & \multirow{2}{*}{$\begin{array}{l}\text { Hill Complex } \\
\text { Midden } \\
88\end{array}$} & \multirow[t]{2}{*}{$\%$ frequency } & \multirow[t]{2}{*}{ Tota } \\
\hline Provenance & Diagnostic & & & \\
\hline \multirow[t]{4}{*}{ Vessel Shape } & Short necked & 17 & 19 & \\
\hline & Tall necked & 15 & 17 & \\
\hline & Constricted & 56 & 64 & \\
\hline & Total & 88 & 100 & \\
\hline \multirow[t]{4}{*}{ Surface Treatment } & Graphite burnished & 24 & 28 & \\
\hline & Polished & 12 & 14 & \\
\hline & $\mathrm{GB} / \mathrm{RO}$ & 51 & 58 & \\
\hline & Total & 87 & 100 & \\
\hline \multirow[t]{13}{*}{ Decoration Motif } & Ia. & & & \\
\hline & Ib. & & & \\
\hline & Ic. & & & \\
\hline & $2 a$. & & & \\
\hline & $2 \mathrm{~b}$. & & & \\
\hline & $2 c$. & 14 & 20 & \\
\hline & $2 \mathrm{~d}$. & 11 & 16 & \\
\hline & $2 \mathrm{e}$ & 14 & 20 & \\
\hline & $2 \mathrm{f}$. & 2 & 3 & \\
\hline & $2 \mathrm{~g}$. & & & \\
\hline & $3 a$. & 23 & 34 & \\
\hline & $4 a$. & 5 & 7 & \\
\hline & Total & 69 & 100 & \\
\hline \multirow[t]{6}{*}{ Decoration Placement } & Neck & 4 & 5 & \\
\hline & Shoulder & 55 & 70 & \\
\hline & Neck/Shoulder & 2 & 3 & \\
\hline & Shoulder/Body & 17 & 21 & \\
\hline & Body & 1 & 1 & \\
\hline & Total & 79 & 100 & \\
\hline \multirow[t]{7}{*}{ Decoration Technique } & Fine Incisions & 27 & 33 & \\
\hline & Broad Incisions & 30 & 36 & \\
\hline & BLI/FLI & 7 & 8 & \\
\hline & PUNC & 2 & 2 & \\
\hline & PUNC/BLI & 9 & 11 & \\
\hline & PUNC/FLI & 8 & 10 & \\
\hline & Total & 83 & 100 & \\
\hline
\end{tabular}




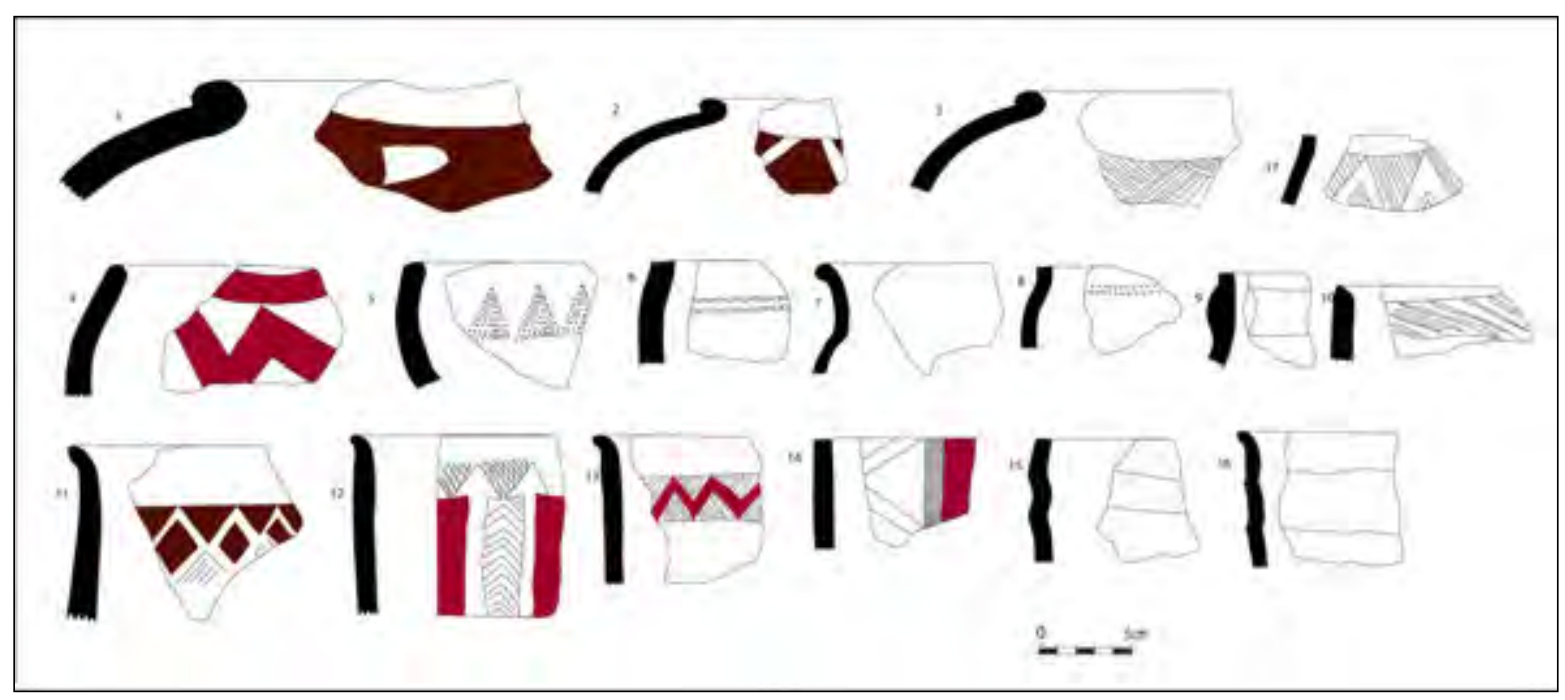

Figure 5.8: Vessel types from MacIver's (1906) excavation on the Hill Complex.

\subsubsection{ROBINSON CERAMICS FROM EXCAVATION 19, EAST OF CROSS RUIN}

Robinson recovered ceramics that he attributed to Leopard's Kopje in his excavation 19, East of the Cross Ruin (Table 5.9; Figure 5.9). My objective in analysing the same material was to enable comparison with other material from Leopard's Kopje so as to make a tentative assignment to either the Mambo or Woolandale phase of the Leopard's Kopje. Comparisons with Woolandale ceramics (Robinson 1985; Huffman 2007) showed that some of the sherds recovered from this trench were part of Woolandale ceramics. These include Nos 1, 6, 8 and 13.

Table 5.9: Ceramic attributes for sherds from Excavation 19 by Robinson (1959).

\begin{tabular}{|l|l|l|l|l|}
\hline Attribute & Level 3 & Level 4 & Total \\
\hline Provenance & Diagnostic & 8 & 19 & 27 \\
\hline \multirow{5}{*}{ Vessel Shape } & Short necked & 5 & 10 & 15 \\
\hline & Tall necked & 1 & 3 & 4 \\
\hline & Constricted & & 2 & 2 \\
\hline & Bowl & 2 & 4 & 6 \\
\hline & Total & 8 & 19 & 17 \\
\hline \multirow{5}{*}{ Surface Treatment } & Graphite burnished & 5 & 14 & 19 \\
\cline { 2 - 5 } & Polished & 2 & 2 & 4 \\
\hline & GB/RO & 1 & 3 & 4 \\
\hline \multirow{5}{*}{ Decoration Motif } & Total & 8 & 19 & 27 \\
& Ia. & & & \\
\hline & Ib. & & & \\
\hline & Ic. & & & \\
\hline & 2a. & & & \\
\hline & 2b. & & & \\
\hline & 2c. & & & \\
\cline { 2 - 5 } & & & & \\
\end{tabular}




\begin{tabular}{|c|c|c|c|c|}
\hline & $2 \mathrm{~d}$. & & & \\
\hline & $2 \mathrm{f}$. & 2 & 3 & \\
\hline & $3 \mathrm{a}$. & 1 & & \\
\hline & $4 \mathrm{a}$. & 1 & 4 & \\
\hline & Total & & & \\
\hline \multirow[t]{5}{*}{ Decoration Placement } & Neck & 4 & 7 & 11 \\
\hline & Shoulder & 2 & 3 & 5 \\
\hline & Neck/Shoulder & 1 & & 1 \\
\hline & Body & & 2 & 2 \\
\hline & Total & 7 & 12 & 19 \\
\hline \multirow{4}{*}{ Decoration Technique } & Broad Incisions & 4 & 5 & 9 \\
\hline & Punctation & 2 & 5 & 7 \\
\hline & FLI/PUNC & 1 & 2 & 3 \\
\hline & Total & 7 & 12 & 19 \\
\hline
\end{tabular}

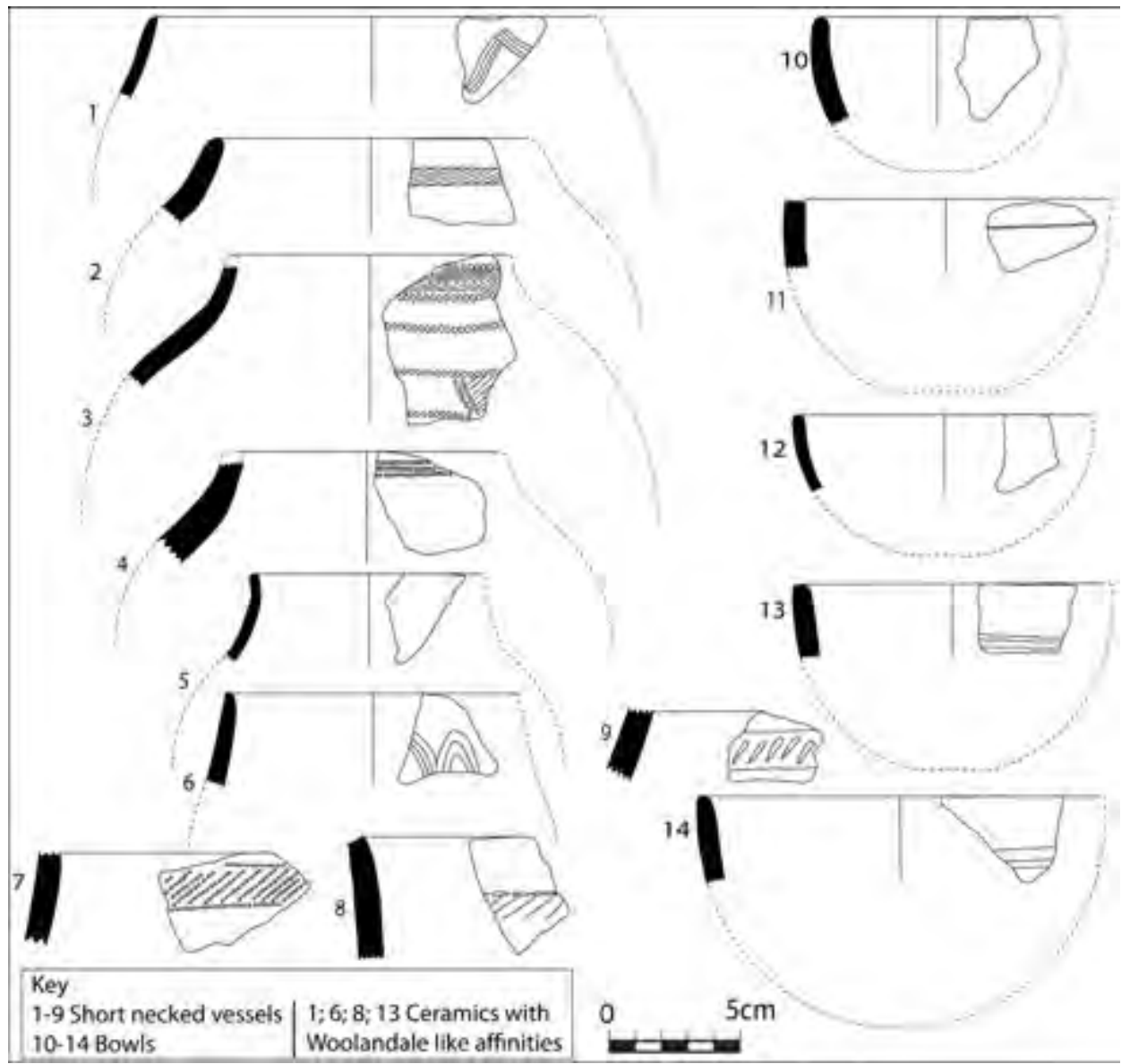

Figure 5.9: Vessel types from Excavation 19 East of the Cross Ruin.

\subsubsection{CERAMICS FROM THE NORTHWEST RIDGE}

The collection from the Northwest Ridge was made up of mainly constricted vessels. The decoration technique employed involved incisions, either fine lines or broad lines. Triangles 
filled with crosshatching dominated in terms of decoration motifs. Decoration was mainly concentrated on the shoulder.

Table 5.10: Ceramic attributes for sherds from the Northwest Ridge.

\begin{tabular}{|c|c|c|c|c|c|}
\hline \multicolumn{2}{|l|}{ Attribute } & Trench 1 & Trench 2 & Trench 3 & Total \\
\hline \multirow[t]{3}{*}{ Provenance } & Diagnostic & 20 & 13 & 17 & 50 \\
\hline & Undiagnostic & 21 & 0 & 0 & 21 \\
\hline & Total & 41 & 13 & 17 & 71 \\
\hline \multirow[t]{5}{*}{ Vessel Shape } & Short necked & 4 & 7 & 12 & 23 \\
\hline & Tall necked & & & 2 & 2 \\
\hline & Constricted & 16 & 6 & 3 & 25 \\
\hline & Bowl & & & & \\
\hline & Total & 20 & 13 & 17 & 50 \\
\hline \multirow[t]{4}{*}{$\begin{array}{l}\text { Surface } \\
\text { Treatment }\end{array}$} & $\begin{array}{l}\text { Graphite } \\
\text { burnished }\end{array}$ & 8 & 7 & 10 & 25 \\
\hline & Polished & 9 & 4 & 5 & 18 \\
\hline & $\mathrm{GB} / \mathrm{RO}$ & 3 & 2 & 2 & 7 \\
\hline & Total & 20 & 13 & 17 & 50 \\
\hline \multirow{13}{*}{$\begin{array}{l}\text { Decoration } \\
\text { Motif }\end{array}$} & Ia. & & & & \\
\hline & Ib. & & & & \\
\hline & Ic. & & & & \\
\hline & $2 a$. & & & & \\
\hline & $2 \mathrm{~b}$. & & & & \\
\hline & $2 c$. & 4 & & & 4 \\
\hline & $2 \mathrm{~d}$. & 1 & & 1 & 2 \\
\hline & $2 \mathrm{e}$ & & & & \\
\hline & $2 \mathrm{f}$. & & & & \\
\hline & $2 \mathrm{~g}$. & & & & \\
\hline & $3 a$. & 2 & & & 2 \\
\hline & $4 a$. & & & & \\
\hline & Total & 7 & & 1 & 8 \\
\hline \multirow{3}{*}{$\begin{array}{l}\text { Decoration } \\
\text { Placement }\end{array}$} & Neck & & & & \\
\hline & Shoulder & 7 & & 1 & \\
\hline & Total & 7 & & 1 & \\
\hline \multirow{4}{*}{$\begin{array}{l}\text { Decoration } \\
\text { Technique }\end{array}$} & Fine Incisions & 5 & & 1 & 6 \\
\hline & Broad incision & 1 & & & 1 \\
\hline & FLI/BLI & 1 & & & 1 \\
\hline & Total & 7 & & 1 & 8 \\
\hline
\end{tabular}




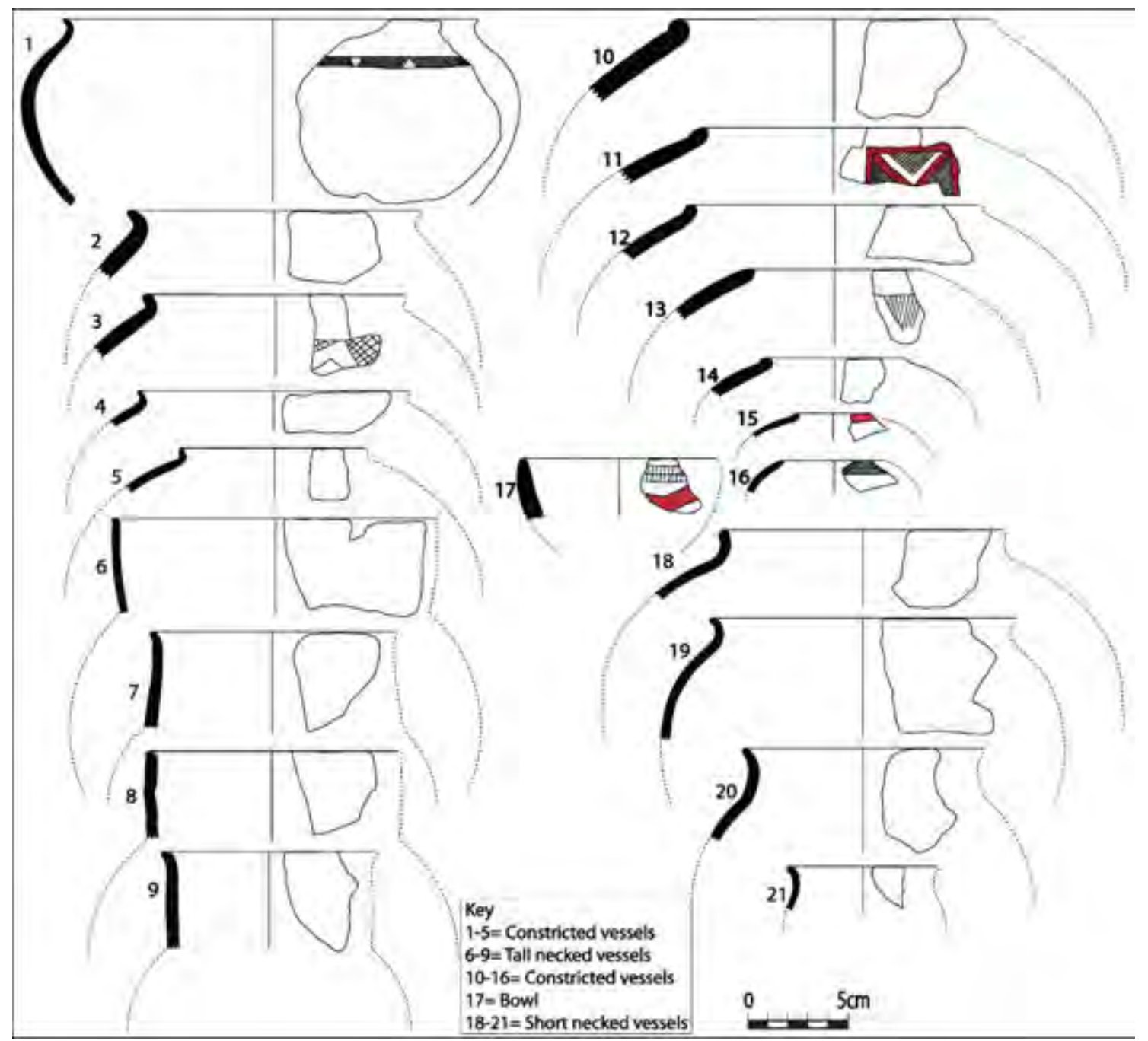

Figure 5.10: Vessel types from the Northwest ridge. Much of the decoration was executed on the shoulders.

\subsection{DISCUSSION}

Tall-necked and constricted vessels dominate the upper levels on Midden 1. There is, however, a consistent distribution of short-necked ceramics across the stratigraphy. Midden 2 Trench 1 also has tall-necked vessels dominating the upper levels and constricted vessels in the lower levels. In Trench 2 of the same midden, short-necked vessels were mostly found in the upper levels and constricted vessels in the lower levels. On Museum Midden 2 Trench 1, there are more tall-necked and constricted vessels in the upper levels. However, on the North Platform Midden all the ceramic shapes are represented and bowls were also noted. MacIver's collection from the Hill Complex midden had a high number of constricted vessels. There is no contextual information for the collection, but the high number of 
constricted vessels might suggest that they dominated across the stratigraphy. A similar trend was noted with the sample from the Northwest Ridge, which had fewer tall-necked vessels but had short-necked dominating the lower levels and constricted vessels in the upper levels. As such, one can observe that there was a significantly lower number of tall-necked vessels around the Hill Complex and Northwest Ridge, with the numbers increasing further away from the Hill Complex. In general, tall-necked vessels are represented in the upper levels more than the other shape categories in contexts outside the stone-walled sections.

In terms of decoration technique and motifs, there is a predominance of incisions and triangles as well as complex motifs across the site. On Midden 1, all diagnostic vessels, save for one, were decorated by incision. Only one sherd was decorated by punctation. Motifs noted on Midden 1 include incised triangles (upper and lower levels), crosshatching, complex motifs (upper levels) and bands of horizontal incisions (upper levels). On Midden 2 Trench 1, incisions also dominated as the decoration technique, and these were classed into either broad or fine. Most of the decoration motifs were noted in the upper levels, including incised triangles, complex motifs, bands of herringbone pattern, cross hatching and bands of horizontal lines. Complex motifs dominated the upper levels on Museum Midden 2, with incised triangles being noted across the stratigraphy. Incisions were also the dominant decoration technique employed. On the North Platform Midden, triangles dominate from the lower to middle levels while cross hatching and complex motifs were noted for the upper levels. As a result, one can conclude that complex motifs, particularly on tall-necked vessels, characterise the upper levels of the assemblage at Khami. The most complex decoration is found on tall-necked vessels at the site. 
Table 5.10: Decoration motifs from Khami according to context.

\begin{tabular}{|c|c|c|c|c|c|c|c|c|c|}
\hline Motif & M1T1 & M2T1 & M2T2 & MM1T1 & MM2T1 & NPMT1 & $\begin{array}{l}\text { MacIver's } \\
\text { Hill } \\
\text { Complex } \\
\text { midden } \\
\end{array}$ & Ex 19 & NWR \\
\hline $\begin{array}{l}\text { 1a. Horizontal } \\
\text { bands of CS } \\
\text { forming } \\
\text { herringbone }\end{array}$ & & & & & & & & 1 & \\
\hline $\begin{array}{l}\text { 1b. Horizontal } \\
\text { band of oblique } \\
\text { CS }\end{array}$ & & & & & 1 & & & 3 & \\
\hline \multicolumn{10}{|l|}{$\begin{array}{l}\text { 1c. Horizontal } \\
\text { band of vertical } \\
\text { CS }\end{array}$} \\
\hline $\begin{array}{l}\text { 2a. Horizontal } \\
\text { band of fine } \\
\text { line of incision } \\
\text { forming } \\
\text { herringbone }\end{array}$ & & 3 & 1 & & 3 & 3 & & & \\
\hline $\begin{array}{l}\text { 2b. Horizontal } \\
\text { band of vertical } \\
\text { fine line of } \\
\text { incision }\end{array}$ & 1 & 6 & 2 & 1 & 4 & 2 & & & \\
\hline $\begin{array}{l}\text { 2c. Fine line of } \\
\text { incision } \\
\text { forming } \\
\text { triangles }\end{array}$ & 10 & 5 & 12 & 5 & 8 & 11 & 14 & & 4 \\
\hline $\begin{array}{l}\text { 2d. Cross } \\
\text { hatching }\end{array}$ & 2 & 2 & 4 & & 4 & 4 & 16 & & 2 \\
\hline $\begin{array}{l}\text { 2e. Horizontal } \\
\text { band of broad } \\
\text { lines of incision } \\
\text { forming } \\
\text { herringbone }\end{array}$ & & & & & & & 20 & 3 & \\
\hline $\begin{array}{l}\text { 2f. Horizontal } \\
\text { band of broad } \\
\text { line of incision }\end{array}$ & 2 & 3 & & & & & 3 & 2 & \\
\hline \multicolumn{10}{|l|}{$\begin{array}{l}2 \mathrm{~g} \text {. Horizontal } \\
\text { band of vertical } \\
\text { broad lines of } \\
\text { incision }\end{array}$} \\
\hline $\begin{array}{l}\text { 3a. Complex } \\
\text { motifs }\end{array}$ & 2 & 6 & 6 & & 3 & 7 & 34 & 1 & 2 \\
\hline $\begin{array}{l}\text { 4a. Horizontal } \\
\text { bands of } \\
\text { punctates }\end{array}$ & & & & & & & 7 & & \\
\hline
\end{tabular}


Table 5.11: Vessel shape categories according to context.

\begin{tabular}{|l|l|l|l|l|l|l|l|l|l|}
\hline Vessel Shape & M1T1 & M2T1 & M2T2 & MM1T1 & MM2T1 & NPMT1 & $\begin{array}{l}\text { MacIver's } \\
\text { Hill } \\
\text { Complex } \\
\text { midden }\end{array}$ & $\begin{array}{l}\text { Ex } \\
19\end{array}$ & NWR \\
\hline Short necked & 29 & 10 & 20 & 4 & 14 & 24 & 17 & 5 & 23 \\
\hline Tall Necked & 39 & 19 & 11 & 3 & 28 & 18 & 15 & 1 & 2 \\
\hline Constricted & 46 & 13 & 15 & 6 & 21 & 18 & 56 & & 25 \\
\hline Bowls & & & & & 3 & 3 & & 2 & \\
\hline Total & $\mathbf{1 1 4}$ & $\mathbf{4 2}$ & $\mathbf{4 6}$ & $\mathbf{1 3}$ & $\mathbf{6 6}$ & $\mathbf{6 3}$ & $\mathbf{8 8}$ & $\mathbf{8}$ & $\mathbf{5 0}$ \\
\hline
\end{tabular}

Table 5.12: Decoration techniques noted at Khami according to context.

\begin{tabular}{|l|l|l|l|l|l|l|l|l|l|}
\hline $\begin{array}{l}\text { DECORATION } \\
\text { TECHNIQUES }\end{array}$ & M1T1 & M2T1 & M2T2 & MM1T1 & MM2T1 & NPMT1 & $\begin{array}{l}\text { MacIver's } \\
\text { Hill } \\
\text { Complex } \\
\text { midden }\end{array}$ & $\begin{array}{l}\text { Ex } \\
19\end{array}$ & NWR \\
\hline $\begin{array}{l}\text { Fine Line of } \\
\text { Incisions (FLI) }\end{array}$ & 16 & 14 & 12 & 6 & 26 & 19 & 27 & & 6 \\
\hline $\begin{array}{l}\text { Broad Line of } \\
\text { Incision (BLI) }\end{array}$ & 10 & 8 & & & 4 & 30 & 9 & 1 \\
\hline $\begin{array}{l}\text { Comb stamping } \\
\text { (CS) }\end{array}$ & & & & & 1 & 1 & & & \\
\hline $\begin{array}{l}\text { Punctation } \\
\text { (PUNC) }\end{array}$ & 1 & & & & & 2 & 2 & 7 & \\
\hline BLI/FLI & & 1 & 8 & & & 3 & 7 & & 1 \\
\hline FLI/PUNC & & 2 & & & & & 8 & 3 & \\
\hline Fluting & & & & & & 2 & & & \\
\hline FLI/CS & & & & & & 3 & & & \\
\hline BLI/PUNC & & & & & & & & & \\
\hline Total & $\mathbf{1 7}$ & $\mathbf{2 7}$ & $\mathbf{2 8}$ & $\mathbf{6}$ & $\mathbf{2 7}$ & $\mathbf{3 4}$ & $\mathbf{8 3}$ & $\mathbf{1 9}$ & $\mathbf{8}$ \\
\hline
\end{tabular}

On the whole, the ceramics recovered from the current study share similarities with those described by previous researchers (Robinson 1959; Hughes 1997; Chirikure et al. 2002). All the vessel shapes previously observed were encountered at the units investigated in this study (Table 5.11). Decoration techniques are similar across the site, and were characterised by the dominance of incisions or combinations of incisions and other techniques. No differentiation was reflected among the people settled on the platforms and those outside the platforms area. Therefore, ceramics as part of the material culture of Khami do not show any differentiation across the various areas of the site. Highly decorated vessels were also encountered in the areas outside the stone walling. 
The evidence from the ceramics confirms that there was an occupation by Leopard's Kopje, followed by Khami (Robinson 1959). These were noted in the lower levels of the Cross Platform midden and in the upper levels of the Museum Midden 2. This is clear evidence of Leopard's Kopje settlement at the site. Overally, ceramics at Khami do not show any differences that could suggest different occupation sequences during the Khami period, as they were characterised by uniformity in terms of both decoration patterns and decoration techniques. Ceramics from this analysis will be incorporated with other material culture, such as glass beads, in Chapter 9, to build a relative chronology of the site. 


\section{CHAPTER 6: GLASS BEADS ANALYSIS AND RESULTS}

\subsection{INTRODUCTION}

As shown in Chapter 4, glass beads are the form of other material culture that was recovered during the excavations at Khami. Glass beads were a critical part of this study for a number of reasons. They are chronological indicators that provide archaeologists with an idea of relative dating based on the dates of their manufacture. Glass beads have also been used to infer status, with the elite being believed to control and manage the trade in glass beads and hence their distribution at the community level (Brumfiel and Earle 1987; Bvocho 2005; Pwiti 2005). I therefore analysed glass beads from Khami with this in mind, and also with a view to understanding their distribution across the site. I initially present a review of bead studies in southern Africa, followed by the methodology that I employed in my analysis. The assemblage from Khami is then presented.

\subsection{BACKGROUND TO GLASS BEAD STUDIES IN SOUTHERN AFRICA}

Glass beads have been recovered on most Zimbabwe Culture sites and have therefore been used as temporal and chronological markers in defining the development of sites prior to the advent of scientific methods of dating, such as radiocarbon dating (Caton-Thompson 1931; Beck 1937; Van Riet Lowe 1955; Schofield 1938; 1958; Robinson 1959; 1961; Wood 2000). Besides being chronological markers, glass beads are also important as symbols of status in society (Brumfiel and Earle 1987; McIntosh 1999b; Bvocho 2005; Pwiti 2005). Evidence from sites such as Mapungubwe has shown that certain burials included glass beads, among other grave goods (Meyer 1998; Huffman 2000). As a result, glass beads have been used as a social-identity marker, differentiating between the elite and non-elite in prehistoric societies. Generally, it has been assumed that the elite received a large share of glass beads; as a result, beads were found in large quantities in elite contexts (Meyer 1998). However, more recent research has shown that even those sites that were considered peripheral had glass beads, which might point to their ubiquity on the landscape (Antonites 2014). Research into glass beads has also enabled a re-creation of the local and international trade-network routes that connected eastern and southern Africa to south Asia (Wood 2000; 2011; Bvocho 2005; Sinclair et al. 2012; Koleini 2015). Bvocho (2005) has shown that in the Shashe Limpopo 
valley, locals exchanged goods with Muslim traders from the Persian Gulf and the ports of Oman. Regional trade routes were also identified through the recovery of similar types of glass beads in the coastal cities and also in the interior (Sinclair et al. 2012).

Due to the important contribution that glass beads had in illuminating pre-historic societies, early archaeologists sought ways to understand their provenance. One of the pioneers in glass bead studies on Zimbabwe Culture sites was Beck, who analysed glass beads from the early excavations at Mapungubwe and K2 (Beck 1937). His analysis showed that many of the K2 and Mapungubwe glass beads were of Indian, not European, origin, contrary to the dominant view in those days. The difference, according to him, was that the older black glass beads were coloured with iron, whereas those from European trade were coloured with manganese. Beck also analysed glass beads from the bedrock levels at Great Zimbabwe, with a view to understanding the early date of the site. The majority of these were black $(30,5 \%)$, pale blue (22\%), pale green (18,5\%), and yellow (15\%) (Beck 1931). The remaining 13\% included orange, reds, white, dark blue, brown and transparent green. Beck noted similarities between these beads from Great Zimbabwe with those from Mapungubwe. He also noted striking similarities with beads from India, which suggested that they came from the same source. In this regard, he suggested a date of between the eight and ninth century, based on similar beads from Tangal and Malay (Beck 1931: 237). Robinson (1959:145) used bead length and diametre to classify beads from Khami into two groups. His Group I has minute cylinders and oblates that had an average length and diametre of $1.5 \mathrm{~mm}$ or less. His Group II is made up of cylinders and oblates with an average length of 2-5 $\mathrm{mm}$ and diametre of 3-4 $\mathrm{mm}$. Colour representation was similar in both groups, with Indian red, dark blue, light blue, green and black represented. He noted that the smaller-sized Group I beads were more represented in the lower layers. Robinson (1959:144) also recorded similar types of beads at Leopard's Kopje with the addition of transparent blue-green and translucent yellow, which do not feature in the Khami series. Van Riet Lowe (1955) felt that it was important to carry out an "exact physical, chemical and spectroscopic analysis" in order to properly understand the age and origins of glass beads. Gardner (1963) developed a glass-bead series for the ShasheLimpopo valley and managed to differentiate between those from K2 and Mapungubwe. Davison (1972) pioneered chemical analysis of glass beads, in a bid to trace their origins. However, she could not determine the provenance of the beads she analysed, owing to limited comparative data. 
Wood $(2005 ; 2012)$ has defined a glass-bead series for southern Africa using morphological and technological characteristics. She has also managed to date these series, using existing radiocarbon chronologies, and identify the glass-bead series with known socio-political transformations occurring in southern Africa. The major traits used in classifying glass beads include shape, size range, diaphaneity and colour. In this regard, six bead series-including Zhizo, K2, Indo-Pacific, Mapungubwe oblates, Zimbabwe period and Khami period-were constructed. Recent chemical analysis done by Robertshaw et al. (2010) has also shown that each bead series has a characteristic chemistry. Zhizo beads are either tubes or cylinders and are frequently a transparent to translucent blue, yellow, blue-green and green (Wood 2005). Chemically, they were made from a plant-ash glass from Persia. K2 beads start to appear in the region from about AD 980. They are characterised by small (2 to $3.5 \mathrm{~mm}$ diametre and 1.2 to $4 \mathrm{~mm}$ long). The colours range from blue-green to greenish-blue and green. The K2 series and the subsequent Indo-Pacific series were made from soda-aluminium glass from south Asia. Robertshaw et al. (2010) sees the shift from Persian manufactured beads in Zhizo to Indian beads in $\mathrm{K} 2$ as a reorientation of the trade networks that saw southern Africa receiving more goods from south Asia than from the Persian region. The mid-thirteenth century saw the arrival of the Mapungubwe oblate series, followed by the Zimbabwe series in the fourteenth century. These series derived from south Asia and were made from a plant-ash glass. Mapungubwe-series beads are small drawn oblate and are characterised by a general uniformity in terms of size (Wood 2005). Opaque black is the most dominant colour in the series. Other colours include blue-green, light green, yellow and orange. They have been recorded at a number of sites in the region, including the early levels of Khami (Garlake 1968). The Zimbabwe series looks similar to the Mapungubwe series but the beads are slightly larger, with fewer oblates than cylinders. The same colours of the Mapungubwe series continued in the Zimbabwe series. The Khami series makes an appearance in the fifteenth century and marks a return to the soda-aluminium glass of the K2 and Indo-Pacific series. There is some similarity, chemically and morphologically, between the Indo-Pacific and the Khami-series. Khami beads were most likely manufactured in south Asia and are slightly larger than the Indo-Pacific series. Khami beads are distinguishable from the early Indo-Pacific by the presence of deep blue and off-white beads. Other colours include yellow, and blue-green (Wood 2000). 
The relationship between glass beads and international trade has proved to be an important chronological marker, as most of the beads can be traced to their origin and time of manufacture (Wood 2005; Bvocho 2005; Robertshaw et al. 2010). Bvocho (2005) has shown that beads recovered from Mwenezi Farm mirrored developments taking place in the region between the eleventh and fifteenth centuries. The site has beads associated with Schroda, K2, Mapungubwe and Great Zimbabwe. More recently, Robertshaw et al. (2010) have studied the chemistry of glass beads from a number of sites in Africa. The results of the chemical analysis have been used to identify the regions where the glass was manufactured. This process also enabled a 'reconstruction of patterns of trade between various regions of Africa and the wider world' (Robertshaw et al. 2010: 1899). As a result of the chemical analysis, the researchers concluded that Khami-series beads were made from mineral soda glass, much like K2 and Indo-Pacific glass beads. As a result, they argue that the origin of the mineralsoda glass, from which the Khami series beads were manufactured, is south Asia.

Koleini et al. (2015) have proposed a new methodology for the classification of glass beads from southern Africa. This classification is the result of a number of experiential tests carried out on beads from a number of sites in the region, primarily the Shashe-Limpopo valley (Prinsloo et al. 2008; 2011; Tournie 2012) and north-eastern Botswana (Koleini et al. 2015). Glass beads were classified using parameters from their Raman signature: namely, soda and soda lime glass (Prinsloo et al. 2012). This method is unique in that it offers the possibility to differentiate bead types where it is not possible to differentiate between beads on morphological grounds. Another important element is the ability to identify the pigments used to colour beads. The new glass bead classification is based initially on a morphological classification, as defined by Wood $(2005 ; 2011)$. Selected representative beads are selected for Raman spectra analyses, which captures features about the production process of the glass used in the manufacture of beads (Figure 6.1) (Prinsloo et al. 2008:80). The classification shows that Group 1 is made up of beads with $\mathrm{Fe}-\mathrm{S}$ chromophore, which belong to the East Coast Indo-Pacific series and the Khami Indo-Pacific series. XRF readings have also shown that black Khami Indo Pacific have a higher $A l$ and $C a$ content than black K2 Indo Pacific. Group 2 includes soda-glass-based beads from the K2 Indo Pacific, East Coast Indo Pacific and Khami Indo Pacific bead series. Khami Indo Pacific beads in this group have higher $A l$, $\mathrm{Ca}$ and $\mathrm{Fe}$ contents than K2 Indo Pacific beads. Group 3 is made up of beads from soda-lime 
glass, which include Mapungubwe oblates and Zimbabwe and Khami Indo Pacific series beads. The iron content of the Mapungubwe oblates and Zimbabwe series is less than in the Khami Indo Pacific beads. $\mathrm{SnO}_{2}$ is also present in the opaque Mapungubwe and Zimbabwe beads. The final group 4 has beads with a higher lead/calcium content. These have not been assigned to any currently known bead series in southern Africa.

\subsection{METHODOLOGY FOR BEAD ANALYSIS}

To date, a number of classification systems for beads have been developed (Beck 1928; Van der Sleen 1967; Kidd and Kidd 1970; Karklins 1985; Wood 2005). Wood (2005) developed a comprehensive classification system for beads from the Shashe-Limpopo region based on works by previous scholars, including Kidd and Kidd (1970), Karklins (1985), and Wood (2000). This system has become standard for analysing beads from southern Africa and Zimbabwe Culture sites based on morphology, and is used here to analyse beads from the Khami excavations. Some of the attributes that Wood studied in the Shashe-Limpopo bead assemblage were shape, size range, length ratio, colour and diaphaneity. These attributes are outlined in detail in the following section.

\section{Shape}

Wood (2005:31) noted that the shape of a bead is the result of the ratio between its diameter and length and the degree to which it was reheated. Seven bead shapes have been observed. However, for the purposes of this study, the focus will be on the four bead shapes that were observed at Khami. These are tubular, oblate, cylinder and barrel. Tubular beads have parallel straight sides. Cylinders are similar to tubular beads, but their ends have been reheated to the point that the bead has a rounded profile. Oblate beads have been reheated to the point that the entire length of the bead has a smoothly rounded profile. The length must be less than the diameter for oblates. A barrel bead is one with rounded sides and flat ends. This designation is mostly used for large wound or moulded beads such as Garden Rollers. 


\section{Size Range}

Wood (2005) developed a size range for southern African beads that took into account the bead sizes of most beads recovered in the region. Thus, while East Africa has a size range that goes as far as $8 \mathrm{~mm}$ (Chittick 1974:464), the one developed for southern Africa goes as far as $4.5 \mathrm{~mm}$.

Table 6.1: Bead size range categories as developed by Wood (2005:34).

\begin{tabular}{|l|l|}
\hline Size Designation & Diametre $(\mathbf{m m})$ \\
\hline Minute & $<2.5$ \\
\hline Small & $2.5-3.5$ \\
\hline Medium & $3.5-4.5$ \\
\hline Large & $>4.5$ \\
\hline
\end{tabular}

\section{Length Ratio}

Length ratio measures the relationship between the length and diameter of the bead, in order to come up with a designation of disc, short, standard, long and very long.

Table 6.2: Length ratio designation formula (after Wood 2005:34).

\begin{tabular}{|l|l|}
\hline Length Ratio & Formula \\
\hline Disc & Length $=<1 / 5$ Diametre \\
\hline Short & Length $=>1 / 5$ and $<4 / 5$ Diametre \\
\hline Standard & Length $=4 / 5$ and $<11 / 5$ Diametre \\
\hline Long & Length $=>11 / 5$ and $<2$ Diametre \\
\hline Very long & Length $=>2$ Diametre \\
\hline
\end{tabular}

\section{Diaphaneity}

Diaphaneity describes the translucency of glass. There are three broad degrees that can be used to define diaphaneity: transparent, translucent and opaque. However, it is also important to identify nuances in translucency, as this can distinguish beads of one series from those of another. However, diaphaneity is affected by a number of things, such as patina, dirt and surface abrasion. As a result, a strong light source was used in conjunction with magnification. 
Table 6.3: Table showing the range of translucency used in the analysis of southern African glass beads (Wood 2005:35).

\begin{tabular}{|l|l|}
\hline Diaphaneity & Description \\
\hline Transparent & Objects can be seen through glass \\
\hline Transparent-translucent & Glass is slightly cloudy (often due to bubbles) \\
\hline Translucent-transparent & Glass is cloudy but light passes through easily through bead \\
\hline Translucent & Light passes through entire bead \\
\hline Translucent-opaque & Glow of light from most of bead \\
\hline Opaque-translucent & Slight glow of light at edges of bead \\
\hline Opaque & Nolight seen through edge of bead \\
\hline
\end{tabular}

\section{Colour}

Wood (2005:36) has noted that beads from the same glass batch could vary in hue depending on the size or shape of the bead. Patination and surface condition also affect colour perception. In this study the colour of the beads was recorded using an artist's water-colour chart produced by Windsor and Newton of London.

Table 6.4: Glass bead classification from southern Africa based on morphological characteristics and chemical composition (after Wood 2011; Robertshaw et al. 2010).

\begin{tabular}{|c|c|c|c|c|}
\hline Bead series & Metric values & Colour & Chemistry & $\begin{array}{l}\text { Sites where typical beads } \\
\text { were found }\end{array}$ \\
\hline Zhizo & $\begin{array}{l}<13 \quad \mathrm{~mm} \\
\text { diametre } \\
<20 \mathrm{~mm} \text { length }\end{array}$ & $\begin{array}{l}\text { Transparent to translucent } \\
\text { blue, yellow, blue-green } \\
\text { and green }\end{array}$ & $\begin{array}{l}\text { Made from plant- } \\
\text { ash }\end{array}$ & $\begin{array}{l}\text { Chibuene; Leopard's Kopje } \\
\text { Main Kraal; Zhizo Hill; } \\
\text { Gokomere tunnel site }\end{array}$ \\
\hline K2 & $\begin{array}{l}2-3.5 \quad \mathrm{~mm} \\
\text { diametre by } 1.2- \\
4 \mathrm{~mm} \text { long }\end{array}$ & $\begin{array}{l}\text { Translucent blue-green and } \\
\text { greenish-blue; transparent } \\
\text { turquoise }\end{array}$ & $\begin{array}{l}\text { Made from soda- } \\
\text { alumina glass of } \\
\text { south Asian } \\
\text { origin. } \\
\text { High levels of } \\
\text { aluminium }\end{array}$ & $\begin{array}{l}\text { Pont Drift; Schroda; K2; } \\
\text { Shashe Limpopo valley sites; } \\
\text { Mmamagwe; } \\
\text { Kgaswe; }\end{array}$ \\
\hline Indo-Pacific & $\begin{array}{ll}2.5-4.5 & \mathrm{~mm} \\
\text { diametre } & \end{array}$ & $\begin{array}{l}\text { Blue-green; green; yellow; } \\
\text { orange; brown-red }\end{array}$ & $\begin{array}{l}\text { Made from soda- } \\
\text { lime glass }\end{array}$ & $\begin{array}{l}\text { Schroda; Pont Drift; post- } \\
\text { Zhizo contexts }\end{array}$ \\
\hline $\begin{array}{l}\text { Mapungubwe } \\
\text { Oblates }\end{array}$ & $\begin{array}{l}2-3.5 \\
\text { diametre }\end{array}$ & $\begin{array}{l}\text { Blue-green; green; yellow; } \\
\text { orange; cobalt; plum }\end{array}$ & $\begin{array}{l}\text { Made from high } \\
\text { alumina, low } \\
\text { calcium plant ash }\end{array}$ & $\begin{array}{lr}\text { Mapela; Ntaba zika Mambo; } \\
\text { Mapungubwe; } \quad \text { Bosutswe; } \\
\text { Skutwater; } & \text { Khami; } \\
\text { Woolandale; } & \text { Great } \\
\text { Zimbabwe Phase III } & \end{array}$ \\
\hline
\end{tabular}




\begin{tabular}{|c|c|c|c|c|}
\hline Zimbabwe & & $\begin{array}{l}\text { Blue-green translucent- } \\
\text { transparent to opaque- } \\
\text { translucent; transparent } \\
\text { green; translucent greyish } \\
\text { green; } \\
\text { Yellow; opaque translucent } \\
\text { orange; Transparent- } \\
\text { translucent cobalt blue; } \\
\text { translucent lime green }\end{array}$ & $\begin{array}{l}\text { Made from high } \\
\text { alumina, low } \\
\text { calcium plant ash }\end{array}$ & Great Zimbabwe \\
\hline $\begin{array}{l}\text { Khami Indo- } \\
\text { Pacific }\end{array}$ & $\begin{array}{ll}2-7 & \mathrm{~mm} \\
\text { diametre } & \end{array}$ & $\begin{array}{l}\text { Opaque black and } \\
\text { brownish red; Translucent- } \\
\text { opaque blue, blue -green, } \\
\text { yellow, dull orange, green }\end{array}$ & $\begin{array}{l}\text { Made from soda- } \\
\text { alumina glass. } \\
\text { Higher } \mathrm{Na}_{2} \mathrm{O} \text {, } \\
\mathrm{MgO}, \mathrm{CaO} \text { and } \\
\text { low } \mathrm{Al}_{2} \mathrm{O}_{3}\end{array}$ & $\begin{array}{l}\text { Faure; Kolope; Bosutswe; } \\
\text { Tora Nju; Toutswe, } \\
\text { Thulamela; Sibudu Cave; } \\
\text { Great Zimbabwe }\end{array}$ \\
\hline
\end{tabular}

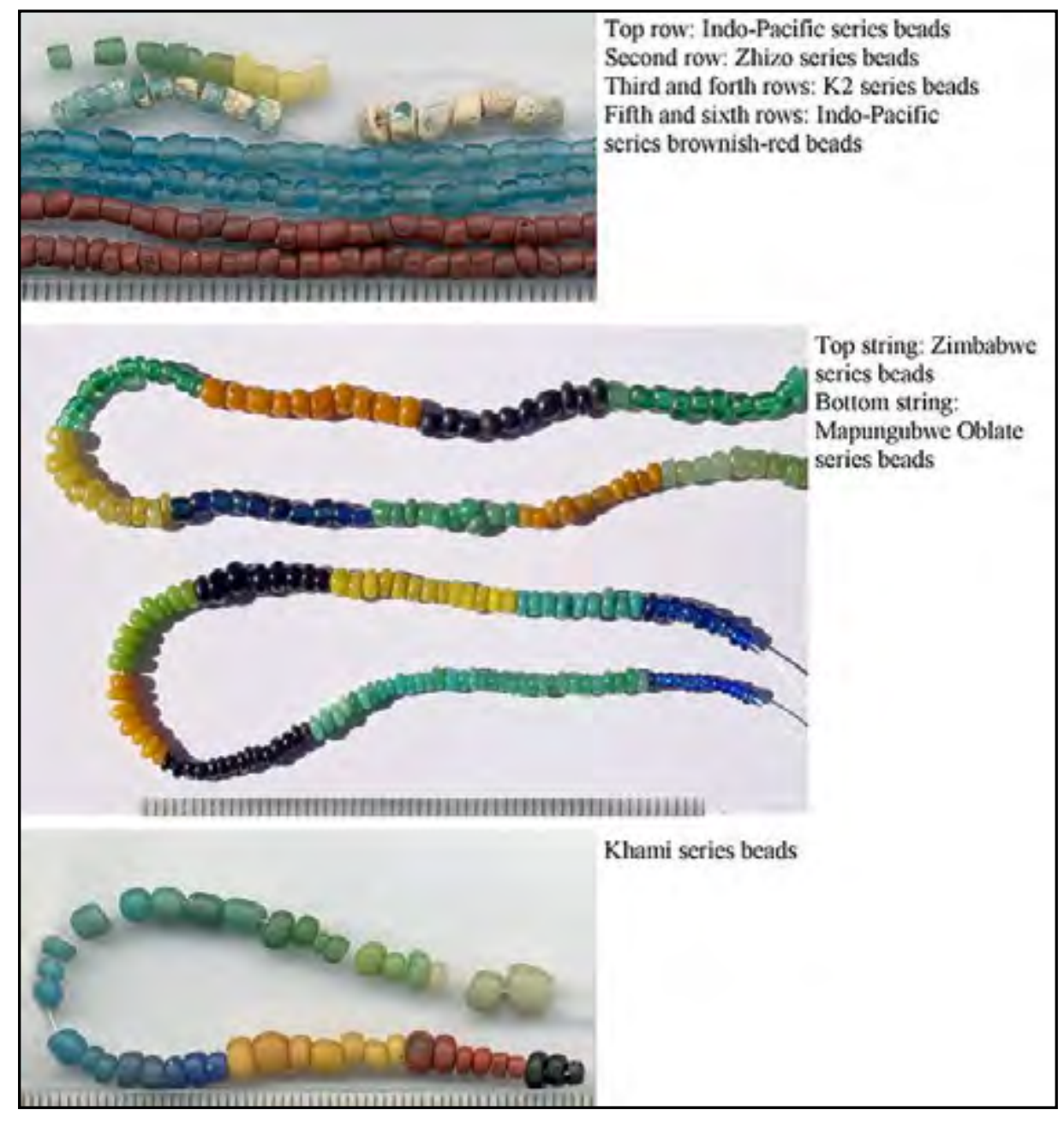

Figure 6.1: Beads from the various bead series of southern Africa discussed (Robertshaw 2010:1900). 


\subsection{KHAMI BEAD ASSEMBLAGE}

A total of 421 glass beads were recovered from the five excavated areas. Indian reds dominated, at $50.59 \%$ of the assemblage, followed by Prussian blue (14.01\%) and cerulean blue (12.11\%). Other colours included yellow, cerulean blue, hookers green and terre verte, as well as black (Table 5.4).

\section{Indian red beads}

Indian red beads accounted for the majority of the beads found at Khami. They made up $50.59 \%$ of the assemblage. Most of the Indian reds tended to be small in size, although some minute- and medium-sized beads were noted. One large-sized bead was recovered in Midden 1. In terms of distribution, Indian reds were evenly distributed across all levels, although higher numbers tended to concentrate in the middle levels of the stratigraphy (Table 5.9, 5.10, $5.11,5.12,5.13$ and 5.14).

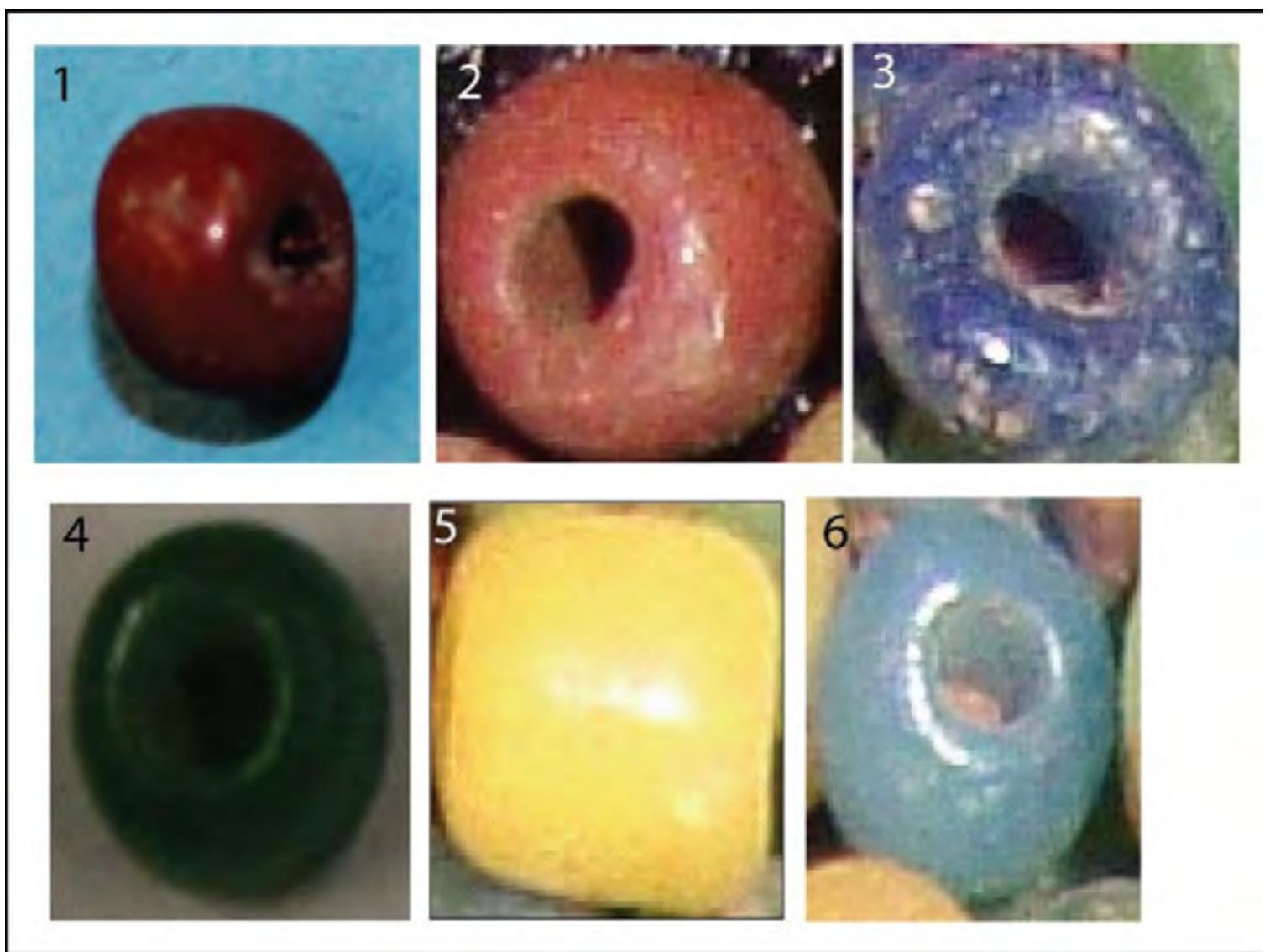

Figure 6.2 Bead colours recovered from Khami. 1- Indian red, 2-cadmium red, 3-prussian blue, 4-green, 5-yellow, 6-cerulean blue 


\section{Prussian blue}

The second most common bead colour was Prussian blue, at 59 beads. Most of the beads fell in the minute-size category, although some small and medium sizes were noted. Shapes were mostly cylinders, although some oblates and a few tubular were recorded. While its spread tended to be even across the stratigraphy, there was a higher concentration form the middle to the lower levels.

\section{Cadmium red}

A total of $23(5.46 \%)$ beads were cadmium red in colour. The cadmium-red-coloured beads were either minute or small sized. In terms of shape, there was a mixture of cylinders and oblates, and a few tubular. One barrel shaped bead was also recorded. Cadmium reds were common in the middle to lower levels in the stratigraphy. In Midden 1, they are more common in the middle levels, while in Midden 2 they tended to be found in the lower levels.

\section{Hookers green}

The other common beads were the hookers green numbering 28 either cylinders or oblates and ranging in size from minute to small. Both dark and light shades of green were also noted. They tended to concentrate in the middle levels of the stratigraphy.

\section{Yellow}

32 yellow beads were recorded at Khami. These were mainly cylinders but also tubular, oblates, and a single barrel. Sizes were mostly concentrated in the minute to medium range; however, one large yellow bead size was also noted. In the stratigraphy, yellow beads tended to occur in the middle to lower levels.

\section{Cerulean blue}

51 cerulean blue beads were recorded. They were mostly oblates, although a few cylinders were also recorded. They ranged in size from small to medium. Cerulean blue beads were mostly found sparsely spread from the upper to the lower levels.

\section{Other colours}

Cobalt turquoise, terre verte and black beads accounted for $3.57 \%$ of the total assemblage. The black bead was recorded in the upper levels of Midden 1 and Museum Midden 2, while 
terre verte occurred in the middle levels of both middens. Cobalt turquoise was recovered in the upper levels of Midden 2.

Table 6.5: Distribution of glass beads from Midden 1 Trench 1 by excavation layers.

\begin{tabular}{|c|c|c|c|c|c|c|c|}
\hline Level & Cadmium Red & Cerulean blue & Hookers green & Indian red & Prussian blue & Terre verte & Yellow \\
\hline 1 & & & & & & & \\
\hline 2 & & & & & 1 & & \\
\hline 3 & & & & & & & \\
\hline 4 & & 1 & & 1 & & & \\
\hline 5 & 1 & & & & & & \\
\hline 6 & 6 & 1 & 1 & 2 & 2 & & \\
\hline 7 & 1 & & & 1 & & 1 & \\
\hline 8 & 2 & & & 1 & 2 & & 3 \\
\hline 9 & & & & & & & \\
\hline 10 & & & & & & & \\
\hline 11 & & & & & & & \\
\hline 12 & & & & & & & \\
\hline 13 & & & & 2 & & 1 & 1 \\
\hline 14 & & & & 2 & 1 & & \\
\hline 15 & 1 & 1 & & 3 & 3 & & \\
\hline 16 & 1 & & & & & & 1 \\
\hline Totals & 12 & 3 & 1 & 12 & 9 & 2 & 5 \\
\hline
\end{tabular}

Table 6.6: Distribution of glass beads from Midden 1 Trench 2A by excavation layers.

\begin{tabular}{|l|l|l|l|l|l|l|l|}
\hline Level & Black & $\begin{array}{l}\text { Cadmium } \\
\text { Red }\end{array}$ & $\begin{array}{l}\text { Cerule an } \\
\text { blue }\end{array}$ & $\begin{array}{l}\text { Hookers } \\
\text { gre en }\end{array}$ & $\begin{array}{l}\text { Indian } \\
\text { red }\end{array}$ & $\begin{array}{l}\text { Prussian } \\
\text { blue }\end{array}$ & Yellow \\
\hline 1 & & & & & & & \\
\hline 2 & & & & & & & \\
\hline 3 & & & & & & & \\
\hline 4 & 1 & & 1 & & & 1 & \\
\hline 5 & & & & & 2 & & \\
\hline 6 & & 1 & 1 & & 1 & 1 & \\
\hline 7 & & & 1 & 2 & 5 & 2 & 1 \\
\hline 8 & & & & & 3 & & \\
\hline 9 & & & 1 & & 1 & 2 & \\
\hline 10 & & & & & 2 & 2 & \\
\hline 12 & & & & 4 & 8 & 6 & 2 \\
\hline 13 & & & & & 2 & & \\
\hline 14 & & & & & & & \\
\hline 15 & & & & & & 1 & \\
\hline Totals & $\mathbf{1}$ & $\mathbf{1}$ & $\mathbf{4}$ & $\mathbf{6}$ & $\mathbf{2 4}$ & $\mathbf{1 5}$ & $\mathbf{3}$ \\
\hline
\end{tabular}


Table 6.7: Distribution of glass beads from Midden 2 Trench 2 by excavation layers.

\begin{tabular}{|c|c|c|c|c|c|c|c|c|}
\hline Level & $\begin{array}{l}\text { Cadmium } \\
\text { Red }\end{array}$ & $\begin{array}{l}\text { Cerule an } \\
\text { blue }\end{array}$ & $\begin{array}{l}\text { Cobalt } \\
\text { turquoise }\end{array}$ & \begin{tabular}{|l|} 
Hookers \\
green
\end{tabular} & $\begin{array}{l}\text { Indian } \\
\text { red }\end{array}$ & $\begin{array}{l}\text { Prussian } \\
\text { blue }\end{array}$ & $\begin{array}{l}\text { Terre } \\
\text { verte }\end{array}$ & Yellow \\
\hline \multicolumn{9}{|l|}{1} \\
\hline \multicolumn{9}{|l|}{2} \\
\hline 3 & & 1 & 1 & 1 & & & & \\
\hline \multicolumn{9}{|l|}{4} \\
\hline 5 & 1 & & 1 & 1 & 2 & & & \\
\hline 6 & & & & & 2 & & & 1 \\
\hline 7 & & & & & 3 & & & \\
\hline 8 & & & & & 6 & & & \\
\hline 9 & & & & 1 & 5 & 3 & & 2 \\
\hline 10 & 2 & & & 3 & 2 & 3 & 1 & 2 \\
\hline 11 & 3 & & & & 1 & 2 & & \\
\hline 12 & 2 & & & & 1 & & & \\
\hline 13 & 1 & & & & & 1 & & \\
\hline \multicolumn{9}{|l|}{14} \\
\hline 15 & 2 & & & & & & & 11 \\
\hline Totals & 11 & 1 & 2 & 6 & 22 & 9 & 1 & 6 \\
\hline
\end{tabular}

Table 6.8: Distribution of glass beads from Midden 2 Trench 1 by excavation layers.

\begin{tabular}{|l|l|l|l|l|}
\hline Level & $\begin{array}{l}\text { Cerulean } \\
\text { blue }\end{array}$ & $\begin{array}{l}\text { Cobalt } \\
\text { turquoise }\end{array}$ & $\begin{array}{l}\text { Hookers } \\
\text { green }\end{array}$ & $\begin{array}{l}\text { Indian } \\
\text { red }\end{array}$ \\
\hline 1 & & 1 & & 3 \\
\hline 2 & & 1 & & \\
\hline 3 & & 1 & 2 & 8 \\
\hline 4 & 1 & & & 6 \\
\hline Totals & $\mathbf{1}$ & $\mathbf{3}$ & $\mathbf{2}$ & $\mathbf{1 7}$ \\
\hline
\end{tabular}


Table 6.9: Distribution of glass beads from North Platform Midden 1.

\begin{tabular}{|l|l|l|l|l|l|l|}
\hline Level & $\begin{array}{l}\text { Cerulean } \\
\text { blue }\end{array}$ & $\begin{array}{l}\text { Indian } \\
\text { Red }\end{array}$ & $\begin{array}{l}\text { Prussian } \\
\text { blue }\end{array}$ & $\begin{array}{l}\text { Hookers } \\
\text { Green }\end{array}$ & Yellow & $\begin{array}{l}\text { Cobalt } \\
\text { Turquoise }\end{array}$ \\
\hline 1 & 1 & 2 & 1 & & & \\
\hline 2 & & & 1 & & & \\
\hline 3 & 2 & 16 & 1 & 3 & & \\
\hline 4 & 2 & 9 & 4 & 2 & 3 & \\
\hline 5 & & & & & & \\
\hline 6 & 1 & 30 & 6 & & 2 & \\
\hline 7 & & & & & & \\
\hline 8 & 6 & 21 & & & 5 & 1 \\
\hline 9 & 6 & 14 & & & 4 & 1 \\
\hline 10 & 1 & 9 & & & 1 & \\
\hline Totals & $\mathbf{1 9}$ & $\mathbf{1 0 1}$ & $\mathbf{1 3}$ & $\mathbf{5}$ & $\mathbf{1 5}$ & $\mathbf{2}$ \\
\hline
\end{tabular}

Table 6.10: Distribution of glass beads from Museum Midden 1 Trench 1.

\begin{tabular}{|l|l|l|l|l|}
\hline Level & $\begin{array}{l}\text { Cerulean } \\
\text { blue }\end{array}$ & $\begin{array}{l}\text { Cobalt } \\
\text { turquoise }\end{array}$ & $\begin{array}{l}\text { Prussian } \\
\text { blue }\end{array}$ & $\begin{array}{l}\text { Indian } \\
\text { red }\end{array}$ \\
\hline 1 & & & & 3 \\
\hline 2 & & & 3 & \\
\hline 3 & & 1 & 2 & 4 \\
\hline 4 & 1 & 2 & & 6 \\
\hline $\mathbf{5}$ & & $\mathbf{2}$ & & \\
\hline 6 & & & & 2 \\
\hline Totals & $\mathbf{1}$ & $\mathbf{5}$ & $\mathbf{5}$ & $\mathbf{1 5}$ \\
\hline
\end{tabular}


Table 6.11: Distribution of glass beads from Museum Midden 2 Trench 1 Square C0.

\begin{tabular}{|l|l|l|l|l|}
\hline Level & $\begin{array}{l}\text { Indian } \\
\text { Red }\end{array}$ & Yellow & $\begin{array}{l}\text { Cerulean } \\
\text { Blue }\end{array}$ & Black \\
\hline $\mathbf{1}$ & 2 & 1 & 1 & \\
\hline $\mathbf{2}$ & & & 1 & \\
\hline $\mathbf{3}$ & & & 2 & 1 \\
\hline $\mathbf{4}$ & 1 & & & \\
\hline $\mathbf{5}$ & 4 & & 2 & \\
\hline $\mathbf{6}$ & & & 1 & \\
\hline $\mathbf{7}$ & & & & \\
\hline $\mathbf{8}$ & 2 & & & \\
\hline $\mathbf{9}$ & 4 & 1 & & \\
\hline $\mathbf{1 0}$ & & & & \\
\hline $\mathbf{1 1}$ & & & 1 & \\
\hline $\mathbf{1 2}$ & 1 & & 1 & \\
\hline Totals & $\mathbf{1 4}$ & $\mathbf{2}$ & $\mathbf{9}$ & $\mathbf{1}$ \\
\hline
\end{tabular}

Table 6.12: Distribution of glass beads from Museum Midden 2 Square A0.

\begin{tabular}{|l|l|l|l|l|l|}
\hline Level & $\begin{array}{l}\text { Cobalt } \\
\text { Turquoise }\end{array}$ & $\begin{array}{l}\text { Indian } \\
\text { Red }\end{array}$ & $\begin{array}{l}\text { Prussian } \\
\text { Blue }\end{array}$ & $\begin{array}{l}\text { Cerulean } \\
\text { Blue }\end{array}$ & Yellow \\
\hline $\mathbf{1}$ & & & & & \\
\hline $\mathbf{2}$ & 1 & & & & \\
\hline $\mathbf{3}$ & & 3 & & & \\
\hline $\mathbf{4}$ & 1 & 2 & & & \\
\hline $\mathbf{5}$ & & & & & \\
\hline $\mathbf{6}$ & & 2 & 1 & 1 & \\
\hline $\mathbf{7}$ & & & 1 & & 1 \\
\hline $\mathbf{8}$ & & 1 & & & \\
\hline $\mathbf{9}$ & & & & & \\
\hline $\mathbf{1 0}$ & & & & & \\
\hline $\mathbf{1 1}$ & 1 & 1 & 1 & & \\
\hline $\mathbf{1 2}$ & & 1 & 1 & 1 & \\
\hline Totals & $\mathbf{3}$ & $\mathbf{1 0}$ & $\mathbf{4}$ & $\mathbf{2}$ & $\mathbf{1}$ \\
\hline
\end{tabular}


Table 6.13: Total number of glass beads recovered from each excavated area by colour.

\begin{tabular}{|c|c|c|c|c|c|c|c|c|c|c|c|c|}
\hline \multirow[b]{2}{*}{ Black } & \multicolumn{2}{|c|}{ Midden 1} & \multicolumn{2}{|c|}{ Midden 2} & \multicolumn{2}{|c|}{$\begin{array}{l}\text { Museum } \\
\text { Midden } 1\end{array}$} & \multicolumn{2}{|c|}{$\begin{array}{l}\text { Museum } \\
\text { Midden } 2\end{array}$} & \multicolumn{2}{|c|}{$\begin{array}{l}\text { North Platform } \\
\text { Midden } 1\end{array}$} & \multicolumn{2}{|c|}{ Total } \\
\hline & 1 & $0.94 \%$ & & & & & 1 & $2.17 \%$ & & & 2 & 0.48 \\
\hline Cadmium Red & 12 & $11.32 \%$ & 11 & $13.58 \%$ & & & & & & & 23 & 5.46 \\
\hline Cerulean blue & 8 & $7.55 \%$ & 2 & $2.47 \%$ & 11 & $33.33 \%$ & 11 & $23.91 \%$ & 19 & $12.26 \%$ & 51 & 12.11 \\
\hline Cobalt Turquoise & & & 5 & $6.17 \%$ & & & 3 & $6.52 \%$ & 2 & $1.29 \%$ & 10 & 2.38 \\
\hline Hookers Green & 8 & $7.55 \%$ & 8 & $9.88 \%$ & 7 & $21.21 \%$ & & & 5 & $3.23 \%$ & 28 & 6.65 \\
\hline Indian Red & 40 & $37.74 \%$ & 39 & $48.15 \%$ & 9 & $27.27 \%$ & 24 & $52.17 \%$ & 101 & $65.16 \%$ & 213 & 50.59 \\
\hline Prussian Blue & 27 & $25.47 \%$ & 9 & $11.11 \%$ & 6 & $18.18 \%$ & 4 & $8.70 \%$ & 13 & $8.39 \%$ & 59 & 14.01 \\
\hline Terre Verte & 2 & $1.89 \%$ & 1 & $1.23 \%$ & & & & & & & 3 & 0.71 \\
\hline Yellow & 8 & $7.55 \%$ & 6 & $7.41 \%$ & & & 3 & $6.52 \%$ & 15 & $9.68 \%$ & 32 & 7.6 \\
\hline Totals & 106 & $100 \%$ & 81 & $100 \%$ & 33 & $100 \%$ & 46 & $100 \%$ & 155 & $100 \%$ & 421 & $100 \%$ \\
\hline
\end{tabular}

North Platform Midden 1 recorded the highest number of glass beads recovered. What is important is that the high number of beads (155) recovered from this midden was irrespective of the fact that only $1 \mathrm{~m}^{2}$ was excavated, in comparison to $3 \mathrm{~m}^{2}$ each for Middens 1 and 2 , which had 106 and 81 glass beads respectively. It is important to also highlight that North Platform Midden 1 is part of the built-up area around Khami. Probably due to the high density of people occupying that area or using that area for refuse disposal, the midden ended up accumulating a high concentration of material culture. This is also attested by the pottery and bone assemblage that was recovered from the midden.

The Indian-red-coloured beads were the most dominant in the individual excavated units. In North Platform Midden 1, Museum Midden 2 and Midden 2 units, Indian reds accounted for over half of the beads in each individual unit. Museum Midden 1 had only 27\% of Indian red beads, but it is also important to note that the number of beads recovered from Museum Midden 1 was very low in comparison with the other excavated units, and that cerulean blue actually dominated in terms of presence. Prussian blue was the overall second most dominant bead colour on all the units, followed by cerulean blue. However, on a comparative level, three of the five excavated units had cerulean blue dominating over Prussian blue. Thus, Museum Midden 1 and 2 and the North Platform Midden 1 recorded more cerulean blue beads compared to Prussian blue. Most of the glass bead colours were common to all the 
excavated units. Only black, cadmium red and terre verte were not recorded in all excavation units. They were all only found on two of the five units. The other six colours were recorded on all the areas suggesting a uniformity in terms of glass bead colour spread at the site.

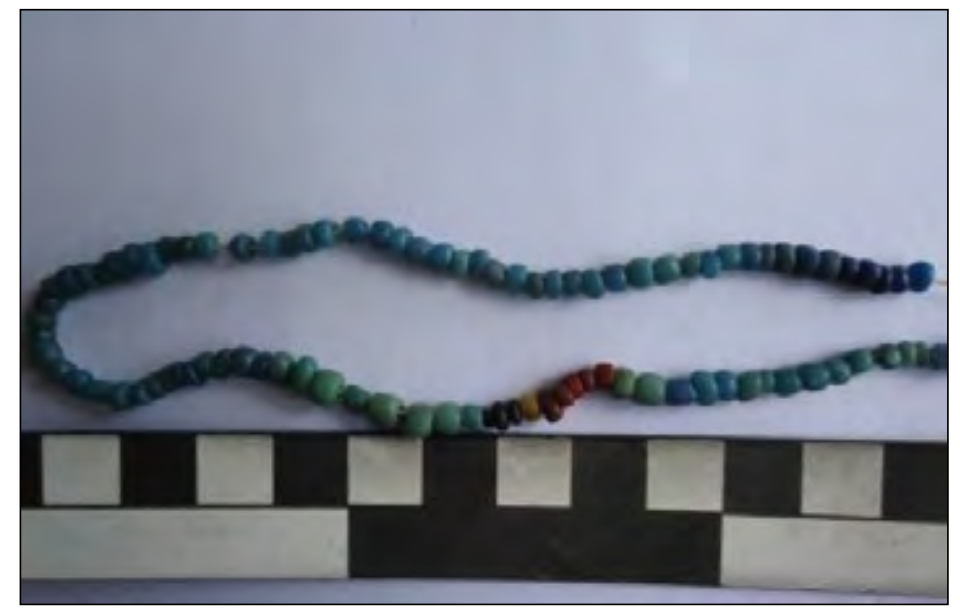

Figure 6.3: Glass beads from Khami showing the varied colours that were recovered.

Four shapes were identified from the Khami bead assemblage. Cylinders dominated both excavated areas, accounting for $54.01 \%$. Oblates were the second most dominant bead shape, with tubular and barrels forming a minority in the assemblage. On a comparative scale, both middens did not have any major differences in terms of glass-bead shape distribution, as can be noted in Table 5.2 above. In their review of the bead series from southern Africa, Robertshaw et al. noted that the Khami series from the Shashe-Limpopo region and northern Botswana were mostly cylinders with rounded ends (Robertshaw et al. 2010:1901)

Table 6.14: Distribution of glass bead shapes.

\begin{tabular}{|l|l|l|l|l|l|l|l|l|l|l|l|l|}
\hline & \multicolumn{3}{|l|}{ Midden 1 } & \multicolumn{3}{|l|}{$\begin{array}{l}\text { Museum } \\
\text { Midden 2 }\end{array}$} & \multicolumn{2}{l|}{$\begin{array}{l}\text { Museum } \\
\text { Midden 2 }\end{array}$} & \multicolumn{2}{l|}{$\begin{array}{l}\text { North Platform } \\
\text { Midden }\end{array}$} \\
\hline Barrel & 3 & $2.83 \%$ & 1 & $1.23 \%$ & 2 & $6.06 \%$ & & & & & $\mathbf{4}$ & $\mathbf{2 . 1 4 \%}$ \\
\hline Cylinder & 62 & $58.49 \%$ & 39 & $48.15 \%$ & 6 & $18.18 \%$ & 5 & $10.87 \%$ & 20 & $12.90 \%$ & $\mathbf{1 0 1}$ & $\mathbf{5 4 . 0 1 \%}$ \\
\hline Oblate & 36 & $33.96 \%$ & 31 & $38.27 \%$ & 24 & $72.72 \%$ & 40 & $86.96 \%$ & 135 & $87.10 \%$ & $\mathbf{6 7}$ & $\mathbf{3 5 . 8 3 \%}$ \\
\hline Tubular & 5 & $4.72 \%$ & 10 & $12.35 \%$ & 1 & $3.03 \%$ & 1 & $2.17 \%$ & & & $\mathbf{1 5}$ & $\mathbf{8 . 0 2 \%}$ \\
\hline Total & $\mathbf{1 0 6}$ & $\mathbf{1 0 0 \%}$ & $\mathbf{8 1}$ & $\mathbf{1 0 0 \%}$ & $\mathbf{3 3}$ & $\mathbf{1 0 0 \%}$ & $\mathbf{4 6}$ & $\mathbf{1 0 0 \%}$ & $\mathbf{1 5 5}$ & $\mathbf{1 0 0 \%}$ & $\mathbf{1 8 7}$ & $\mathbf{1 0 0 \%}$ \\
\hline
\end{tabular}




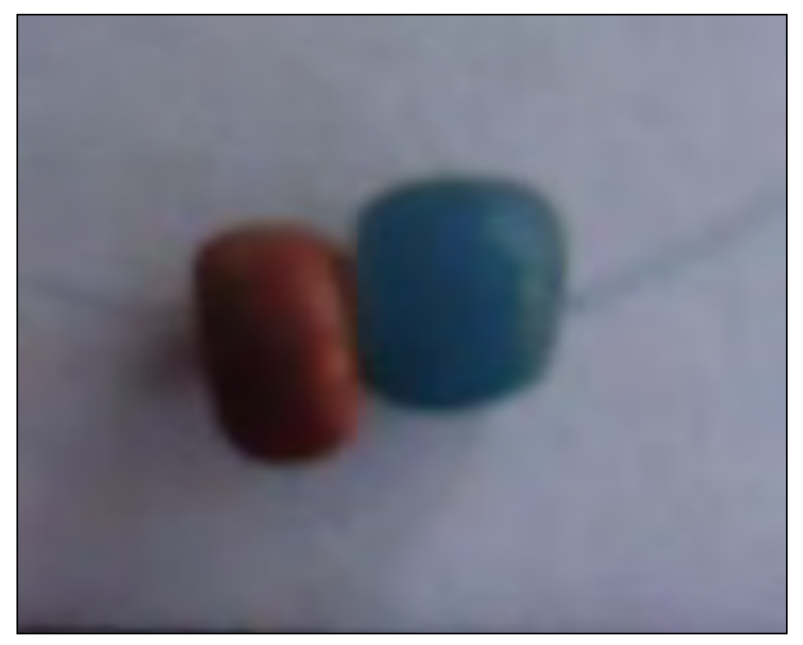

Figure 6.4: An Indian red cylinder and a cerulean blue oblate.

In terms of sizes, small beads dominated the assemblage, accounting for $59.38 \%$. Also, in each individual excavation unit, the small-sized beads were dominant, accounting for more than the assemblage per excavation unit. Medium-sized beads formed only $14.96 \%$, while only 3 beads $(0.71 \%)$ could be classified as large. However, it is interesting to note that, irrespective of the dominance of one bead shape in one excavation area compared to another, overall the five excavated areas all had the three dominant glass-bead shapes, albeit in different proportions. This is significant in that it reflects a distribution that is even across the various parts of the site.

Table 6.15: Distribution of glass bead sizes.

\begin{tabular}{|l|l|l|l|l|l|l|l|l|l|l|l|l|l|}
\hline & \multicolumn{2}{|l|}{ Midden 1 } & \multicolumn{2}{l}{ Midden 2 } & \multicolumn{2}{l|}{$\begin{array}{l}\text { Museum } \\
\text { Midden 1 }\end{array}$} & \multicolumn{2}{l|}{$\begin{array}{l}\text { Museum } \\
\text { Midden 2 }\end{array}$} & \multicolumn{2}{l|}{$\begin{array}{l}\text { Porth } \\
\text { Mlatform }\end{array}$} & \multicolumn{2}{l|}{ Total } \\
\hline Minute & 46 & $43.40 \%$ & 22 & $27.16 \%$ & 2 & $6.06 \%$ & 2 & $4.35 \%$ & 33 & $21.29 \%$ & $\mathbf{1 0 5}$ & $\mathbf{2 4 . 9 4 \%}$ \\
\hline Small & 50 & $47.17 \%$ & 45 & $55.56 \%$ & 18 & $54.55 \%$ & 27 & $58.70 \%$ & 110 & $70.97 \%$ & $\mathbf{2 5 0}$ & $\mathbf{5 9 . 3 8 \%}$ \\
\hline Medium & 8 & $7.55 \%$ & 14 & $17.28 \%$ & 13 & $39.39 \%$ & 16 & $34.78 \%$ & 12 & $7.74 \%$ & $\mathbf{6 3}$ & $\mathbf{1 4 . 9 6 \%}$ \\
\hline Large & 2 & $1.89 \%$ & 0 & $0 \%$ & & & 1 & $2.17 \%$ & 0 & $0 \%$ & $\mathbf{3}$ & $\mathbf{0 . 7 1 \%}$ \\
\hline Totals & $\mathbf{1 0 6}$ & $\mathbf{1 0 0} \%$ & $\mathbf{8 1}$ & $\mathbf{1 0 0} \%$ & $\mathbf{3 3}$ & $\mathbf{1 0 0 \%}$ & $\mathbf{4 6}$ & $\mathbf{1 0 0 \%}$ & $\mathbf{1 5 5}$ & $\mathbf{1 0 0 \%}$ & $\mathbf{4 2 1}$ & $\mathbf{1 0 0 \%}$ \\
\hline
\end{tabular}


Close to three quarters of the assemblage was classified as short, while just over $20 \%$ were classified as standard. In total, these two sizes made up $97 \%$ of the assemblage.

Table 6.16: Length ratio designations for glass beads from Khami.

\begin{tabular}{|l|l|l|l|l|l|l|l|l|l|l|l|}
\hline & \multicolumn{3}{|l}{ Midden 1 } & \multicolumn{3}{l|}{ Midden 2 } & \multicolumn{3}{l|}{ Museum Midden } & \multicolumn{2}{l}{$\begin{array}{l}\text { North } \\
\text { Midden }\end{array}$} \\
\hline Disc & & & & & & & 27 & $17.42 \%$ & 27 & 7 \\
\hline Short & 77 & $72.64 \%$ & 62 & $76.54 \%$ & 44 & $95.65 \%$ & 128 & $82.58 \%$ & 311 & 80 \\
\hline Standar & 27 & $25.47 \%$ & 16 & $19.75 \%$ & 2 & $4.35 \%$ & & & 45 & 12 \\
\hline Long & 2 & $1.89 \%$ & 3 & $3.70 \%$ & & & & & 5 & 1 \\
\hline Totals & $\mathbf{1 0 6}$ & $\mathbf{1 0 0} \%$ & $\mathbf{8 1}$ & $\mathbf{1 0 0} \%$ & $\mathbf{4 6}$ & $\mathbf{1 0 0} \%$ & $\mathbf{1 5 5}$ & $\mathbf{1 0 0 \%}$ & $\mathbf{3 8 8}$ & $\mathbf{1 0 0}$ \\
\hline
\end{tabular}

\subsection{DISCUSSION}

The above description of the beads from Khami conforms to the description by Wood (2005: 56) as belonging to the Khami Indo-Pacific period. On Midden 1 Trench 2, minute-sized translucent Prussian blue beads were found in the lower levels, together with light green oblates and yellow cylinders. Yellow-coloured beads appear in the lower levels of all the excavations at the site. The upper levels had dark green and opaque cerulean-blue beads, and an individual black bead. This was the same trend on Midden 2 Trench 1, with the addition of cobalt turquoise in the upper levels. In contrast to Midden 1 and Midden 2, cerulean blue occurs throughout the whole levels of North Platform Midden 1 trench. The middle to upper levels also included cobalt turquoise, green, yellow and Prussian blue oblates. Museum Midden 1 Trench 1 had Prussian blue, light green and cerulean blue at the lower levels, and these were found throughout the stratigraphy. On Museum Midden 2 Prussian blue and cerulean blue were the earliest. Cobalt blue and black make an appearance in the middle levels. Radiocarbon dates from Museum Midden 2, Level 13 (Figure 4.12), show that the site was associated with glass beads from the formative years in the early fifteenth century.

In his excavation of two houses on the Northwest Ridge, Hughes (1997: 11) recorded 516 glass beads, of which over $80 \%$ were recovered from the floors of the houses he excavated. Most of the bead colours that he recovered were also noted in the current excavations. Robinson's (1959) glass beads, while similar to those recovered during this study, do not have contextual information, making it difficult to draw comparisons with those that were 
recovered from my excavations. An interesting observation is that other studies have noted the presence of the Indo-Pacific beads over a wide area that includes Great Zimbabwe (Chirikure et al. 2016; Pikirayi 2013; Pwiti 1996). This suggests that there was a much wider participation in the international trade by polities on the southern Zambezia that included the Mutapa state, Great Zimbabwe and the Butua state. This is important in so far as understanding the relationships among the various Zimbabwe culture states, an issue that I will return to later in Chapter 9.

Bvocho (2005) has argued for a move away from the traditional approach of looking at beads in isolation, without contextualising them within the social history of the societies in which they were found. Using ethnographic parallels from Shona communities in Zimbabwe, he has shown that glass beads played a very important social role in the lives of the Shona people. This is reflected in the range of ceremonial, religious and everyday objects that the Shona made with glass beads. Objects such as walking sticks, daggers, spears, and wooden snuffboxes could be decorated with glass beads to form various motifs, including chevron patterning and triangles (Bvocho 2005:420). Glass beads were also used by women in the manufacturing of a range of products that reflected their social status. For instance, white bead necklaces were meant to signify the purity of mature virgin women ready for marriage (Bvocho 2005:420). These ethnographic parallels illustrate the various roles that beads potentially played at Khami.

\subsection{SUMMARY}

This chapter has shown that the distribution of glass beads was uniform across the site. As such, glass beads were not part of a material culture that had restrictions placed on it in terms of access and use by members of the community at Khami. It appears that even those who lived outside the stone-walled areas had equal access to glass beads. The recovery of more glass beads from the built-up areas should hardly be a surprise. Most of the early excavations at Khami targeted collapsed houses and house floors (Robinson 1959; Hughes 1997). Such contexts tend to yield more material culture that would have been left over by the last occupants of the site. This is in contrast to the middens, which were essentially refuse material. The beads recovered from the middens would in most instances have been swept away, probably during cleaning processes, and discarded with any other refuse material from 
the household. It has also been noted that the multilayered ritual and social importance of glass beads kept them in circulation for a long period of time after their manufacture; for this reason, their full temporal distribution might be difficult to know (DeCorse 1989). The presence of glass beads will therefore be combined with other datasets to build a chronology of the site. 


\section{CHAPTER 7: FAUNAL ANALYSIS}

\subsection{INTRODUCTION}

The excavations at Khami generated abundant faunal remains that make it possible to reconstruct significant information relating to the animal economy at the site. Faunal remains provide material evidence of the diets of the people who lived at Khami and of which animals were killed and consumed at the site (Klein and Cruz-Uribe 1984). This allows us to understand the animals that were exploited, which is an indicator of the economic activities at the site. For instance, a high rate of cattle remains would mean that cattle were probably an important component of the economy. On the other hand, a high rate of wild-animal remains would suggest an economy that was also hinged on hunting. As such, in the analysis, the question of relative species diversity and abundance was dealt with, as a way of understanding the range of species exploited. The faunal analysis also sought to explore the similarities and differences in two different zones of the site: a walled and a non-stone-walled settlement area. Consequently, I analysed material from two excavated areas: the North Platform Midden, associated with the stone-walled settlement area, and Midden 2, associated with the non-stone-walled settlement. Generally, cattle dominated in terms of species abundance in both middens. Wild animal species were also recorded on both middens, although Midden 2 had much fewer animals recorded compared to the North Platform Midden. Interestingly, the North Platform Midden also had a high incidence of cranial and foot-bone material, which are generally assumed to have been reserved for non-elites (Fathereley 2009).

\subsection{OVERVIEW OF FAUNAL STUDIES IN SOUTHERN AFRICAN ARCHAEOLOGY}

Faunal studies in the region have focused on a number of issues, such as the use of animal bones in tool manufacture, ornaments and rituals (MacIver 1906; Cooke and Robinson 1954; Robinson 1959; Voigt 1983; Thorp 1984; 1995; Murray and Manyanga 2008). Evidence from a number of both Stone Age and Iron Age sites in the region bear testimony to the important role that bones played after discard, as they were remanufactured into various tools (Cooke and Robinson 1954; Voigt 1983). These include whistles made from tubular bone, rib bone 
used as skin preparers, bone-arrow points and ornaments made from the bone tubes of various animal species. The presence of certain faunal-species remains at some sites has been interpreted to reflect ritual and cultural practices. At koBulawayo, Murray and Manyanga (2008) have interpreted the presence of otter, pangolin, aardvark, python and raptor skeletal material as evidence of such practices, while at Murahwa, a large cache of worked metapodials of common duiker has been linked to traditional healing activities (Shenjere 2006).

Faunal studies have also been used to show the presence of social stratification in precolonial southern African societies (Thorp 1995; Fatherely 2009). Thorp (1995) argued that social stratification at Great Zimbabwe was reflected through a high proportion of fauna from young animals at the Hill Complex midden. This was distinct from the commoner areas, which had higher proportions of older animals. She thus concluded that the elite preferred consuming tender meat from young cattle, and that this could be used as a basis for social stratification at prehistoric sites. However, due to a lack of ethnographic parallels in the region on this practice, Shenjere-Nyabezi et al. (2013) have argued this finding could be a reflection of the consumption patterns associated with ceremonial activities, where young bulls were slaughtered and consumed during rituals conducted at the site.

Human and environment relationships have also been understood through faunal studies (Manyanga 2000; 2001; 2007). In his study in south-eastern Zimbabwe, Manyanga concluded that there was a dynamic relationship between farming communities and their environment; humans took advantage of opportunities presented by the environment and also learnt to adapt to the vagaries of its constraints. Both hunting and herding were seen to be important in the diets of the inhabitants of the area, as reflected in the faunal sample composition from the excavated areas. The importance of both hunting and herding in southern Africa's Iron Age communities is also reflected at a number of sites, such as Kasekete in northern Zimbabwe (Pwiti and Mawoko 1997), the Shashe-Limpopo valley (Voigt 1983), and northern Botswana (Denbow 1984). Recent research is also focusing on the exploitation of animal resources by humans in varied environments, particularly those that were considered to be inhospitable to human beings (Manyanga 2000; 2001; 2007). This has the potential to deep our knowledge of 
animal-resource demographic trends (Manyanga 2006: 183). For instance, Manyanga (2006) has suggested that the prevalence of wild-animal bones at the site of Mwenezi Farm reflects a declining environment that could not support the development of cattle herds.

Faunal remains have also formed an important part of reconstructing cultural lifeways in relation to animal-meat procurement, consumption, and discard patterns. In her analysis of the faunal sample from Murahwa Hill, Shenjere (2006) has shown that there was differential animal-resource exploitation over time. The Early and Later Farming Communities at the site had a variety of wild species and few domestic stock. This was in comparison to the Refuge Period at the site, which had numerous remains of domestic stock in relation to wild species, indicating a growing move towards herding, with hunting complementing their diet. This trend has also been noted at various other sites, such as in the Shashe Limpopo Basin (Voigt 1983; Manyanga 2001; 2006) and northern Zimbabwe (Pwiti 1996). Pwiti (1996) and Pwiti and Mawoko (1997) have shown that domestic stock, in particular cattle, did not play a major role in the economy of the early farming community at Kadzi. This contrasts with the late farming community at Kasekete, where cattle became the mainstay of the economy. The animal economy of Danangombe was also reconstructed by Tapfuma (2010) through faunal analysis of remains from the site. Her analysis showed that herding was an important element of the economy at Danangombe, although it was supplemented by the occasional hunting of food animals such as kudu, hartebeest, zebra, and rock rabbit.

The above synthesis has shown that faunal studies have come a long way in the region and have contributed a great deal to our better understanding of the economies of prehistoric societies in southern Africa. The discipline's potential-particularly when techniques from the natural sciences are harnessed to investigate archaeological concerns-has also been recognised, and is being applied to many case studies in the region. The following section describes the animal species that have been recorded in the recent historic past around Khami. This discussion is important, since it allows comparisons to be made with the archaeological record and with the trends in species present. 


\subsection{CURRENT SPECIES DISTRIBUTION AROUND KHAMI}

This study benefitted from a number of studies that were done to understand the animalspecies distribution of the area around Khami and south-western Zimbabwe in particular. These studies include those by early hunters in southern Africa, such as Frederick Selous, as well as biodiversity monitoring projects by a number of institutions in the region (Smithers and Wilson 1979; Smithers 1966; Selous 1890; Roberts 1951). Various species have been recorded as occurring in the south-western parts of Zimbabwe. These include Raphicerus campestris, Sylvicapra grimma, Aepyceros melampus, Hippotragus niger and Taurotragus oryx. Syncerus caffer, Connochaetes taurinus, Tragelaphus strepsiceros and Tragelaphus scriptus had sparse distribution in south-western Zimbabwe. Vegetation preference for some of the recorded species is also typical of the vegetation environment around Khami (Ndoro and Pwiti 1999). The open mopane and Acacia woodland is preferred by Raphicerus campestris, Aepyceros melampus and Tragelaphus strepsiceros. In addition to the above habitats, other species also survive in Terminalia and Brachystegia woodlands. These include Sylvicarpa grimma and Hippotragus niger. All these habitats are found in south-western Zimbabwe, in the vicinity of Khami. Early hunters such as Baines and Selous also recorded sightings of large herds of Taurotragus oryx and Syncerus caffer throughout their journeys on the plateau (Smithers and Wilson 1979; Selous 1890).

\subsection{METHODOLOGY}

Preliminary sorting of the faunal material was conducted in the field, where the fauna was bagged separately from other cultural material such as pottery and beads. The faunal material was cleaned with a soft brush and further sorted at the Natural History Museum of Zimbabwe Mammalogy Laboratory. Various scholars have come up with different methodologies for the analysis of bone samples from archaeological sites (Voigt 1983; Klein 1984; Manyanga 2001). In this study, I have followed the methodology employed by Manyanga (2001). At the museum, the material was broadly categorised as "identifiable" or "non-identifiable". Identifiable remains include bovid teeth, bovid post-cranial material and non-bovid material (Klein and Cruz-Uribe 1984:17). The non-identifiable material included the following skeletal components: vertebra; rib fragments; bone flakes; skull fragments; and miscellaneous fragments (Klein and Cruz-Uribe 1984:17). These were counted and weighed, and any bone 
modifications, such as cut marks, were identified and recorded. The identifiable sample was also bagged separately in preparation for further analysis.

A variety of attributes were noted in the identifiable faunal sample, and these were recorded on a recording sheet. The attributes include species, size, category, condition of the sample, metric attributes, orientation, age, the presence or absence of butchery marks, bone modification and damage. The metric attributes of complete faunal samples were recorded following standard dimensions, as suggested by von den Driesch (1976). It was also important to note the bone-surface modifications, as these provide one of the most secure confirmations of the involvement of humans with a bone assemblage (Voigt 1983; Fisher 1995; Manyanga 2000).

Bovine samples that were too fragmentary for positive identification were assigned to one of the four bovine classes, as shown below (Table 7.3). However, scholars have had different approaches to bovine classification: in certain instances, scholars assign one species to different body-size groups (Brain 1981; Manyanga 2000), while in others, scholars split one body size group into sub-groups (Voigt 1979). Indeed, some scholars have come up with five body-size groups while others have come up with four (Brain 1974; Plug 1999; Manyanga 2000). In this study, I have used Manyanga's (2001) bovine-classification system as outlined in Table 7.1.

The estimation of taxonomic abundance was performed by counting the Number of Identifiable Specimens (NISP). This process is based on the assumption that the number of identifiable skeletal parts of those species in a particular sample reflects the relative abundance of those species in the sample (Klein and Cruz-Uribe 1984). The shortcoming of this method is the overrepresentation of species with more skeletal parts than those with fewer skeletal elements (Manyanga 2001:47). The method also tends to over-represent those species with skeletal parts that are easily identifiable (Manyanga 2000; 2001:47). The other method is the Minimum Number of Individuals (MNI), which denotes the minimum expected number of animals in the excavated sample. This number is based on the occurrence of the 
most abundant skeletal part of each species in the sample. MNI also takes into account the orientation, size, age and sex of the species represented. Its major shortcoming is its extreme conservatism, and its inclination to exaggerate species represented by small NISP (Klein and Cruz-Uribe 1984; Plug 1990).

Table 7.1: Class sizes for bovid species found in Zimbabwe (Manyanga 2001).

\begin{tabular}{|l|l|}
\hline Bovid Size Class & Species \\
\hline Bov I (Small) 0-23kg & $\begin{array}{l}\text { Common duiker (Sylvicapra grimmia) } \\
\text { Steenbok (Raphicerus campestris) } \\
\text { Klipspringer (Oreotragus oreotragus) }\end{array}$ \\
\hline Bov II (Medium) 23-84 kg & $\begin{array}{l}\text { Bushbuck (Tragelaphus scriptus) } \\
\text { Impala (Aepyceros melampus) } \\
\text { Sheep (Ovis aries) }\end{array}$ \\
\hline Bov III (Large) $84-296 \mathrm{~kg}$ & $\begin{array}{l}\text { Goat (Capra hircus) } \\
\text { Blue wildebeest (Connochaetes taurinus) } \\
\text { Tsessebe (Damaliscus lunatus) }\end{array}$ \\
& $\begin{array}{l}\text { Sable (Hippotragus niger) } \\
\text { Waterbuck (Kobus ellipsiprymnus) } \\
\text { Cattle (Bos Taurus) }\end{array}$ \\
\hline Bov IV (Very Large) $>296 \mathrm{~kg}$ & $\begin{array}{l}\text { Buffalo (Syncerus caffer) } \\
\text { Eland (Tragelaphus oryx) }\end{array}$ \\
\hline
\end{tabular}

\subsection{KHAMI FAUNAL ASSEMBLAGE}

Tables 7.2 and 7.3 give a breakdown of the skeletal-part representation and proportion of identifiable to non-identifiable fauna, respectively. A total of 715 faunal samples were classified as identifiable to either the species level or the much broader Bovid class. This was $10.23 \%$ of the total bone assemblage of the 6986 collected from the two middens. The sample from North Platform Midden had a higher rate (13.26\%) of identifiable material, as compared to Midden 2 Trench 1 (6.93\%) and Trench 2 (9.29\%). For this analysis, identifiable samples include tooth enamel and identifiable bone (Table 7.2). 
Table 7.2: Bone count of the Khami faunal assemblage according to skeletal part. Tooth enamel as well as identifiable bone were the two skeletal compositions that were used in identifying species representation.

\begin{tabular}{|c|c|c|c|c|c|c|c|c|}
\hline \multirow[b]{3}{*}{ Skeletal part } & \multirow{2}{*}{\multicolumn{2}{|c|}{$\begin{array}{ll}\text { North } & \text { Platform } \\
\text { Midden Tr. } 1 & \end{array}$}} & \multicolumn{4}{|l|}{ Midden 2} & \multirow{2}{*}{\multicolumn{2}{|c|}{ Total }} \\
\hline & & & \multicolumn{2}{|l|}{ M2 Tr. 2} & \multicolumn{2}{|l|}{ M2Tr. 1} & & \\
\hline & No. of bones & Weight & No. of bones & Weight & No. of bones & Weight & No. of bones & Weight \\
\hline Miscellaneous fragments & 13 & 170 & 4 & 10 & 0 & 0 & 17 & 180 \\
\hline Vertebra & 172 & 2186.8 & 63 & 647.7 & 33 & 74 & 268 & 2908.5 \\
\hline Rib Fragments & 540 & 4589.1 & 322 & 2486.6 & 187 & 600 & 1049 & 7675.7 \\
\hline Tooth enamel & 98 & 689.5 & 72 & 318.6 & 26 & 336 & 196 & 1344.1 \\
\hline Bone flakes & 1634 & 8052.7 & 1119 & 5338.12 & 1824 & 2661 & 4577 & 16051.8 \\
\hline Skull fragments & 231 & 1627.06 & 92 & 594.4 & 37 & 85 & 360 & 2306.46 \\
\hline Identifiable bone & 298 & 5989.65 & 92 & 1808.2 & 129 & 736 & 519 & 8533.85 \\
\hline TOTAL & & & & & & & 6986 & 39000.4 \\
\hline
\end{tabular}

Table 7.3: Bone count according to identifiable and non-identifiable samples

\begin{tabular}{|l|l|l|l|l|l|l|l|l|l|l|l|l|l|l|l|l|}
\hline & \multicolumn{1}{|l|}{ North Platform Midden Tr. 1 } & \multicolumn{3}{l|}{ Midden 2 Tr. 2 } \\
\hline Sample Type & $\begin{array}{l}\text { Bone } \\
\text { Count }\end{array}$ & Total \% & Mass (g) & Total \% & $\begin{array}{l}\text { Bone } \\
\text { Count }\end{array}$ & Total \% & Mass (g) & Total \% & $\begin{array}{l}\text { Bone } \\
\text { Count }\end{array}$ & Total \% & Mass (g) & Total \% & $\begin{array}{l}\text { Bone } \\
\text { Count }\end{array}$ & Total \% & Mass (g) & Total \% \\
\hline Total Identifiable & 396 & 13.26 & 5989.65 & 25.7 & 164 & 9.29 & 1808.2 & 16.14 & 155 & 6.93 & 736 & 16.38 & 715 & 10.23 & 8533.85 & 21.88 \\
\hline Total Non-Identifiable & 2590 & 86.74 & 17315.2 & 74.3 & 1608 & 90.71 & 9395.42 & 83.86 & 2081 & 93.07 & 3756 & 83.62 & 6279 & 89.77 & 30466.6 & 78.12 \\
\hline TOTAL & $\mathbf{2 9 8 6}$ & $\mathbf{1 0 0}$ & $\mathbf{2 3 3 0 4 . 8}$ & $\mathbf{1 0 0}$ & $\mathbf{1 7 6 4}$ & $\mathbf{1 0 0}$ & $\mathbf{1 1 2 0 3 . 6}$ & $\mathbf{1 0 0}$ & $\mathbf{2 2 3 6}$ & $\mathbf{1 0 0}$ & $\mathbf{4 4 9 2}$ & $\mathbf{1 0 0}$ & $\mathbf{6 9 8 6}$ & $\mathbf{1 0 0}$ & $\mathbf{3 9 0 0 0 . 4}$ & $\mathbf{1 0 0}$ \\
\hline
\end{tabular}

The faunal assemblage from the North Platform Midden 1 excavation showed that both domestic and wild species were exploited (see Figure 7.1; Table 7.4). The domestic species include Bos taurus and Ovis/Capra. Wild-game species included Sylvicarpa grimma, Aepyceros melampus, tragelaphus scriptus, tragelaphus strepsiceros, hippotragus niger, connochaetes taurinus, damaliscus lunatus, taurotragus oryx and syncerus caffer. Rodents were also recovered in the excavation, including heterohyrax brucei, procavia capensis, lepus saxatilis, and paracynictis selousi. The remains of a tortoise were also identified.

There was a general trend that was noted in terms of species abundance in the stratigraphy of North Platform Midden trench. The domestic species, Bos taurus and Ovis/Capra, had high levels of incidence at all levels. This is reflected in the weight of Bos Taurus recovered 
(Figure 7.1; Table 7.4). The important role of domestic animals in precolonial southern Africa has been particularly emphasised. This is seen at Great Zimbabwe (Garlake 1978; Beach 1980; Thorp 1995), in the Shashe-Limpopo valley (Voigt 1983; Manyanga 2000; 2001; 2007) and the Mutapa state (Mudenge 1974; 1988; Beach 1980) among many others. One wild species, Syncerus caffer, was also found to be common in all levels of the trench, indicating that it was probably an important source of livelihood for the Khami inhabitants. According to Selous (1890) and Baines (quoted in Smithers and Wilson 1979), Syncerus caffer occurred widely on the precolonial Zimbabwe plateau in large herds of over a thousand. This wide distribution in large numbers could possibly explain why it was recovered in all levels of the excavation. In his research at Kadzi, an early Iron Age site in northern Zimbabwe, Pwiti (1996) also noted the dominance of Syncerus caffer among the wild species recorded at the site. This contrasted with the Late Iron Age site of Kasekete, where cattle appeared to dominate, indicating a greater reliance on animal husbandry in the Late Iron Age, although hunting was still practiced (Pwiti and Mawoko 1997). However, it appears that at Khami Syncerus caffer continued to be an important dietary source, even with the increased importance of domesticated stock.

Some of the species had an irregularly occurring pattern, characterised by presence in between the two and four levels (Table 7.4). These were Sylvicapra grimma (L3, L4, L8), Aepyceros melampus (L8, L10), Tragelaphus strepsiceros (L2, L4, L7, L10), Hippotragus niger (L5, L8), Damaliscus lunatus (L2, L6, L10), Procavia capensis (L3, L7). Other species were once-off occurring. These include Racipherus campestris, Tragelaphus scriptus, Taurotragus oryx, Paracynictis selousi and Tortoise. 


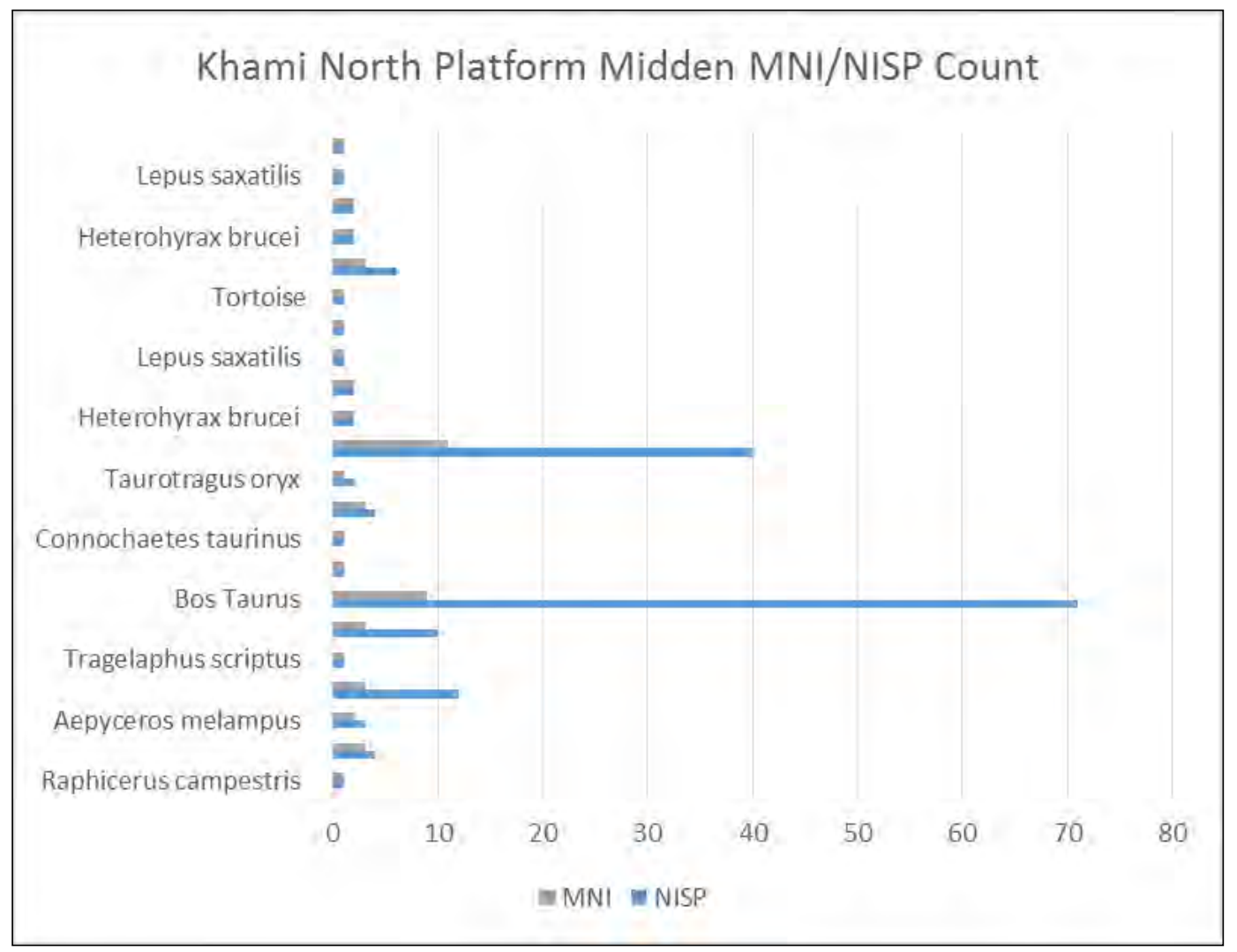

Figure 7.1: NISP/MNI count for assemblage from the North Platform Midden.

Table 7.4: Summary of faunal species from North Platform Midden 1 Trench 1 according to excavation level.

\begin{tabular}{|l|l|l|l|l|l|l|l|l|l|l|l|l|}
\hline Species & L1 & L2 & L3 & L4 & L5 & L6 & L7 & L8 & L9 & L10 & L11 & L12 \\
\hline Ovis/Capra & 2 & & 1 & 1 & 1 & 1 & & 1 & 2 & 2 & & \\
\hline Bos Taurus & 3 & 1 & 2 & 12 & 15 & 5 & 5 & 4 & 5 & 13 & 3 & \\
\hline Syncerus caffer & & 1 & 1 & 2 & 5 & 4 & 2 & 2 & 5 & 9 & 3 & 2 \\
\hline Tragelaphus strepsiceros & & 2 & & 8 & & & 1 & & & 3 & & \\
\hline Damaliscus lunatus & & 1 & & & & 1 & & & & 1 & & \\
\hline Raphicerus campestris & & & 1 & & & & & & & & & \\
\hline Conochaetes gnou & & & 1 & & & & & & & & & \\
\hline Procavis capensis & & & 1 & & & & 2 & & & & & \\
\hline Paracynitis selous & & & 1 & & & & & & & & & \\
\hline Sylvicapra grimmia & & & 1 & & & & & 1 & & 1 & & \\
\hline Aepyceros melampus & & & & 1 & & & & 2 & 2 & 2 & & \\
\hline Hippotragus niger & & & & & 1 & & & 1 & & & & \\
\hline Tortoise & & & & & & 1 & & & & & & \\
\hline Taurotragus oryx & & & & & & & & & 1 & & & \\
\hline Heterohyrax brucei & & & & & & & & & & 1 & & \\
\hline Lepus saxatilis & & & & & & & & & & 1 & & \\
\hline Bird & & & 2 & & & & & & & & & \\
\hline Bov I & 1 & & 1 & & & & & & & & & \\
\hline Bov II & & & & & & & & & & 2 & & \\
\hline Bov III & 14 & 14 & 11 & 18 & 11 & 7 & 8 & 23 & 29 & 1 & 1 \\
\hline
\end{tabular}


Analysis of the Midden 2 assemblage also revealed the presence of both domestic and wild species. Bos taurus as well as Ovis/Capra were recorded and were noted to have been exploited more than wild animals (Table 7.5; Figure 7.2; Table 7.7). The wild species recorded were Raphicerus capestris, Aepyceros melampus, Tragelaphus strepsiceros, Damaliscus lunatus and Syncerus caffer. Bos taurus was the most exploited species as reflected in the bone-mass count (323.90g) (Table 7.3).

Table 7.5: Summary of faunal species from Midden 2 Trench 1 according to excavation level.

\begin{tabular}{|l|l|l|l|l|l|l|l|l|l|l|l|l|l|l|l|}
\hline Spe cies & L1 & L2 & L3 & L4 & L5 & L6 & L7 & L8 & L9 & L10 & L11 & L12 & L13 & L14 & L15 \\
\hline Ovis/Capra (sheep/goat) & & 2 & & & & 1 & & 1 & & & & & & & \\
\hline Bos Taurus (Cow) & & 7 & & 8 & & 8 & 6 & 3 & & & & 3 & & 6 & \\
\hline Syncerus caffer (Buffalo) & & & & & & & & 1 & & & & & & & \\
\hline Tragelaphus strepsiceros (Kudu) & & & & & & & & & & 1 & & & & & \\
\hline Raphicerus campestris (Steenbok) & & & & & & & & & & & & & & 1 & \\
\hline Aepyceros melampus (Impala) & & & & & & & & & & 1 & & & & & \\
\hline Hippotragus niger (Sable) & & & & & & & & & & & & & & & \\
\hline Bov III & 10 & & 8 & & & 4 & & 3 & & 1 & 2 & 4 & & 6 \\
\hline
\end{tabular}

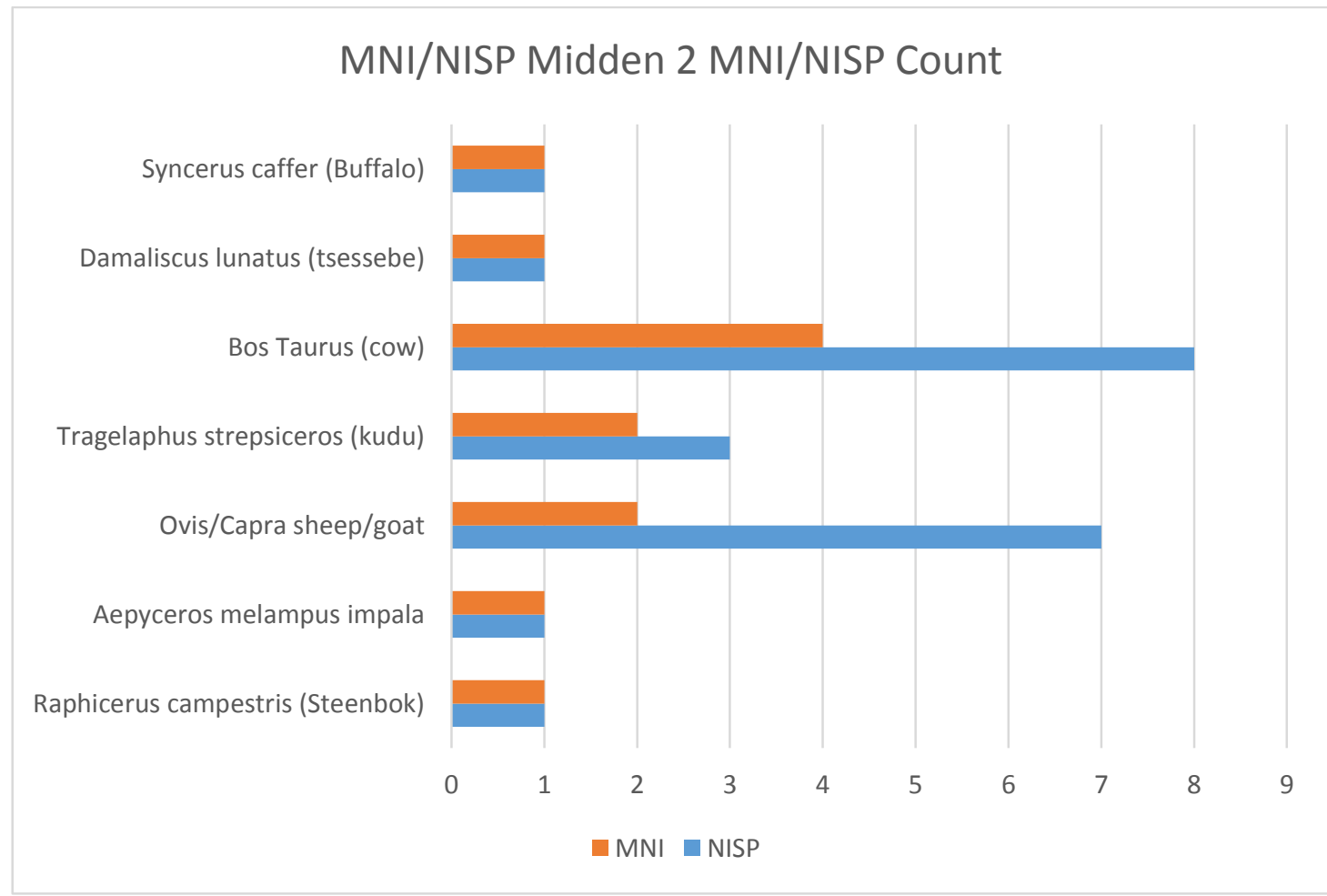

Figure 7.2: NISP/MNI count for the assemblage from Midden 2. 
Table 7.6: Weights of the exploited animals at Khami North Platform Midden 1 by Bovid class.

\begin{tabular}{|l|l|l|l|l|}
\hline SPECIES & NISP & QSP & MNI & MASS \\
\hline Bov I & & & & gram \\
\hline Raphicerus campestris (Steenbok) & 1 & 1 & 1 & 3.8 \\
\hline Sylvicarpa grimma (duiker) & 4 & 8 & 3 & 33.5 \\
\hline Total & & & & $\mathbf{3 7 . 3}$ \\
\hline Bov II & & & & \\
\hline Aepyceros melampus (impala) & 3 & 3 & 2 & 20.3 \\
\hline Ovis/capra (sheep/goat) & 12 & 13 & 3 & 189.3 \\
\hline Tragelaphus scriptus (Bushbuck) & 1 & 1 & 1 & 4.8 \\
\hline Total & & & & $\mathbf{2 1 4 . 4}$ \\
\hline Bov III & & & & \\
\hline Tragelaphus strepsiceros (kudu) & 10 & 5 & 3 & 174.5 \\
\hline Bos Taurus (cow) & 71 & 39 & 9 & 1790.5 \\
\hline Hippotragus niger (sable) & 1 & 1 & 1 & 16.2 \\
\hline Connochaetes taurinus (blue wildebeest) & 1 & 1 & 1 & 22.1 \\
\hline Damaliscus lunatus (tsessebe) & 4 & 2 & 3 & 61.9 \\
\hline Total & & & & $\mathbf{2 0 6 5 . 2}$ \\
\hline Bov IV & & & & \\
\hline Taurotragus oryx (Eland) & 2 & 2 & 1 & 139.6 \\
\hline Syncerus caffer (Buffalo) & 40 & 28 & 11 & 958.8 \\
\hline Total & & & & $\mathbf{1 0 9 8 . 4}$ \\
\hline
\end{tabular}

Table 7.7: Weights of the exploited animal species at Khami Midden 2 by Bovid Class.

\begin{tabular}{|l|l|l|l|r|}
\hline SPECIES & NISP & QSP & MNI & \multicolumn{2}{l|}{ MASS } \\
\hline BOV I & & & & gram \\
\hline Raphicerus campestris (Steenbok) & 1 & 1 & 1 & 15.6 \\
\hline Total & & & & $\mathbf{1 5 . 6}$ \\
\hline BOV II & & & & 1 \\
\hline Aepyceros melampus (impala) & 1 & 1 & 1 & 114.1 \\
\hline Ovis/capra (sheep/goat) & 7 & 8 & 2 & $\mathbf{1 1 5 . 1}$ \\
\hline Total & & & & \\
\hline BOV III & & & & 153.9 \\
\hline Tragelaphus strepsiceros (kudu) & 3 & 2 & 2 & 323.9 \\
\hline Bos Taurus (cow) & 8 & 9 & 4 & 95.8 \\
\hline Damaliscus lunatus (tsessebe) & 1 & 1 & 1 & $\mathbf{5 7 3 . 6}$ \\
\hline Total & & & & \\
\hline BOV IV & & & & 1.5 \\
\hline Syncerus caffer (Buffalo) & 1 & 1 & 1 & $\mathbf{1 . 5}$ \\
\hline Total & & & & \\
\hline TOTAL & & & & $\mathbf{7 0 5 . 8}$ \\
\hline
\end{tabular}


The analysis also shows that Bovid III animals were more exploited than any other class. The important role of the domestic Bos Taurus is also reflected in the large mass of its identifiable bone count. This trend has also been noted in other later faming communities, such as the Toutswe states in north-eastern Botswana (Denbow 1984), Great Zimbabwe (Thorp 1995) and Shashe Limpopo River basin sites (Voigt 1983; Manyanga 2006). As noted in Chapter 3 , the environment of south-western Zimbabwe is conducive to animal rearing due to the presence of good pasturage and reliable water supplies that would have sustained a cattle economy. This feature was also noted by the Portuguese in their journals: they showed concern about the locals' lack of interest in mining gold, which they attributed to their keen interest in tending to their cattle (Mudenge 1974; Beach 1980; van Waarden 2012).

Faunal assemblage from the two areas is comparable. The absence of certain species in the other area can be attributed to the limited excavation trenches carried out at each of the investigated areas, limited to $1 \mathrm{~m}^{2}$ for North Platform Midden 1 and $3 \mathrm{~m}^{2}$ for Midden 2. Both domestic and wild species were recorded in the two areas. While there was an expectation that there could be differences in the species exploited, this was not the case. Interestingly, the assemblage from both areas had a significant amount of skeletal parts from the cranium as well as the lower leg and foot bones. Some researchers (Fatherely 2009) have argued that cranial and lower leg/foot bone were reserved for herdsmen. This, however, does not tally with their recovery in the North Platform Midden excavation, which is associated with the elite class because of its stone walling and other attributes.

\subsection{DISCUSSION}

The faunal analysis has shown the widespread exploitation of cattle at the site, based on bone count and the frequency of cattle remains in the stratigraphic record. This point is noted both horizontally and vertically across the sampled units. It has been shown in the past that cattle played an important role in the development of the economy at Khami (Beach 1980; Mudenge 1974). These historical sources have been corroborated by archaeological evidence, which shows that cattle were the most exploited in terms of animal consumption at the site (Thorp 1995). On the other hand, it was noted that wild species also supplemented the dietary requirements of the people at Khami. Evidence of wild animal species is sparse and is 
suggestive of a complimentary diet. These include the Syncerus caffer, which was noted to have been exploited more than other wild species. Midden 2 had a lower incidence of wild species. However, this could be a sampling issue, considering that only $6.93 \%$ of the assemblage was identifiable, compared to $13.26 \%$ from the North Platform Midden.

Thorp (1995) excavated a Hill Complex midden that had been excavated by Robinson (1959: 91) and recorded a huge number of faunal remains. The midden is located on the floor of the north-eastern slopes of the Hill Complex. Thorp targeted the midden because Robinson (1959) and Huffman (1981) had made an association between the Hill Complex and the midden. The midden also yielded a lot of domestic stock, with cattle accounting for $82.84 \%$ of the bone fragment from the Hill Complex midden. Other wild animals recorded included duiker, steenbok, klipspringer, jackal hyena, civet, genet, mongoose, wild cat, serval, leopard, lion, cheetah, antbear, dassie, zebra, wild pig, hare, guinea-fowl-sized bird, francolin-sized bird and tortoise. The midden content from Thorp's excavation contained a particularly high number of non-food animals. This finding was explained as the result of ritual activities that took place at the Hill Complex, particularly in House Cb1, which Robinson interpreted as the centre for ritual activities at the site, based on the nature of the objects he recovered there (Robinson 1959: 44-50; Thorp 1995: 58). These included divining bones and carved ivory lions. Using the ethnological collection of traditional healers at the Zimbabwe Museum of Human Science, Thorp managed to relate most of the non-food wild species recovered from the Hill Complex to the activities of ritual propitiation at the site. These faunal remains included tortoise, springhare, hare, jackal and genet. Small bovid horns recovered from the same context might also have been used for as medicine containers (Thorp 1995:61). Other species, such as the lion and leopard, were revered by leaders for their animal skin, which was worn as a symbol of authority and power.

The faunal analysis also included checking for the presence or absence of modification patterns like cut marks, tooth marks and burning on both the identifiable and non-identifiable assemblage. The results showed that there are very few faunal remains with modification marks. Modified bones constitute $1.99 \%$ of the total assemblage recovered at Khami. Cut marks were generally observed on ribs and shaft bones of large bovids. Midden 2 had a 
higher percentage of bone modification compared to North Platform Midden 1. Burnt bones were also recorded throughout the stratigraphy. There were no specific skeletal elements exposed to burning, as many of them belong to different body parts.

The role of cattle in the domestic economies in precolonial Zimbabwe has been explicated by a number of scholars (Garlake 1973; 1978; Mudenge 1974; 1988; Beach 1980; Hall 1986). Cattle were used as a form of wealth, and this was reflected in their use as brideprice. As a result, those who had many cattle were able to marry more than one wife and thus have a big family, which meant increased labour for various activities that sustained the household, such as agriculture, metalworking, construction, hunting and other craft-production activities (Hall 1986). Larger households also come with more influence in society, and the ability to command respect among members of society. This was an important element that potentially manifested in the creation of an elite class that came to construct and occupy the stone-walled platforms scattered at Khami. Mudenge (1974) has also noted that cattle could be loaned out to other less advantaged members of community to look after, in a system known locally as kuronzera. In this concept, the loaner retained ownership of the cattle but gave the borrower rights over use for draught power and proceeds of milk. The concept of kuronzera most likely had an important economic benefit for society at the site, as it meant that most households including the poor could fend for themselves based on the use of cattle loaned from others. While cattle played a major role as a form of wealth in the economy, wild-animal species were equally important in balancing the dietary needs of the people at Khami. Wild-animal species have other uses that are related to ritual activities that have been noted in traditional Shona society (Gelfand 1959; 1977). This involves the manufacturing of paraphernalia for traditional healers using certain skeletal parts from specific species and the use of particular bone parts for divination.

The majority of the identifiable material from the North Platform Midden was made up of teeth samples and foot bone. These include metatarsus, metacarpals, phalanges, and mandible. Some scholars have noted that faunal remains can be used to infer social status in the Zimbabwe Culture. Fatherely (2009: 28) has argued that cattle were distributed according to skeletal parts, depending on one's status in society or in relation to the one who is 
slaughtering the cattle. As a result, foot bones and cranial material are normally reserved for herdsmen, people who are thought to be of a lower status in society. As such, the presence of a concentration of certain skeletal parts, such as tarsus, metatarsus, carpus, metacarpus, crania, caudal vertebrae, phalanges and metapodials, is indicative of a commoner-occupation area (Fatherely 2009: 27). On the other hand, skeletal parts from the forequarter and the hindquarter, including vertebrae, scapula, limb bones, the pelvic girdle and ribs, are indicative of elite occupation (Fatherely 2009: 27). However, this is not reflected at Khami where skeletal remains from what Fatherely referred to as 'low status' share of meat have been recovered in the stonewalled areas, whilst skeletal parts associated with the elite have also been recovered in non-elite areas. Manyanga (2007) has noted that meat processing and discard behaviour impacts on what archaeologists recover. For instance, it is common in Shona society for males to congregate and have their meals together at a common meeting place, dare, and resultantly discard will be deposited in one area. This then makes it difficult to rely on faunal remains distribution patterns to understand class relations at Khami.

At the level of the Zimbabwe Culture, it has been noted that cattle dominated the diets of the occupants of most Zimbabwe Culture sites (Fagan 1966; Garlake 1972; 1974) At Great Zimbabwe, 98\% of the bone sample from the Western Enclosure were of cattle (Brain 1974). The important role of cattle has also been noted in the Leopard's Kopje communities of south-western Zimbabwe and north-eastern Botswana (Huffman 1974; Robinson 1966). Voigt (1983) has argued that cattle were an important element in the cementing of society at Mapungubwe and constituted more than half the animals represented. Van Waarden (1987; 2012) recorded the presence of large cattle posts in north-eastern Botswana. Cattle were kept and maintained for pasturage away from the rest of the community. The creation of such cattle posts was motivated by the need for pasturage that supported the growing herds and that could not be sustained close to the major settlement. For instance, at Matanga, a Khami phase cattle post in north-eastern Botswana, the site consisted of five kraals and a few grain bins. The kraals had a diametre of 10 to $25 \mathrm{~m}$ with ashy deposits 20 to $50 \mathrm{~cm}$ thick. This points to societies that emphasised the important role of cattle in their economies. 


\subsection{SUMMARY}

This chapter has shown that both wild and domestic species were exploited at Khami. However, there is evidence of increased exploitation of domestic species, particularly Bos Taurus, which indicates that cattle played an important role in the development and sustenance of the capital. The presence of Bos Taurus and Ovis/capra species at all the levels of the excavation trenches is also significant, as it reflects the important role that cattle played in sustaining the dietary needs of the people at Khami. As such, it appears that wild species played a complimentary role. However, the analysis has shown that the wild-animal species exploited were varied, reflecting a rich natural environment around Khami that had the potential to sustain varied wild species. Historical records also attest to the presence of most of the species recorded in the early days of the twentieth century, further corroborating the archaeological reference to the presence of those species. The important role of cattle is also mirrored in other Zimbabwe Culture capitals, such as Great Zimbabwe (Beach 1980; Garlake 1978; 1983; Thorp 1984; 1995), where cattle played an important role in the growth of the state. However, there was a range of activities carried out at the site that also contributed to its growth and development. These are discussed in the next chapter. 


\section{CHAPTER 8: CRAFT PRODUCTION AT KHAMI}

\subsection{INTRODUCTION}

Humans have always exploited their natural environments as part of their survival skills. This has resulted in humans coming up with a rich production industry, manufacturing a range of craft products that were key to their survival (Costin 2005). The inhabitants of Khami were no exception to this: they manufactured a range of objects for their own utilisation as well as for trading purposes with other groups, both locally and globally, through the Indian Ocean trade network. Some scholars have argued that this production industry resulted in the growth of a class of people specialising in various modes of craft production. In particular, scholars have sought to understand the organisation of craft production in the prehistoric era and how it contributed to the development of prehistoric societies (Costin and Hagstrum 1995; Costin 2005; Bandama et al. 2016). This chapter presents data related to the manufacturing and craft industry at Khami. A number of objects were recovered during the excavations that attest to a vibrant craft-production industry involving metalworking, cloth production, jewellery and tool manufacture. Recourse was also made to material collected by Robinson (1959) and MacIver (1906). The objects covered in this chapter include bone tools, ivory products and waste, spindle whorls used in the spinning of cotton, and metal objects, as well as evidence of metal processing at the site. The chapter sheds light not only on life at Khami but also on trade relations with Swahili and Portuguese traders from the Indian Ocean East Coast. The chapter begins with an overview of the studies on craft production in southern Africa and presents the evidence recovered from the present excavations as well as from previous investigations at the site. A discussion on the nature and organisation of craft production and its subsequent activities (such as trade) is also provided.

\subsection{UNDERSTANDING CRAFT PRODUCTION}

Studies of craft production have gained momentum over the years due to their importance in the broader study of material culture, economic organisation, socio-political organisation and exchange (Costin 2001; 2005; Hagstrum 2001; Bandama et al. 2016). Costin (2005: 1032) considers craft production as 'any transformational process involving skill, aesthetics and cultural meaning and consider the results of that crafting to be crafts'. Over the years, archaeologists working on craft production have normally considered tangible goods and 
portable objects to be craft goods. However, consideration is now also being given to nonportable material like architecture (Hagstrum 2001). Examples of craft objects that have been recognised in various contexts include ceramics, stone tools, ornaments, baskets, textiles, structural remains and metal objects. The study of craft production is important for a number of reasons. Firstly, craft-production studies are important in the reconstruction of the ancient lifeways of prehistoric communities. Craft-production studies also highlight the role of material culture in daily social and ritual life. Inferences can also be made about a variety of topics, including technology, material culture, economic organisation and social reproduction (Costin 2001).

In studying craft production, Costin (2005: 1035) has noted that there are a set of six constituent components that need to be taken into account. These are the artisans, the means of production, the organisation and social relations of productions, objects, relations of distribution, and consumers. This multilayered system calls for a broad contextualisation of craft production studies. Costin (2005) argues that production, distribution and consumption are interlinked. As such, they cannot be studied in isolation and are more useful when studied in relation to each other. This study considers production, distribution and consumption in an attempt to understand the nature of craft production at the site, based on an analysis of various material objects.

\subsection{OVERVIEW OF STUDIES ON CRAFT PRODUCTION IN SOUTHERN AFRICA}

As indicated earlier on, craft production materialises in the form of various objects and structures that archaeologists study in order to understand past societies (Costin 2005). In southern Africa, these varied material evidence of craft production have been noted at a number of sites and have been key in helping archaeologists interpret the development of these sites (Robinson 1959; Gardner 1963; Summers 1969; Garlake 1973; Huffman 1974; Voigt 1983; Swan 1994; van Waarden 2012). Examples of such crafts include worked bone, ivory objects and residue, spindle whorls, local ceramics, architectural structures, working tools, domestic utilitarian objects, and objects of adornment, as well as waste from various processing activities that took place at these sites. This section synthesises current understandings of precolonial craft production in southern Africa. In particular, attention is given to early studies on craft production, evidence of crafting, the organisation of craft 
production across the region, and the relationship between craft production and contact with the outside world.

Material evidence recorded at various sites in the region attests to crafting activity at these sites. In this regard, the importance of mining has been noted and recognised. Summers (1969) has shown that a number of areas in the region were mined for minerals like gold, copper and iron. These were processed and worked on to make a range of objects for local consumption or for trading with the Swahili and Portuguese from the Indian Ocean coast. Gold in particular was exchanged with traders from the Indian Ocean's east coast. The mineral was in high demand in Europe and other parts of Asia. Locally, gold was also used in the manufacturing of a range of products, particularly jewellery (Miller 2002). Its importance locally was noted through the fact that a number of high-status burials that have been recovered in the region, in particular at Mapungubwe, contained gold objects such as rings, necklaces and bangles (Gardner 1963; Miller et al. 2000; Miller 2002). Copper products were noted in the form of jewellery and other utilitarian objects like wires. The working of iron was also an important element of precolonial mining and metal working. Various scholars have shown that precolonial iron working took place at various places in the region from the Early Iron Age period (Childs and Dewey 1996; Miller 2002; Chirikure 2007). Iron was used in the manufacture of a range of objects that included jewellery, weaponry, building materials, farming equipment and domestic utilitarian utensils. The processing of all these minerals also produced debris which can be noted in the archaeological record and has been used by archaeologists to attest to metal working at various stages in the past. All this evidence from mining and mineral processing activities is evidence of crafting that was part of the economies of most prehistoric communities of southern Africa.

Crafting in the region was not only limited to mining and metal working. Ivory and ivory waste has been recovered from a number of sites in the region (MacIver 1906; Robinson 1959; Garlake 1973, Voigt 1983). At K2, the recovery of a major part of an ivory tusk has been used to show that ivory was brought raw to the site and processed there to come up with a number of objects. Robinson (1959) also recovered raw ivory in the Upper Passage of the Hill Complex at Khami. Raw ivory was particularly important as a trade item. It was sought 
out by Swahili and Portuguese traders from the Indian Ocean East Coast, who shipped it to the Far East and Europe, where it was in high demand (Mudenge 1988). However, as with gold, not all ivory was exchanged raw with traders. Evidence from various sites shows that the working of ivory occurred at various scales in the region. Some of the large-scale ivory working has been noted at sites such as KwaGandaganda, Ndondondwane, and Wosi (Coutu et al. forthcoming). Various faunal material was worked with, to come up with a range of objects for utilitarian or adornment purposes. Ivory from elephants, hippopotamus and warthogs was worked on to produce a range of adornment products like bangles and amulets (Robinson 1959; Garlake 1973; Voigt 1983; Whitelaw 1994; Forssman et al. 2014; Coutu et al. forthcoming).

Another important element of crafting in southern Africa was cloth making. Material evidence of cloth manufacturing is in the form of spindle whorls and pins and needles (MacIver 1906; Robinson 1959; Huffman 1971; Garlake 1973). Other evidence of cloth making comes from Portuguese sources, who describe cloth making in southern Africa (Beach 1980).

One of the critical issues in the study of metal production in the region has been its organisation. This relates to both the control of the production process as well as the manner in which the production process was conducted. Miller (2002) and Chirikure (2007) have noted that the organisation of metal production in southern Africa varied over time. For instance, in the Early Iron Age, copper and iron were worked to produce mainly jewellery and small implements (Miller 2002: 1127). In contrast, the second millennium saw the introduction of wire drawing and the casting of larger copper ingots for ritual or trade purposes. Larger iron items like spear heads, axe heads and hoes also begin to be noticed in the second millennium, which, according to Miller (2002), is a reflection of the growing production of iron. The second millennium also witnessed the appearance of gold and bronze in the archaeological record. Bronze has been recorded from a number of sites in the region, including Mapungubwe, Great Zimbabwe, Danangombe, Thulamela, Bosutswe, Matendera and Ingombe Ilede (Bandama et al. 2015). In terms of organisation, it has been argued that the specialist production of metals was critical in the rise of centres of power; these centres of 
power were dominated by independent specialists who came to play a leading role in sociopolitical centralisation in the region through the control of metal-production activity (Calabrese 2000; Chirikure 2007: 94, Herbert 1996). This was distinct from the Late Iron Age, where specialist production was critical in the sustenance of elites and the state systems from the thirteenth century onwards (Calabrese 2000; Chirikure 2007: 94, Herbert 1996). Through the expropriation of surplus, it is argued the elite were able to control and maintain the structures that were key to the control of the state, particularly through regulating trade and distributing these mineral commodities. However, research at Great Zimbabwe (Bandama et al. 2016) has shed new light on the organisation of crafting in the region. Following their investigation of the metal remains from Great Zimbabwe, Bandama et al. (2016) have argued that production at the site was probably household-based, with each household manufacturing items for its own use. This was based on the distribution of metallurgical debris from the site, which showed that metal working was not concentrated in one area but in various places that correlated with household areas at the site- hence the argument for a household-based production system at the site (Bandama et al. 2016).

One of the issues that has also been central to craft-production studies in the region has been the provenance of crafting. Some early scholars argued that, while most of the crafting that was noted in the archaeological record had been practiced by the indigenous inhabitants of the sites, the technology had been exported from other areas (Summers 1969; Garlake 1973; Huffman 1971). The first synthesis on precolonial goldmining on the Zimbabwean plateau, while acknowledging the role of Africans in mining, did not ascribe its antiquity to the indigenous communities (Summers 1969). Summers (1969) argued that the technology of mining had been brought to the region by Indians, who imparted it to the locals. Parallels were drawn with similar developments in mining in India, suggesting they could have played a role in the spread of mining technology in southern Africa (Summers 1969). However, such perceptions have been debunked with time, as many sites actually show evidence of highquality mining, processing and manufacturing of metal products in the precolonial period, proving the control that locals had over the whole process (Miller 2002; Chirikure 2007). The technology of cloth production was also argued to have been imported into the region (Huffman 1971). However, scholars have recently shown that crafting was local in origin and that there is evidence of various craft-production activities prior to contact with the outside 
world (Ruwitah 1999). Using ethnographic and linguistic evidence, Ruwitah (1999) argues, for instance, that cloth production was indigenous to southern Africa.

One of the lasting effects of crafting in the region was the establishment of trade relations with the outside world. In particular, Swahili and Portuguese traders from the east coast began to penetrate into the interior, with a view to trading gold, ivory, animal skins and other locally produced objects. In return, they offered the locals glass beads, cloth, and ceramics from Europe and Asia.

\subsection{METHODOLOGY}

\section{MATERIAL ANALYSES}

An analysis of objects recovered from the current and previous excavations was done. The collection from previous excavations is housed in the Zimbabwe Museum of Human Science. The objective of the analysis was to identify objects that attest to craft production at the site, with a particular focus on their spatial distribution. An understanding of the spatial distribution of craft items is important for identifying the production areas and modes of distribution and for understanding the consumption patterns of the various products. Such information can be useful in conceptualising the status of the people who occupied various areas of the site (Costin and Earle 1989). Evidence of craft items was noted, as well as evidence of production in the form of production debris. These were distributed across the various platforms and non-stone walled sections that were investigated (Robinson 1959; Hughes 1997). These objects include metals in the form of hoes, axes, jewellery and other items of personal adornment, nails, pins and spears. Other objects include spindle whorls, ivory bangles, amulets and local ceramics. Evidence of production processes noted was in the form of slag, incomplete spindle whorls, and ivory waste. a variety of metals, such as copper, gold, iron and bronze, were used in the manufacturing of crafts at the site.

\subsection{EVIDENCE OF METAL PRODUCTION}

The excavations at Khami recovered a number of metal objects and fragments that can be used to reconstruct the nature of the metal-working industry at the site. Generally, fragments of wound wire were recovered from all excavated units and were found at all levels in most of the trenches. Wire, either iron or copper, was wound around a vegetable core to form 
objects that could be used as bracelets or bangles. XRF analysis was performed on some of the material from Midden 1. The results showed that the pieces were made of copper (Appendix 8.1). However, iron was also used to manufacture bangles and bracelets from wound wire. The presence of iron-wound wire was also noted in all the excavated units. Evidence of metal processing was also recovered during the excavations. This evidence includes slag and copper moulds. Slag is an important indicator of metal smelting at a site. It was noted in Level 1 and 3 of the Museum Midden 1 Trench 1. An iron axe head recovered from the same trench also provides evidence of some of the tools that were manufactured at the site.

Table 8.1: Metal recovered from Midden 1, Trench 1.

\begin{tabular}{|l|l|l|}
\hline Object & Material & Provenance \\
\hline Wound wire & Iron & M1T1L3 \\
\hline Wound wire & Copper & M1T1L3 \\
\hline Wound wire & Copper & M1T1L4 \\
\hline Wound wire & Copper & M1T1L4 \\
\hline Wound wire & Copper & M1T1L5 \\
\hline Wound wire with veg core & Copper & M1T1L12 \\
\hline Wound wire with veg core & Copper & M1T1L12 \\
\hline Wound wire on quartzite flake & Copper & M1T1L14 \\
\hline Wound wire & Copper & M1T1L15 \\
\hline
\end{tabular}

Table 8.2: Metal recovered from Midden 1, Trench 2.

\begin{tabular}{|l|r|l|l|}
\hline Object & Quantity & Material & Provenance \\
\hline Wound coil & 1 & Copper & M1T2L1 \\
\hline Wound coil & 1 & Copper & M1T2L1 \\
\hline Wire folded into a bunch & 1 & Copper & M1T2L2 \\
\hline Wound wire & 4 & Copper & M1T2L2 \\
\hline Wound coil & 1 & Copper & M1T2L3 \\
\hline Wire & 1 & Copper & M1T2L3 \\
\hline Wound coil with fibre & 1 & Copper & M1T2L5 \\
\hline Wire folded into pendant & 1 & Copper & M1T2L5 \\
\hline Slag & 2 & Iron & M1T2L5 \\
\hline Wound wire & 3 & Iron & M1T2L7 \\
\hline Wound wire with veg core & 4 & Iron & M1T2L9 \\
\hline Wound wire & 2 & Copper & M1T2L9 \\
\hline
\end{tabular}




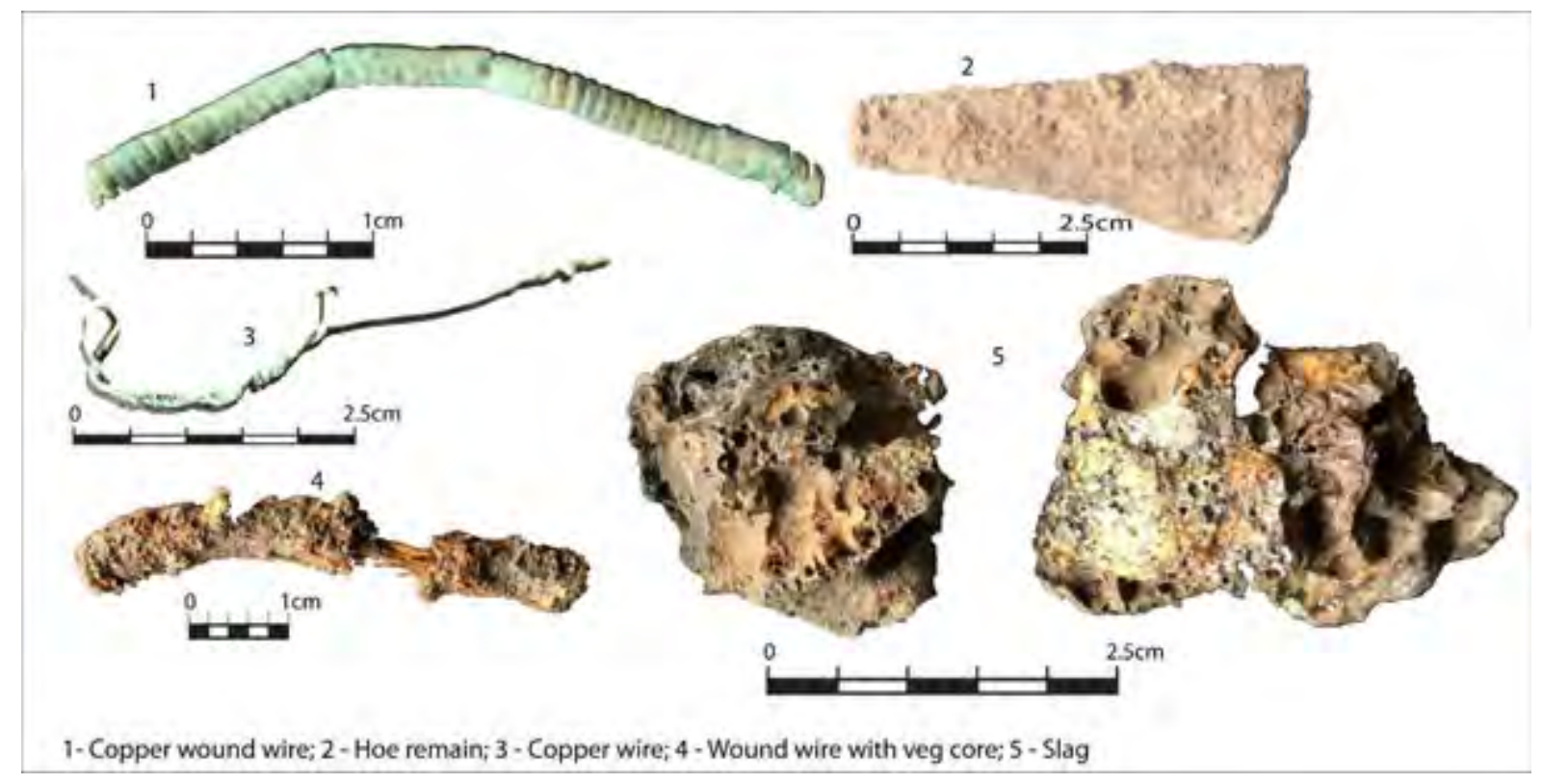

Figure 8.1: Some of the objects recovered from Midden 1 Trench 2.

Table 8.3: Metal remains from Midden 1, Trench 1.

\begin{tabular}{|l|l|l|}
\hline Object & Material & Provenance \\
\hline Wound wire & Iron & M1T1L3 \\
\hline Wound wire & Copper & M1T1L3 \\
\hline Wound wire & Copper & M1T1L4 \\
\hline Wound wire & Copper & M1T1L4 \\
\hline Wound wire & Copper & M1T1L5 \\
\hline Wound wire with veg core & Copper & M1T1L12 \\
\hline Wound wire with veg core & Copper & M1T1L12 \\
\hline Wound wire on quartzite flake & Copper & M1T1L14 \\
\hline Wound wire & Copper & M1T1L15 \\
\hline
\end{tabular}


Table 8.4: Metal fragments from Midden 1, Trench 2.

\begin{tabular}{|l|r|l|l|}
\hline Object & Quantity & Material & Provenance \\
\hline Wound coil & 1 & Copper & M1T2L1 \\
\hline Wound coil & 1 & Copper & M1T2L1 \\
\hline Wire folded into a bunch & 1 & Copper & M1T2L2 \\
\hline Wound wire & 4 & Copper & M1T2L2 \\
\hline Wound coil & 1 & Copper & M1T2L3 \\
\hline Wire & 1 & Copper & M1T2L3 \\
\hline Wound coil with fibre & 1 & Copper & M1T2L5 \\
\hline Wire folded into pendant & 1 & Copper & M1T2L5 \\
\hline Slag & 2 & Iron & M1T2L5 \\
\hline Wound wire & 3 & Iron & M1T2L7 \\
\hline Wound wire with veg core & 4 & Iron & M1T2L9 \\
\hline Wound wire & 2 & Copper & M1T2L9 \\
\hline
\end{tabular}

Table 8.5: Metal fragments from Midden 2 Trench 2.

\begin{tabular}{|l|r|l|l|}
\hline Object & Quantity & Material & Provenance \\
\hline Wire & 1 & Copper & M2T2L4 \\
\hline Wound coil with fibre & 12 & Iron & M2T2L4 \\
\hline Wound coil with fibre & 8 & Iron & M2T2L5 \\
\hline Coiled wire & 1 & Copper & M2T2L5 \\
\hline Coiled wire & 1 & Copper & M2T2L6 \\
\hline Wound coil with fibre & 3 & Iron & M2T2L6 \\
\hline Wound coil & 3 & Iron & M2T2L7 \\
\hline Wound coil with fibre & 1 & Iron & M2T2L7 \\
\hline Copper mould & 8 & Copper & M2T2L7 \\
\hline Coiled wire & 9 & Copper & M2T2L8 \\
\hline Wound coil with fibre & 9 & Copper & M2T2L9 \\
\hline Wound coil with fibre & 5 & Iron & M2T2L10 \\
\hline Wire & 3 & Iron & M2T2L10 \\
\hline Coiled wire & 6 & Copper & M2T2L10 \\
\hline Wound coil with fibre & 4 & Iron & M2T2L12 \\
\hline Wound coil with fibre & 3 & Iron & M2T2L13 \\
\hline
\end{tabular}




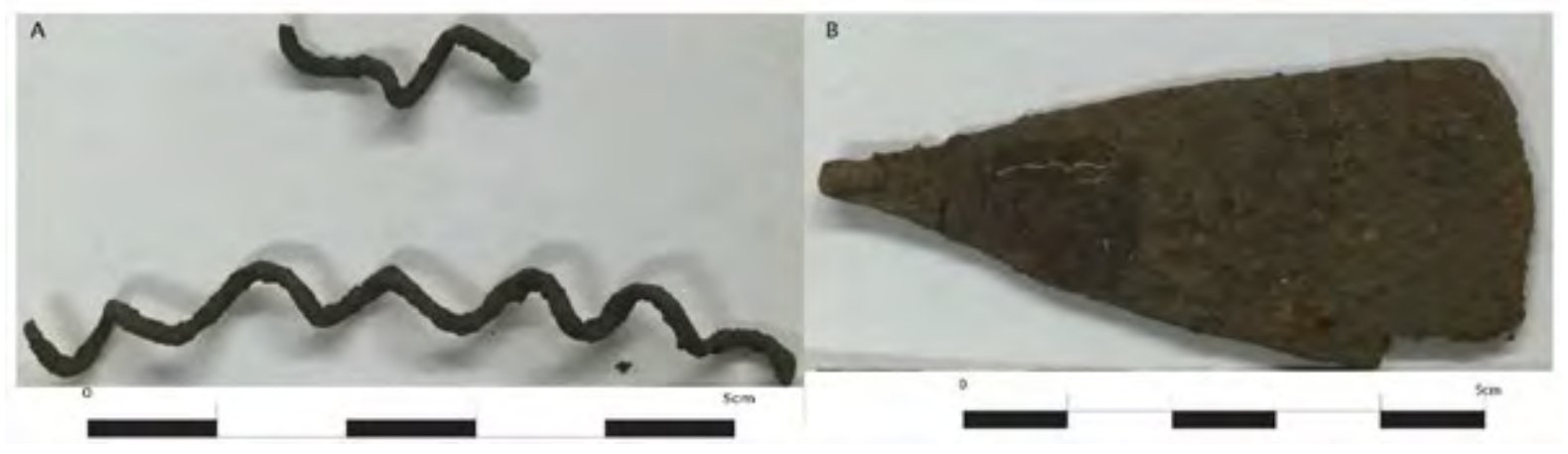

Figure 8.2: Part of the metals collection recovered from Midden 2 Trench 2. Twisted wire (A) and axe head (B).

Table 8.6: Various metal pieces recovered from the North Platform Midden 1 Trench 1.

\begin{tabular}{|l|r|l|l|}
\hline Object & Qty & Metal & Provenance \\
\hline Coiled wire & 1 & Iron & North Platform Midden 1 Trench 1 L1 \\
\hline Coiled wire & 6 & Iron & North Platform Midden 1 Trench 1 L2 \\
\hline Bangles & 9 & Iron & North Platform Midden 1 Trench 1 L3 \\
\hline Coiled wire on fibre & 6 & Copper & North Platform Midden 1 Trench 1 L4 \\
\hline Twisted wire & 4 & Copper & North Platform Midden 1 Trench 1 L8 \\
\hline Coiled wire & 3 & Copper & North Platform Midden 1 Trench 1 L8 \\
\hline Coiled wire & 2 & Iron & North Platform Midden 1 Trench 1 L8 \\
\hline Twisted wire & 5 & Copper & North Platform Midden 1 Trench 1 L9 \\
\hline Coiled wire with fibre core & 1 & Iron & North Platform Midden 1 Trench 1 L9 \\
\hline Coiled wire with fibre core & 12 & Iron & North Platform Midden 1 Trench 1 L10 \\
\hline Coiled wire & 2 & Copper & North Platform Midden 1 Trench 1 L11 \\
\hline Coiled wire & 6 & Copper & North Platform Midden 1 Trench 1 L12 \\
\hline Twisted wire & 1 & Copper & North Platform Midden 1 Trench 1 L12 \\
\hline
\end{tabular}


Table 8.7: Metal objects recovered from Museum Midden 1 Trench 1.

\begin{tabular}{|l|r|l|l|}
\hline Object & Qty & Metal & Provenance \\
\hline Slag & 3 & Iron & Museum Midden 1 Trench 1 L1 \\
\hline Wire & 1 & Iron & Museum Midden 1 Trench 1 L1 \\
\hline Coiled wire & 2 & Iron & Museum Midden 1 Trench 1 L2 \\
\hline Slag & 2 & Copper & Museum Midden 1 Trench 1 L3 \\
\hline Axe head & 1 & Iron & Museum Midden 1 Trench 1 L3 \\
\hline Coiled wire on fibre core & & Iron & Museum Midden 1 Trench 1 L3 \\
\hline Coiled wire on fibre core & 4 & Iron & Museum Midden 1 Trench 1 L4 \\
\hline Coiled wire & 1 & Iron & Museum Midden 1 Trench 1 L4 \\
\hline Wire & 1 & Iron & Museum Midden 1 Trench 1 L5 \\
\hline Wound wire & 2 & Iron & Museum Midden 1 Trench 1 L5 \\
\hline Twisted wire & 1 & Iron & Museum Midden 1 Trench 1 L5 \\
\hline Wound wire & 1 & Copper & Museum Midden 1 Trench 1 L6 \\
\hline Wound wire on fibre & 1 & Iron & Museum Midden 1 Trench 1 L6 \\
\hline Coiled wire & 1 & Copper & Museum Midden 1 Trench 1 L7 \\
\hline Wire & 1 & Iron & Museum Midden 1 Trench 1 L7 \\
\hline Coiled wire on fibre core & 1 & Iron & Museum Midden 1 Trench 1 L7 \\
\hline Coiled wire on fibre core & 1 & Iron & Museum Midden 1 Trench 1 L8 \\
\hline
\end{tabular}

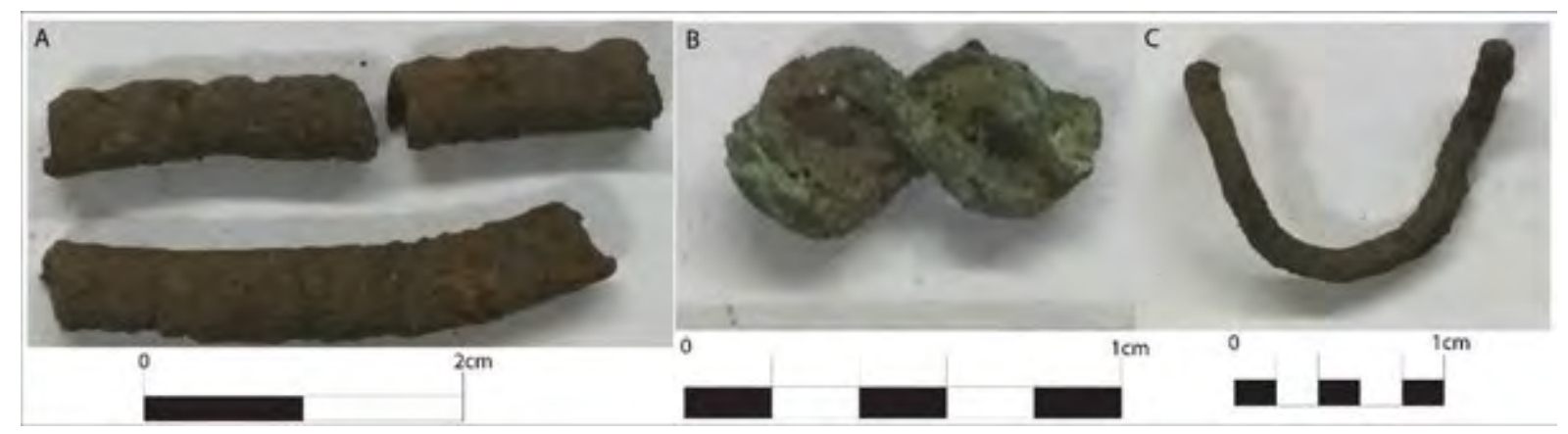

Figure 8.3: A selection of metal objects from Museum Midden 1 Trench 1. Coiled wire (A); twisted wire (B) and piece of wire (C). 
Table 8.8: Metal objects from Museum Midden 2 Trench 1.

\begin{tabular}{|l|r|l|l|}
\hline Object & \multicolumn{1}{|l|}{ Qty } & Metal & Provenance \\
\hline Wound wire on fibre core & 2 & Iron & Museum Midden 2 L3 \\
\hline Wire pieces & 1 & Iron & Museum Midden 2 L4 \\
\hline Wound wire on fibre core & 2 & Iron & Museum Midden 2 L11 \\
\hline Twisted Copper wire & 2 & Copper & Museum Midden 2 L11 \\
\hline Coiled wire fragments & 9 & Copper & Museum Midden 2 L13 \\
\hline
\end{tabular}

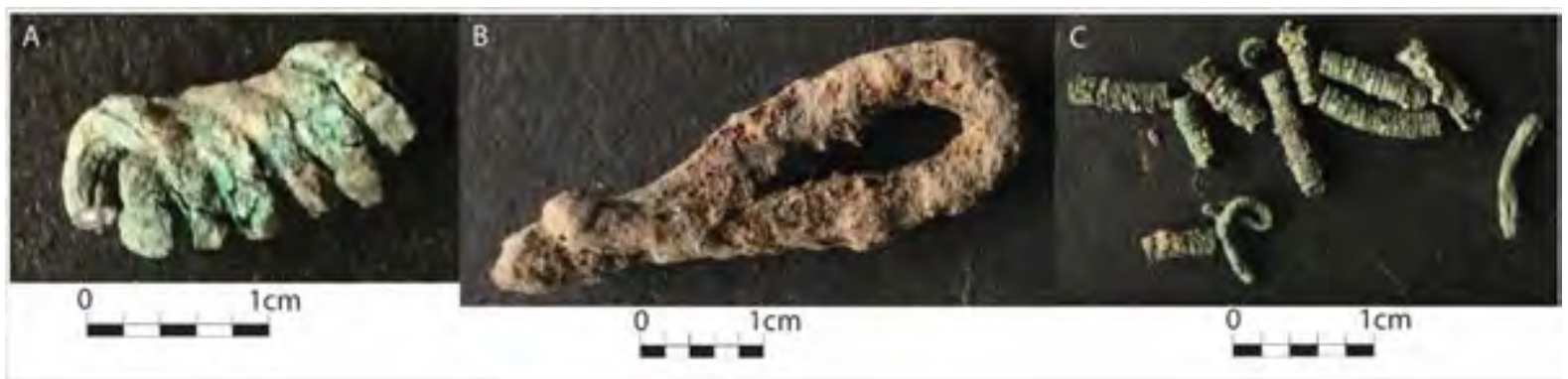

Figure 8.4: A sample of metal pieces from Museum Midden 2 Trench 1. Coiled copper wire (A); Iron wire (B); and more coiled copper wire (C).

\section{METAL OBJECTS FROM PREVIOUS EXCAVATIONS}

Previous excavations have also resulted in the recovery of a wide array of metal objects. Domestic utilitarian objects like farming tools were also recovered. These include hoes, axes, chisels and chains. The objects were recovered from varied contexts, including the Hill Complex Platform B, Hill Complex House Cb1, Passage platform, Vlei platform (Robinson 1959) and the Northwest Ridge (Hughes 1997). The working of various ores to produce metals for object-making is evidenced by the presence of metal-working residue in the form of slag. Slag was recovered at Khami from the Hill Complex (MacIver 1906; Robinson 1959) and the Northwest Ridge (Hughes 1997). 


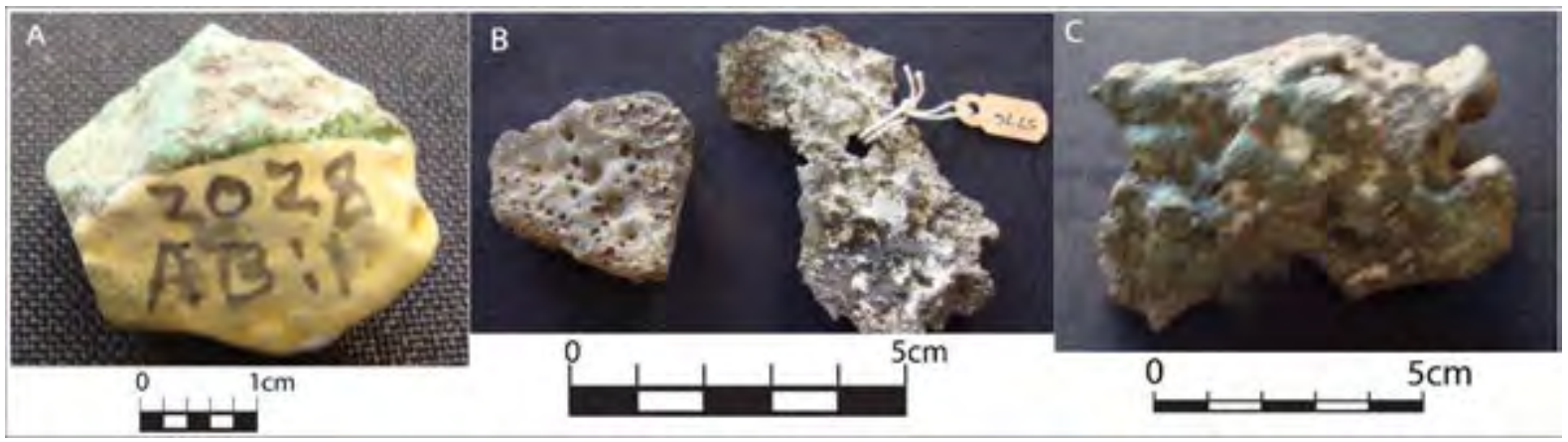

Figure 8.5: Evidence of metal processing at Khami. Copper mould (A) copper slag (B) from the eastern slopes of the Hill Complex and copper slag (C) from the Hill Complex (Robinson 1959). The objects are housed in the Zimbabwe Museum of Human Science.

The presence of pins (Figure 8.3 and Table 8.8), while attesting to the metal-working industry at the site, is also evidence of cloth production at the site. Objects of adornment were observed from the fragments of wound coil or coiled wire of iron or copper (Tables 8.9; 8.10; $8.11 ; 8.13$ and 8.14). Various metal beads made of different materials, including gold, copper and bronze, have also been recovered from the site in the past (Hall and Neal 1902; MacIver 1906; Robinson 1959). The alloying of various metals has also been thought to occur at the site. Some of the beads were recovered individually while others were part of an attachment to a coil of wire. Van Waarden has argued that the copper used in the manufacturing of objects at Khami came from the copper mines of north-eastern Botswana, including Thakadu (Van Waarden 1998; Huffman et al. 1995). Thakadu copper mine was one of the largest precolonial copper mines in southern Africa. However, it is important that scientific studies be conducted to prove this. If the copper worked at Thakadu was indeed coming from Thakadu, this would also serve as an indicator of the local exchange networks that existed prior to the opening up of the interior to the Indian Ocean coast trade network. 

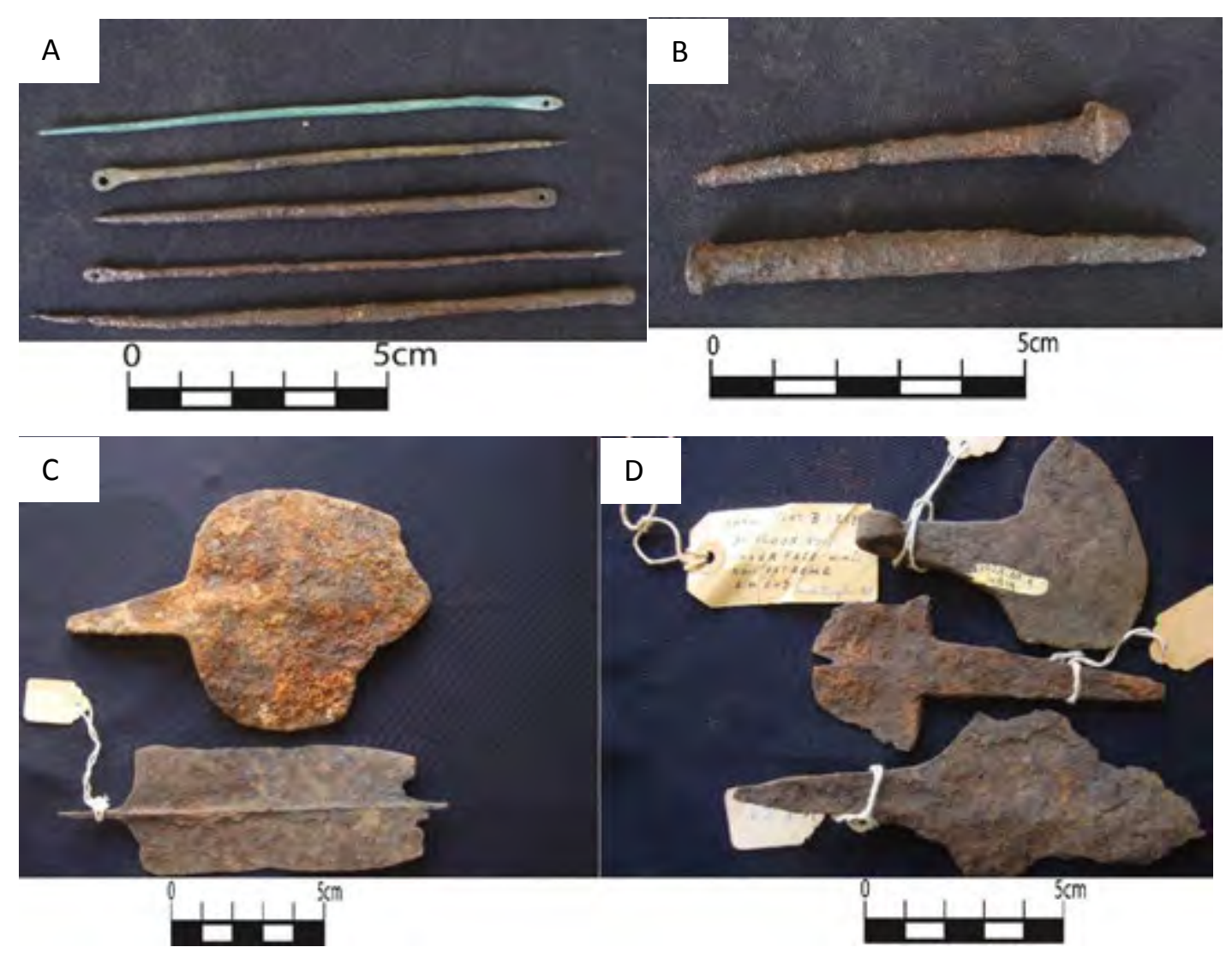

Figure 8.6: Utilitarian metal objects from the Hill Complex (MacIver 1906; Robinson 1959). These are copper and iron needles (A); iron nails and a selection of iron hoes (C and D) housed in the Zimbabwe Museum of Human Sciences.

Gold beads were also recovered from the site (Hall and Neal 1902; MacIver 1906; Robinson 1959). However the current excavations did not yield any gold ornaments. The absence of gold in the current research can be attributed to the works of the early antiquarians, who worked to recover most of the gold and golden objects from the site. Gold was also an export commodity during the prehistoric period, in demand from Portuguese and Swahili traders; therefore, one would not expect to find it in as much abundance as other metals like iron and copper (Swan 2008). Robinson (1959: 91) recovered a gold bead and a pellet in a trench from his excavation on Site IV, which is a terraced platform east of the Cross Platform. The gold pellet was recovered on bedrock, at $120 \mathrm{~cm}$, while the bead was recovered in the upper midden material. Other gold objects were recovered from the Hill Complex, particularly the house floors and parts of the passage leading to the summit of the Hill Complex (Robinson 1959: 60, 85, 173). Summers (1969) and Swan (2008) have shown that the control and management of gold mining was a key enabler in the control of polities around the Zimbabwe 
plateau. This also ensured that the controllers of the mining were also in control of trade networks with the East Coast.

While it has been documented that gold was recovered by Neil and Johnson at Khami, there are no clear indications as to the quantities that were found (Table 8.16; Hall and Neal 1902). However, the most important observation is that the processing of gold was a major craft production at the site, as reflected in the gold beads, pellets, tacks and other jewellery items recovered from the site (Table 8.6 and 8.13). For instance, on the Upper and Middle Passage of the Hill Complex, an unspecified amount of gold was recovered in the form of beads, plaited wire work and pellets (Hall and Neal 1902). Alloys of copper and gold were also recovered in the same locality.

Another critical element in gold mining and production was its alloying with other metals, particularly copper. This alloy was used in the manufacturing of wires for bracelets, plaited wire work, bangles and beads. Besides alloying, precolonial metal workers also used different metals in the manufacturing of one object. This was typical of the ceremonial axe, which was made of iron but also had a copper disk in the middle of the blade (Robinson 1959). In other instances, copper sheathing was used to cover the handle of the axe. Copper was also alloyed with gold and used in the manufacturing of items of personal adornment, such as beads (Robinson 1959).

Weapons were manufactured from iron, although some were also made in copper. Such weapons included arrowheads, axes, knives and spearheads. Robinson (1959) recovered most of these on the floor surface of the houses on the Hill Complex, particularly in House Cb1. This included a bronze spearhead that was part of a hoard from House Cb1 floor level (Figure 8.7). Robinson is of the opinion that this hoard was ceremonial, as it showed a high standard of workmanship in comparison to other weapons recovered at the site. Some of the weapons in the hoard, such as an iron axe-head with inlaid copper disk, had no parallels locally (Robinson 1959: 119). Robinson argued that the axe was comparable to two axes of probable Congolese origin that were recovered from the site by Neville Jones. He thus concluded that there could have been some form of contact between the inhabitants of Khami and the people of Central Africa (Robinson 1959). De Jager (1964) compared one of the axes of Congolese origin with axes from the Congo housed in the F S Malan Ethnological Museum at the University College of Fort Hare. Based on similarities that included human faces on the mid tang of the axes, a copper-covered shaft of wood and the use of copper tacks and punched 
decorations, he corroborated Robinson's conclusion that the axe from Khami was of Central African origin (de Jager 1964: 2). Hughes (1997) also recovered weaponry from Trench 1 that included an axe-head.

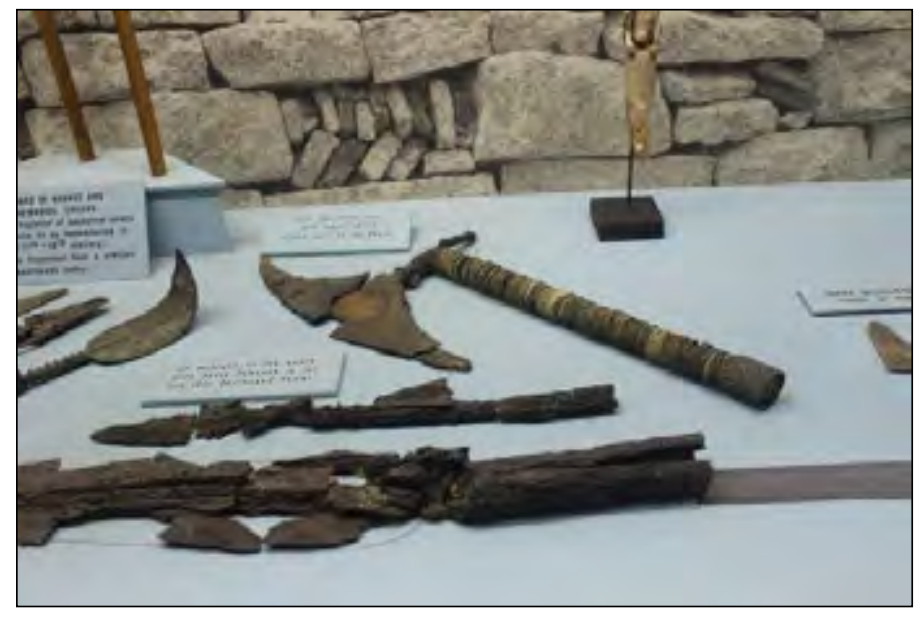

Figure 8.7: Weaponry objects recovered from House CB1 on the Hill Complex on display at the Natural History Museum of Zimbabwe.

The material is comparable to the material recovered by Robinson and MacIver in earlier investigations at the site. Both copper and iron were noted as the dominant metals exploited at the site, with copper being used more for ornamental objects, although other objects such as spears were also made using copper. Besides collecting metal objects from the surface floors, Robinson (1959: 81, 91) also recorded metal objects in his trenches. This discovery is an indication of the widespread use and exploitation of varied metals at the site, and the current research proves that this was not limited to the stone-walled areas of the site. All the metals noted at Khami appeared to occur from the earliest phases of the settlement, which is an indication that the exploitation of minerals was an important activity at the capital. This feature is understandable, since farmers required hoes for cultivation, and hunters required arrowheads and spears, while the adornment of ornamental objects that was noted in the Leopard's Kopje continued during the period of the Khami capital.

\subsection{EVIDENCE OF BONE AND IVORY OBJECTS PRODUCTION}

Ivory has been defined as a specialised tooth that grows outwardly, protruding from the mouth of the animal, and is associated in southern Africa with elephants, warthogs and 
hippopotami (Coutu et al. forthcoming). Samples of raw ivory have been recovered from the Hill Complex. Other samples have been recovered in the form of waste as well as bangles and amulets (MacIver 1906; Robinson 1959). Robinson also recovered an unworked ivory tusk from the Hill Complex, which he also used to associate the Hill Complex with the king.

The present study did not yield any bone or ivory tools and objects. Most of the fauna material was analysed as part of the subsistence patterns at the site (see Chapter 7). However, previous studies had resulted in the recovery of bone tools and objects (Hall and Neal 1902; MacIver 1906; Robinson 1959).

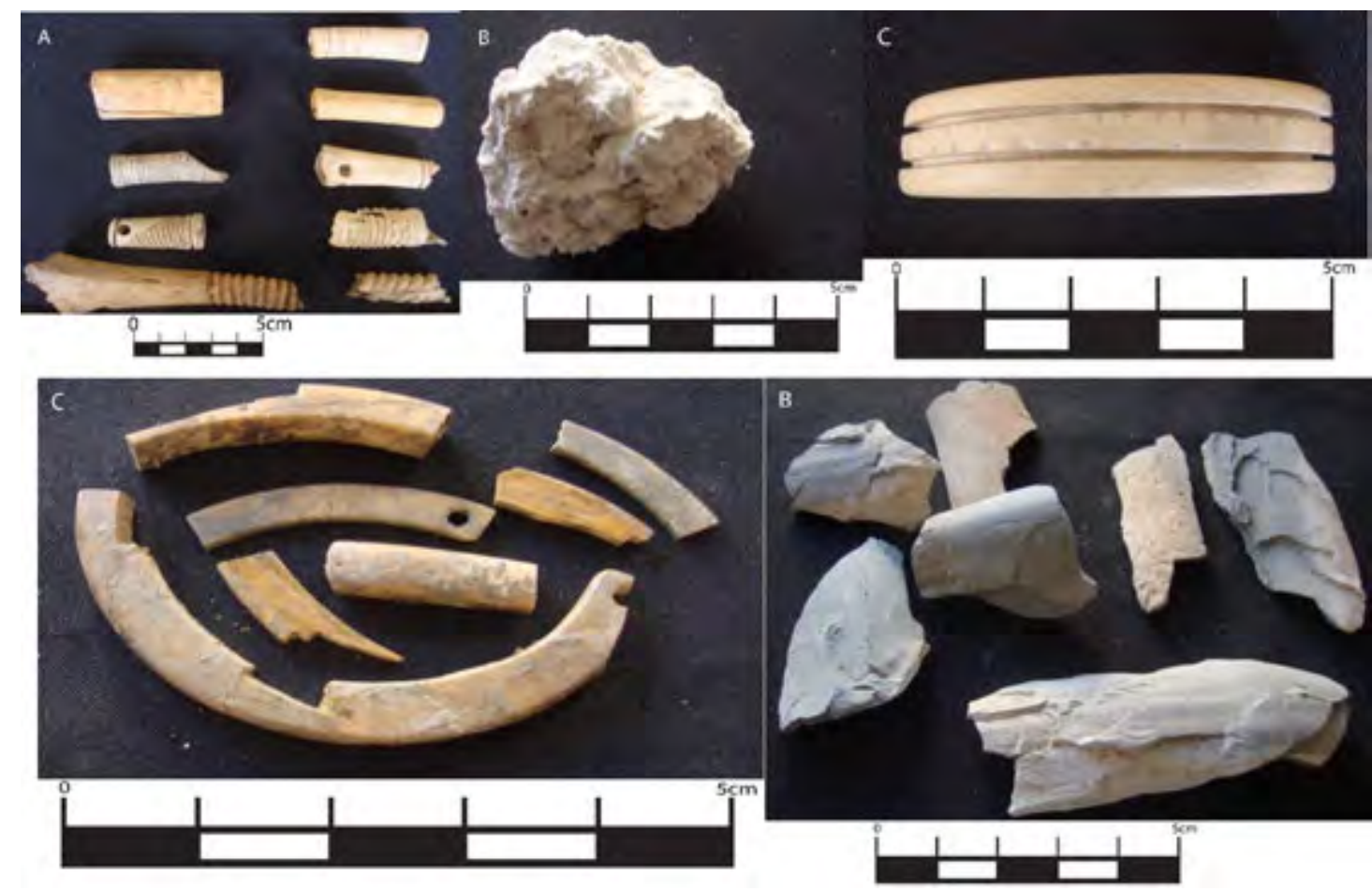

Figure 8.8: A collection of ivory and bone objects and debris. Amulets made from bone recovered on the Hill Complex (A); ivory waste recovered from the Passage Platform (B); armbands made from ivory also recovered from the Passage Platform (C), MacIver (1906) and Robinson (1959). The objects are housed in the Zimbabwe Museum of Human Sciences.

A broken ivory armband (Figure 8.6C) was recovered by MacIver (1906). It had a diameter of about $7 \mathrm{~cm}$. The armband was neatly decorated on the outer surface with a band of parallel 
grooves running right round. MacIver (1906) also recovered evidence of ivory waste on the Passage platform. The waste is evidence of ivory working at the site. However, Robinson (1959: 53) also came across more evidence of ivory working at Khami. This was in the form of an ivory carving of two small felines, carved on one side of the body and base with the diamond pattern. The other side is plain. Five divining dices made of ivory were also recovered (Robinson 1959:155). As with the felines, they are also decorated on one side with chevron patterning. An ivory human figurine was also recovered by Robinson (1959) on the Vlei platform (Summers 1949).

Table 8.9: Some of the ivory objects recovered from Khami.

\begin{tabular}{|l|l|l|}
\hline Object & Material & Context Description \\
\hline Armband decorated with parallel grooving & Ivory & Hill Complex \\
\hline Waste / Residue & Ivory & Passage Platform (Robinson 1959) \\
\hline Feline carvings $\mathrm{x} 2$ & Ivory & House Cb1 (Robinson 1959) \\
\hline Divining dices x 5 & Ivory & House Cb1 (Robinson 1959) \\
\hline Human figurine & Ivory & Vlei Platform (Robinson 1959) \\
\hline Burnt fragments of ivory & Ivory & Upper Passage (Robinson 1959) \\
\hline Burnt fragments of ivory & Ivory & Middle Passage (Robinson 1959) \\
\hline Fragment of bracelet & Ivory & Floor 1, Excavation 17a Platform B, Hill Complex (Robinson 1959) \\
\hline Bracelets $x$ 11 & Ivory & Hill Complex Midden (Thorp 1995) \\
\hline
\end{tabular}

Hall and Neal (1902) also make reference to recovering ivory products from the site. Unfortunately, as with most of their data, there is no contextual information. The objects include an ivory stylo, needles and an elephant's tusk.

\subsection{EVIDENCE OF CLOTH PRODUCTION}

Due to their organic nature, remains of cloth do not persist for very long in the archaeological record. The presence of prehistoric cloth was observed in carbonised cloth with a coarse weave on the blade of a bronze spearhead (Robinson 1959: 49). Fragments of cloth have also been observed at other sites, such as Great Zimbabwe (Caton-Thompson 1931), Dambarare (Garlake 1969), Ingombe Ilede (Fagan, Phillipson and Daniels 1969) and Mtilikwe (Hall 1902). The other line of evidence for cloth production in the region is the presence of spindle whorls, which have been recovered and are discussed below. The presence of pins and 
needles, while not directly attesting to cloth production, signifies that there was cloth at the site that was being worked on using those needles and pins.

This analysis also included the collection that is housed in the Zimbabwe Museum of Human Sciences. In terms of the material used to manufacture the spindle whorls, ceramic was the most dominant, with $76.47 \%$ of the assemblage having been made from ceramic. The other two materials used in the manufacturing process were soapstone and clay, accounting for $13.73 \%$ and $9.8 \%$ of the collection respectively. In terms of perforations, 32 samples had 1 perforation per sample in the middle of the spindle whorl. One of the samples had a middle perforation and other smaller perforations surrounding the middle one. The sample was broken, so the specific count of the smaller perforations could not be made. However, six of the smaller perforations were clear from the unbroken side. One could assume, based on the outline of the spindle whorl, that there were most likely ten smaller perforations. Other samples also showed evidence of attempts at creating smaller perforations, although this effort was not completed (Figures 8.8 and 8.9). Some of the spindle whorls, particularly those made from ceramic sherds, had decorations emanating from the pots that they were made from. However, in other instances, specific decoration of the spindle whorl was done through engraving. Typically, this involved engraving lines from the centre perforation to the edge of the whorl. In other instances engravings were also made on the rim of the whorl. 

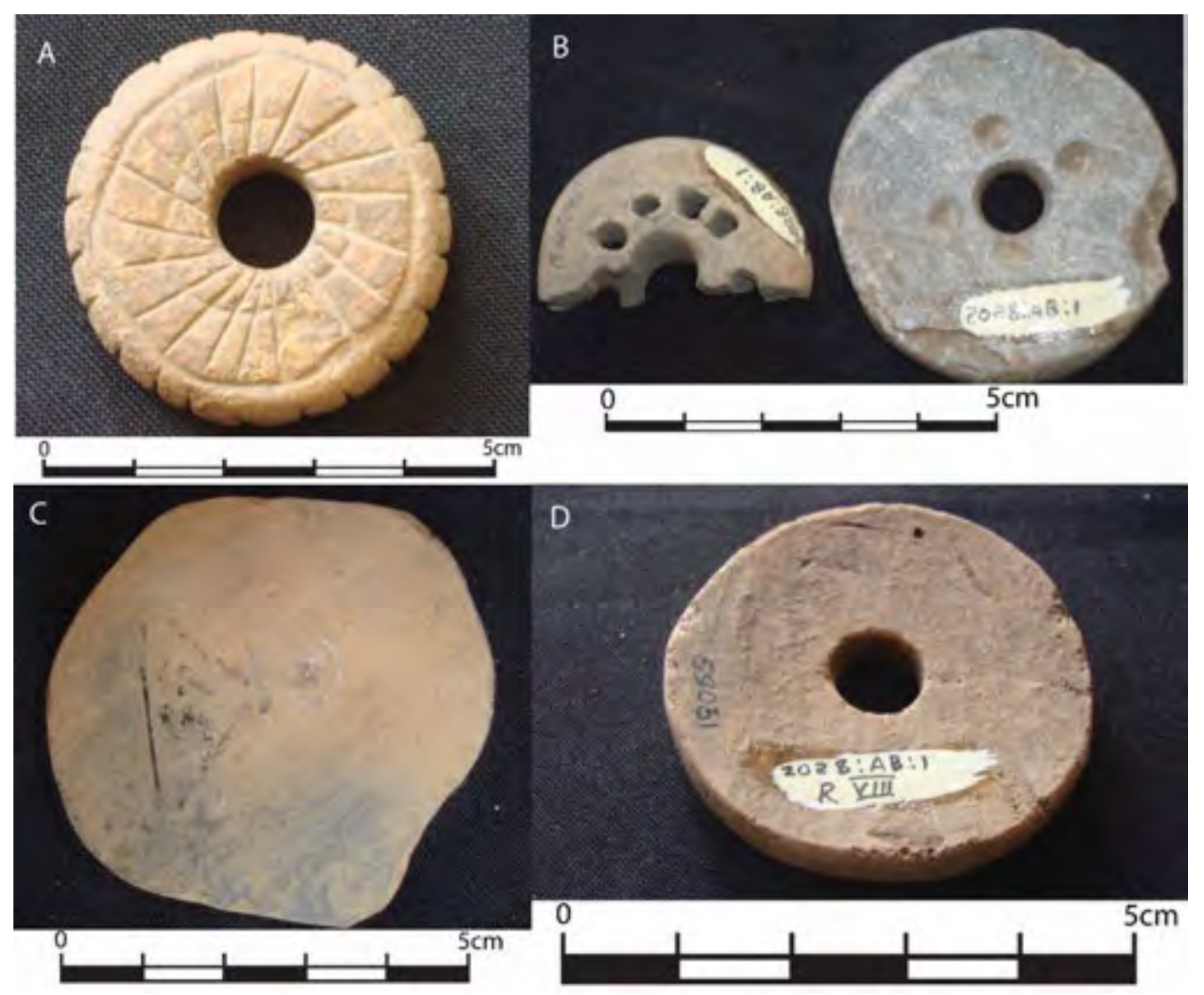

Figure 8.9: Spindle whorls from Khami. Some spindle whorls were decorated (A) while others were made from soapstone and clay and had multiple perforations (B). These are all from the Hill Complex. (C) shows a spindle whorl that was still in the production stage and (D) shows a plain one, both from the Passage Platform.

\subsection{DISCUSSION}

One of the objective of this chapter was to understand distribution of craft material across the site. The analysis also incorporates previously excavated material so as to provide a holistic understanding of the material distribution across the site. In making the intra-site comparison, it should be noted that some of the areas were excavated extensively compared to others. The Hill Complex in particular had the most extensive investigations, which included excavation and reconstruction of sections of the platform. All the twelve house-remains on the platform were also excavated by Robinson. By contrast, all the other units investigated focused on middens, and no more than $3 \mathrm{~m}^{2}$ were excavated per unit. As a result, there is a large volume of objects from the Hill Complex compared to the rest of the excavated units. This could 
partially account for other objects and materials that were recovered on the Hill Complex only, such as gold.

Table 8.10 demonstrates that there is a uniform distribution of material culture across the site. The presence of jewellery on most of the platform suggests that access to these metal products was not restricted to any particular group, whether in- or outside the stone-walled sections. The jewellery was made mainly from copper and iron from all the investigated areas. However, on the Hill Complex, jewellery made of gold, bronze and gold/copper alloys was also recovered (Table 8.11). This finding reveals that items of adornment could be owned by all members of the society, hence their distribution across the site. Ceramics were also recorded on all the investigated areas. Objects associated with farming were also recovered in both the walled and non-walled areas, which affirms the importance attached to agriculture by all the inhabitants of the site. Spindle whorls were also recovered in both the walled and non-walled contexts, attesting to the widespread spinning and weaving of cotton at the site.

Table 8.10 Distribution of craft material at Khami

\begin{tabular}{|c|c|c|c|c|c|c|c|c|c|}
\hline & Midden 1 & Midden 2 & $\begin{array}{l}\text { Museum } \\
\text { Midden } 1\end{array}$ & $\begin{array}{l}\text { Museum } \\
\text { Midden } 2\end{array}$ & $\begin{array}{l}\text { North } \\
\text { Platform }\end{array}$ & $\begin{array}{l}\text { Hill } \\
\text { Complex }\end{array}$ & $\begin{array}{l}\text { Passage } \\
\text { Platform }\end{array}$ & $\begin{array}{l}\text { Vlei } \\
\text { Platform }\end{array}$ & $\begin{array}{l}\text { North-west } \\
\text { Ridge }\end{array}$ \\
\hline Ceramics & $\checkmark$ & $\checkmark$ & $\checkmark$ & $\checkmark$ & $\checkmark$ & $\checkmark$ & $\checkmark$ & $\checkmark$ & $\checkmark$ \\
\hline Amulets & & & & & & $\checkmark$ & & & \\
\hline Ivory objects & & & & & & $\checkmark$ & $\checkmark$ & $\checkmark$ & \\
\hline $\begin{array}{l}\text { Spindle } \\
\text { whorls }\end{array}$ & $\checkmark$ & & & & $\checkmark$ & $\checkmark$ & & $\checkmark$ & \\
\hline $\begin{array}{l}\text { Jewellery } \\
\text { items }\end{array}$ & $\checkmark$ & $\checkmark$ & $\checkmark$ & $\checkmark$ & $\checkmark$ & $\checkmark$ & $\checkmark$ & & $\checkmark$ \\
\hline $\begin{array}{l}\text { Farming } \\
\text { objects }\end{array}$ & & $\checkmark$ & & $\checkmark$ & & $\checkmark$ & $\checkmark$ & & $\checkmark$ \\
\hline $\begin{array}{l}\text { Other metal } \\
\text { objects/tools }\end{array}$ & & & & & & $\checkmark$ & & & $\checkmark$ \\
\hline
\end{tabular}


Table 8.11 Distribution of objects at the site according to material.

\begin{tabular}{|l|r|r|r|r|r|l|l|l|r|}
\hline & Midden 1 & Midden 2 & $\begin{array}{l}\text { Museum } \\
\text { Midden 1 }\end{array}$ & $\begin{array}{l}\text { Museum } \\
\text { Midden 2 }\end{array}$ & $\begin{array}{l}\text { North } \\
\text { Platform }\end{array}$ & $\begin{array}{l}\text { Hill } \\
\text { Complex }\end{array}$ & $\begin{array}{l}\text { Passage } \\
\text { Platform }\end{array}$ & $\begin{array}{l}\text { Vlei } \\
\text { Platform }\end{array}$ & $\begin{array}{l}\text { North- } \\
\text { west Ridge }\end{array}$ \\
\hline Copper & $\checkmark$ & $\checkmark$ & $\checkmark$ & $\checkmark$ & $\checkmark$ & $\checkmark$ & & & $\checkmark$ \\
\hline Iron & $\checkmark$ & $\checkmark$ & $\checkmark$ & $\checkmark$ & $\checkmark$ & $\checkmark$ & $\checkmark$ & & $\checkmark$ \\
\hline Gold & & & & & $\checkmark$ & $\checkmark$ & & & \\
\hline Ivory & & & & & & $\checkmark$ & $\checkmark$ & $\checkmark$ & \\
\hline Bronze & $\checkmark$ & $\checkmark$ & $\checkmark$ & $\checkmark$ & $\checkmark$ & $\checkmark$ & $\checkmark$ & $\checkmark$ & $\checkmark$ \\
\hline Soapstone & & & & & & $\checkmark$ & & & \\
\hline Tin & & & & & & $\checkmark$ & & & \\
\hline Bone & $\checkmark$ & & $\checkmark$ & $\checkmark$ & $\checkmark$ & $\checkmark$ & & & \\
\hline
\end{tabular}

Evidence of the production of crafts was also recovered in the form of waste from the production process. Slag was recorded in the non-walled contexts on Midden 1 and Museum Midden 1. The Hill Complex also had evidence of metal processing in the form of slag. Moulds of copper were also noted on Midden 2 and the Hill Complex. The pattern emerging from the distribution of waste suggests that the production of the various craft goods recovered at Khami was not necessarily restricted to one area. The quantities of recovered waste was also not commensurate with the large-scale production characteristic of trading. This suggests that craft production at the site was done for the home-based subsistence economy.

The stratigraphic evidence from the site reflects the fact that the working of iron, copper and gold was associated with Khami from its formative period. Robinson (1959: 91) recovered a gold pellet from the lower levels of Excavation 22, east of the Cross platform. During my own excavation, the presence of both copper and iron in the lower level of the trenches was also noted. Midden 1 had copper wound wire in the lowest level (Table 8.1). Similarly, Midden 2 also had iron in the lower levels (Table 8.4 and 8.5). 
The above findings potentially suggest that craft production at Khami was based on the need to meet the demands of a household subsistence economy. There was no evidence of the mass production of any of the material objects that were recovered from the site, which would have suggested production for trade. At some sites, evidence of craft production has been found, leading scholars to suggest that objects were mass produced for trade, under the control of an elite class (Voigt 1983). For instance, at Mapungubwe, Voigt (1983) has argued that bone objects manufactured at the site were most likely meant for trade due to their huge numbers and that their production was centrally controlled. Ivory objects and waste recovered in KwaZulu Natal has been argued to be evidence of mass production of ivory products at the site (Coutu et al. forthcoming). However, at Khami, no such concentrations of material remains were observed, and nothing indicated intensive craft production carried out by specialised groups under the authority of the elite, as has been suggested of other regions (Vaughn 2006). In Moche, for example, the first indigenous state in the Andes, workshops that were dedicated to the production of various crafts were common, and these were easily identifiable in the archaeological record by the significantly high volumes of waste recovered (Vaughn 2006: 329; Chapdelaine 2002: 72). Instead, the distribution of metal residue points to production for local household subsistence use. Therefore, craft production at Khami was organised and run at the household level in order to meet the demands of the household units similar to that suggested for Great Zimbabwe (Bandama et al. 2016).

One of the critical aspects of this study involved incorporating evidence from both the stonewalled and non-walled sections of the site. This process is important for identifying patterns in similarities and differences between the material cultures from the two areas, which can assist us in understanding the nature of socio-political organisation at Khami. The material culture distribution pattern has shown that there are no major differences between the materials recovered from the two areas; one small difference was in the presence of ivory workings, which were collected from the stone-walled sections of the Hill Complex and Passage platform. Evidence of production was also found even in contexts that have been said to be residences of the king and elite, which is somewhat of an anomaly, given that craft production would be expected outside elite zones. 
A discussion on craft production at Khami leads to a discussion on the exchange networks between the site and the East African coast. Chirikure (2015) has noted that it is important that scholars also focus on understanding the southern African hinterland in any attempt to understand the intercontinental trade between Africa and Asia, rather than focus entirely on the coastal areas (LaViolette and Fleisher 2005; Antonites 2012). Most of the resources that found their way to Asia were collected from the interior, and foreign goods were also used by Swahili and Portuguese traders in this exchange network (Garlake 1974; Pwiti 1991; 2005; Pikirayi 1993; 2001). While some of the natural resources found within the Khami hinterland, such as gold and ivory, were used to manufacture a range of goods, some of it was bought off by traders from the East African coast. Evidence from a number of sites in the ShasheLimpopo region and other sites has also shown that ivory trade was a critical component of the Indian Ocean trade network (Voigt 1983; Huffman 2000; Chirikure 2015; Forssman et al. 2014). As has been noted earlier, craft production at the site was mostly limited to subsistence produce for domestic consumption. As such, the growth of the craft-production industry at Khami has to be looked at in terms of the broader relationships with other capitals and sites, and with the east coast in particular. This is because Khami played a key role in supplying and receiving material for the sustenance of the trade network. While Khami was trading away its gold, ivory and other products, it was also receiving material objects from the east African coast, such as Chinese celadon, glass beads, brown-glazed ware and blueand red-glazed ware from Asia and Europe (Robinson 1961).

Various craft products at Iron Age sites in southern Africa have been used to define class and status at these sites. This argument is based on the perceived appearance of certain status goods in elite contexts and their perceived non-availability in commoner contexts (Huffman 2000; 2007). However, Chirikure (2015) has noted that such an argument lacks merit, as there is little evidence from commoner sites on the Zimbabwean plateau to warrant that they were not part of the east Africa trade network. In fact, the evidence from Khami collected in this study suggests that commoner contexts also contained the material that has traditionally been associated with elites, such as glass beads and metal adornment (see also Chapter 6). 
In understanding the origins of craft production in southern Africa, some scholars have attempted to interpret it as a result of foreign influence. For instance, the technology of cotton weaving was assumed to have been brought into southern Africa from Asia (Ruwitah 1999). However, historical documents by the Portuguese attest to the local manufacturing of cloth in southern Africa (Mudenge 1974; 1988; Beach 1980). In his analysis of Portuguese documents and records, Huffman (1971) noted that it appears that the production of cotton in the region preceded the arrival of the Portuguese, as they reported an activity that they found already in progress. Weaving has also been reported as one of the major craft activities in northern Zimbabwe (Theal 1898, 7: 207). The other strand of evidence comes from the recent past. Ethnographic researches conducted in the region attested to prehistoric cotton production and cloth making (Davison and Harries 1980; Huffman 1971; Beach 1977; Ruwitah 1999).

Huffman's work at the Leopard's Kopje site provides us with an opportunity to understand metal working before Khami. He recorded the presence of slag, copper bangles, iron and copper rings within the Zhizo context at the site in levels dated to $\mathrm{AD} 745+/-45$. This suggests that the working of metal in the area had been going on for a very long time some six centuries before Khami. He also noted the presence of copper rings and slag in the Mambo phase, which succeeded Zhizo in the area. All the slag was from iron smelting. Huffman (1974) concludes that the distribution of slag and tuyeres throughout the deposits suggest the working of iron in all occupations at Leopard's Kopje site.

\subsection{SUMMARY}

This chapter has shown that there were a number of craft products that were manufactured at Khami. The evidence of this was found across both the walled and non-walled sections of the site in the form of both production waste and finished products. Some of the goods were used to support the domestic local economy. On the other hand trade was also enhanced with the people at Khami receiving an assortment of objects such as glass beads in return for items such as gold, ivory and other mineral based products. The distribution of exotic and high status goods that was noticed at Khami suggests a uniform distribution of goods across all settlement areas i.e. stone walled and non-stone walled. This has implications in our understanding of the nature of the settlement at Khami, in particular how the various people 
that occupied the various settlement areas interrelated with each other. The next chapter discusses the evidence presented in this and previous chapter and how they assist in our understanding of the development of the site. 


\section{CHAPTER 9: DISCUSSION}

\subsection{INTRODUCTION}

This chapter discusses the research based on the findings presented in the previous chapters. In particular, the distribution of material culture at the site is used to interpret and reconstruct the site's development and the lifeways of its people. Material culture is also compared with that of earlier traditions like the Leopard's Kopje to obtain an understanding of the relations that might have existed between the two sites (van Waarden 1998; 2012; Chirikure et al. 2013a). Relations with the Great Zimbabwe state and Mapungubwe are also explored, with a view to better understanding the development of the Zimbabwe Culture in the region, and in light of the new chronology from Khami. Finally, avenues for future research are suggested.

\subsection{THE CHRONOLOGY OF KHAMI}

It has been shown that the area of Khami had a Leopard's Kopje settlement prior to the wallconstruction phase (Robinson 1959). The excavation on the North Platform also yielded Leopard's Kopje ceramics, but these were not in the basal levels. Settlement at Khami appears to have been centred initially on the Hill Complex, as indicated by the presence of a midden on the bedrock of the hill prior to wall construction. The platform walls expanded with time to accommodate an increasing population at the centre. Later, some community members who were settled on the Hill Complex must have moved and established their own households within the vicinity of the Hill Complex. This move materialised in the form of the following platforms: Vlei, No 6, Precipice, Passage, Monolith, No 10, No 11, No 13 and Circular. The very dense middens around the Hill Complex, as opposed to those on the other platforms, support this interpretation of the settlement sequence of the site (Robinson 1959). However, there is need for further research on the individual platforms to understand their chronological ordering. In particular, there is need for radiocarbon dates, particularly of the Hill Complex, since evidence from material culture suggests that the settlement expanded from there. 
The above settlement sequence can be regarded as a general ordering of the development of the site in a broad sense. However, there is a lack of understanding of which areas of the walling were established first, because no study has been conducted to understand the architectural chronology of the walls. Unlike freestanding walls, terraced walls normally have the first walls covered by an outer one, as the result of the terracing and expansion of the platform (Figure 3.22). As such, to understand the construction sequence of the walls requires dismantling sections of the walling. Therefore, current evidence can only suggest a general sequence, which suggests settlement around the Hill Complex first, followed by expansion into other parts of the site.

Van Waarden $(2011 ; 2012)$ and Chirikure et al. (2013) have noted similarities between the material culture from Khami and the Woolandale phase of the Leopard's Kopje in southwestern Zimbabwe. Accordingly, they have suggested that there could be a relationship between the two in terms of cultural succession. The Woolandale phase has been dated to the fourteenth century, with Khami emerging in the fifteenth century. Robinson has shown from the ceramics collected at Woolandale that there is increased use of fine incision, a point that was also noted by Huffman (1974: 107), who has shown that incision dominates in terms of the decoration techniques employed on Woolandale ceramics. The same trend is also typical of Khami ceramics. The other decoration techniques that Robinson noted for Woolandalecomb stamping and punctates - have also been noted in the Khami assemblage.

My ceramic analysis has shown that the ceramics at the site were homogenous suggesting one group settled at the site. As such, I could not come up with a phased settlement sequence that could be demonstrated in changes in ceramic. The ceramics from the non-walled areas and those from the walled areas were all similar, and correlated with dates from the excavations, which suggest a fifteenth-to-seventeenth century occupation of the site. Glass beads from the site have been shown to fit into the Khami Indo-Pacific series, as suggested by Wood's (2005) classification. The presence of deep blue and off whites, which Wood (2005) found to be characteristic of the Khami Indo-Pacific series, were noted at Khami; in particular, deep blue occurred throughout the stratigraphy in the excavations. Indo-Pacific beads have been dated to between roughly AD 1450 and the seventeenth century. Radiocarbon dates were also 
collected for the site. These are contemporaneous with the glass bead sequence and show that it developed between the fifteenth and the seventeenth centuries. Dates from the Hill Complex obtained by Robinson also demonstrate that the Hill Complex Platform B was constructed in stages over a period of about a hundred years (Sheppard and Swart 1967).

\subsection{MATERIAL CULTURE AND DISTRIBUTION OF ACTIVITIES AT KHAMI}

An important element of the material culture at Khami are the platforms, and the accompanying houses that surround these platforms. Evidence presented in Chapter 4 on Circular Platform gives an idea of the settlement organisation at the site. The platform has a house inside and is surrounded by seven houses on the outside. This was also noted on other platforms at the site, such as the Hill Complex (MacIver 1906), suggesting that the platforms were centres of households and were probably where most of the activities associated with each household were conducted. This observation suggests that Khami was made up of a number of households centred on the various platforms at the site. The analysis of material distribution is therefore guided by the understanding that individual household units, centred on the various platforms, collectively make up the site of Khami (Chirikure and Pikirayi 2008).

One of the objectives of this study was to understand the material culture of Khami, with a special emphasis on its distribution and how that could help in reconstructing the development and lifeways of the people at Khami. The investigation on both the walled and non-walled contexts showed that there was a general uniformity of material culture recovered diachronically and synchronically. Evidence of craft production was recovered in both the walled and non-walled contexts. Dominant models of socio-political development suggest that elite centres like Khami are associated with elite-controlled mass production of craft goods (Costin and Earle 1989; Costin 2001; 2005). This pattern is supposed to be evidenced by elite-controlled workshops producing primarily for their own consumption or trade. However, this model is not reflected at Khami. Instead we see production that is based at the household level, and designed to meet the demands of individual household units. Dominant models also suggest that rulers and the elites do not necessarily carry out crafting but have specialist members of society producing for them (Costin 2005). However, research at some 
sites in the region suggests otherwise. In a study of metallurgy at Great Zimbabwe, Bandama et al. (2016: 14) have noted that the archaeological evidence of metallurgy from the site did not tally with the dominant models of production, in which elites had specialists crafting for them. The recovery of production debris from various parts of the site suggested householdbased production and consumption (Bandama et al. 2016). Evidence from Portuguese documents also suggests that crafting at the site was probably done at the household level. Mudenge (1974) noted that the Portuguese complained about the locals' reluctance to undertake gold mining, preferring to attend to their agricultural pursuits. This observation from the Portuguese does not give an impression of attached specialists working for the elite.

Production-related evidence was also recovered at the site. This was in the form of slag from both copper and iron working, and ivory waste. Slag was recovered from the Hill Complex, Northwest Ridge and Museum Midden 1. This discovery suggests that there was no centralisation of metal-working activities at the site and that individual household-based production must have been the dominant mode of production. The very small quantities of slag recovered are not consistent with intensive specialised production. Ivory waste is also evidence of ivory working at the site. This evidence was recovered on the Passage platform and Hill Complex. Ivory working appears to have been a limited trade, based on the limited amount of both artefacts and waste recovered. Indeed, on many other sites in the region where ivory has been recovered, evidence for ivory working in the form of waste has hardly been found (Forssman et al. 2014). Spindle whorls also appear to have been manufactured at the site, as a means to support cloth production. Evidence also shows that they were not concentrated in one region of the site, suggesting that there were multiple centres of cloth production.

The nature of the organisation of trade between the interior of southern Africa and the east coast of the Indian Ocean is not very clear. Unfortunately for Khami, and unlike the Mutapa state, there are no Portuguese documents articulating how trade was conducted (Mudenge 1988). However, based on the widespread recovery of trade goods at the site, it can be argued that the locals took advantage of pre-existing local trade networks to participate in exchange with the Swahili and Portuguese. Trade appears not to have been centralised at Khami, based on the recovery of trade goods in multiple contexts, including the non-walled areas. This suggests that individuals could trade freely and retain proceeds from trade after paying a tax 
(Bandama et al. 2016). This fact would account for the widespread distribution of trade goods across all the investigated units at Khami.

The other material culture that needs discussion is the stone walling found at the site. As mentioned earlier, stone walling was used in the construction of platforms, on top of which houses for the elite were constructed. Stone platforms have been associated with the elite, and non-stone-walled contexts with the non-elite (Robinson 1959; Huffman 1981, 1996). As such, stone walling has been used as a measure of differentiation in society. However, it is important to note that on most platforms not all the houses of the elite were located on top of a platform. Evidence has shown that most of the platforms, with the exception of the Hill Complex, typically had one or two houses on top and others outside the platform. Circular platform, which was discussed in Chapter 4, has one house on the platform and six other houses just outside the platforms. These were certainly houses associated with those that occupied the platform. Robinson noted that the Passage platform had two houses occupied during its final phase. Hall and Neal (1902) observed the presence of house floors in the area outside the Hill Complex. This suggests that our understanding of the nature of the society at Khami needs to be based on a firm understanding of the relations between those occupying the platforms and those occupying the houses just outside the platforms. An understanding of the architectural development of the site, as a gradual process, has to be taken into account when seeking to interpret the site. Evidence from Excavation 17a Platform B of the Hill Complex is important in this regard (Robinson 1959: 81). The excavation showed the gradual development of the platform. At one point, walling on the platform consisted of wall XVa at Floor II. Wall XVa was gradually increased to the level of Floor III before the construction of a new wall that increased the size of the platform, as we now understand.

The material culture distribution can be used to interpret and reconstruct lifeways at the site. The distribution of the stone-walling and platforms suggests that these were occupied by household lineage groups. The lineage groups would have occupied houses on the platform as well as those just outside the platform. This conforms to a chronology of the site, based on the stone-walled structures, that suggests that the Hill Complex was occupied first, before the settlement expanded with time (Robinson 1959). Ideally this would have involved either the 
children of the ruler moving out to establish their own households (musha) but still remaining part of the capital. Hence, we observe that the platforms around Khami are not clustered in one area but are spread out, with some being over two kilometres away. The wide distribution of similar material across the site conforms to this interpretation. Each household would ideally be responsible for the production of its own goods and objects, such as walling, pottery, spindle whorls and cloth, and tending to their fields and cattle. Other known Shona practices, such as nhimbe (communal working practice), could have been employed as and when necessary. Thus, the stone-walled platforms at the site represent centres of individual household lineages. It is difficult to understand their relations with those settled on the Hill Complex, but these were certainly the same people who took advantage of the population expansion and developed their own household centres.

It is also important to understand the organisation of production at the site. Due to limited evidence of intensive production, it can be suggested that there was household-based production particularly designed to meet the needs of the household and facilitate trade with others within the capital. Even the mining of gold does not appear to have been centralised by the elite, despite what has been suggested elsewhere (van Waarden 2012). The Portuguese are said to have complained that the people of the Butua were lazy and did not like to go looking for gold, preferring to tend to their cattle. This comment suggests that gold mining was not centrally organised and depended on the availability of the people to adopt mining as a secondary pursuit to agriculture (van Waarden 2012: 66). McIntosh (1997) has emphasised that one of the most important sources of wealth for African rulers was wealth-in-people or social wealth. This meant that rulers had to make sure that the needs of their communities were met first before attending to the needs of the traders. This principle explains why gold mining was a seasonal labour conducted mainly during the dry season, and why the Portuguese went as far as complaining about the limited gold reaching the coast. However, for the locals, gold also had aesthetic appeal. Gold was purportedly used in various societies to manufacture a range of objects, such as beads, rings or head rings. These objects could also be important status signifiers in society, as not everyone would have had access to gold ornaments, which would have been reserved for a certain class of elders. 
Spiritual activities were also central to the lifeways of the people at Khami. These activities, while not readily available in the archaeological record, can be extrapolated from the material culture. Bvocho (2005) and Chirikure (2015) have suggested that the colour of items, particularly beads, was and remains an important element in Shona ritual activities. Specifically, the colours red, black and white were associated with ritual ceremonies, which could explain why these colours dominate in terms of the bead assemblage from the region. This study has shown that red was dominant at the site in all contexts. This dominance can be explained by the fact that ancestral worship associated with these objects was performed at various levels, from the household to the state level (Chirikure 2015).

Another important consideration in the interpretation of life at Khami is the issue of classstatus distinction, which has been argued to have characterised the centre (Robinson 1959; Huffman 1996). Huffman has argued there were two classes at Khami, the elite and commoner, with the king being a sacred leader who resided in seclusion on the Hill Complex. Stone walling has been used to legitimise this class distinction. However, as I have demonstrated, other material culture at the site does not show this class differentiation. As such, there is need to look for other correlates that could have defined the various groups at Khami, and not necessarily according to their status in society. Bvocho (2005) has argued that some ornaments had cultural significance because they communicated age-grade, status, rank, religion and marital status. These include bangles made from various metals such as copper and iron and also ivory. At Khami, bangles were recovered in all the contexts that were investigated. Robinson (1959) and MacIver (1906) also recovered bangles from the stone-walled section, suggesting that access to these was not limited by status, or based on which area one was living in. Since it has been suggested that such ornaments communicated a number of status levels in society, it can be argued that such objects of adornment can better illuminate the status of the people who lived at Khami. Unfortunately, it is not possible to pinpoint exactly who was who in the society. However, what this does suggest is that status at Khami was not necessarily determined by where one was living. Other determinants such as age-grade, rank, and responsibilities in society are important factors that have to be taken into consideration. 
Across Africa, ruling elites employed a cocktail of measures to maintain power in their respective constituencies (Pwiti 2005; Fleisher and Wynne-Jones 2010; Monroe 2010, 2013; de Maret 2012; Pikirayi 2013). Whilst the evidence presented suggests non-discrimination in terms of access to both local and exotic goods at Khami, there is a need to explain the issue of power at Khami and how it manifested. A number of scholars in southern Africa have pointed to a number of factors such as religion (Garlake 1973; Pwiti 1996), control of external trade (Mudenge 1974, 1988; Pikirayi 1993; Pwiti 1996; Manyanga 2007; van Waarden 2012), control of large cattle herds (Mudenge 1974, 1988; Pwiti 1996b; van Waarden 2012) as having been key sources of the power of ruling elites. Religion can be argued to have played a role at Khami in building and maintaining political power amongst the elite. Religion was and is still being used in present day communities to promote unity and exert influence by a minority over the larger populace (Garlake 1973; Beach 1980; Mudenge 1988). The important contribution of cattle in the economies of the communities of south-western Zimbabwe and northern Botswana has also been noted to have played a significant role in development of the communities of south-western Zimbabwe and northern Botswana to statehood (Beach 1980; Pikirayi 2001). Control of this cattle must have played a role in defining power dynamics. Mudenge (1988) has shown that the rulers of the Mutapa state amassed a lot of wealth by employing the Shona concept of kuronzera, where cattle were leased out to other members of the community. The leaseholder had control over the cattle, including access to milk and draught power but could not slaughter the animal. This could have served as a source of power for the rulers at Khami as both archaeological and historical evidence suggest that cattle were key in the economy of Khami. Whilst excavation data has shown that access to resources was enjoyed by most members of the community, some form of control or management could have existed. Based on the recovered data, the management system of resources possibly was geared towards creating a competitive environment where the ruling elite encouraged individual prosperity for the greater good of the economy. Hence individuals could for instance participate in trade but remitting a tax to the ruling authority. This ensured that the ruling elite maintained control of the state and also contributed to its economic development, which manifested in large cattle herds, thriving craft production and participation in trade with the east coast in such products such as ivory, animal skins and gold (van Waarden 2012). 
In summation, it can be noted that the chronology and material culture of Khami suggest the presence of multiple centres around the site that operated as independent households. There appears to be general uniformity and heterarchy for the inhabitants of the site, as suggested by the uniform material distribution. This is in sharp contrast to previous interpretations, which focused mainly on the evidence from the walled areas, with no comparative evidence from the non-walled sections (Robinson 1959; Huffman 1981; 1984; 1996). Huffman's structural interpretation of the development of the site ignores the critically important dynamism exhibited in the architectural development of the site. His interpretation mirrors a static site, yet evidence on the ground suggests that the site was growing and developing. Any interpretation of the site should take this dynamism into account. While the interpretation offered here takes into account this dynamism, there is still need to investigate further other parts of the site, in order to develop a concrete model for the development of the site. I will now focus on the site's relations within the Zimbabwe Culture.

\subsection{KHAMI WITHIN THE ZIMBABWE CULTURE}

Scholars have noted that Khami is part of the Zimbabwe Culture and the capital of the Butua/Torwa, a state that is believed to have arisen after the demise of the Zimbabwe state in the fifteenth century (Robinson 1959; Huffman 1984; 2000; 2009; Pikirayi 2001; 2006). This conclusion was reached based on a correlation of the terminal date for Great Zimbabwe and the basal date for Khami (Sheppard and Swart 1967; Robinson 1961b; Huffman and Vogel 1991) and the perceived similarities between the material cultures of the two sites. However, recent research has demonstrated that Great Zimbabwe did not collapse in the fifteenth century, as was previously thought (Collett 1992; Bandama et al. 2016). Instead it continued to flourish well into the sixteenth century, at a time when Khami was also developing in south-western Zimbabwe (Collett 1992). Material evidence from the two sites do not show any similarities that could suggest that the two were successor states (Chirikure et al. 2013a; 2016). The walled sections at Great Zimbabwe are made up of mainly freestanding walls, which enclosed the houses of the elite (Garlake 1973). In contrast, Khami's walls were constructed to create artificial platforms, on top of which houses were constructed (Robinson 1959; Pikirayi 2013). This contrast is particularly glaring when one considers that the Leopard's Kopje tradition in south-west Zimbabwe and north-eastern Botswana is also 
characterised by terraced walling similar to those at Khami (Chirikure et al. 2014). Van Waarden $(2011 ; 2012)$ and Robinson (1985) have shown that in north-eastern Botswana and south-western Zimbabwe, Leopard's Kopje and Khami sites co-occur. This co-occurrence therefore suggests that the origin of Khami lies not at Great Zimbabwe but most likely in the Leopard's Kopje tradition.

Some scholars have also argued for a similarity between the ceramics of Great Zimbabwe and those of Khami, thereby justifying the assumption that Khami developed from Great Zimbabwe (Robinson 1959). As demonstrated in this study, ceramics from Khami are highly decorated with band and panel and painted with red ochre. This is in contrast to Great Zimbabwe ceramics, most of which are plain and graphite-burnished (Robinson 1961d). There is a lack of the high levels of decoration and red painting that is found in Khami ceramics. As such it can be argued that the two ceramic traditions are not related (Chirikure et al. 2013a). Since Leopard's Kopje and Khami co-occur in southwestern Zimbabwe, northeastern Botswana and northern South Africa, there is a strong possibility of a relationship between the two. This possibility is strengthened if one considers the dating evidence from Woolandale, the final phase of the northern Leopard's Kopje. Woolandale is dated from the thirteenth to the sixteenth centuries in south-western Zimbabwe (Huffman 1974: 99; 2007). The terminal date coincides with the rise of Khami in the same region, so there is a possibility of a relationship between the two. Because of this succession in the region, there is therefore a high likelihood of the two being related. While an in-depth study of the ceramics from the two traditions is needed to understand their relationship, some basic conclusions can be derived from the published material. Huffman (1974) has demonstrated that Woolandale ceramics are dominated by incisions and bordered bands of interlocking triangles, something that has also been demonstrated in Khami ceramics in this study. This trend contrasts with what Robinson (1961b: 217) noted with regard to ceramics from Great Zimbabwe, which were lacking in terms of decorated material.

More recently, van Waarden $(2011 ; 2012)$ has noted that in northern Botswana, Woolandale sites and Khami sites co-occur strengthening the argument that Khami evolved out of Woolandale. Robinson (1985) has also shown that the two co-occur in the Umguza Valley in 
south-western Zimbabwe. As such, Van Waarden (2012) posits that a Woolandale chief based at Khami might have grown powerful and united the fragmented Woolandale chiefdoms to create the Butua state. She links the rise of Khami to the collapse or Great Zimbabwe arguing that Great Zimbabwe might have collapsed due to the growing dominance of Khami as an economic powerhouse in the southern Zambezia (van Waarden 2012: 50). In particular she noted that Great Zimbabwe did not produce much of the trade items such as gold and ivory and this came from Woolandale communities probably as taxes. One of the problems with this argument is that it relies on a framework that recognises that Great Zimbabwe collapsed at 1450 AD (Huffman 1991). However, current evidence suggests that this is no longer the position and Great Zimbabwe continued to flourish to the seventeenth century (Collett et al. 1992; Bandama et al. 2016; Chirikure et al. 2016). Thus it is no longer tenable to try to create a causal relationship between the collapse of Great Zimbabwe and the rise of Khami.

Material culture evidence from the two sites also suggest that there are marked differences in their material record. For instance, Khami developed its own architectural canon that was different from that at Great Zimbabwe (Robinson 1959; Summers 1971; Pikirayi 2013). Khami architecture is made up of terraced dry-stone walling, while Great Zimbabwe's architecture consists mainly of freestanding walls. The issue of architecture at Khami has to be looked in the context of the region of south-western Zimbabwe and northern Botswana, where van Waarden $(2011 ; 2012)$ has shown that terraced walling developed in the area much earlier than at Mapungubwe, which is believed to have the earliest stone-walling in southern Africa. This feature makes the terraced walling at Khami a continuation of the terraced architecture from Woolandale, in contrast to the freestanding-walled Great Zimbabwe. Thus, on the basis of material-culture differences, one can cautiously conclude that Khami developed out of Woolandale in south-western Zimbabwe. In northern Zimbabwe, a similar trend has been noted: Pwiti (1996) has argued that, to account for the changes that led to the formation of complex societies in the region, it is more useful to look at the internal changes that took place in individual societies rather than to ascribe such change to external factors, especially when there is no evidence to support the latter hypothesis. This view was also a significant departure from migrationist frameworks, which accounted for the development of new societies through migrations and the collapse of other societies. Thus, while Pwiti (1996) 
noted a cultural relationship between the Mutapa and Great Zimbabwe states, there was no evidence to suggest that one was dominant over the other, or that the Mutapa broke away from Great Zimbabwe.

In the case of Khami I would go along with the suggestion by van Waarden (2012) that Khami developed out of Woolandale. However I suggest that Khami's development was not necessarily tied to Great Zimbabwe. The Woolandale chiefdoms could have developed trade routes, independent of Great Zimbabwe, just like in the fifteenth century when another route was opened along the Zambezi River. However as Pwiti (1996) it is important to also take into account the local factors that could have precipitated the rise of Khami. As shown in Chapter 3, south-western Zimbabwe is richly endowed with many natural resources that could support both human and animal life. As a result communities in the area managed to grow large herds of cattle, which was an important form of wealth in precolonial southern Africa. This coupled with the vast gold deposits in the area made south-western Zimbabwe an ideal environment for political centralisation, which manifested at Khami.

Khami also has a relationship with the Shashe-Limpopo region. It has traditionally been seen as the successor in that region, following the demise of Mapungubwe state (Huffman 2007). However, recent evidence is suggesting that the Mapungubwe state might not have collapsed towards the end of the thirteenth century and that it persisted well after AD 1290 (Prinsloo et al. 2005). Following analysis of shards recovered from Mapungubwe, Prinsloo et al. (2005) show that the ceramics were manufactured in China during the Yuan or Ming dynasty (c. AD 1279-1368), which is not consistent with the chronology of Mapungubwe Hill that puts the last occupation at the site at around AD 1280. These new dates from Chinese shards extend the chronology of Mapungubwe, meaning that the site could have overlapped with both Great Zimbabwe and Khami. A spectroscopic study conducted by Prinsloo et al. (2011) has also shown the presence of various pigments manufactured in the post-thirteenth century period in glass beads that were recovered in sealed archaeological contexts, with some dating as late as the nineteenth century. This has serious implications for our understanding of the nature and development of the Zimbabwe Culture in southern Africa and calls into question the dominant unilineal perspective on the development of the Zimbabwe Culture (Chirikure et al. 2012; 2013a; 2013b; 2016; van Waarden 2011; 2012). This new evidence on the contemporaneity of the major Zimbabwe Culture sites allows for new thinking about how the Zimbabwe Culture developed in southern Africa, and the relations that existed between the 
various sites. However, more research on these sites is still needed, particularly to make sense of their chronologies.

The various polities that made up the Zimbabwe Culture could be looked at as competing entities that shared the same landscape at a broadly similar time (Chirikure et al. 2013a; 2013b; 2016). These polities were different and operating independently in their areas. For instance, it is difficult to imagine how Khami could have controlled entities in northern Botswana that were over $200 \mathrm{~km}$ away, or in the Soutpansberg region. Logistically, this would have posed serious challenges. As such, while there could be some relations among the people who occupied these places, there is a possibility that there was significant independence. This is a tentative proposal, though, since the chronology of Mapungubwe is not clear at the moment, especially given Prinsloo's $(2005 ; 2011)$ suggestion that its chronology could overlap well into the nineteenth century. A Bayesian chronology of Great Zimbabwe also shows that it was already an important place by AD 1276, prior to the collapse of Mapungubwe in AD 1290 (Chirikure et al. 2013b). Research into the Zimbabwe Culture has also suffered from the "big sites" mentality, where dedicated research has been directed toward the large sites at the expense of the smaller sites (Chirikure 2015). This leaves the discussion on the Zimbabwe Culture focused on the major sites, with little contribution from the smaller sites. As such, there is need for dedicated research that also targets smaller sites to understand how they fit into the chronology of the Zimbabwe Culture and how they help illuminate the overlaps among the various states of the Zimbabwe Culture.

Prior to the Zimbabwe Culture, south-western Zimbabwe was dominated by the Leopard's Kopje tradition (Robinson 1966; 1985; Huffman 1974; 2007). Robinson (1966) showed that the Mambo phase was the first in the region, followed by the Woolandale phase. Research conducted in north-eastern Botswana and south-western Zimbabwe (Robinson 1985; van Waarden 2011; 2012) has shown that there are significant similarities and overlaps between Woolandale sites and Khami sites. This suggests that Woolandale was predecessor to Khami. Evidence for this is in the form of terraced walling, and coursed walling constructed of dressed blocks typical of Khami-style construction. For instance, at Nali Hill, Robinson (1985:30) noted extensive Khami settlements around the area of the Hill. Robinson has also 
shown, based on radiocarbon dates, that Great Zimbabwe, Mapungubwe and Woolandale sites such as Nali were contemporaneous from as early as the twelfth century, with traits of complexity being reflected in all the three sites. Occupation at Mapungubwe coincided with occupation at Nali, a major Woolandale site in south-western Zimbabwe, and Period III at Great Zimbabwe. In particular, Robinson noted that by AD 1130 at Great Zimbabwe, dhaka cement floors were already being constructed, and trade in glass beads was already being conducted. Robinson also recovered gold artefacts, which was evidence that gold was already being worked at the site by about the twelfth century. This inter-site analysis is further evidence that the development of the Zimbabwe Culture needs to be studied through a holistic approach that incorporates evidence from a number of sites, including the Leopard's Kopje sites, which preceded Khami in south-western Zimbabwe.

The setting of Khami also makes it ideal for the development of a centre, independent of happenings at other sites like Great Zimbabwe. I have shown earlier that the landscape around Khami was well suited to the rearing of livestock, and that this practice was corroborated by Portuguese writers (Mudenge 1974: 388). Mudenge concludes that wealth in the Shona state did not consist of trade goods from the Swahili or the Portuguese but instead of produce from agricultural and pastoral pursuits. As a result, the rich people were those who could amass large herds of cattle. Mudenge has shown that these elite obtained the following of others who were less privileged by loaning out their cattle through a system known as kuronzera, or use loan. Under this system, powerful men with more resources could afford to command the respect and loyalty of the rest of the community, and hence attract labour for their agricultural pursuits, accumulating ever more power and respect, and enabling significant nucleation at a single site.

However, I do not think that all platforms were constructed as part of conscripted labour. Some of the outlying platforms could have been constructed by individual households with assistance from other members of the community through the well-known Shona system of helping community members who are constrained by labour (nhimbe). This system is also evidenced by the fact that the platforms were not constructed as a once-off event. Rather they were a series of workings that took long to develop into what we know of them today. The 
dates from the Hill Complex Platform B Excavation show that the platforms could have taken about a hundred years to be fully developed from its earliest walls.

\subsection{CONCLUSION AND DIRECTION FOR FUTURE RESEARCH}

One of the central questions that this research managed to answer pertained to the material culture of the site and its distribution. Through excavations done at the site, I have managed to show that there was a general uniformity in terms of the objects recovered from the various areas that were investigated. These include areas that were investigated in the past by previous researchers at the site. The uniformity of material culture relates to both local and imported objects. Metal objects were recovered from most of the investigated areas, including the non-walled areas, suggesting that they could also be accessed by those who lived outside the walls. The recovery of imported objects in non-walled contexts also shows that trade items were also accessible to everyone at the site. As shown, this becomes problematic when trying to define commoners and elites at Khami. Aside from the stone walling, there does not appear to be any other material culture that separates the two classes. In this regard, it is important that scholars re-investigate the relationships among the residents of Khami and avoid the use of arbitrary class distinctions that are based on the presence or absence of walling, with no other material correlates. As suggested by other scholars working in other parts of Africa, there is a need to consider heterarchical organisation and avoid a hierarchical classification of society that has no basis (S K McIntosh 1999a; 1999b). This consideration is vitally important, since it allows us to note variability among various communities rather than clustering them all together into one model that frames their development. Looking at sites as homogenous units deflects from recognising some of the salient points that are critical in understanding the nature of society at Khami.

An understanding of Khami should also be complimented by an understanding of related sites within its vicinity and those further afield. These include Ntaba ye gwalo, Ngulungundu and Matalitali among others. This is critical so as to understand how Khami related to sites in its immediate environs, which could have served as extensions of the centre. This understanding is also critical in answering questions relating to the nature of prehistoric trade relations, both domestic and international. More research should enable a detailed understanding of each site 
in its own context and not subsume them under the type site. Most small sites in the region have been understood on the basis of surface collections, which have been used to classify sites based on our understanding of the type-site. This process is dangerous, because it does not account for changes that happen at sites and gives a false impression of the distribution of some sites. As such, there is need for research that also incorporates smaller sites into the framework, in order to understand how these smaller sites related to the much larger sites, which have been the focus of most of the research to date.

One of the key issues that also requires further interrogation is the relationship between the Khami and Woolandale sites. I have shown here that there is a possibility of a relation between the two based on ceramic data. Robinson (1985), Van Waarden (2011;2012) and Chirikure et al. (2013b) have also demonstrated that evidence from stone walling points to similarities between the architectures of Khami and of Woolandale. This finding is affirmed by the co-occurrence of Khami and Woolandale sites in south-western Zimbabwe, northeastern Botswana and northern South Africa (Robinson 1985). As such there is need for a comparative study of the material culture of the two traditions, which would help clarify their relationship.

The research also sought to understand the chronology of the site. Using architectural data from the stone walling, I have shown that the site must have been settled initially on the Hill Complex before the people started occupying other areas and constructing other platforms. This is a reflection of the growing nature of the site. It is, however, necessary to collect more dates for the Hill Complex, as the area of the first settlement, so that we understand its evolution. Material culture has already suggested that the site underwent significant changes throughout its occupation, as evidenced by the stone walling. Future research also needs to focus on other platforms, as a way of broadening our understanding of the site in its entirety and also of determining the spatial extent of the site that served as the capital of the Butua/Torwa state. 
There is also a need for research that focuses on material studies of the various objects found at the site, with a particular view to understanding the provenance of the ores that were used in the manufacturing of some of the objects. For instance, copper that was used in manufacturing objects has been argued to have come from Thakadu in north-eastern Botswana (van Waarden 2012). However, this conclusion was reached with no scientific research to back the findings. Such research is particularly important to reconstruct regional pattern of exchange networks, and in particular to explore how various materials, such as gold and ivory, found their way to Khami from their source-places.

Some scholars have argued that the subject of state formation and urbanisation in Africa has not been adequately appreciated, resulting in a deeply ingrained conviction that pre-colonial tropical Africa consisted only of scattered villages of mud or grass huts, with their inhabitants leading a nomadic way of life (Connah 1987; McIntosh 1999b; Monroe 2013; Chirikure et al. 2013b). As a result, some scholars who developed frameworks for state formation and urbanisation, such as Moorey (1979) and Cotterell (1983), largely ignored Africa's own experiences. S K McIntosh (1999b) is of the view that this exclusion stems from a desire to apply models developed in different contexts to the African context, despite these contexts being radically different. Eurocentric models for urban development emphasised issues like the existence of professionals, a religious hierarchy, a centralised exchequer and the presence of monumental structures, as well as the development of the art of writing (Childe 1951; Clark 1962). Clastres (1987) thus argues, for instance, that models of power from a Western cultural context may obscure the beliefs and experiences of those that the social scientist seeks to understand. It has also been observed that collectors of early African ethnographic literature failed to comprehend the diverse and variable nature of prehistoric African societies. As a result, ethnographies collected for one particular group were in some instances used to try and understand the past of other, entirely different groups. Early theorists on Africa's past introduced structural functionalism into their accounts of Africa's past (Fortes and Evans-Pritchard 1940). This situation reduced Africa's past to a static and ahistorical phenomenon, and failed to take advantage of the benefits of applying diachronic formulations, which could have helped in better understanding the dynamics of prehistoric state systems in Africa (McIntosh 1999b). 
Southern Africa has suffered in this regard from the colonial mentality belief that sites such as Khami were not products of local innovation but rather derived from foreign cultures (Hall and Neal 1902). Even after it was shown that these sites were local in nature (MacIver 1906; Caton-Thompson 1931), some scholars continued to attribute foreign influence, in the form of international trade, to the development of prehistoric towns in the region (Huffman 2000; 2009).

Of late, African scholars have begun to make their own contributions to models of state formation and urbanisation on the continent, particularly in the sub-Saharan region. As a result, complexity is now being conceptualised as the degree of internal differentiation, both horizontally and vertically, and the intricacy of relations within a system (Paynter 1989, McIntosh 1999b: 11). Alternative pathways to understanding complexity have been developed, which, while recognising the concept of hierarchy, also focus on heterarchy as an alternative framework. Heterarchy is defined by the presence of overlapping and decentralised political institutions (Crumley 1995; McIntosh 1999a, 1999b). The two concepts are not mutually exclusive, and research in many parts of Africa has actually shown that the two existed along independent sliding scales of horizontal and vertical complexity (McIntosh: 1999a, b, Monroe 2013). With increased emphasis on prehistoric African centres in complex societies, researchers are increasingly examining political centralisation in terms of the complexity of the strategies used by elites to acquire their power. As a result, it is important that the nature of urbanism at Khami be examined in more detail, with a view to understanding how the results of the current study enlighten us on urbanism in the region. This examination requires a multi-disciplinary approach that employs a geographical understanding of urban society, and a philosophical understanding of urbanism in the African context.

While the nature of urbanism Khami is beyond the scope of this study, tentative ideas can be made. Khami appeared to be a centre that attracted a significant population clustered at the site. A variety of activities such as smelting and smithing, cotton spinning and weaving and other craft production activities sustained this centre and made it a self-sustaining unit. However, the residence would also venture outside the centre for other activities such as mining and hunting. As demonstrated earlier on mining appears to have been done on a part time basis with agriculture being the mainstay of the economy. The centre was surrounded by 
a number of sites. I would argue that the ones close to it such as Ngulungundu and Ntaba ya gwalo were under the direct control of the Khami and probably represented the expansion of the site as families moved to establish their own households. However the authority of Khami would have waned the further other centres were from it even though these were the same people sharing same language and culture.

\subsection{SUMMARY}

This study has provided new answers to some century-old questions about the chronology and sequence of the Zimbabwe Culture. Radiocarbon dates, ceramic data and glass beads have been combined to build a relative and absolute chronology of Khami. The study combined a culture-historical framework with new chronological information from other Zimbabwe Culture sites in the region, to show that our understanding of the development of the Zimbabwe Culture has been flawed. Instead of a lineal sequence from Mapungubwe to Khami, via Great Zimbabwe, the study suggests that these entities were most likely competing entities in the region that overlapped in terms of chronology. The study makes no claims to being exhaustive: more research is required, at Khami, other Zimbabwe Culture sites and also Leopard's Kopje sites, to further refine this new mode of thinking. The homogeneity of the material culture at the site points to a subsistence-based economy, and more research needs to be aimed at understanding Khami's relationship with its hinterland, particularly in terms of mobilising trade items with the east coast. Affinities between the material cultures of Khami and Woolandale also suggest that Khami developed out of Woolandale and not Great Zimbabwe, contrary to past hypotheses and assumptions about the site's development. This finding, too, needs further investigation, so that more conclusive evidence can be uncovered. 


\section{REFERENCES}

Ames. M. 1994. Cannibal tours, glass boxes and the politics of interpretation. Pearce. S. M. Interpreting objects and collections. London: Routledge: 98-106

Amm, F. L. 1940. The geology of the country around Bulawayo. Geological Survey Bulletin No. 35

Antonites, A. 2012. Political and Economic Interaction in the hinterland of the Mapungubwe Polity, c. AD 1200-1300. Unpublished Ph.D. thesis, University of Yale

Balfour, H. 1906. Flint engraved pottery from the ruins at Khami and Dhlo-Dhlo. Man 6: 1719

Bandama, F., Hall, S. and Chirikure, S. 2015. Eiland crucibles and the earliest relative dating for tin and bronze working in southern Africa. Journal of Archaeological Science 62: 82-91

Bandama, F., Moffett, A. J., Thondhlana, T. P. and Chirikure, S. 2016. The production, distribution and consumption of metals and alloys at Great Zimbabwe. Archaeometry DOI:10.1111/arcm.12248

Barker, G. 1978. Economic models for the Manekweni Zimbabwe, Mozambique. Azania 13: $71-100$

Beach, D. N. 1977. The Shona economy: Branches of production. Palmer, R and Parsons, W. (eds) The roots of rural poverty in central and southern Africa. London: Heinemann: 37-65

Beach, D. N. 1980. The Shona and Zimbabwe 900-1850: an outline of Shona history. Gwelo: Mambo Press

Beach, D. N. 1984. Zimbabwe before 1900. Gweru : Mambo Press

Beach, D. N., Bourdillon, M. F. C., Denbow, J., Hall, M., Lane, P., Pikirayi, I. and Pwiti, G. 1997. Review of Snakes and crocodiles: Power and symbolism in ancient Zimbabwe, by Thomas Huffman. South African Archaeological Bulletin 52 (166): 125-138

Beach, D. N. 1998. Cognitive archaeology and the imaginary history of Great Zimbabwe. Current Anthropology 39: 47-72 
Beck, H. C. 1928. Classification and nomenclature of beads and pendants. Archaeologia 77: $1-76$

Beck, H. C. 1931. Rhodesian beads from the 1929 excavation. Caton-Thompson, G. The Zimbabwe Culture: Ruins and Reactions. Oxford: Clarendon Press: 229-242

Beck, 1937. The beads of the Mapungubwe district. Fouche, L (ed) Mapungubwe: Ancient Bantu civilisation on the Limpopo. Cambridge: Cambridge University Press: 104-113

Bent, J. T. 1892. The ruined cities of Mashonaland. London: Routledge

Brain, C. K. 1974. Some suggested procedure in the analysis of bone accumulations from southern African quaternary sites. Annals of the Transvaal Museum 29 (1): 1-8

Brumfiel, E. M and Earle, T. K. 1987. Specialisation, exchange and complex societies: an introduction. Brumfiel, E. M and Earle, T. K. (ed.) Specialisation, exchange and complex societies. Cambridge: Cambridge University Press

Bvocho, G. 2005. Ornaments as social and chronological icons: A case study of south-eastern Zimbabwe. Journal of Social Archaeology 5 (3): 409-424

Calabrese, J. A. 2000. Metals, ideology and power: the manufacture and control of materialised ideology in the area of the Limpopo-Shashe confluence, c. AD 900 to 1300. South African Archaeological Society Goodwin Series 8: 100-111

Caple. C. 2006. Objects: Reluctant witnesses to the past. London: Routledge

Caton-Thompson, G. 1931. The Zimbabwe Culture: Ruins and Reactions. Oxford: Clarendon Press

Chapano, C. 2002. A checklist of Zimbabwean grasses. Pretoria: National Botanical Institute

Chapdelaine, C. 2002. Out in the Streets of Moche: Urbanism and Socio-political Organisation at a Moche IV Urban Centre. Isbell, W. H, and Silverman, H, Andean Archaeology I: Variations in socio-political organisation. New York: Kluwer Academic 
Chase, A. F and Chase, D. Z. 1992. Mesoamerican elites: Assumptions, definitions and models. Chase, D. Z. and Chase, A. F (eds.) Mesoamerican elites: an archaeological assessment. Norman: University of Oaklahoma: 3-17

Childe, V. G. 1951. Social Evolution. London: Watts

Childs, S. T. 1991. Style, technology and iron smelting furnaces in Bantu speaking Africa. Journal of Anthropological Archaeology, 10: 332-359

Childs, S. T. and Dewey, W. J. 1996. Forging symbolic meaning in Zaire and Zimbabwe. Schmidt P. R. (ed.) The Culture and Technology of African iron production. Gainesville: University Press of Florida

Chilton, E. S. 1999. Material meanings: critical approaches to the interpretation of material culture. Utah: University of Utah Press

Chipunza, K.T. 1994. A diachronic analysis of the architecture of the Hill Complex at Great Zimbabwe. Uppsala: Societas Archaeologica Upsaliensis

Chirikure, S. 2006. New light on Njanja ironworking: towards systematic encounter between ethnohistory and archaeometallurgy. South African Archaeological Bulletin 61 (184): 142151

Chirikure, S. 2007. Metals and society: Iron production and its position in Iron Age communities of southern Africa. Journal of Social Archaeology 7 (1): 74-103

Chirikure, S. 2015. Land and sea links: 1500 years of connectivity between southern Africa and the Indian Ocean rim regions, AD 700 to 1700. African Archaeological Review 31: 705724

Chirikure, S., Pikirayi, I. and Pwiti, G. 2002. A comparative study of Khami pottery, Zimbabwe. Chami, F. and Pwiti, G. (eds.) People, Contacts and the Environments in the African Past, 106-131

Chirikure, S. and Rehren, T. 2004. Ores, furnaces, slags and prehistoric societies: aspects of iron working in the Nyanga agricultural complex AD 1300-1900. African Archaeological Review 21 (3): 135-152 
Chirikure, S. and Pikirayi, I. 2008. Inside and outside the dry stone walls: Revisiting the material culture of Great Zimbabwe, Antiquity 82: 976-993

Chirikure, S., Manyanga, M. and Pollard, M. 2012. When science alone is not enough: Radiocarbon timescales, history, ethnography and elite settlements in southern Africa. Journal of Social Archaeology 12(3), 356-379

Chirikure, S., Pollard, M., Manyanga, M and Bandama, F. 2013a. A Bayesian chronology for Great Zimbabwe: re-threading the sequence of a vandalised monument. Antiquity 87: 854872

Chirikure S., Manyanga, M., Pikirayi I and Pollard, M. 2013b. New pathways of sociopolitical complexity in southern Africa. African Archaeological Review 30: 339-366

Chirikure S., Manyanga M., Pollard A. M., Bandama F., Mahachi G., and Pikirayi, I. 2014 Zimbabwe Culture before Mapungubwe: New Evidence from Mapela Hill, South-Western Zimbabwe. PLoS ONE 9(10): e111224. doi:10.1371/journal.pone.0111224

Chirikure, S., Mukwende, T. and Taruvinga, P. 2015. Postcolonial heritage conservation in Africa: Perspectives from Africa. International Journal of Heritage Studies, DOI: $10.1080 / 13527258.2015 .1103300$

Chirikure, S., Bandama, F., House, M., Moffett, A., Mukwende, T. and Pollard, M. 2016. Decisive evidence for multidirectional evolution of sociopolitical complexity in Southern Africa. African Archaeological Review DOI 10.1007/s10437-016-9215-1

Chittick N. 1974. Kilwa: An Islamic trading city on the East African Coast; The finds, 2. Nairobi: The British Institute in East Africa

Clark, J. D. 1962. Africa, south of the Sahara. Braidwood, R and G. Willey (eds.) Courses towards urban life: archaeological considerations of some cultural alternates. London: Aldine Books

Clarke, D. V., Cowie, T. G. and Foxon, A. 1985. Symbols of power: at the time of Stonehenge. Edinburgh: National Museums and Antiquities of Scotland 
Collett D, Vines A and Hughes G. 1991. The chronology of the Valley Enclosures: implications for the interpretation of Great Zimbabwe. The African Archaeological Review 10: $139-161$

Connah, G. 1987. African Civilisations. Precolonial cities and states in tropical Africa: An archaeological perspective. Cambridge: Cambridge University Press

Cotterell, A. (ed.). 1983. The encyclopaedia of ancient civilisations. London: Mcmillan

Cooke, C. K. 1950. The Middle Stone Age site at Khami, Southern Rhodesia: a further examination. The South African Archaeological Bulletin 5 (18): 60-68

Cooke, C. K. 1953. Examination of Ash-Filled Pits in the Magosian Deposit at Khami. Occasional Papers of the National Museum of Southern Rhodesia 2 (18): 529-531

Cooke, C. K and Robinson, K. R. 1954. Excavation at Amadzimba Cave, located in the Matopos Hills, southern Rhodesia. Occasional Papers of the National Museums, Southern Rhodesia 2, 699-728

Cooke, C. K., Summers, R. and Robinson, K. R. 1966. Rhodesian prehistory re-examined: Part II, the Iron Age. Arnoldia 2, 1-11

Costin, C. L. 2001. Craft Production Systems. Feinman, G. and Price T. D. (eds.) Archaeology at the millennium: A source book. New York: Kluwer Academic

Costin, C. L. 2005. Craft Production. Maschner, H. (ed.) Handbook of Methods in Archaeology. Walnut Creek: Altamira Press: 1032-1105

Costin, C. L and Earle, T. 1989. Status distinction and legitimation of power as reflected in changing patterns of consumption in late Prehispanic Peru. American Antiquity 54 (4): 691714

Costin, C. L. and Hagstrum, M. B. 1995. Standardisation, labour investment, skill and the organisation of ceramic production in late prehispanic Highland Peru. American Antiquity 60 (4): 619-639 
Coutu, A.N., Whitelaw, G., LeRoux, P. and Sealy, J. (accepted) Earliest evidence for the ivory trade in southern Africa: isotopic and ZooMS analysis of 7th-10th century AD ivory from KwaZulu-Natal. African Archaeological Review.

Crabtree, P. J. 1990. Zooarchaeology and complex societies: some uses of faunal analysis for the study of trade, social status and ethnicity. Archaeological Method and Theory 2: 155-205

Davison, P. 1972. Glass beads in African archaeology. Unpublished PhD thesis. University of California

Davison, P. and Harries, P. 1980. Cotton weaving in south-east Africa: its history and technology. Textile History 11 (1): 175-192

DeCorse, R. C. 1989. Beads as chronological indicators in West African archaeology: A reexamination. BEADS: Journal of the Society of Bead Researchers 1: 41-53

De Jager, E. J. 1964. A further note on Jones's ancient battle axe from Khami Ruins. Arnoldia 1 (9): 1-4

De Maret, P. 1999. The power of symbols and the symbols of power through time: probing the Luba past. McIntosh, S. K. Beyond Chiefdoms: Pathways to Complexity in Africa. Cambridge: Cambridge University Press: 151-165

De Maret, P. 2012. From kinship to kingship: an African journey into complexity. Azania 47: $314-26$

Denbow, J. 1979. Cenchrus ciliaris: an ecological indicator of Iron Age middens using aerial photography in eastern Botswana. South African Journal of Science 75: 405-408

Denbow, J. 1984. Cows and Kings: A spatial and economic analysis of a hierarchical settlement system in eastern Botswana. Hall, M., Avery, G., Avery, D., Wilson, M. and Humphreys, A (eds.), Frontiers: Southern African archaeology today. Oxford: British Archaeological Reports: 24-39

Denbow, J., Smith, J., Ndobochani, N. M., Atwood, K., and Miller, D. 2008. Archaeological excavations at Bosutswe, Botswana: cultural chronology, paleo-ecology and economy. Journal of Archaeological Science 35: 459-480 
Dussubieux, L., Robertshaw, P. and Glascock, M. D. 2009. LA-ICP-MS analysis of African glass beads: Laboratory inter-comparison with an emphasis on the impact of corrosion on data interpretation. International Journal of Mass Spectrometry 284: 152-161

Ellert, H. 1993. Rivers of Gold. Gweru: Mambo Press

Fagan, B. M., Phillipson, D. W. and Daniels, S. G. H. 1969. Iron Age cultures of Zambia. London: Chatto and Windus

Fatherley, K. 2009. Socio-political status of Leokwe people in the Shashe-Limpopo Basin during the Middle Iron Age through faunal analysis. Unpublished MSc dissertation. University of Witwatersrand, Johannesburg

Fisher, J. W. 1995. Bone surface modifications in Zoo-archaeology. Journal of Archaeological Method and Theory 2(1): 7-68

Fleisher, J., and La Violette, A. 1999. Elusive wattle-and-daub: finding the hidden majority in the archaeology of the Swahili coast. Azania: Archaeological Research in Africa 34(1): 87108

Fleisher, J and Wynne-Jones, S. 2010. Authorisation and the process of power: the view from African archaeology. Journal of World Prehistory 32: 177-193

Forssman, T., Page, B. and Selier, J. 2014. How important was the presence of elephants as a determinant of Zhizo settlement of the Greater Mapungubwe Landscape. Journal of African Archaeology 12: 75-87

Fouche, L. 1936. Mapungubwe: Ancient Bantu civilisations on the Limpopo. Cambridge: Cambridge University Press

Fredriksen, P. D. and Chirikure, S. 2015. Beyond Static Models: An evaluation of present status and future prospects for Iron Age research in southern Africa. Cambridge Archaeological Journal 25 (3): 597-614

Gambiza, J and Nyama, C. nd. Country pasture/forage resource profile: Zimbabwe http://www.fao.org/ag/agp/agpc/doc/counprof/zimbabwe/zimbab.htm Accessed on 2 February 2015 
Garbutt, H.W. and Johnson, J.P. 1912. Hut at Khami Ruins. Man 12: 110-112

Gardner, G. A. 1963. Mapungubwe: Volume II. Pretoria: J. L. van Schaik

Garlake, P. S. 1968. The value of imported ceramics in the dating and interpretation of the Rhodesian Iron Age. The Journal of African History 9(1): 13-33

Garlake, P. S. 1970. Rhodesian ruins - a preliminary assessment of their styles and chronology. Journal of African History 11 (4): 495-513.

Garlake, P. S. 1973. Great Zimbabwe. London: Thames and Hudson.

Garlake, P. 1978. Pastoralism and Zimbabwe. Journal of African History 19(4), 479-93

Gill, J.W. 1903. A comparison between the ruins at the Khami River and at Zimbabwe. Proceedings and Transactions of the Rhodesian Scientific Association 1: 9-10.

Hagstrum, M. 2001. Household production in Chaco Canyon Society. American Antiquity 66 (1): 47-55

Hall, M. 1983. Tribes, traditions and numbers: the American model in southern African Iron Age ceramic studies. South African Archaeological Bulletin 38 (138): 51-57

Hall, M. 1984. Pots and politics: ceramic interpretations in southern Africa. World Archaeology 15 (3): 262-273

Hall, M. 1987. The Changing Past: farmers, kings and traders in southern Africa 200-1860. Cape Town: David Phillip

Hall, R. N. and Neal, W. G. 1902. The Ancient Ruins of Rhodesia. London: Methuen and Co Hall, R.N. 1909. Prehistoric Rhodesia. London: T. Fisher Unwin Hall, R.N. 1910. Guide to Khami Ruins. Bulawayo: Philpott and Collins Hanisch, E. 1980. An archaeological interpretation of certain Iron Age sites in the Limpopo / Shashi valley. Masters dissertation, University of Pretoria 
Herbert, 1996. Metals and power at Great Zimbabwe. Pwiti, G and Soper, R (eds) Aspects of African Archaeology: Papers from the 10 ${ }^{\text {th }}$ congress of the Pan African Association for Prehistory and Related Studies. Harare: University of Zimbabwe Publications

Hodder, I. 1986. Reading the past: Current approaches to interpretation in archaeology. Cambridge: Cambridge University Press

Hodder, I. 1987. The archaeology of contextual meanings. Cambridge: Cambridge University Press

Huffman, T. N. 1971. Cloth from the Iron Age in Rhodesia. Arnoldia 14 (5): 1-19

Huffman, T. N. 1972. An Arab coin from Zimbabwe. Arnoldia 32:1-7

Huffman, T. N. 1974. The Leopard's Kopje Tradition. Museum Memoir 6. Salisbury: National Museums and Monuments of Rhodesia.

Huffman, T. N. 1978. 'The origins of Leopard's Kopje: an 11th century difaqane', Arnoldia 8 (23): $1-8$

Huffman, T. N. 1980. Ceramics, classifications and Iron Age entities. African Studies 29 (2), $123-174$

Huffman, T. N. 1981. Snakes and Birds: expressive space at Great Zimbabwe. African Studies 40: 131-150

Huffman, T. N. 1984. Expressive space in the Zimbabwe culture. Man (New Series) 19 (4): 593-612

Huffman, T. N. 1986. Iron Age settlement patterns and the origins of class distinctions in Southern Africa. F. Wendorf and E. Close (eds) Advances in World Archaeology 5: 291-338

Huffman, T. N. 1996. Snakes and crocodiles: Power and symbolism in ancient Zimbabwe. Johannesburg: Witwatersrand Press.

Huffman, T. N. 2000. Mapungubwe and the origins of the Zimbabwe Culture. Leslie, M. and Maggs, T. (eds), African Naissance: The Limpopo Valley 1000 Years Ago, The South African Archaeological Society Goodwin Series 8: 14-29. 
Huffman, T. N. 2007. Handbook to the Iron Age: The Archaeology of Pre-colonial farming societies in Southern Africa. Pietermaritzburg: University of KwaZulu-Natal Press.

Huffman, T. N. 2009. Mapungubwe and Great Zimbabwe: The origin and spread of social complexity in southern Africa. Journal of Anthropological Archaeology, 28: 37-54.

Huffman, T. N. 2014. Social complexity in southern Africa. African Archaeological Review, DOI $10.1007 / \mathrm{s} 10437-014-9166-3$

Huffman, T. N. 2015. Mapela, Mapungubwe and the origins of states in southern Africa, South African Archaeological Bulletin 70 (201): 15-27

Huffman, T. N. and Vogel, J. C. 1991. The chronology of Great Zimbabwe. South African Archaeological Bulletin, 46 (154): 61-70

Huffman, T. N., van der Merwe, H. D., Grant, M. R and Kruger, G. S. 1994. Early copper mining at Thakadu, Botswana. The Journal of the South African Institute of Mining and Metallurgy (March/April 1995): 53-61

Hughes, G. 1997. Excavations from the peripheral area of settlement of Khami, Zimbabwea 5: $3-21$

Joy. J. 2009. Reinvigorating object biography: reproducing the drama of object lives. World Archaeology 41 (4): 540-556

Jones, A. 2002. Archaeological Theory and Scientific Practice. Cambridge: Cambridge University Press

Karklins, K. 1985. Glass beads: The $19^{\text {th }}$ century Levin catalogue and venetian bead book and guide to description of glass beads. Studies in Archaeology, Architecture and History. Ottawa: Parks Canada

Kidd, K. E. and Kidd, M. A. 1970. A classification system for glass beads for the use of field archaeologists. Canadian Historic Sites: Occasional Papers in Archaeology and History 1: 45-89

Kim, N and Kusimba, C. 2008. Pathways to social complexity and political centralisation in the southern Zambezian region. African Archaeological Review 25, 131-152. 
Kingery, D. W. 1996. Materials science and material culture. Kingery, D. W. (ed.) Learning from things: method and theory of material culture studies. Washington DC: Smithsonian Institution: 181-203

Klein, R. G. and Cruz-Uribe, K. 1984. The analysis of animal bones from archaeological sites. Chicago: Chicago University Press

Koleini, F., Prinsloo, L. C., Biemond, W. M., Colomban, P., Ngo, A., Boeyens, J. C. A. and van der Ryst, M. M. 2015. Towards refining the classification of glass trade beads imported into southern Africa from the $8^{\text {th }}$ to the $16^{\text {th }}$ century AD. Journal of Cultural Heritage http://dx.doi.org/101016/j.culher.2015.11.003

Kopytoff, I. 1986. The cultural biography of things: commoditisation as process. Appadurai, A, The social life of things: Commodities in cultural perspective. Cambridge: Cambridge University Press

Kuper, A. 1980. Symbolic dimensions of the southern Bantu homestead. Africa 50: 8-23

La Violette, A. 2008. Swahili cosmopolitanism in Africa and the Indian Ocean world, AD 600-1500, Archaeologies: Journal of the World Archaeological Congress DOI $10.1007 /$ s11759-008-9064-X

La Violette, A and Fleisher, J. 2005. The archaeology of sub-Saharan urbanism: Cities and their country sides. Stahl, A. B. (ed) African Archaeology: A Critical Introduction. Malden: Blackwell Publishing

Lindahl, A and Matenga, E. 1995. Present and past: ceramics and homesteads: an ethnoarchaeological project in the Buhera district, Zimbabwe. Studies in African Archaeology 11. Uppsala: Societas Archaeologica Upsaliensis

Lubar, S. 1996. Learning from technological things. Kingery, D. Learning from things: Method and theory of material culture studies, 31-35

Manyanga, M. 2000. Choices and Constraints: Animal resource exploitation in south-eastern Zimbabwe c. AD 900-1500 (Studies in African Archaeology 18). Uppsala: Department of Archaeology and Ancient History. 
Manyanga, M. 2001. Human response and contribution to environment change. Chami, F., Pwiti, G., and Radimilahy, C (eds). People, contacts and environment in the African Past, Dar es alaam: DUP: 16-27

Manyanga, M. 2006. Resilient Landscapes: Socio-environmental dynamics in the ShashiLimpopo Basin, Southern Zimbabwe c. AD 800 to the present. Uppsala: Societa Archaeologica Uppsaliensis

Maquet, J. 1993. Objects as instruments, objects as signs. Lubar, S and Kingery, D. W. History from things: Essays on material culture. New York: Smithsonia Institute: 30-40

MacEachern, S., Archer, D.J.W. and Garvin, R.D. (eds). 1989. Households and Communities: Proceedings of the Twenty-first Annual Conference of the Archaeological Association of the University of Calgary. University of Calgary, Archaeological Association.

MacIver, D. R. 1906. Medieval Rhodesia. London: Macmillan

McIntosh, S. K. 1997. Urbanism in sub-Saharan Africa. Vogel, J. O. Encyclopaedia of precolonial Africa. Walnut Creek: Altamira Press: 461-465

McIntosh, S. K. 1999a. Modelling political organisation in large scale settlement clusters: a case study from the Inland Niger Delta. McIntosh, S. K. (ed.) Beyond Chiefdoms: Pathways to Complexity in Africa. Cambridge: Cambridge University Press.

McIntosh, S. K. 1999b. Pathways to Complexity: An African perspective. McIntosh, S. K. (ed.) Beyond Chiefdoms: Pathways to Complexity in Africa. Cambridge: Cambridge University Press.

Meskell, L. 2005. Objects in the mirror appear closer than they are. Miller, D (ed.) Materiality. Durham: Duke University Press

Miller, D. 1987. Material Culture and Mass Consumption. Oxford: Basil Blackwell

Miller, D. 2002. Smelter and smith: Iron Age metal fabrication technology in southern Africa. Journal of Archaeological Science 29: 1083-1131

Miller, D., Desai, N. and Lee-Thorp, J. 2000. Precolonial gold mining in southern Africa: a review. South African Archaeological Bulletin Goodwin Series 8: 91-99 
Miller, D. and Tilley, C. 1996. Editorial. Journal of material culture 1: 5-14

Monroe, J. C. 2013. Power and agency in precolonial African states. Annual Review of Anthropology 42: 17-35

Moorey, P. R. S. 1979. The origins of civilisations: Wolfson College Lectures 1978. Oxford: Clarendon Press

Mudenge, S. I. 1974. The role of foreign trade in the Rozvi empire: a reappraisal. Journal of African History 15 (3): 373-391

Mudenge, S. I. 1988. A political history of Munhumutapa. Harare: Zimbabwe Publishing House

Muringaniza, S. J. and Ruwitah, A. 1996. Ethnography and archaeological interpretation of use of space at Zimbabwe Tradition sites. Zimbabwea 4: 23-33

Murray, E and Manyanga, M. 2008. Pythons, Pangolins and Panthera: Faunal remains from ko Bulawayo, a $19^{\text {th }}$ century Ndebele capital western Zimbabwe. Museum Memoir (New Series) 2. Harare: National Museums and Monuments of Zimbabwe

Ndoro, W. 1996. Towards the meaning and symbolism of archaeological pottery assemblages. Pwiti, G and Soper, R. Aspects of African Archaeology. Harare: University of Zimbabwe Publications

Ndoro, W. 2005. The preservation of Great Zimbabwe: your monument, our shrine. Rome: ICCROM

Ndoro, W and Pwiti, G. 1999. Khami World Heritage Site Condition Survey Report and Management Plan. A report prepared for the National Museums and Monuments of Zimbabwe

Pearce, S. 1994a. Objects as meaning; or narrating the past. Pearce, S (ed) Interpreting objects and collections. London: Routledge: 19-29

Pearce, S. 1994b. Thinking about things. Pearce, S (ed) Interpreting objects and collections. London: Routledge: 125-132 
Pikirayi, I. 1993. The Archaeological Identity of the Mutapa State: Towards an Historical Archaeology of Northern Zimbabwe, Studies in African Archaeology 6 Uppsala: Societas Archaeologica Upsaliensis

Pikirayi, I. 1997. Pots, people and culture: an overview of ceramic studies in Zimbabwe. Pwiti, G. Caves, Monuments and Texts: Zimbabwean Archaeology Today, Studies in African Archaeology 14, Uppsala: Societas Archaeologica Upsaliensis: 69-108

Pikirayi, I. 1999. Taking southern African ceramic studies into the Twenty-first century: A Zimbabwean perspective. African Archaeological Review 16(3): 185-189

Pikirayi, I. 2001. The Zimbabwe Culture: origins and decline in Southern Zambesian states in Southern Africa. Walnut Creek: Altamira Press

Pikirayi, I. 2006. The demise of Great Zimbabwe, AD 1420-1550: an environmental reappraisal. A. Green and R. Leech (eds) Cities in the World, 1500-2000. The Society for Post-Medieval Archaeology Monograph 3, Leeds, UK: Maney Publishing: 31-47

Pikirayi, I. 2007. Ceramics and group identity: Towards a social archaeology in southern African Iron Age ceramic studies. Journal of Social Archaeology 7(3): 286-301

Pikirayi, I. 2013. Stone architecture and the development of power in the Zimbabwe tradition AD 1270-1830, Azania: Archaeological Research in Africa

Pikirayi, I. and Chirikure, S. 2011. Debating Great Zimbabwe. Azania: Archaeological Research in Africa, 46: 2, 221-231

Pikirayi, I. and Lindahl, A. 2013. Ceramics, ethnohistory, and ethnography: Locating meaning in southern African Iron Age ceramic assemblages. African Archaeological Review DOI: $10.1007 / \mathrm{s} 10437-0139145-0$

Plug, I. 1990. The faunal remains from recent excavation at uMgugundhlovu. South African Archaeological Bulletin 45: 47-52

Prinsloo, L. C., Wood, N., Loubser, M., Verryn, S. M. C and Tiley, S. 2005. Re-dating of Chinese celadon shards excavated on Mapungubwe Hill, a $13^{\text {th }}$ century Iron Age site in South 
Africa, using Raman spectroscopy, XRF and XRD. Journal of Raman Spectroscopy 36: 806816

Prinsloo, L. C. and Colomban, P. 2008. A Raman spectroscopic study of the Mapungubwe oblates: glass trade beads excavated at an Iron Age archaeological site in South Africa. Journal of Raman Spectroscopy 39: 79-90

Prinsloo, L. C., Tournie, A. and Colomban, P. 2011. A Raman spectroscopic study of glass trade beads excavated at Mapungubwe hill and K2, two archaeological sites in southern Africa, raises questions about the last occupation date of the hill. Journal of Archaeological Science 38: 3264-3277

Prinsloo, L. C., Boeyens, J. C. A., van der Ryst, M. M. and Webb, G. 2012. Raman signatures of the modern pigment $(\mathrm{Zn}, \mathrm{Cd}) \mathrm{S}_{1_{-} \mathrm{x}} \mathrm{Se}_{\mathrm{x}}$ and glass matrix of a red bead from Magoro Hill, an archaeological site in Limpopo Province, South Africa, recalibrate the settlement chronology, Journal of Molecular Structure 1023: 123-127

Pwiti, G. 1991. Trade and Economies in southern Africa: the archaeological evidence. Zambezia 18: 119-29

Pwiti, G. 1994. Prehistoric farming communities of the mid Zambezi valley, northern Zimbabwe. Zimbabwean Prehistory 21: 7-14

Pwiti, G. 1996a. Continuity and Change: An Archaeological Study of Farming Communities in Northern Zimbabwe, AD 500-1700, Studies in African Archaeology 13. Uppsala: Societas Archaeologica Upsaliensis

Pwiti, G. 1996b. Peasants, Chiefs and Kings: A model for the development of cultural complexity in northern Zimbabwe. Zambezia XXIII (i): 31-52

Pwiti, G. 1997. The origins and development of the stone building cultures of Zimbabwe. Dewey, W. and Pakmenaer, E. (eds.) Legacies of stone: Zimbabwe past and present. Tervuren: Royal Museum for Central Africa: 77-96

Pwiti, G. 2005. Southern Africa and the East African Coast. Stahl, A. B. (ed.) African Archaeology: A Critical Introduction. Malden: Blackwell Publishing 
Pwiti, G and Mawoko, 1997. Faunal remains from Kasekete, a Zimbabwe Tradition site in the Zambezi valley, Northern Zimbabwe. Zimbabwea 5: 22-29

Randles, W. G. L. 1981. The empire of Monomotapa from the $15^{\text {th }}$ to the $19^{\text {th }}$ century. Gwelo: Mambo Press

Reid, A and Segobye, A. K. 2000. An ivory cache from Botswana. Antiquity 74: 326-331

Robertshaw. P., Wood, M., Melchiorre, E., Popelka-Filcoff, R. S. and Glascock, M. D. 2010. Southern African glass beads: Chemistry, glass sources and patterns of trade. Journal of Archaeological Science 37 (8): 1898-1912

Robinson, K. R. 1957. Excavations at Khami Ruins, Matabeleland. Clark, J.D. (ed.) The Third Pan-African Congress on Prehistory, Livingstone 1955. London: Chatto and Windus: $357-365$

Robinson, K. R. 1958. Four Rhodesian Iron Age sites: a brief account of stratigraphy and finds. Occasional Papers of the National Museums of southern Rhodesia 2 (22a)

Robinson, K. R. 1959. Khami Ruins. Cambridge: Cambridge University Press

Robinson, K. R. 1961a. Dated imports from Khami Ruins, South African Archaeological Bulletin 16 (62): 66-67

Robinson, K. R. 1961b. Excavations on the Acropolis Hill. Occasional Papers of the National Museums of Southern Rhodesia 23A: 159-192

Robinson, K. R. 1961c. Zimbabwe Beads. Occasional Papers of the National Museums and Monuments of Southern Rhodesia 23A: 193-226

Robinson, K. R. 1961d. Zimbabwe Pottery. Occasional Papers of the National Museums and Monuments of Southern Rhodesia 23A: 227-229

Robinson, K. R. 1966. The Leopard's Kopje Culture, its position in the Iron Age of Southern Rhodesia. South African Archaeological Bulletin 21: 5-51

Robinson, K. R. 1985. Dated Iron Age sites from the Upper Umguza valley 1982: their possible implications. South African Archaeological Bulletin 43: 49-52 
Roskams, S. 2002. Excavation. Cambridge: Cambridge University Press

Ruwitah, A. R. 1999. Precolonial cotton production and trade in the Zambezi and Save valleys. Zimbabwea 7.1

Schiffer, M. 1999. The material life of human beings: artefacts, behaviour and communication. London: Routledge

Schiffer, M. and Skibo, J. M. 1987. Theory and experiment in the study of technological change. Current Anthropology 28: 595-622

Schmidt, P. R. 1996. Cultural representation of African iron production. Schmidt. P. R. (ed.) The culture and technology of African iron production. Orlando: University Press of Florida

Schmidt, P. R. 1997. Iron technology in East Africa: Symbolism, science and archaeology. Indiana: Indiana University Press.

Schofield, J. F. 1937. Pottery of Mapungubwe district. Fouche, L (ed.) Mapungubwe: Ancient Bantu civilisations on the Limpopo. Cambridge: Cambridge University Press

Schofield, J. F. 1948. Primitive Pottery. An Introduction to South African Ceramics, Prehistoric and Protohistoric. Cape Town: The South African Archaeological Society

Selous, F. 1890. Travel and adventure in south-east Africa. London: Rowland Ward and Company

Shenjere, P. 2006. Faunal remains from Murahwa's Hill in Manyikaland, Eastern Zimbabwe. Zimbabwea 9: 83-94

Shenjere-Nyabezi, P., Pwiti, G. and Manyanga. M. 2013. Making the most out of rubbish: trends in archaeozoological studies in post-independence Zimbabwe. Manyanga, M. and Katsamudanga, S. Zimbabwean archaeology in the post-independence era. Harare: SAPES Books: 117-142

Shepherd, N. 2002. The politics of archaeology in Africa. Annual Review of Anthropology 31: 189-209 
Sheppard, J. G and Swart, E. R. 1967. Rhodesian radiocarbon measurements III. Radiocarbon 9: 382-386

Sibanda, H. M. and Ndlovu, L. R. 1992. The value of indigenous browsable tree species in livestock production in semi-arid communal grazing areas of Zimbabwe. Stares, J. E. S., Said, A. N. and Kategile, J. A. (eds.) The complimentarity of feed resources for animal production in Africa. Proceedings of the joint feed resources networks workshop held in Gaborone, Botswana, 4-8 March 1991: 55-62

Sinamai, A. 2009. Dry stone structures, Domboshaba, Botswana. Joffroy, T and Moriset, S. (eds.) Projet Situes: Ten Years of Experience. Grenoble: CRAterre Editions: 86-93

Sinclair, P. J. J. and Lundmark, H. 1984. A spatial analysis of archaeological sites from Zimbabwe. M. Hall, G. Avery, D. M. Avery, M. L. Wilson and A. J. B. Humphreys (eds). Frontiers: Southern Africa Archaeology Today. BAR International Series 207

Sinclair, P. J. J., Shaw, T and Andah, B. 1993. Introduction. Shaw, T., Sinclair, P., Andah, B. and Okpoko, A (eds). The Archaeology of Africa: Food, metals and towns. London: Routledge

Sinclair, P. J. J., Ekblom, A. and Wood, M. 2012. Trade and society on the south-east African coast in the later first millennium AD: the case of Chibuene. Antiquity 86: 723-737

Smithers, R. H. 1966. The mammals of southern African sub-region. Pretoria: University of Pretoria

Smithers, R. H and Wilson, V. J. 1979. Checklist and atlas of the mammals of ZimbabweRhodesia. Salisbury: National Museums and Monuments of Rhodesia

Soper, R. 1997. Reviews. Azania: Archaeological research in Africa, 32 (1): 118-127 DOI: $10.1080 / 00672709709709511592$

Soper, R. 2002. Nyanga: Ancient fields, settlements and agricultural history in Zimbabwe, Memoirs of the British Institute in East Africa, Number 16. London: The British Institute in East Africa 
Stein, G. J. 1998. Heterogeneity, power and political economy: some current issues in the archaeology of old world complex societies. Journal of Archaeological Research 6 (1): 1-44

Summers, R. 1949. An ancient ivory figurine from Khami Ruins. Man 49 (139)

Summers, R. 1969. Ancient mining in Rhodesia and adjacent areas. Museum Memoir No. 3, Salisbury: National Museums of Rhodesia.

Summers, R. 1971. Ancient Ruins and vanished civilisations of Southern Africa. Cape Town: T V Bulpin.

Swan, L. 1994. Early Gold Mining on the Zimbabwean Plateau. Studies in African Archaeology 9. Uppsala: Societas Archaeologica Upssaliensis

Swan, L. 2007a. Early Iron manufacturing industries in semi-arid, south-eastern Zimbabwe. Journal of African Archaeology 5 (2): 315-338

Swan, L. 2007b. Economic and ideological roles of copper ingots in prehistoric Zimbabwe. Antiquity 81 (314): 999-1012

Tapfuma, P. 2010. An analysis of faunal remains from the site of Danan'ombe. A Zimbabwe tradition site in central Zimbabwe. Unpublished Honours dissertation. University of Zimbabwe

Thorp, C. 1984. A cultural interpretation of faunal assemblage from Khami. Hall, M., Avery, G., Avery, D. M., Wilson M. L., and Humphreys A. J. B. (eds.) Frontiers: Southern African Archaeology Today. BAR International Series 207

Thorp, C. 1995. Kings, Commoners and Cattle at Zimbabwe Tradition Sites. Museum Memoir (New Series) 1. Harare: National Museums and Monuments of Zimbabwe

Tilley, C. 1989. Interpreting material culture. Hodder, I (ed.) The meaning of things: material culture and symbolic expression. London: Unwin Hyman

Tilley, C. 2006. Introduction. Tilley, C., Keane, W., Kuchler, S., Rowlands, M and Spyer, P. (eds.) Handbook of material culture. London: Sage 
Timberlake, J. J., Fagg, C. W and Barnes, R. D. 1999. Field guide to acacias of Zimbabwe. Harare: CBC Publishing

Tournie, A., Prinsloo, L. C. and Colomban, P. 2012. Raman classification of glass beads excavated on Mapungubwe Hill and K2, two archaeological sites in South Africa. Journal of Raman Spectroscopy 43: 532-542

Trigger, B. G. 1989. A history of archaeological thought. Cambridge: Cambridge University Press

Trigger, B. G. 2003. Understanding early civilisations: A comparative study. Cambridge: Cambridge University Press

Unganai, L. S. 1996. Historic and future climatic change in Zimbabwe. Climate Research Vol. 6: 137-145

Van Riet Lowe, C. 1955. The glass beads of Mapungubwe. Pretoria: Government Printer

Van Waarden, C. 1987. Matanga, a Late Zimbabwe cattle post. South African Archaeological Bulletin 42: 107-124

Van Waarden, C. 1988. Oral history of the Bakalanga of Botswana. Occasional Paper No. 2, Gaborone: Botswana Society

Van Warden, C. 1989. The granaries of Vumba: structural interpretation of a Khami period commoner site. Journal of Anthropological Archaeology 8: 131-157

Van Waarden, C. 1998. The Later Iron Age. Lane, P., Reid, A. and Segobye, A. (eds.) Ditswa Mmung: The Archaeology of Botswana. Gaborone: Pula Press and the Botswana Society: $115-60$

Van Waarden, C. 2011. The origin of the Zimbabwe Tradition walling. Zimbabwean Prehistory 29: 54-77

Van Waarden, C. 2012. Butua and the end of an era: The effect of the collapse of the Kalanga state on ordinary citizens: An analysis of behaviour under stress. Oxford: Archaeopress 
Vincent, V. and Thomas, R. G. 1960. An agricultural survey of southern Rhodesia. Salisbury: Government Printer

Voigt, E. 1979. The faunal remains from Icon. South African Archaeological Society. Goodwin Series 3: 80-84

Voigt, E. 1983. Mapungubwe: An Archaeozoological interpretation of an Iron Age community. Pretoria: Transvaal Museum

Von den Driesch, A. 1976. A guide to the measurement of animal bones from archaeological sites: as developed by the Institut for Plaeoanatomie, Domestikationsforschung und Geschichte der Tiermedizin of the University of Munich. Munich: Peabody Museum Press

White, F. 1901. On the Khami Ruins, Rhodesia. Man 1: 101-102.

White, F. 1903. On the Khami ruins, near Bulawayo. Proceedings and Transactions of the Rhodesian Scientific Association 1: 11-18

Whitty, A. 1961. Architectural Style at Great Zimbabwe. Occasional Paper of the National Museums of Southern Rhodesia 23a: 289-305

Wood, M. 2000. Making connections: Relationships between international trade and glass beads from the Shashe-Limpopo area. Leslie, M and Maggs, T. (eds) African Naissance: The Limpopo Valley 1000 years ago. The South African Archaeological Society Goodwin Series 8: $78-90$

Wood, M. 2005. Glass beads and pre-European trade in the Shashe-Limpopo Region. Unpublished M.A. Dissertation, University of Witwatersrand

Wood, M. 2011. A glass bead sequence for southern Africa from the $8^{\text {th }}$ to the $16^{\text {th }}$ century AD. Journal of African Archaeology 9 (1): 67-84

Woodward, I. 2007. Understanding material culture. London: Sage Publications

Wynne-Jones, S. 2013. Material culture, space and identity. Mitchell, P and Lane, P. The Oxford handbook of African archaeology. Oxford: Oxford University Press 


\section{APPENDIX A: POTTERY DATA CAPTURE SHEET}

Pottery Data Capture Sheet

\begin{tabular}{|c|c|c|c|}
\hline Site Name Khomi & Trench $1 \not 0$ & level 8 & Sheet Number \\
\hline \multicolumn{4}{|l|}{$\begin{array}{l}\text { Vessel Part } \\
\text { Vereel Form }\end{array}$} \\
\hline Vessel Form & & & \\
\hline \multicolumn{4}{|l|}{$\begin{array}{l}\text { Lip Form } \\
\text { Rim Diametre }\end{array}$} \\
\hline \multicolumn{4}{|l|}{$\begin{array}{l}\text { Rim Diametre } \\
\text { Raim / Sherd Thickness }\end{array}$} \\
\hline \multicolumn{4}{|l|}{$\begin{array}{l}\text { Pim / Sherd Thickness } \\
\text { Neck Height }\end{array}$} \\
\hline Neck Height & $m$ & • & \\
\hline \multicolumn{4}{|l|}{$\begin{array}{l}\text { Surface Treatment } \\
\text { Colour }\end{array}$} \\
\hline \multicolumn{4}{|l|}{$\begin{array}{l}\text { Colour } \\
\text { Decoration Motif }\end{array}$} \\
\hline \multicolumn{3}{|l|}{ Decoration Motif } & $66 \mathrm{~L}$ \\
\hline \multicolumn{4}{|l|}{$\begin{array}{l}\text { Decoration Placement } \\
\text { Decoration Technique }\end{array}$} \\
\hline \multicolumn{4}{|l|}{$\begin{array}{l}\text { Decoration Technique } \\
\text { Illustration Number }\end{array}$} \\
\hline \multicolumn{4}{|l|}{$\begin{array}{l}\text { Illustration Number } \\
\text { Comments }\end{array}$} \\
\hline Comments & & & \\
\hline
\end{tabular}

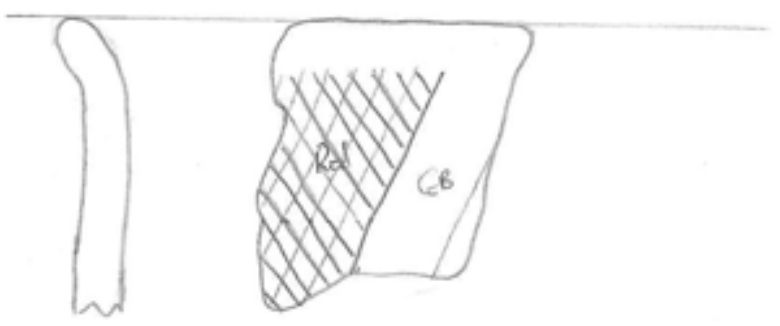




\section{APPENDIX B: XRF READINGS FOR METAL SAMPLES FROM KHAMI MIDDEN 1 TRENCH 2}

\begin{tabular}{|c|c|c|c|c|c|}
\hline Number & Object & $\mathbf{C u}$ & Sn & $\mathbf{F e}$ & Weight (g) \\
\hline KHA01 & $\begin{array}{l}\text { Wire folded into a } \\
\text { bunch } 5 \mathrm{~cm}\end{array}$ & 64.72 & 8.86 & 0.5 & 1.31 \\
\hline KHA02 & $\begin{array}{l}\text { Wound core with } \\
\text { veg core } 2.5 \mathrm{~cm}\end{array}$ & 88.79 & 9.95 & 0.97 & 0.83 \\
\hline KHA03 & $\begin{array}{l}\text { Wire folded into } \\
\text { pendant } 1.5 \mathrm{~cm}\end{array}$ & 56.34 & 2.72 & 1.8 & 0.77 \\
\hline KHA04 & Wound coil $1 \mathrm{~cm}$ & 49.05 & 2.59 & 1.5 & 0.71 \\
\hline KHA05 & Wound coil $2 \mathrm{~cm}$ & 57.23 & 6.58 & 0.56 & 0.69 \\
\hline KHA06 & Wound coil $1.5 \mathrm{~cm}$ & 39.85 & 4.52 & 2.6 & 0.74 \\
\hline KHA07 & Wound coil $1.5 \mathrm{~cm}$ & 54.56 & 7.19 & 0.6 & 0.61 \\
\hline KHA08 & Wound wire $5 \mathrm{~cm}$ & 67.59 & 5.07 & 0.7 & 0.89 \\
\hline KHA09 & $\begin{array}{l}\text { Wound wire with } \\
\text { veg core } 4 \mathrm{~cm}\end{array}$ & 61.36 & 6.17 & 0.86 & 1.59 \\
\hline KHA10 & Wound wire $2 \mathrm{~cm}$ & 24.21 & 0.08 & 46.37 & 2 \\
\hline KHA11 & Wound wire $1 \mathrm{~cm}$ & 50.88 & 7.97 & 0.9 & 0.61 \\
\hline KHA12 & Wound wire $0.5 \mathrm{~cm}$ & 56.47 & 7.18 & 1.39 & 0.62 \\
\hline KHA13 & Wound wire $1 \mathrm{~cm}$ & 55.52 & 1.19 & 1.56 & 0.62 \\
\hline KHA14 & $\begin{array}{l}\text { Wound wire on } \\
\text { quartzite flake }\end{array}$ & 22.21 & 0.44 & 1.18 & 3.12 \\
\hline KHA15 & $\begin{array}{l}\text { Wound wire with } \\
\text { veg core } 0.5 \mathrm{~cm}\end{array}$ & 47.61 & 2.82 & 13.27 & 0.65 \\
\hline KHA16 & $\begin{array}{l}\text { Wound wire with } \\
\text { veg core } 4.5 \mathrm{~cm}\end{array}$ & 51.53 & 2.64 & 1.23 & 1.47 \\
\hline KHA17 & Wound wire $1 \mathrm{~cm}$ & 56.43 & 0.00 & 2.01 & 0.59 \\
\hline KHA18 & Wound wire $1 \mathrm{~cm}$ & 51.25 & 4.41 & 0.8 & 0.69 \\
\hline KHA19 & Wound wire $2.5 \mathrm{~cm}$ & 4.76 & 0.19 & 0.44 & 0.67 \\
\hline KHA20 & Wound wire $4 \mathrm{~cm}$ & 58.91 & 7.07 & 1.07 & 0.92 \\
\hline
\end{tabular}




\section{APPENDIX C: SPINDLE WHORLS FROM KHAMI}

\begin{tabular}{|c|c|c|c|c|c|c|c|}
\hline Context & Material & Wt (g) & $T /$ ness $(\mathrm{mm})$ & Tot Dia $(\mathrm{mm})$ & Perf Dia (mm) & No of Perf & Inco Perf \\
\hline Behind Robinson House & Ceramic & 31 & 12.87 & 44.62 & - & 0 & 0 \\
\hline North Platform Ex 22 & Ceramic & 9 & 5.54 & 36.34 & - & 0 & 0 \\
\hline Ex 27 Grain bin 3 & & 27 & 7.4 & 56.3 & & 0 & 0 \\
\hline Hill Complex & Ceramic & 4 & 7.47 & 21.2 & - & 0 & 0 \\
\hline Hill Complex & Ceramic & 8 & 7.56 & 30.74 & - & 0 & 0 \\
\hline Hill Complex B5 & Ceramic & 15 & 6.45 & 39.65 & - & 0 & 0 \\
\hline Hill Complex Mid L4 & Ceramic & 6 & 7.7 & 24.72 & - & 0 & 0 \\
\hline Hill Complex Mid L4 & Ceramic & 6 & 9.68 & 22.83 & - & 0 & 0 \\
\hline \multirow[t]{4}{*}{ Hill Complex Mid L4 } & Ceramic & 10 & 9.12 & 32.09 & - & 0 & 0 \\
\hline & ceramic & 24 & 7.08 & 50.02 & - & 0 & \\
\hline & ceramic & 27 & 9.03 & 45.25 & - & 0 & \\
\hline & ceramic & 27 & 8.18 & 47.17 & - & 0 & \\
\hline Behind Robinson House & Soapstone & 16 & 8.16 & 49.87 & 10.89 & 1 & 0 \\
\hline North Platform Ex 22 & Ceramic & 6 & 8.01 & 37.08 & & 1 & 0 \\
\hline North Platform Ex 22 & Ceramic & 8 & 9.72 & & & 1 & 0 \\
\hline North Platform Ex 22 & Ceramic & 8 & 8.18 & & & 1 & 0 \\
\hline North Platform Ex 22 & Ceramic & 9 & 7.87 & 42.32 & 7.29 & 1 & 0 \\
\hline North Platform Ex 22 & Ceramic & 11 & 9.15 & & & 1 & 0 \\
\hline North Platform Ex 22 & Ceramic & 11 & 7.42 & 49.54 & 9.23 & 1 & 0 \\
\hline North Platform Ex 22 & Ceramic & 14 & 9 & 49.73 & 10.01 & 1 & 0 \\
\hline North Platform Ex 22 & Ceramic & 19 & 12.76 & 46.03 & 11.19 & 1 & 0 \\
\hline North Platform Ex 22 & Ceramic & 26 & 10.05 & 44.05 & 11.43 & 1 & 0 \\
\hline North Platform Ex 22 & Ceramic & 27 & 9.81 & 43.77 & 9.78 & 1 & 0 \\
\hline Vlei Platform, Frog midden & Ceramic & 31 & 10.58 & 48.87 & 11.92 & 1 & - \\
\hline Hill Complex & Ceramic & 43 & 13.98 & 51.14 & 12.16 & 1 & 0 \\
\hline Hill Complex Ex 19 & ceramic & 29 & 9 & 50.69 & 12.17 & 1 & 0 \\
\hline Hill Complex & Ceramic & 29 & 9.82 & 48.19 & 9.84 & 1 & 0 \\
\hline Passage platform entrance & Ceramic & 42 & 8.08 & 61.98 & 12.18 & 1 & 0 \\
\hline Plat E of Cross Platform & Ceramic & 11 & 9.25 & & & 1 & 0 \\
\hline \multirow[t]{16}{*}{ Plat E of Cross Platform } & Ceramic & 26 & 9.8 & 41.91 & 11.15 & 1 & 0 \\
\hline & Ceramic & 5 & 7.34 & 23.5 & 2.94 & 1 & 0 \\
\hline & Ceramic & 10 & 8.37 & 31.46 & 10.47 & 1 & 0 \\
\hline & ceramic & 11 & 8.27 & 29.82 & 10.2 & 1 & 0 \\
\hline & ceramic & 15 & 7.78 & 42.65 & 9.7 & 1 & 0 \\
\hline & Ceramic & 19 & 9.54 & 39.86 & 9.52 & 1 & 0 \\
\hline & Ceramic & 32 & 13.12 & 43.75 & 11.18 & 1 & \\
\hline & Ceramic & 41 & 14.77 & 47.22 & 11.55 & 1 & \\
\hline & clay & 12 & 11.39 & 48.08 & 13.7 & 1 & \\
\hline & Soapstone & 7 & 5.47 & 33.9 & 10.13 & 1 & 0 \\
\hline & soapstone & 14 & 10.36 & 36.65 & 12.17 & 1 & 0 \\
\hline & soapstone & 25 & 7.6 & 47.66 & 9.63 & 1 & 0 \\
\hline & soapstone & 35 & 10.38 & 42.28 & 9.62 & 1 & 0 \\
\hline & soapstone & 62 & 8.41 & 61.01 & 11.06 & 1 & 5 \\
\hline & soft stone & 24 & 8.6 & 39.56 & 10.46 & 1 & 0 \\
\hline & clay & 21 & 12.23 & 46.36 & 14.5 & 10 & 0 \\
\hline Ex 22 & Ceramic & 6 & 6.78 & & & & \\
\hline Ex 22 & Ceramic & 12 & 9.23 & & & & \\
\hline \multirow[t]{5}{*}{ HC B5 } & Ceramic & 5 & 7.36 & & & & \\
\hline & ceramic & 10 & 10.54 & & & & \\
\hline & Clay & 10 & 9.64 & 27.24 & - & & \\
\hline & clay & 15 & 8.93 & 29.47 & - & & \\
\hline & clay & & 9.16 & 29.15 & & & \\
\hline
\end{tabular}




\begin{tabular}{|c|c|c|c|c|c|c|c|}
\hline Context & Material & $\mathbf{W t}(\mathrm{g})$ & $T /$ ness (mm) & Tot Dia (mm) & Perf Dia (mm) & No of Perf & Inco Perf \\
\hline Behind Robinson House & Ceramic & 31 & 12.87 & 44.62 & - & 0 & 0 \\
\hline North Platform Ex 22 & Ceramic & 9 & 5.54 & 36.34 & - & 0 & 0 \\
\hline Ex 27 Grain bin 3 & & 27 & 7.4 & 56.3 & & 0 & 0 \\
\hline Hill Complex & Ceramic & 4 & 7.47 & 21.2 & - & 0 & 0 \\
\hline Hill Complex & Ceramic & 8 & 7.56 & 30.74 & - & 0 & 0 \\
\hline Hill Complex B5 & Ceramic & 15 & 6.45 & 39.65 & - & 0 & 0 \\
\hline Hill Complex Mid L4 & Ceramic & 6 & 7.7 & 24.72 & - & 0 & 0 \\
\hline Hill Complex Mid L4 & Ceramic & 6 & 9.68 & 22.83 & - & 0 & 0 \\
\hline \multirow[t]{4}{*}{ Hill Complex Mid L4 } & Ceramic & 10 & 9.12 & 32.09 & - & 0 & 0 \\
\hline & ceramic & 24 & 7.08 & 50.02 & - & 0 & \\
\hline & ceramic & 27 & 9.03 & 45.25 & - & 0 & \\
\hline & ceramic & 27 & 8.18 & 47.17 & - & 0 & \\
\hline Behind Robinson House & Soapstone & 16 & 8.16 & 49.87 & 10.89 & 1 & 0 \\
\hline North Platform Ex 22 & Ceramic & 6 & 8.01 & 37.08 & & 1 & 0 \\
\hline North Platform Ex 22 & Ceramic & 8 & 9.72 & & & 1 & 0 \\
\hline North Platform Ex 22 & Ceramic & 8 & 8.18 & & & 1 & 0 \\
\hline North Platform Ex 22 & Ceramic & 9 & 7.87 & 42.32 & 7.29 & 1 & 0 \\
\hline North Platform Ex 22 & Ceramic & 11 & 9.15 & & & 1 & 0 \\
\hline North Platform Ex 22 & Ceramic & 11 & 7.42 & 49.54 & 9.23 & 1 & 0 \\
\hline North Platform Ex 22 & Ceramic & 14 & 9 & 49.73 & 10.01 & 1 & 0 \\
\hline North Platform Ex 22 & Ceramic & 19 & 12.76 & 46.03 & 11.19 & 1 & 0 \\
\hline North Platform Ex 22 & Ceramic & 26 & 10.05 & 44.05 & 11.43 & 1 & 0 \\
\hline North Platform Ex 22 & Ceramic & 27 & 9.81 & 43.77 & 9.78 & 1 & 0 \\
\hline Vlei Platform, Frog midden & Ceramic & 31 & 10.58 & 48.87 & 11.92 & 1 & - \\
\hline Hill Complex & Ceramic & 43 & 13.98 & 51.14 & 12.16 & 1 & 0 \\
\hline Hill Complex Ex 19 & ceramic & 29 & 9 & 50.69 & 12.17 & 1 & 0 \\
\hline Hill Complex & Ceramic & 29 & 9.82 & 48.19 & 9.84 & 1 & 0 \\
\hline Passage platform entrance & Ceramic & 42 & 8.08 & 61.98 & 12.18 & 1 & 0 \\
\hline Plat E of Cross Platform & Ceramic & 11 & 9.25 & & & 1 & 0 \\
\hline \multirow[t]{16}{*}{ Plat E of Cross Platform } & Ceramic & 26 & 9.8 & 41.91 & 11.15 & 1 & 0 \\
\hline & Ceramic & 5 & 7.34 & 23.5 & 2.94 & 1 & 0 \\
\hline & Ceramic & 10 & 8.37 & 31.46 & 10.47 & 1 & 0 \\
\hline & ceramic & 11 & 8.27 & 29.82 & 10.2 & 1 & 0 \\
\hline & ceramic & 15 & 7.78 & 42.65 & 9.7 & 1 & 0 \\
\hline & Ceramic & 19 & 9.54 & 39.86 & 9.52 & 1 & 0 \\
\hline & Ceramic & 32 & 13.12 & 43.75 & 11.18 & 1 & \\
\hline & Ceramic & 41 & 14.77 & 47.22 & 11.55 & 1 & \\
\hline & clay & 12 & 11.39 & 48.08 & 13.7 & 1 & \\
\hline & Soapstone & 7 & 5.47 & 33.9 & 10.13 & 1 & 0 \\
\hline & soapstone & 14 & 10.36 & 36.65 & 12.17 & 1 & 0 \\
\hline & soapstone & 25 & 7.6 & 47.66 & 9.63 & 1 & 0 \\
\hline & soapstone & 35 & 10.38 & 42.28 & 9.62 & 1 & 0 \\
\hline & soapstone & 62 & 8.41 & 61.01 & 11.06 & 1 & 5 \\
\hline & soft stone & 24 & 8.6 & 39.56 & 10.46 & 1 & 0 \\
\hline & clay & 21 & 12.23 & 46.36 & 14.5 & 10 & 0 \\
\hline Ex 22 & Ceramic & 6 & 6.78 & & & & \\
\hline Ex 22 & Ceramic & 12 & 9.23 & & & & \\
\hline \multirow[t]{5}{*}{ HC B5 } & Ceramic & 5 & 7.36 & & & & \\
\hline & ceramic & 10 & 10.54 & & & & \\
\hline & Clay & 10 & 9.64 & 27.24 & - & & \\
\hline & clay & 15 & 8.93 & 29.47 & & & \\
\hline & clay & & 9.16 & 29.15 & & & \\
\hline
\end{tabular}




\section{APPENDIX D: METAL OBJECTS FROM PREVIOUS EXCAVATIONS (MACIVER 1906; ROBINSON 1959)}

\begin{tabular}{|c|c|c|c|c|}
\hline & Object & Qty & Metal & Context Description \\
\hline 1 & Adze-head & 1 & Iron & Hill Complex \\
\hline 2 & Arrowhead & 1 & Iron - barbed & Hill Complex; east slopes Ex 23 \\
\hline 3 & Arrowhead & 7 & Iron & Hill Complex; surface \\
\hline 4 & Arrowhead & 1 & Iron & Hill Complex; Upper passage \\
\hline 5 & $\begin{array}{l}\text { Arrowhead with long } \\
\text { shaft }\end{array}$ & 2 & Iron & Site IV East of North Platform Ex 22 L2 \\
\hline 6 & Axe & 1 & $\begin{array}{l}\text { Iron with inlaid copper } \\
\text { disk }\end{array}$ & Hill Complex; house Cb1 floor \\
\hline 7 & Axe heads & 2 & Iron & Hill Complex; House Cb1 floor \\
\hline 8 & Axe-head & 2 & Iron & Hill Complex; house Cb1 floor \\
\hline 9 & Bangle & 1 & Copper/Bronze & $\begin{array}{l}\text { Hill Complex Platform B; Excavation 17b } \\
\text { Floor } 1 \text { Layer } 7\end{array}$ \\
\hline 10 & Bangle & 1 & Bronze & Hill Complex; House Cb1 floor \\
\hline 11 & Bangle & 1 & Bronze & Hill Complex; Platform B House Ba 1 \\
\hline 12 & Bangle frags & & & Hill Complex; House Cb1 floor \\
\hline 13 & Bangles & 2 & Copper & Hill Complex; Platform B Ex 17 Floor V \\
\hline 14 & Bangles & & $\begin{array}{l}\text { Copper/Bronze with } \\
\text { gold alloy }\end{array}$ & Hill Complex; Platform B Ex 17 Layer 7 \\
\hline 15 & Bangles wire & & Copper & Hill Complex; east slopes Ex 23 \\
\hline 16 & Bead & 1 & Gold & Hill Complex; east slopes Ex 23 \\
\hline 17 & Bead & 1 & Copper/bronze & Hill Complex; House Cb1 floor \\
\hline 18 & Bead & 1 & Gold & $\begin{array}{l}\text { Hill Complex; Middle passage Ex } 9 \text { Layer } \\
2\end{array}$ \\
\hline 19 & Bead & 3 & Copper/Bronze & Hill Complex; Upper passage \\
\hline 20 & Bead and pellet & 2 & Gold & Hill Complex; Platform B Ex 17 Floor 1 \\
\hline 20 & Beads & & Copper & Hill Complex; east slopes Ex 23 \\
\hline 22 & Beads & & Gold & Hill Complex; Upper passage \\
\hline 23 & Beads(rings and disks) & & Copper & Cross Platform midden Layer $3 \& 4$ \\
\hline 24 & Beads(rings and disks) & & Copper/bronze & Cross Platform midden Layer $3 \& 4$ \\
\hline 25 & Bracelet wire & & Copper-gold alloy & Hill Complex; east slopes Ex 23 \\
\hline 26 & Bracelets wire & & Copper & Hill Complex; east slopes Ex 23 \\
\hline 27 & Bracelets wire & & $\begin{array}{l}\text { Copper-gold alloy } \\
\text { coiled }\end{array}$ & Hill Complex; east slopes Ex 23 \\
\hline 28 & Chain & 1 & Iron & Hill Complex; House Cb1 floor \\
\hline 29 & Chisel & 1 & Iron & Hill Complex; east slopes Ex 23 \\
\hline 30 & Chisel & 1 & Iron & Hill Complex; Upper passage \\
\hline 31 & Fragments & & Copper & Hill Complex; Platform B Ex 17 Floor V \\
\hline 32 & Frags & & Iron & Cross Platform midden Layer 1 \\
\hline
\end{tabular}




\begin{tabular}{|c|c|c|c|c|}
\hline 33 & Frags & & Iron & Cross Platform midden Layer 3 \\
\hline 34 & Frags & & Copper & Hill Complex; east slopes Ex 23 \\
\hline 35 & Frags of bracelet & 2 & Iron & Hill Complex; Platform B Ex 17 Layer 7 \\
\hline 36 & $\begin{array}{l}\text { Frags of copper } \\
\text { bindings }\end{array}$ & & Copper & Hill Complex; House Cb1 floor \\
\hline 37 & $\begin{array}{l}\text { Frags of tin with } \\
\text { copper in cracks }\end{array}$ & 3 & Tin and copper & Hill Complex; House Cb1 floor \\
\hline 38 & Frags of wound wire & & Copper & Hill Complex; Platform B Ex 17 Layer 7 \\
\hline 39 & Hoe head & 1 & Iron & $\begin{array}{l}\text { Hill Complex Platform B; Ex 17a Floor } 1 \\
\text { Level } 6\end{array}$ \\
\hline 40 & Hook & 1 & Iron & Hill Complex; east slopes Ex 23 \\
\hline 41 & Hook & 1 & Iron & Hill Complex; midden \\
\hline 42 & Knife/spear blade & 2 & Iron & Hill Complex; east slopes Ex 23 \\
\hline 43 & Needle & 1 & Iron & Hill Complex; east slopes Ex 23 \\
\hline 44 & Needle & 1 & Copper & Hill Complex; midden \\
\hline 45 & Ore & & & Hill Complex; Chamber floor \\
\hline 46 & Pellet & 1 & Gold & Hill Complex; Middle passage Ex 8 \\
\hline 47 & Pellet & 1 & Copper & Hill Complex; Passage \\
\hline 48 & Pellet & 1 & Gold & Hill Complex; Platform B Ex 17 Layer 7 \\
\hline 49 & Pellet & 1 & Gold & $\begin{array}{l}\text { Site IV East of North Platform Ex } 22 \text { L8 } \\
\text { below bottom floor }\end{array}$ \\
\hline 50 & Pin & 1 & Iron & Vlei Platform; surface \\
\hline 51 & Pin head & 1 & Iron & Hill Complex; Upper passage \\
\hline 52 & Pins & & Iron -conical heads & Hill Complex; east slopes Ex 23 \\
\hline 53 & Plaited wire work & & Copper-gold alloy & Hill Complex; Middle passage \\
\hline 54 & Razor & & Iron & Hill Complex; east slopes Ex 23 \\
\hline 55 & Razor & 1 & Bronze & Hill Complex; upper passage floor \\
\hline 56 & Ring & 1 & Iron & Hill Complex; east slopes Ex 23 \\
\hline 57 & Ring & 1 & Bronze & Hill Complex; House Cb1 floor \\
\hline 58 & Ring & 1 & Copper & Hill Complex; Lower passage \\
\hline 59 & Rods & & Iron & Site IV East of North Platform Ex 22 L2 \\
\hline 60 & Snuff spoon & 1 & Bronze & $\begin{array}{l}\text { Hill Complex Platform B below wall } \\
\text { debris }\end{array}$ \\
\hline 61 & Spearhead & 1 & Iron & Hill Complex; east slopes Ex 23 \\
\hline 62 & Spearhead/knifeblade & 1 & Iron & Hill Complex; east slopes Ex 23 \\
\hline 63 & Spearheads & 7 & Copper/bronze & Hill Complex; House $\mathrm{Cb} 1$ floor \\
\hline 64 & Strip & 1 & Copper & Hill Complex; Platform C \\
\hline 65 & Tools & & Iron & Hill Complex; Platform B Ex 17 Floor V \\
\hline 66 & Wire & & Bronze & $\begin{array}{l}\text { Hill Complex; House Cb1 floor and } \\
\text { Passage }\end{array}$ \\
\hline 67 & Wire & & Copper & Hill Complex; Platform B Ex 17 Layer 7 \\
\hline 68 & Wire & & Copper & Hill Complex; Platform B Ex 17 Layer 7 \\
\hline 69 & Wire & & Iron over fibre core & Hill Complex; Platform B Ex 17 Layer 7 \\
\hline 70 & Wire & & Iron & Hill Complex; Platform C House Cb7 \\
\hline 71 & Wire - bent & 1 & Iron & Hill Complex; east slopes Ex 23 \\
\hline
\end{tabular}




\begin{tabular}{|r|l|r|l|l|}
72 & Wire - plaited & 10 & Copper & Hill Complex; House Cb1 floor \\
\hline 73 & Wire bangles & & Iron & Hill Complex; east slopes Ex 23 \\
\hline 74 & Wire binding & & Iron & Hill Complex; House Cb1 floor \\
\hline 75 & Wire bindings & 18 & Copper & Hill Complex; Platform C House Cb7 \\
\hline 76 & Wire bracelets & & Copper and iron & Hill Complex; Platform B Ex 17 Floor 1 \\
\hline 77 & Wire coils & & Iron & Hill Complex; House Cb1 floor \\
\hline 78 & Wire frags & & Copper and iron & Hill Complex; Platform B Ex 17 bedrock \\
\hline 79 & Wire plaited & & Copper & Hill Complex; Platform B Ex 17 Floor V \\
\hline 80 & Wire, beads and & & & Hill Complex; Platform B Ex 17 Floor V \\
\hline 81 & Woven wire & & Copper & Hill Complex; House Cb1 floor \\
\hline 82 & Zapozap axe & & $\begin{array}{l}\text { Iron sheathed with } \\
\text { copper }\end{array}$ & Hill Complex / Passage Platform \\
\hline
\end{tabular}

